\title{
Molekulare, biochemische und strukturelle Untersuchungen an amylolytischen Enzymen von Thermotoga maritima MSB8
}

\author{
Dissertation \\ zur Erlangung des Doktorgrades \\ der Mathematisch-Naturwissenschaftlichen Fakultäten \\ der Georg-August-Universität zu Göttingen
}

vorgelegt von

Carsten Raasch

aus Northeim

Göttingen 2001 
D 7

Referent:

Prof. Dr. W. Liebl

Korreferent:

Prof. Dr. G. Gottschalk

Tag der mündlichen Prüfung:

03.05.2001 


\section{INHALTSVERZEICHNIS}

\section{ABKÜRZUNGEN}

1. EINLEITUNG

2. MATERIAL UND METHODEN

2.1 Organismen und Plasmide

2.2.1 Nährmedien 12

2.2.2 Antibiotika und andere Medienzusätze 12

2.2.3 Zellanzucht 13

2.2.4 Reinheitskontrolle und Stammhaltung 13

$\begin{array}{ll}\text { 2.2.5 Messung der optischen Dichte } & 13\end{array}$

$\begin{array}{lll}2.3 & \text { Standardtechniken für das Arbeiten mit DNA } & 14\end{array}$

2.3.1 Behandlung von Geräten und Lösungen für das Arbeiten mit Nukleinsäuren 14

2.3.2 Phenol/Chloroform/Isoamylalkohol-Extraktion 14

$\begin{array}{lll}\text { 2.3.3 Fällung von DNA mit Isopropanol oder Ethanol } & 14\end{array}$

2.3.4 Agarose-Gelelektrophorese von DNA 15

2.3.5 Färbung und Photographie von DNA in Agarosegelen 15

2.3.6 Konzentrationsbestimmung von Nukleinsäuren 15

2.3.7 Größenbestimmung von DNA-Fragmenten 16

$\begin{array}{lll}2.4 & \text { Isolierung von DNA } & 16\end{array}$

2.4.1 Schnelle Plasmid-Isolierung aus E. coli („Cracking“) 16

2.4.2 Minipräparation von Plasmid-DNA (Birnboim und Doly, 1979, mod.) 17

$\begin{array}{lll}\text { 2.4.3 Plasmidisolierung durch „QIAprep Spin Miniprep“ } & 18\end{array}$

$\begin{array}{lll}\text { 2.4.4 Isolierung von DNA-Fragmenten aus Agarosegelen } & 18\end{array}$

$\begin{array}{lll}2.5 & \text { Enzymatische Modifikationen von DNA } & 18\end{array}$

2.5.1 Verdauung von DNA durch Restriktionsendonukleasen 18

2.5.2 Herstellung von glatten Enden (,blunt ends“) 19

2.5.3 Dephosphorylierung von DNA-Fragmenten 19

$\begin{array}{ll}\text { 2.5.4 Ligation von DNA-Fragmenten } & 20\end{array}$ 
2.6 Amplifikation von DNA-Fragmenten mit Hilfe der PolymeraseKettenreaktion (PCR)

2.7 Ortsspezifische Mutagenese

$2.8 \quad$ Transformationsverfahren 21

2.8.1 Hocheffiziente Transformation von E. coli (Inoue et al., 1990) 21

2.8.1.1 Präparation kompetenter Zellen für die Transformation 21

2.8.1.2 Transformation der kompetenten E. coli-Zellen 22

2.8.2 Der X-Gal-Test zur Selektion auf rekombinante E. coli-Klone 23

2.8.3 Elektroporation von E. coli 23

2.8.3.1 Präparation von kompetenten Zellen 23

2.8.3.2 Transformation kompetenter Zellen durch Elektroporation 24

$2.9 \quad$ Sequenzierung doppelsträngiger Plasmid-DNA 24

2.10 Standardtechniken für das Arbeiten mit Proteinen 24

2.10.1 Quantitative Proteinbestimmung 24

2.10.2 SDS-Polyacrylamidgelelektrophorese (SDS-PAGE) (mod. nach Laemmli, 1970) 25

2.10.3 Färbung von Proteinen 26

2.10.3.1 Coomassie-Färbung (Weber und Osborn, 1969, mod.) 26

2.10.3.2 Proteinfärbung mit Ponceau S Rot 27

2.10.4 Größenbestimmung von Proteinen 27

2.10.5 Native Gelelektrophorese 28

2.10.6 Konzentrierung von Proteinen 28

2.10.7 Umpufferung durch Diafiltration 29

$2.11 \quad$ Western-Blot (Towbin et al., 1979) 29

2.12 Immunologische Methoden 29

2.12.1 Herstellung von polyklonalen Antiseren gegen MTase 29

2.12.2 Dot Blot für immunologischen Nachweis 30

2.12.3 Immundetektion von Proteinen mit alkalische Phosphatase$\begin{array}{ll}\text { konjugierten Antikörpern } & 30\end{array}$

2.13 Chromatographische Verfahren zur Produktanalyse 31

2.13.1 Dünnschicht-Chromatographie (TLC) 31

2.13.2 Hochleistungs-Flüssig-Chromatographie (HPLC) 32

2.13.3 HPLC-Analyse der Stärkeumsetzung 33 
2.14 Gewinnung und Reinigung von cytosolischen Proteinen

2.14.1 Präparation des Zellextraktes 34

2.14.2 Abtrennung thermolabiler Proteine durch Hitzedenaturierung 35

2.14.3 Fast Protein Liquid Chromatography (FPLC) 35

2.14.3.1 Geräte und Säulen $\quad 35$

2.14.3.2 Trennprinzipien 36

lonenaustausch-Chromatographie $\quad 36$

Hydrophobe Interaktions-Chromatographie $\quad 37$

Gelfiltration $\quad 38$

$2.15 \quad$ Enzymaktivitätstests 39

2.15.1 $\quad \mathrm{I}_{2} / \mathrm{KI}$-Test zur Bestimmung von Transferaktivitäten 39

2.15.1.1 $\quad \mathrm{I}_{2} / \mathrm{KI}$-Test zur Bestimmung der Maltosyltransferase-Aktivität $\quad 39$

2.15.1.2 $\quad \mathrm{I}_{2} / \mathrm{KI}$-Test zur Bestimmung der 4- $\alpha$-Glucanotransferase-Aktivität $\quad 40$

2.15.2 Hydrolyse von para-Nitrophenyl-Substraten 41

2.15.3 Enzymaktivitätstest auf Agarplatten 43

2.15.4 DNSA-Test zur Bestimmung reduzierender Zucker $\quad 43$

$2.16 \quad$ Charakterisierung von Enzymen $\quad 45$

2.16.1 Cofaktor-Abhängigkeit der Aktivität 45

2.16.1.1 Reduzierende Agenzien $\quad 45$

2.16.1.2 Einfluß verschiedener Salze auf die Aktivität 45

2.16.1.3 Nukleotide $\quad 46$

2.16.2 Enzymkinetik 46

2.16.2.1 Kinetik der $\alpha$-Glucosidase $\quad 46$

2.16.2.2 Einfluß potentieller metabolischer Regulatoren und Kinetik der Inhibition $\quad 47$

2.16.3 Temperaturabhängigkeit der Aktivität 49

2.16.4 Thermische Inaktivierung 49

$\begin{array}{lll}2.17 & \text { Zentrifugationen }\end{array}$

$2.18 \quad$ Chemikalien, Biochemikalien und Enzyme 50

3. EXPERIMENTE UND ERGEBNISSE 52

3.1 Klonierung der $\alpha$-Glucosidasen aglB aus T. maritima und agIA aus T. neapolitana $\quad 52$

3.1.1 Klonierung von aglB aus T. maritima in E. coli 52

3.1.2 Klonierung von aglA aus T. neapolitana in E. coli 54 
3.1.3 Heterologe Expression, Reinigung und erste Charakterisierung von AgIA (T. neapolitana)

3.2 Thermotoga maritima AglA, eine extrem thermostabile NAD ${ }^{+}$-, $\mathrm{Mn}^{2+}$ - und thiolabhängige $\alpha$-Glucosidase (Raasch et al., 2000) 60

3.2.1 Sequenzanalyse von agIA 60

3.2.2 Einfluß von Cofaktoren auf die Aktivität des rekombinanten Proteins 62

3.2.2.1 Reduzierende Agenzien 62

3.2.2.2 Einfluß divalenter Metallionen 63

$\begin{array}{lll}\text { 3.2.2.3 Nukleotide } & 64\end{array}$

3.2.3 Gelfiltrationsstudien und kinetische Parameter der Substrathydrolyse 65

3.2.4 Ortsspezifische Mutagenese der potentiellen NAD+-Bindungsstelle und eines konservierten Cysteinrestes

3.2.5 Expression und Reinigung der AglA-Mutanten sowie Kinetik der $\begin{array}{ll}\mathrm{NAD}^{+} \text {-Bindung } & 72\end{array}$

3.2.6 Kinetik der Inhibition durch Fructose-1,6-Diphosphat 75

3.3 Optimierung der heterologen Überexpression der GTase in E. coli und vereinfachte, hocheffiziente Aufreinigung des rekombinanten Proteins

3.3.1 Klonierung von $m g t A$ in den Expressionsvektor pET21c 78

3.3.2 Expression und Reinigung der rekombinanten 4- $\alpha$-Glucano$\begin{array}{ll}\text { transferase } & 80\end{array}$

3.3.3 HPLC-Analyse der Stärkeumsetzung 82

3.3.4 Inhibitoren der GTase im Hinblick auf die Strukturanalyse 84

3.4 Aufklärung der Proteinstruktur der rekombinanten Maltosyltransferase (MmtA) aus T. maritima (Roujeinikova et al., 2001) 86

3.4.1 Reinigung und Kristallisation des rekombinanten Proteins (Burke et al., 2000) 86

3.4.2 Gelfiltrationsstudie 87

3.4.3 Maltosebindung und Lokalisierung der putativen aktiven Aminosäuren 88

3.4.4 MTase als Dimer 89

3.4.5 Molekulare Basis der Transferaktivität 91

3.4.6 Einfluß potentieller metabolischer Regulatoren auf die Aktivität 92

3.5 Gezielte ortsspezifische Mutagenese von mmtA und Austausch strukturell bedeutender Aminosäuren $\quad 93$

3.5.1 Mutagenese der katalytisch aktiven Aminosäuren 94

$\begin{array}{ll}\text { 3.5.2 } & \text { Versuche zur Modifizierung der Transfereigenschaften und zur } \\ & \text { Erhöhung der hydrolytischen Aktivität der MTase }\end{array}$ 
3.5.3 Die Mutante V110R 100

3.5.4 Nachweis der Monomerisierung durch Gelfiltration und Nativ-PAGE 101

3.5.5 Temperaturabhängigkeit der Aktivität und thermische Inaktivierung 102

3.5.6 Transfer- und Hydrolyse-Aktivitäten der MTase-Mutanten im Vergleich

4. DISKUSSION

$\begin{array}{lll}4.1 & \alpha \text {-Glucosidasen von T. maritima } & 109\end{array}$

4.1.1 Genetischer Kontext der $\alpha$-Glucosidasen aglA und aglB 109

4.1.2 Weitere Glucosidasen in T. maritima 111

4.2 Cofaktor-Abhängigkeit von AgIA und anderen Enzymen der Glycosylhydrolase - Familie 4

4.3 Optimierte Aufreinigung und Stärke-modifizierende Aktivität der rekombinanten GTase aus T. maritima

$\begin{array}{lll}4.4 & \text { Die Kristallstruktur der Maltosyltransferase } & 121\end{array}$

4.4.1 Sekundär- und Domänenstruktur der MTase 121

$\begin{array}{lll}\text { 4.4.2 Maltosebindung } & 123\end{array}$

$\begin{array}{lll}\text { 4.5 Ortsspezifische Mutagenese der Maltosyltransferase } & 125\end{array}$

4.5.1 Aktives Zentrum, Reaktionsmechanismus, Substratbindung und Transferspezifität 126

$\begin{array}{ll}\text { 4.5.2 Oligomerisation und Thermostabilität } & 131\end{array}$

4.5.3 Potentielle Funktion der MTase 135

$\begin{array}{lll}\text { 5. ZUSAMMENFASSUNG } & 137\end{array}$

$\begin{array}{ll}\text { 6. LITERATUR } & 140\end{array}$

DANKSAGUNGEN 


\section{ABKÜRZUNGEN}

A

Abb.

Amp

APS

As

BCIP

bp

BSA

bzw.

C

$\mathrm{cm}$

d

$\mathrm{Da}$

demin.

dest.

d. h.

DMSO

DNA

DNSA

ds

DTT

E.

E-Cup

EDTA

Ek.

et al.

evt.

Fa.

g

$G_{x}$

ggf.
Ampere

Abbildung

Ampicillin

Ammoniumpersulfat

Aminosäure $(\mathrm{n})$

5-Brom-4-Chlor-3-Indolyl-Phosphat

Basenpaar(e)

Rinderserumalbumin

beziehungsweise

Celsius

Zentimeter

Desoxy-; Küvettenschichtdicke, Tag

Dalton

demineralisiert

destilliert

das heißt

Dimethylsulfoxid

Desoxyribonukleinsäure

Dinitrosalicylsäure

doppelsträngig/Doppelstrang-

Dithiothreitol

Escherichia

Eppendorfreaktionsgefäß

Ethylendiamintetraacetat

Endkonzentration

et alii: und andere

eventuell

Firma

Gramm

$\alpha-1,4-G l u c o o l i g o m e r$ mit Polymerisationsgrad $\mathrm{x}$ gegebenenfalls 


\begin{tabular}{|c|c|}
\hline $\mathrm{h}$ & Stunde(n) \\
\hline Hrsg. & Herausgeber \\
\hline i. d. R. & in der Regel \\
\hline IPTG & Isopropyl-B-d-thiogalactopyranosid \\
\hline $\mathrm{k}$ & Kilo- $\left(1 \times 10^{3}\right)$ \\
\hline kB & Kilobasen \\
\hline Konz. & Konzentration \\
\hline I & Liter \\
\hline LB & Luria-Bertani (ein Komplexmedium) \\
\hline $\mathrm{m}$ & Milli- $\left(1 \times 10^{-3}\right)$, Meter \\
\hline M & Molar (mol/l), molekulare Masse \\
\hline $\max$. & Maximal \\
\hline MCS & Multiklonierungsstelle (multiple cloning site) \\
\hline$\mu$ & Mikro- $\left(1 \times 10^{-6}\right)$ \\
\hline $\min$ & Minute \\
\hline mind. & mindestens \\
\hline mod. & modifiziert \\
\hline $\mathrm{n}$ & Nano- $\left(1 \times 10^{-9}\right)$ \\
\hline NBT & Nitroblue-Tetrazolium \\
\hline Nr. & Nummer \\
\hline $\mathrm{OD}_{600}$ & Optische Dichte bei einer Wellenlänge von $600 \mathrm{~nm}$ \\
\hline ORF & Offener Leserahmen (open reading frame) \\
\hline PAGE & Polyacrylamid-Gelelektrophorese \\
\hline PCR & Polymerase-Ketten-Reaktion \\
\hline PEG & Polyethylenglycol \\
\hline persönl. & persönlich \\
\hline pNP (-) & para-Nitrophenol (para-Nitrophenyl-) \\
\hline RNA & Ribonukleinsäure \\
\hline RT & Raumtemperatur \\
\hline s & Sekunde, sensitiv \\
\hline SDS & Natriumdodecylsulfat \\
\hline sog. & sogenannt(en) \\
\hline SV & Säulenvolumen \\
\hline Tab. & Tabelle \\
\hline
\end{tabular}




$\begin{array}{ll}\text { TAE } & \text { Tris-Acetat-EDTA-Puffer } \\ \text { TE } & \text { Tris-EDTA-Puffer } \\ \text { TEMED } & \text { N,N,N',N'-tetramethylethylendiamin } \\ \text { Tris } & \text { Tris-(hydroxymethyl)-aminomethan } \\ \text { U } & \text { Unit (Einheit der Enzymaktivität) } \\ \text { Upm } & \text { Umdrehungen pro Minute } \\ \text { UV } & \text { Ultraviolett } \\ \text { V } & \text { Volt } \\ \text { v/v } & \text { Volumen pro Volumen } \\ \text { Vol. } & \text { Volumen (anteil) } \\ \text { w/v } & \text { Gewicht pro Volumen } \\ \text { wt } & \text { Wildtyp } \\ \text { X-Gal } & \text { 5-Brom-4-Chlor-3-Indolyl-B-D-galactopyranosid } \\ \text { z. B. } & \text { zum Beispiel } \\ \text { z. T. } & \text { zum Teil }\end{array}$

\section{Nukleotidbasen}
A Purinbase Adenin
G Purinbase Guanin
C Pyrimidinbase Cytosin
$\mathrm{T}$ Pyrimidinbase Thymidin

\section{Aminosäuren}
A Alanin
M Methionin
C Cystein
$\mathrm{N}$ Asparagin
D Aspartat
$\mathrm{P} \quad$ Prolin
E Glutamat
Q Glutamin
F Phenylalanin
R Arginin
G Glycin
$S \quad$ Serin
$\mathrm{H} \quad$ Histidin
T Threonin
I Isoleucin
V Valin
K Lysin
W Tryptophan
L Leucin
Y Tyrosin 


\section{EINLEITUNG}

\section{Thermotoga maritima und Aspekte der (Hyper-) thermophilie}

Die in dieser Arbeit näher charakterisierten Enzyme $\alpha$-Glucosidase, 4- $\alpha$-Glucanotransferase (GTase) und Maltosyltransferase (MTase) stammen alle aus dem hyperthermophilen Bakterium Thermotoga maritima MSB8 (DSM 3109). Die Gruppe der Hyperthermophilen umfaßt Organismen, die sich bei einer Temperatur von $80^{\circ} \mathrm{C}$ oder mehr optimal vermehren und deren obere Wachstumsgrenze bei mindestens $90^{\circ} \mathrm{C}$ liegt (Kelly und Adams, 1994). Es wird allgemein angenommen, daß Veränderungen verschiedenster Wechselwirkungen (elektrostatische und hydrophobe Interaktionen, Aminosäureaustausche, Oligomerisation, Packungsdichte) in der Proteinstruktur letztlich die Adaptation der Proteine an hohe Temperaturen bedingen (Scandurra et al., 1998). Unter den Eukaryonten wurden noch keine hyperthermophilen Mikroorganismen isoliert und auch bei den Bacteria sind bisher nur bei den Ordnungen Thermotogales und Aquificiales hyperthermophile Vertreter gefunden worden (Abb. 1).

\section{Eukarya}

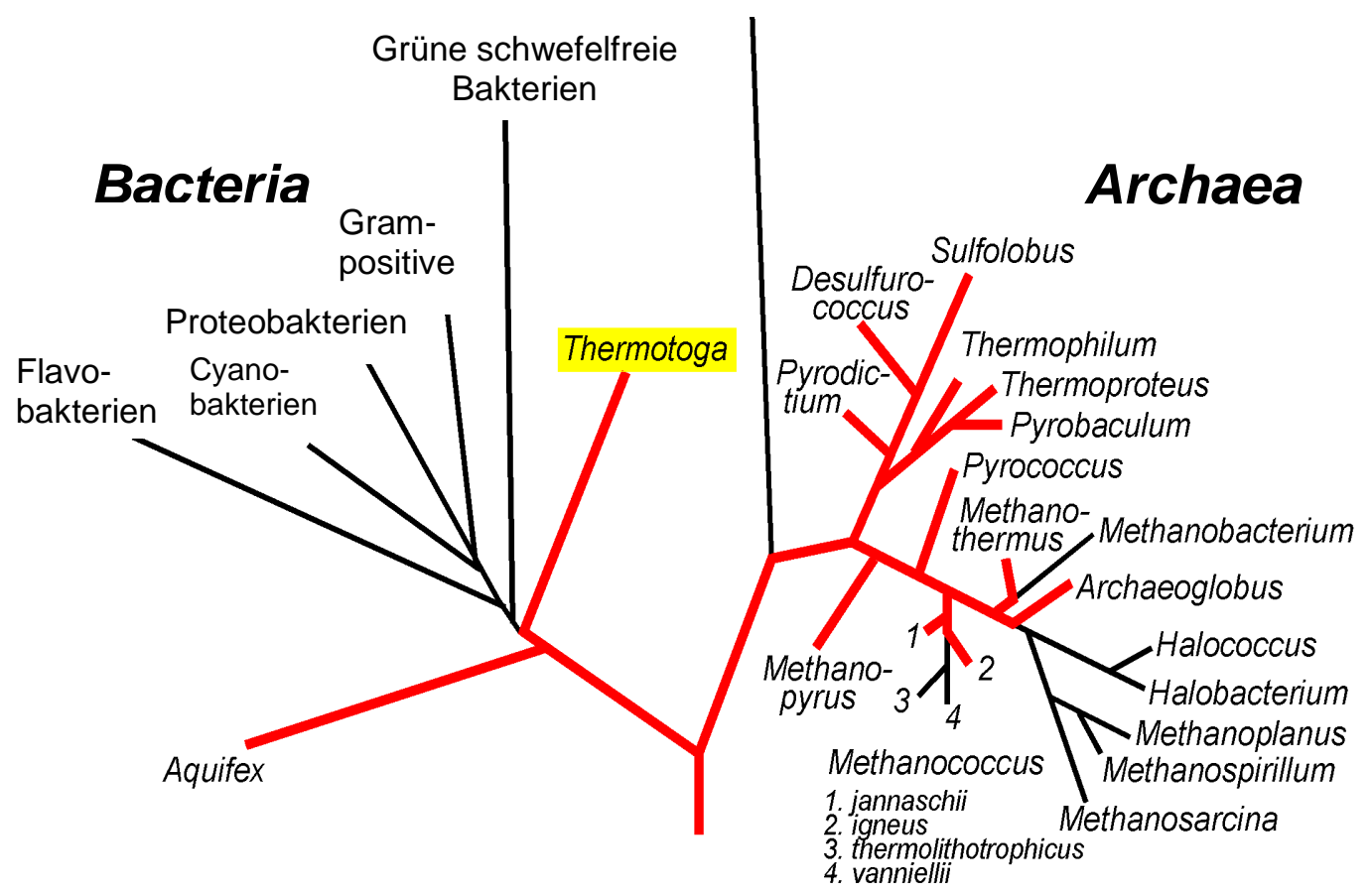

Abb. 1: Ausschnitt aus dem phylogenetischen Stammbaum, basierend auf 16S rRNA-Daten; hyperthermophile Entwicklungslinien sind durch dicke rote Striche gekennzeichnet (verändert entnommen aus Stetter, 1996). 
Das strikt anaerobe, stäbchenförmige, Gram-negative Bakterium Thermotoga maritima wurde aus geothermal erhitzten Meeressedimenten bei Vulcano (Sizilien) isoliert und stellt mit einem pH-Bereich von 5,5 bis 9,0 (Optimum: 6,5) und einem Wachstumstemperaturbereich zwischen 55 und $90^{\circ} \mathrm{C}$ eines der thermophilsten der bisher entdeckten Bakterien dar (Huber et al., 1986). Der Organismus ist obligat chemoorganoheterotroph, verwertet durch fermentativen Stoffwechsel eine Vielzahl organischer Polymere wie z.B. Stärke (Amylose, Amylopektin), Glykogen, Xylan oder Cellulose und bildet vor allem Acetat, $\mathrm{CO}_{2}$ und $\mathrm{H}_{2}$, in geringeren Mengen aber auch L-Lactat (Selig et al., 1997). Phylogenetische Studien, basierend auf vergleichende Analysen der 16S rRNA, ermöglichten die Einordnung der Ordnung der Thermotogales (mit dem Genus Thermotoga) im Stammbaum als einen der ursprünglichsten und nur sehr langsam evolvierenden Zweig der Domäne der Bacteria (AchenbachRichter et al., 1987). Es ist allgemein anerkannt, daß bakterielle und archaeelle Hyperthermophile die Vorläufer der mesophilen Mikroorganismen darstellen. Neuere Forschungsergebnisse lassen aber auch eine anders ausgerichtete Sichtweise zu. Hyperthermophile könnten sich demnach durch Adaption an hohe Temperaturen aus mesophilen Einzellern entwickelt haben (Galtier et al., 1999).

Nach der kürzlich erfolgten Sequenzierung des Thermotoga maritima Genoms (Nelson et al., 1999) liegt nun die genetische Information eines faszinierenden Mikroorganismus offen, die neben der Grundlagenforschung zum Verständnis der Thermophilie und Phylogenie auch ein enormes Potential für das Feld der angewandten Biotechnologie eröffnet. Die Vorteile thermostabiler Biokatalysatoren aus (hyper-) thermophilen Organismen in einem industriellen Prozeß liegen auf der Hand: Neben einer gesteigerten und schnelleren Produktausbeute durch die erhöhte Löslichkeit und Diffusionsrate der Substrate und Produkte, ist eine vereinfachte Prozeßführung durch die intrinsische Stabilität der Enzyme gegenüber denaturierenden physikalischen als auch chemischen Faktoren möglich. Zusätzlich kann die Kontaminationsgefahr durch das Anlegen hoher Produktionstemperaturen gesenkt werden (Sterner und Liebl, 2001). Die hohen Temperaturen führen jedoch auch dazu, daß die Energetik nach ökologischen Gesichtspunkten nicht unbedingt vorteilhaft ist. Thermostabile Biokatalysatoren spielen schon heute eine wichtige Rolle in den Bereichen Chemie (Produktion von Bio-(fein)chemikalien), Molekularbiologie (z.B. TaqPolymerase für die PCR), Papier-, Waschmittelindustrie (Lipasen, Proteasen) und vor allem in der Stärke verarbeitenden Industrie (z.B. $\alpha$-Amylasen, Glucoamylasen). 


\section{Struktur und Abbau von Stärke}

Die vorherrschende Speichersubstanz der Pflanzen ist die Stärke, welche sich aus den Glucanen Amylose (15-27\%) und Amylopektin zusammensetzt. Im Getreidekorn kann dieses typisch pflanzliche Reservekohlenhydrat bis zu 70\% des Frischgewichtes ausmachen. Amylose besteht aus unverzweigten Ketten von D-Glucose, die $\alpha-1,4-g l u c o s i d i s c h$ miteinander verknüpft sind. Die Glucoseketten nehmen eine schraubenförmige Konformation ein und sind für die typische Blaufärbung mit lod verantwortlich. Amylopektin ist ebenfalls eine Poly- $\alpha-1,4-D-G l u c o s e$, aber zusätzlich an etwa jedem 25. Glucosemolekül noch in 1,6-Stellung verzweigt. Die Stärketypen verschiedener Herkunft unterscheiden sich bezüglich Verzweigung, Polymerisationsgrad und anderen Eigenschaften erheblich (Schlegel, 1992).

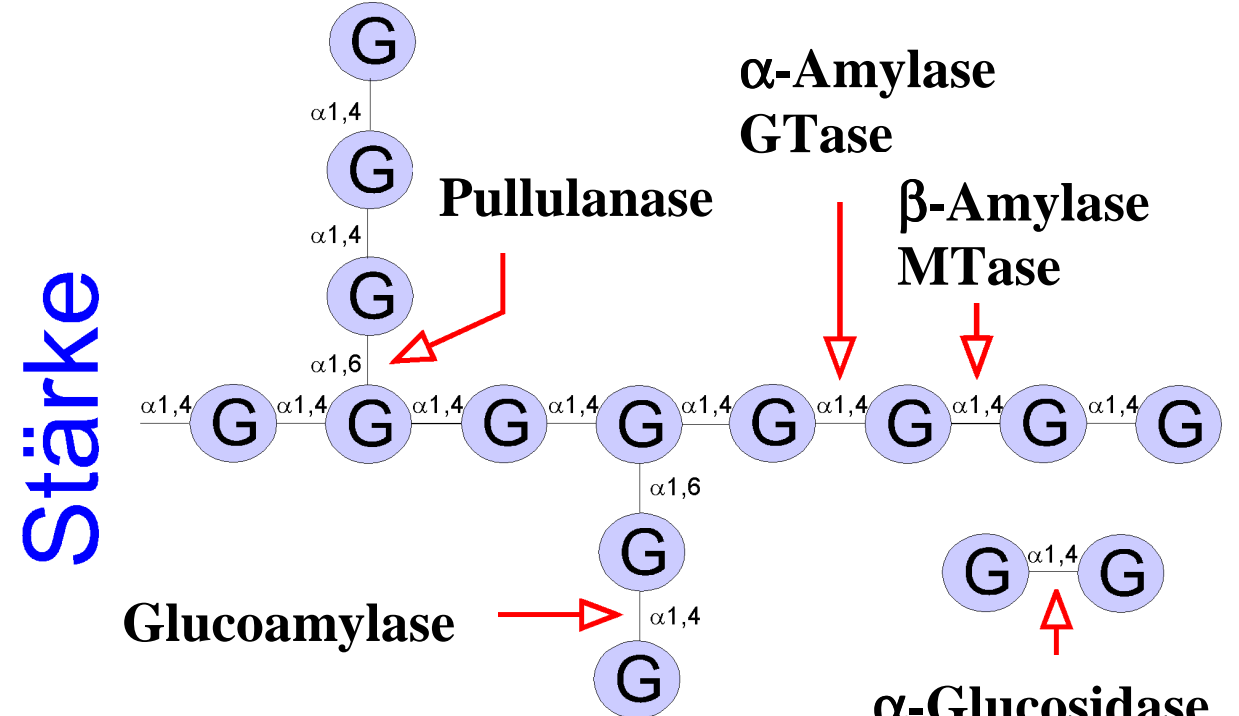

Abb. 2: Ausschnitt aus einem hypothetischen Stärkemolekül und Angriffspunkte der an der Hydrolyse beteiligten Enzyme. G = D-Glucose; GTase: 4- $\alpha$-Glucanotransferase; MTase: Maltosyltransferase

In Abb. 2 sind verschiedene Enzymaktivitäten, die an der Hydrolyse der Stärke beteiligt sein können, dargestellt. Man unterscheidet drei Typen des enzymatischen Abbaus von Glucanen im allgemeinen:

- Phosphorolyse: Übertragung eines Glycosylrestes zwischen einem ZuckerHydroxyl und einem Phosphathydroxyl (Phosphorylasen)

- Hydrolyse: Übertragung eines Glycosylrestes zwischen einem Zucker-Hydroxyl und einem „Wasser-Hydroxyl“ (z. B. $\alpha$-Glucosidasen)

- Transglycosylierung: Übertragung eines Glycosylrestes von einem ZuckerHydroxyl auf ein anderes (Glycosyltransferasen) 
Gegenstand dieser Arbeit sind die sich vom Mechanismus her ähnelnden Glycosylhydrolasen und -transferasen. Daher sollen im folgenden die $\alpha$-Glucosidasen und die Maltodextrin Glycosyltransferasen, welche auch geringe hydrolytische Eigenschaften aufweisen können, näher erläutert werden.

\section{$\alpha$-Glucosidasen}

$\alpha$-Glucosidasen sind im allgemeinen Enzyme, die hydrolytisch $\alpha$-glycosidische Bindungen in Glucose-haltigen Oligosacchariden spalten können. Polymere, wie z. B. Amylose oder Amylopektin werden in der Regel nicht abgebaut (Ausnahmen: Rolfsmeier et al., 1998; Suzuki et al., 1992). Die meisten der bisher bekannten $\alpha$-Glucosidasen sind Exoenzyme, d. h. der enzymatische Angriff erfolgt gerichtet von außen und nicht zufällig innerhalb des Substratmoleküls. Die bevorzugten Substrate sind Maltose (O- $\alpha$-D-Glucopyranosyl-(1 $\rightarrow 4)$-D-Glucose) oder andere Maltooligosaccharide mit $\alpha-1,4-$ glycosidischen Bindungen. Einige $\alpha$-Glucosidasen können auch die $\alpha$-1,6-Bindungen der Isomaltose (O- $\alpha$-D-Glucopyranosyl-(1 $\rightarrow 6)$-D-Glucose) oder anderer verzweigter Maltooligosaccharide spalten. Ebenso können Disaccharide wie

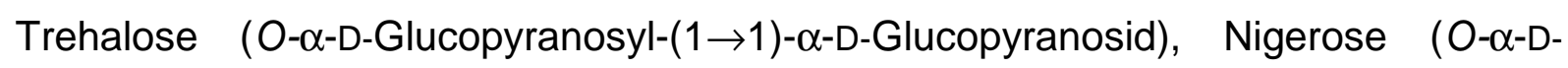
Glucopyranosyl-(1 $\rightarrow 3)$-D-Glucose), Saccharose (O- $\alpha$-D-Glucopyranosyl-( $1 \rightarrow 2)-\beta-D$ Fructofuranosid), Turanose (O- $\alpha$-D-Glucopyranosyl-(1 $\rightarrow 3)-\beta-D-F r u c t o f u r a n o s e)$ oder Melizitose (O- $\alpha$-D-Glucopyranosyl-( $1 \rightarrow 3)$-O- $\beta$-D-Fructofuranosyl-( $2 \rightarrow 1)-\alpha-D-G l u c o p y-$ ranosid) gespalten werden. Cyclodextrinasen sind Endoenzyme (Endo- $\alpha$-Glucosidasen), welche zirkuläre Maltooligosaccharide spalten können. Einige $\alpha$-Glucosidasen sind auf phosphorylierte Substrate (z. B. Maltose-6-Phosphat) spezialisiert (6-Phospho- $\alpha$-Glucosidasen). Die $\alpha$-Glucosidase MalL aus Bacillus subtilis kombiniert Saccharase-, Isomaltase- und Maltaseaktivität (Schönert et al., 1998).

$\alpha$-Glucosidasen konnten in zahlreichen Prokaryonten und Eukaryonten gefunden werden. Allerdings sind die Kenntnisse über Vorkommen und Eigenschaften dieser Enzymklasse in hyperthermophilen Organismen sehr begrenzt. Lediglich in den Archaeen Thermococcus sp. (Piller et al., 1996), Pyrococcus furiosus (Badr et al., 1994; Constantino et al., 1990) und Sulfolobus solfataricus (Rolfsmeier et al., 1998; Rolfsmeier und Blum, 1995) wurden $\alpha$-Glucosidasen näher charakterisiert. Keines dieser Enzyme benötigt Cofaktoren für die Aktivität. 
Die $\alpha$-Glucosidase AglA aus Thermotoga maritima, welche in dieser Arbeit näher charakterisiert werden sollte, ist das erste Beispiel einer $\alpha$-Glucosidase aus einem hyperthermophilen Bakterium mit einem zudem höchst ungewöhnlichem Bedürfnis für Aktivatoren (Raasch et al., 2000).

\section{Maltodextrin Glycosyltransferasen}

Es sind drei verschiedene Typen nicht-hydrolytischer Enzyme bekannt, die Glycosyltransferreaktionen mit $\alpha-1,4-$ Glucanen (Stärke/Maltodextrine) als Substrate durchführen können. Maltodextrin Glycosyltransferasen und Cyclodextrin Glycosyltransferasen spalten $\alpha$-1,4-glycosidische Bindungen und formieren ( $\alpha$-1,4-verknüpfte) neue lineare oder zyklische Produkte. Amylose und Amylopektin sind die Substrate des Glykogen-Verzweigungsenzyms. Diese Transferase spaltet $\alpha-1,4$-glycosidische Bindungen und fügt anschließend neue $\alpha-1,6$-Verzweigungen in das Polymer ein. Der dritte Typ ist das Glykogen-Entzweigungsenzym (Amylo-1,6-Glucosidase/4- $\alpha$ Glucanotransferase), die neben einer Maltotriosyl-Transferase- auch eine $\alpha$-Glucosidase-Aktivität besitzt.

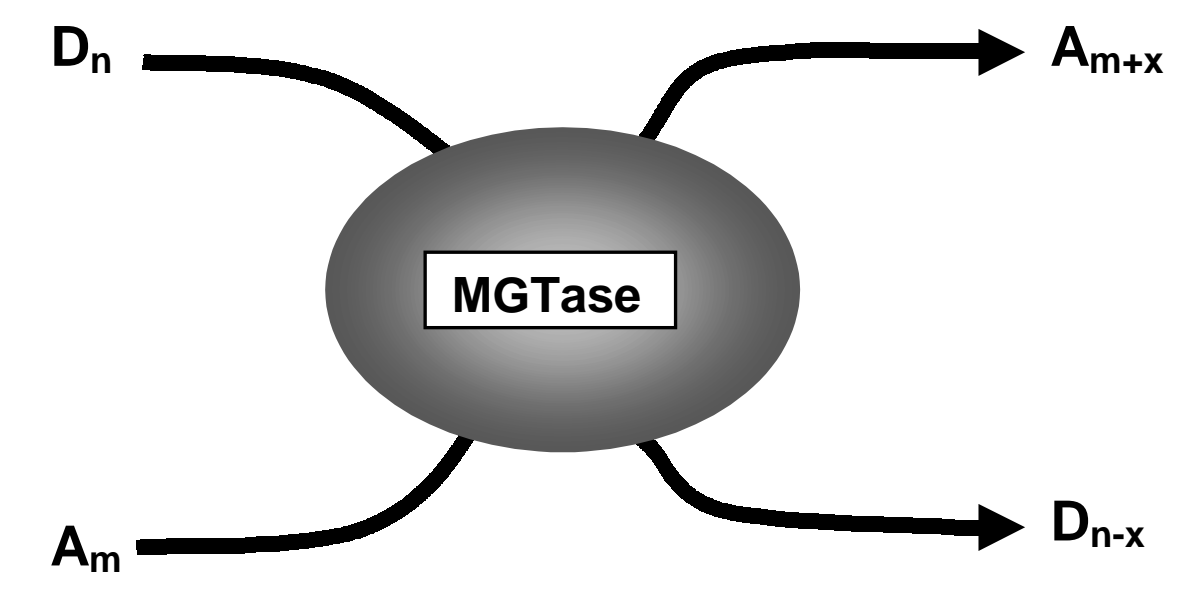

\begin{tabular}{|c|c|c|c|}
\hline Enzym & \multicolumn{3}{|c|}{ Transferspezifität } \\
& $\mathbf{n}$ & $\mathbf{m}$ & $\mathbf{x}$ \\
\hline GTase & $\geq 4$ & $\geq 2$ & $\geq 2$ \\
\hline MTase & $\geq 3$ & $\geq 1$ & $\mathbf{2}$ \\
\hline
\end{tabular}

Abb. 3: Allgemeines Reaktionsschema des Glycosyltransfers durch MGTasen aus Thermotoga maritima. $D_{n}=$ Donor-Glucan mit Polymerisationsgrad $n ; A_{m}=$ Akzeptor-Substrat mit Polymerisationsgrad $\mathrm{m} ; \mathrm{x}=$ Polymerisationsgrad des übertragenen Glycosylsegments (nach Meissner, 1997) 
In Abb. 3 ist das Reaktionsschema für die zwei Maltodextrin Glycosyltransferasen dargestellt, die in dieser Arbeit charakterisiert wurden.

Die 4- $\alpha$-Glucanotransferase (GTase) aus T. maritima überträgt Maltosyl- oder größere Glucanosyleinheiten. Als Produkt entsteht eine lückenlose Serie linearer Oligosaccharid-Produkte, beginnend mit Maltose. Bei der Umsetzung von löslicher Stärke, Amylopektin und Amylose verändert sich die Anfärbbarkeit mit lod. Diese Änderung ließ sich durch Zugabe eines Glucanosylakzeptor-Moleküls noch steigern. Weitere experimentelle Daten (Liebl et al., 1992) legen nahe, daß bei der GTase ein endo-Mechanismus vorliegt.

Die extrem thermostabile Maltosyltransferase (MTase) aus T. maritima stellt einen völlig neuen Typ einer Maltodextrin Glycosyltransferase dar, die Stärke und Maltooligosaccharide als Substrate umwandeln kann. Die Transferaktivität ist streng auf die Übertragung von Maltosyleinheiten beschränkt. Dies zeigt das Produktspektrum der Transferreaktion: Bei Substraten mit ungeradzahligen Polymerisationsgrad (DP) entstehen nur ungeradzahlige Produkte, geradzahlige Substrate liefern ausschließlich geradzahlige Produkte (zumindest bei nicht-extensiver Inkubation). Die MTase bildet dabei mehr längerkettige Produkte als die GTase (Meissner und Liebl, 1998; Meissner, 1997) und agiert nach einem Exo-Mechanismus. Dies steht im Gegensatz zu allen anderen bisher beschriebenen Maltodextrin Glycosyltransferasen. Die Analyse der MTase-Primärstruktur ergab geringe, lokal begrenzte Übereinstimmungen zur Glycosyl-Hydrolase Familie 13 ( $\alpha$-Amylase Familie). Diese Familie umfasst über 30 verschiedene Enzymtypen, die als Hydrolasen, Transferasen und Isomerasen klassifiziert wurden (Janecek, 1997; Kuriki und Imanaka, 1999). Die Gemeinsamkeit

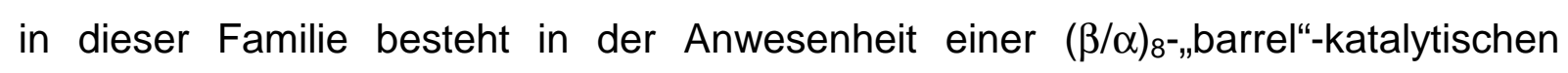
Kerndomäne mit einer großen Schleife oder Domäne (Domäne $B$ ) zwischen dem dritten $\beta$-Strang und der dritten $\alpha$-Helix (Abb. 4). Diese Domäne B ist bei den Familie 13-Enzymen derjenige Bereich mit der geringsten Ähnlichkeit, konnte aber bei einigen Enzymen funktionell der Substraterkennung zugeordnet werden (u.a. Buisson et al., 1987; Matsuura et al., 1984). 
Domäne N

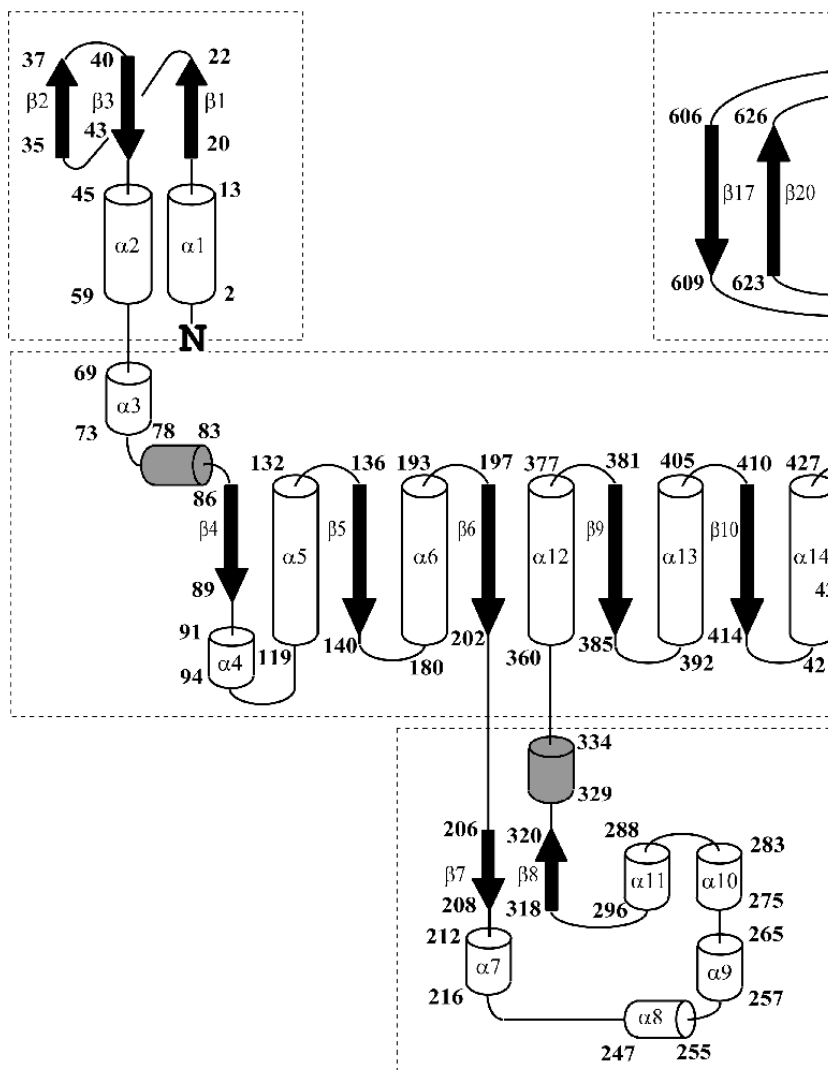

Domäne C
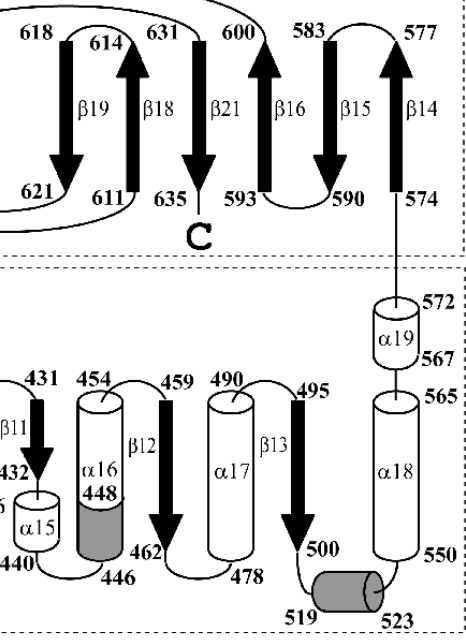

Domäne A

Domäne B

Abb. 4: Topologie der Sekundärstrukturelemente der MTase (T. maritima). $\alpha$-Helices sind durch Zylinder, 3/10-Helices durch graue Zylinder und $\beta$-Stränge durch Pfeile dargestellt (Roujeinikova et al., 2001).

\section{Die Ziele dieser Arbeit waren,}

- die Cofaktor-abhängige enzymatische Aktivität der ersten $\alpha$-Glucosidase eines hyperthermophilen Bakteriums molekulargenetisch und proteinbiochemisch zu charakterisieren.

- durch Kristallisation und Aufklärung der dreidimensionalen Struktur einer Maltodextrin Glycosyltransferase aus T. maritima, in Zusammenarbeit mit Prof. Dr. D.W. Rice (Sheffield, UK), weitere Kenntnisse über die molekularen Grundlagen der Thermostabilität und des Katalysemechanismus dieses Enzyms zu erhalten.

- parallel zur Strukturaufklärung der rekombinanten Maltosyltransferase durch ortsspezifische Mutagenese-Studien neue Erkenntnisse über die Bedeutung ausgewählter Aminosäuren für die enzymatische Spezifität, die Substratbindung und die Oligomerisierung zu gewinnen. 


\section{MATERIAL UND METHODEN}

\subsection{Organismen und Plasmide}

Die in dieser Arbeit verwendeten Bakterienstämme und Plasmide sind mit ihren charakteristischen geno- und phänotypischen Eigenschaften in den Tabellen 1 und 2 aufgeführt.

Tab. 1: Verwendete Bakterienstämme

\begin{tabular}{|c|c|c|}
\hline Stamm & $\begin{array}{l}\text { Relevanter Geno }{ }^{a)} \text { - oder Phäno- } \\
\text { typ }\end{array}$ & Herkunft/Referenz \\
\hline E. coli BL21(DE3) & $\begin{array}{l}\text { hsdF, gal( } \lambda \text { clts } 857 \text { ind1 Sam7 } \\
\text { nin5 lacUV5-T7 gene 1) }\end{array}$ & Studier und Moffat, 1986 \\
\hline E. coli $\mathrm{DH} 5 \alpha$ & $\begin{array}{l}\mathrm{F}^{-}, \text {lacZ } \Delta M 15, \text { recA1, hsdR17, } \\
\text { supE44, } \triangle(\text { lacZYA, argF }\end{array}$ & $\begin{array}{l}\text { Gibco-Bethesda Research } \\
\text { Laboratories, Eggenstein }\end{array}$ \\
\hline E. coli JM83 & $\begin{array}{l}\text { ara, } \Delta \text { (lac-proAB), rpsL, } \Phi 80 \\
\text { lacZ } \Delta \text { M15 }\end{array}$ & Yanish-Perron et al., 1985 \\
\hline E. coli XI1-Blue & 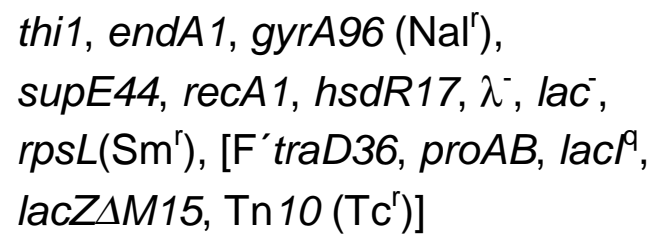 & Bullock et al., 1987 \\
\hline
\end{tabular}

a) Genotypenbezeichnungen: s. Bachmann, 1987

Tab. 2: Verwendete Plasmide

\begin{tabular}{llcl}
\hline Plasmid & relevante Eigenschaften $^{\text {a) }}$ & $\begin{array}{c}\text { Größe } \\
(\mathrm{kB})\end{array}$ & Herkunft/Referenz \\
\hline pBluescript II SK ${ }^{+-}$ & Amp $^{\mathrm{r}}$, lacPOZ & 3,0 & $\begin{array}{l}\text { Stratagene, San } \\
\text { Diego, Cal., USA }\end{array}$ \\
pET-21a $(+), \mathrm{c}$ & siehe Abbildung & 5,4 & $\begin{array}{l}\text { Stratagene, San } \\
\text { Diego, Cal., USA }\end{array}$ \\
pET21c-mgtA & $\begin{array}{l}\text { Amp }{ }^{\mathrm{r}} \text {, mgtA mittels Ndel+EcoRI } \\
\text { in pET21c }\end{array}$ & 6,8 & diese Arbeit
\end{tabular}




\begin{tabular}{|c|c|c|c|}
\hline рTAA3 & $\begin{array}{l}\text { Amp }{ }^{r} \text {, Tet', pUN121-Derivat zur } \\
\text { konstitutiven Expression der } \\
\text { MTase }\end{array}$ & 8,5 & Meissner, 1997 \\
\hline pWBE2.4 & $\begin{array}{l}\mathrm{Amp}^{\mathrm{r}}, \mathrm{Kan}^{\mathrm{r}} \text {, aglA-Gen auf } \\
\text { einem 2,4 kB EcoRV(partial)- } \\
\text { BamHI Fragment, kloniert in } \\
\text { den Smal-geschnittenen } \\
\text { Expressionsvektor pWLQ2 }\end{array}$ & 11,0 & Goßlar, 1992 \\
\hline pJF118ut-agIA & $\begin{array}{l}\text { Amp }^{r} \text {, Tet', } 2,4 \text { kB-EcoRI- } \\
\text { Fragment aus pM2 (Liebl, } \\
\text { persönl. Mitteilung) mit aglA- } \\
\text { Gen (T. neapolitana), kloniert } \\
\text { in EcoRI geschnittenen } \\
\text { Expressionsvektor pJF118ut }\end{array}$ & 8,8 & diese Arbeit \\
\hline pET21a-agIA & $\begin{array}{l}\text { Amp }{ }^{r} \text {, aglA aus pWBE2.4 mit- } \\
\text { tels EcoRI+Hindlll in pET21a }\end{array}$ & 6,9 & diese Arbeit \\
\hline pET21a-G10A & $\begin{array}{l}\text { Amp }{ }^{r} \text {, aglA aus pWBE2.4 mit } \\
\text { Punktmutation (As-Austausch: } \\
\text { G10A) mittels EcoRI+Hindlll in } \\
\text { pET21a }\end{array}$ & 6,9 & diese Arbeit \\
\hline pET21a-G12A & $\begin{array}{l}\text { Amp }{ }^{r} \text {, aglA aus pWBE2.4 mit } \\
\text { Punktmutation (As-Austausch: } \\
\text { G12A) mittels EcoRI+HindllI in } \\
\text { pET21a }\end{array}$ & 6,9 & diese Arbeit \\
\hline pET21a-S13A & $\begin{array}{l}\text { Amp }^{r} \text {, aglA aus pWBE2.4 mit } 2 \\
\text { Basenaustauschen (As-Aus- } \\
\text { tausch: } \mathrm{S} 13 \mathrm{~A} \text { ) mittels EcoRI+ } \\
\text { HindllI in pET21a }\end{array}$ & 6,9 & diese Arbeit \\
\hline pET21a-C174S & $\begin{array}{l}\text { Amp }{ }^{r}, \text { aglA aus pWBE2.4 mit } \\
\text { Punktmutation (As-Austausch: } \\
\text { C174S) mittels EcoRI+Hindlll in } \\
\text { pET21a }\end{array}$ & 6,9 & diese Arbeit \\
\hline pET21a-aglB & $\begin{array}{l}\text { Amp }{ }^{r}, \text { aglB mittels } \mathrm{Ndel}+\mathrm{Xhol} \text { in } \\
\text { pET21a }\end{array}$ & 6,8 & diese Arbeit \\
\hline
\end{tabular}




\begin{tabular}{|c|c|c|c|}
\hline pET21a-mmtA & $\begin{array}{l}\text { Amp }{ }^{r}, m m t A \text { aus pTAA3 mittels } \\
\text { Ndel }+ \text { Hindlll in pET21a }\end{array}$ & 7,3 & diese Arbeit \\
\hline pET21a-K151A & $\begin{array}{l}\text { Amp }^{r}, \text { mmtA aus pTAA3 mit } 2 \\
\text { Basenaustauschen (As-Aus- } \\
\text { tausch: K151A) mittels Ndel+ } \\
\text { Hindlll in pET21a }\end{array}$ & 7,3 & diese Arbeit \\
\hline pET21a-T206H & $\begin{array}{l}\text { Amp }^{r}, \text { mmtA aus pTAA3 mit } 3 \\
\text { Basenaustauschen (As-Aus- } \\
\text { tausch: T206H) mittels Ndel+ } \\
\text { Hindlll in pET21a }\end{array}$ & 7,3 & diese Arbeit \\
\hline pET21a-D385N & $\begin{array}{l}\text { Amp }^{r}, m m t A \text { aus pTAA3 mit } \\
\text { Punktmutation (As-Austausch: } \\
\text { D385N) mittels Ndel+Hindlll in } \\
\text { pET21a }\end{array}$ & 7,3 & diese Arbeit \\
\hline pET21a-E414Q & $\begin{array}{l}\text { Amp }{ }^{r}, m m t A \text { aus pTAA3 mit } \\
\text { Punktmutation (As-Austausch: } \\
\text { E414Q) mittels Ndel+Hindlll in } \\
\text { pET21a }\end{array}$ & 7,3 & diese Arbeit \\
\hline pET21a-T466N & $\begin{array}{l}\text { Amp }^{r}, \text { mmtA aus pTAA3 mit } 2 \\
\text { Basenaustauschen (As-Aus } \\
\text { tausch: T466N) mittels Ndel+ } \\
\text { Hindlll in pET21a }\end{array}$ & 7,3 & diese Arbeit \\
\hline pET21a-P467H & $\begin{array}{l}\text { Amp }^{r}, m m t A \text { aus pTAA3 mit } \\
\text { Punktmutation (As-Austausch: } \\
\text { P467H) mittels Ndel+Hindlll in } \\
\text { pET21a }\end{array}$ & 7,3 & diese Arbeit \\
\hline $\begin{array}{l}\text { pET21a- } \\
\text { T206H/P467H }\end{array}$ & $\begin{array}{l}\text { Amp }^{r}, \text { mmtA - Doppelmutante } \\
\text { (As-Austausch: T206H+P467H) } \\
\text { mittels Ndel+Hindll in pET21a }\end{array}$ & 7,3 & diese Arbeit \\
\hline pET21a-V110R & $\begin{array}{l}\text { Amp }{ }^{r}, m m t A \text { aus pTAA3 mit } 2 \\
\text { Basenaustauschen (As-Aus- } \\
\text { tausch: V110R) mittels Ndel+ } \\
\text { HindllI in pET21a }\end{array}$ & 7,3 & diese Arbeit \\
\hline
\end{tabular}




\begin{tabular}{|c|c|c|c|}
\hline pET21a-A230R & $\begin{array}{l}\text { Ampr }{ }^{r}, m m t A \text { aus pTAA3 mit } 3 \\
\text { Basenaustauschen (As-Aus- } \\
\text { tausch: A230R) mittels Ndel+ } \\
\text { Hindlll in pET21a }\end{array}$ & 7,3 & diese Arbeit \\
\hline $\begin{array}{l}\text { pET21a- } \\
\text { V110R/A230R }\end{array}$ & $\begin{array}{l}\text { Amp }{ }^{r}, \text { mmtA - Doppelmutante } \\
\text { (As-Austausch: V110R+A230R) } \\
\text { mittels Ndel+Hindlll in pET21a }\end{array}$ & 7,3 & diese Arbeit \\
\hline pET21a-D317A & $\begin{array}{l}\text { Amp }^{r}, \text { mmtA aus pTAA3 mit } \\
\text { Punktmutation (As-Austausch: } \\
\text { D317A) mittels Ndel+Hindll in } \\
\text { pET21a }\end{array}$ & 7,3 & diese Arbeit \\
\hline $\begin{array}{l}\text { pET21a- } \\
\text { K151A/D317A }\end{array}$ & $\begin{array}{l}\text { Amp }{ }^{r}, \text { mmtA -Doppelmutante } \\
\text { (As-Austausch: K151A+D317A) } \\
\text { mittels Ndel+Hindll in pET21a }\end{array}$ & 7,3 & diese Arbeit \\
\hline
\end{tabular}

a) Phänotypbezeichnungen: $\mathrm{Amp}^{r}$, Ampicillin-Resistenz; Tetr', Tetracyclin-Resistenz; Genotypbezeichnung: lacPOZ', Promotor-Operator-Region des Lactose-Operons und $\alpha$-Peptid der $\beta$-Galactosidase

Abb. 5: Der Expressionsvektor $\mathbf{p E T}-21 \mathrm{a}(+)$ verfügt über ein Ampicillinresistenzgen und ein mit IPTG induzierbares T7-Promotor/lac-Operator-Element.

pET-21c(+) ist ein 5441 bp Plasmid. Diesem fehlen 2 bp neben der BamHI-Schnittstelle (198).

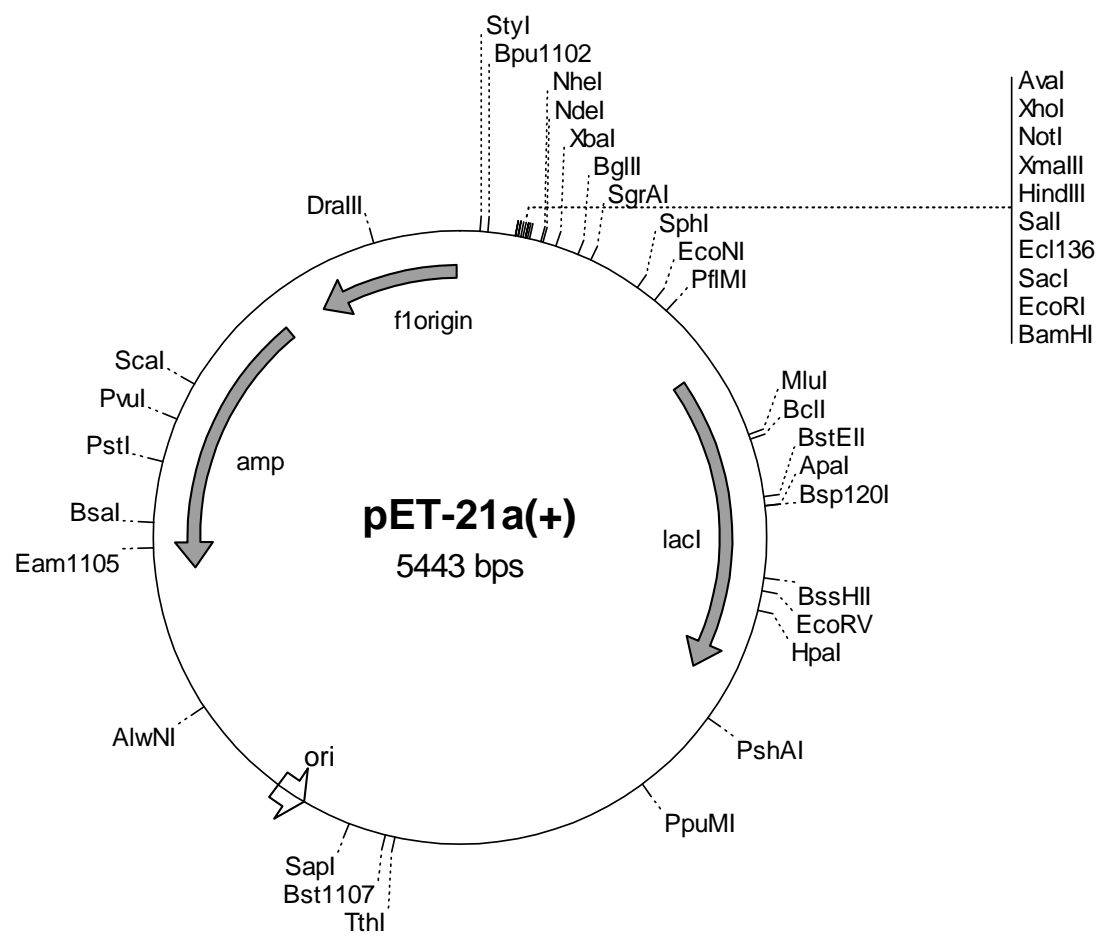


Abb. 6: Der Überexpressionsvektor pJF118ut wurde von Binder (1987) konstruiert. Er enthält ein Ampicillin- und Tetracyclinresistenzgen, sowie einen tac-Promotor, der unter Kontrolle des lac-Repressors steht.

\subsection{Zellanzucht}

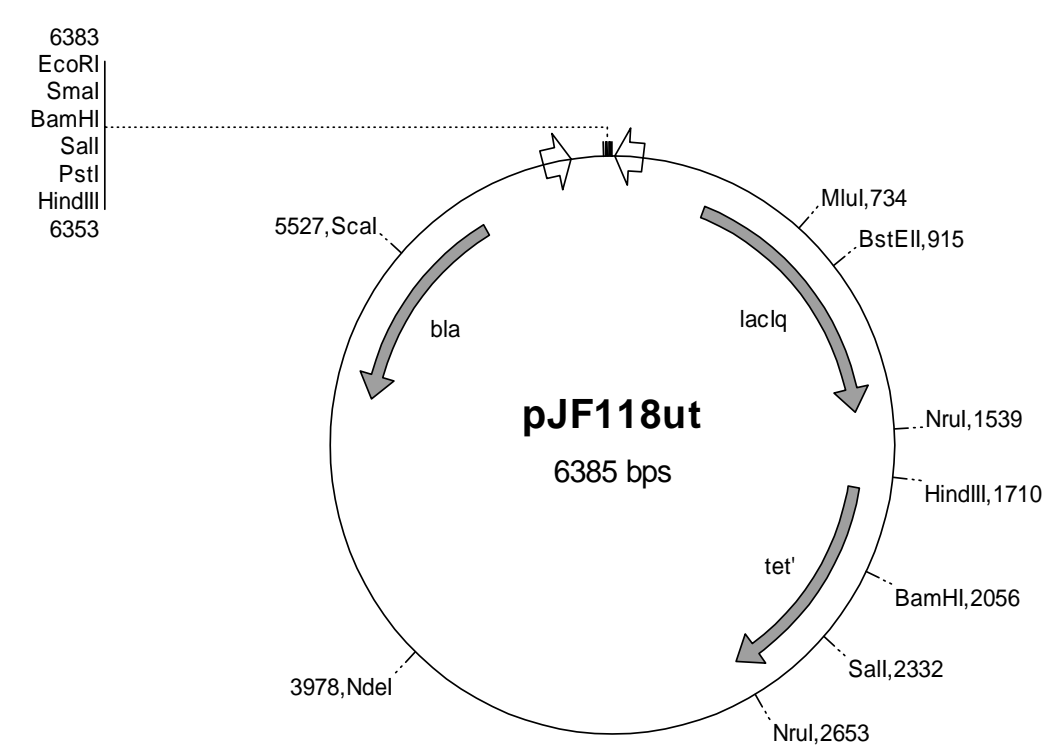

\subsubsection{Nährmedien}

Alle Lösungen und Medien wurden, falls nicht anders angegeben, durch 20-minütiges Autoklavieren sterilisiert. Zur Herstellung von festen Nährböden wurde den Medien 1,5\% (w/v) Agar zugesetzt.

LB-Medium (Sambrook et al., 1989)

Zur Kultivierung von E. coli Kulturen wurde standardmäßig ein Luria-Bertani- (LB-) Medium mit folgender Zusammensetzung verwendet:

$\begin{array}{lrl}\text { Trypton } & 10 & \mathrm{~g} \\ \text { Hefeextrakt } & 5 & \mathrm{~g} \\ \mathrm{NaCl} & 5 & \mathrm{~g} \\ \mathrm{H}_{2} \mathrm{O}_{\text {demin. }} & \text { ad } 1000 & \mathrm{ml}\end{array}$

\subsubsection{Antibiotika und andere Medienzusätze}

Sofern im Text nicht anders beschrieben, wurden Stammlösungen angesetzt, sterilfiltriert und bei $-20^{\circ} \mathrm{C}$ gelagert. Die Lösungen wurden autoklavierten Nährmedien nach deren Abkühlung auf $\leq 55^{\circ} \mathrm{C}$ in entsprechender Menge zugegeben (Tabelle 3). 
Tab. 3: Konzentrationen der verwendeten Antibiotika und anderer Medienzusätze

\begin{tabular}{cccc}
\hline Substanz & Lösungsmittel & Stammlösung $(\mathrm{mg} / \mathrm{ml})$ & Endkonzentration $(\mu \mathrm{g} / \mathrm{ml})$ \\
\hline Ampicillin & $\mathrm{H}_{2} \mathrm{O}$ dest. & 100 & 100 \\
IPTG & $\mathrm{H}_{2} \mathrm{O}$ dest. & $24(0,1 \mathrm{M})$ & $24(0,1 \mathrm{mM})$ \\
X-Gal & Dimethylformamid & 20 & 64 \\
\hline
\end{tabular}

\subsubsection{Zellanzucht}

Alle E. coli-Stämme wurden aerob, bei $37^{\circ} \mathrm{C}$ schwenkend, in Flüssigkulturen in Reagenzgläsern oder Erlenmeyerkolben angezogen, deren Volumina das zehnfache des Kulturvolumens entsprachen. Alle plasmidhaltigen Stämme wurden dabei stets durch Zugabe eines geeigneten Antibiotikums unter Selektionsdruck gehalten. Hauptkulturen wurden 2-3\%-ig (v/v) mit einer Vorkultur angeimpft. Die Kultivierung auf festen Medien erfolgte beim Wachstum auf LB-Platten bei $37^{\circ} \mathrm{C}$ über Nacht.

\subsubsection{Reinheitskontrolle und Stammhaltung}

Zur Überprüfung der Reinheit einer Bakterienkultur wurde die Einheitlichkeit der Zellen mikroskopisch und die Koloniemorphologie und -färbung nach Verdünnungsausstrich auf Komplexmedium makroskopisch überprüft.

Für eine längere Konservierung der Bakterienstämme wurde eine Stammsammlung angelegt, die bei $-75^{\circ} \mathrm{C}$ aufbewahrt wurde. Dafür wurde eine Reinkultur über Nacht in LB-Medium (in Gegenwart der jeweiligen Antibiotika) angezogen und mit $10 \%(\mathrm{v} / \mathrm{v})$ Dimethylsulfoxid (DMSO) versetzt. Davon wurde $1 \mathrm{ml}$ in einem sterilen SchraubEppendorf-Reaktionsgefäß bei $-75^{\circ} \mathrm{C}$ eingefroren. Für den schnellen Gebrauch von Bakterienstämmen wurden diese auf Agarplatten mit Selektivmedium angezogen, die bei $4^{\circ} \mathrm{C}$ in der Regel mehrere Wochen lang lagerfähig waren.

\subsubsection{Messung der optischen Dichte}

Die optische Dichte von Flüssigkulturen wurde in Einmalküvetten mit einer Schichtdicke von $1 \mathrm{~cm}$ photometrisch bei einer Wellenlänge von $600 \mathrm{~nm}$ bestimmt (Pharmacia Biotec; Ultraspec 3000), wobei als Nullwert unbeimpftes Medium verwendet wurde. Bei OD-Werten $\geq 0,5$ wurden die Proben mit dem entsprechenden 
Medium verdünnt, da nur im Extinktionsbereich von 0-0,5 eine ausreichende Linearität der Beziehung Bakterienzahl / $\mathrm{ml} \approx \Delta \mathrm{E}_{600}$ gegeben ist.

\subsection{Standardtechniken für das Arbeiten mit DNA}

\subsubsection{Behandlung von Geräten und Lösungen für das Arbeiten mit Nukleinsäuren}

Zur Inaktivierung von Nukleasen wurden alle hitzestabilen Geräte und Lösungen autoklaviert. Nicht autoklavierbares Gerät wurde mit 70 \%-igem (v/v) Ethanol behandelt und falls möglich abgeflammt. Hitzelabile Lösungen wurden sterilfiltriert.

\subsubsection{Phenol/Chloroform/Isoamylalkohol-Extraktion}

Zur Extraktion von Proteinen wurden die DNA-Lösungen 1:1 mit einem Phenol/ Chloroform/Isoamylalkohol-Gemisch (25:24:1 (v/v/v)) versetzt und kräftig gemischt. Zur besseren Phasentrennung wurden die Proben $10 \mathrm{~min}$ in einer Kühlzentrifuge zentrifugiert $\left(13000 \mathrm{Upm}, 4^{\circ} \mathrm{C}\right)$ und die wäßrige, DNA-haltige Oberphase vorsichtig abgehoben. Gegebenenfalls wurde zur Entfernung von Phenolresten noch eine 1:1 Extraktion mit Chloroform/Isoamylalkohol (24:1, (v/v)) durchgeführt, allerdings genügte oftmals eine sich anschließende Fällung.

\subsubsection{Fällung von DNA mit Isopropanol oder Ethanol}

Die DNA-Lösung wurde mit 1/8 Vol. einer $3 \mathrm{M} \mathrm{Na-Acetat-Lösung}(\mathrm{pH} \mathrm{5,2)}$ und 0,7 Vol. Isopropanol oder 2,5 Vol. eiskaltem unvergälltem Ethanol (96\% (v/v)) versetzt. Nach Durchmischung (bei Ethanol-Fällung Lagerung bei $-20^{\circ} \mathrm{C}$ für $0,5-12 \mathrm{~h}$ ) konnte die DNA durch Zentrifugation (13000 Upm, $4^{\circ} \mathrm{C}, 15-30 \mathrm{~min}$ ) pelletiert werden. Das Pellet wurde einmal mit eiskaltem, unvergälltem, 70 \%-igen (v/v) Ethanol gewaschen und dann in der Vakuumzentrifuge (Speed Vac ${ }^{\circledR}$ Plus SC110A Savant) für 5-10 min getrocknet. Die so gewonnene DNA wurde im gewünschten Volumen $\mathrm{H}_{2} \mathrm{O}_{\text {dest. }}$ oder Puffer resuspendiert. 


\subsubsection{Agarose-Gelelektrophorese von DNA}

Alle DNA-Proben wurden vor der Auftragung mit 0,25 Vol. DNA-Färbelösung zur Beschwerung versetzt.

$\begin{array}{lll}\text { DNA-Färbelösung: } & \text { EDTA, 0,2 M; pH 8,0 } & 5 \mathrm{ml} \\ & \text { Ficoll } 400 & 1,5 \mathrm{~g} \\ & \text { Bromphenolblau } & 10 \mathrm{mg} \\ & \mathrm{H}_{2} \mathrm{O}_{\text {dest. }} & 5 \mathrm{ml}\end{array}$

Gelelektrophoretische Auftrennungen von Nukleinsäuren für sowohl analytische als auch präparative Zwecke erfolgten in horizontalen Elektrophoresekammern (Hoefer ${ }^{\circledR}$ HE33 Mini Horizontal Submarine Unit von Pharmacia Biotech). Gewöhnlich wurde 0,8-1,0\%-ige (w/v) Agarose in 1 x TAE-Puffer verwendet, welcher zugleich auch als Elektrophoresepuffer diente. Die Auftrennung erfolgte mit einer angelegten Spannung von 70-100 V.

$\begin{array}{llr}20 \times \text { TAE-Puffer: } & \text { Tris-Acetat } & 96,8 \mathrm{~g} \\ & \text { EDTA } & 7,4 \mathrm{~g} \\ & \mathrm{H}_{2} \mathrm{O}_{\text {demin. }} & \text { ad } 1000 \mathrm{ml} \\ & \mathrm{pH} 8,0 & \end{array}$

\subsubsection{Färbung und Photographie von DNA in Agarosegelen}

Nach Beendigung der Gelelektrophorese wurden die Nukleinsäuren im Gel in einer wäßrigen Ethidiumbromid-Lösung $(1 \mu \mathrm{g} / \mathrm{ml})$ 15-30 min gefärbt und anschließend in $\mathrm{H}_{2} \mathrm{O}_{\text {dest. }}$ gespült. In der Gel-Dokumentationsanlage (BioRad ${ }^{\circledR}$ GelDoc 1000) wurde die DNA bei UV-Licht durch das eingelagerte Ethidiumbromid sichtbar gemacht, photographisch dokumentiert und eventuell nachträglich bearbeitet (Multi-AnalystV.1.1.1.-Dokumentationsprogramm). Mittels eines Thermodruckers (Mitsubishi Video Copy Prozessor P66DE) konnten diese Bilder ausgedruckt werden.

\subsubsection{Konzentrationsbestimmung von Nukleinsäuren}

In der Regel erfolgte eine Abschätzung der DNA-Konzentration in Ethidiumbromidgefärbten Agarosegelen an Hand eines Fluoreszenzvergleiches mit einem DNAStandard bekannter Konzentration. Als Standard diente meist eine 1 kB-DNA-Leiter 
(Gene RulerTM 1kB DNA Ladder, MBI Fermentas), welche in einer Konzentration von $0,05 \mu \mathrm{g} / \mu \mathrm{l}$ eingesetzt wurde.

Die Reinheit von DNA-Lösungen wurde durch die Bildung des Quotienten von Absorptionwerten bei verschiedener Wellenlänge ermittelt (280 nm für Proteine, 230 $\mathrm{nm}$ für niedermolekulare Verbindungen wie z. B. Pyridinnukleotide). Die Messungen erfolgten in Quarzküvetten. Für reine DNA-Lösungen gelten folgende Richtwerte:

$$
\begin{array}{ll}
O_{260}: D_{280}=1,8-2,0 & \text { (Sambrook et al., 1989) } \\
\mathrm{OD}_{230}: \mathrm{OD}_{260}: \mathrm{OD}_{280}=0,45: 1: 0,515 \text { (Marmur, 1961) }
\end{array}
$$

\subsubsection{Größenbestimmung von DNA-Fragmenten}

Die Bestimmung von DNA-Fragmenten erfolgte nach Auftrennung im Agarosegel (2.3.4) anhand der Laufstrecken eines mitaufgetrennten internen Standards. Als Größenstandard diente dabei eine 1 kB-Leiter (s.o.).

\subsection{Isolierung von DNA}

\subsubsection{Schnelle Plasmid-Isolierung aus E. coli („Cracking“)}

Zur schnellen Analyse von E. coli-Transformanten, deren Plasmide (mit hoher Kopienzahl) hinsichtlich ihrer Größe charakterisiert werden sollten, diente diese Methode.

Dazu wurde von einer frisch bewachsenen Agarplatte eine Kolonie ausreichender Größe mit einem Zahnstocher abgenommen und in $50 \mu l 10 \mathrm{mM}$ EDTA (pH 8) resuspendiert. Es folgte die Zugabe von $50 \mu$ frisch angesetztem Aufschluß-Puffer und eine fünfminütige Inkubation bei $70^{\circ} \mathrm{C}$. Nach der Abkühlung auf Raumtemperatur wurden $1,5 \mu \mathrm{l} 4 \mathrm{M} \mathrm{KCl}$ und 1,0 $\mu \mathrm{l}$ DNA-Färbelösung zugegeben, $5 \mathrm{~min}$ auf Eis inkubiert und 5 min bei 13000 Upm $\left(4^{\circ} \mathrm{C}\right)$ zentrifugiert. Zur Agarose-Gelelektrophorese wurden $20 \mu$ l des Überstandes eingesetzt.

\section{Aufschluß-Puffer:}

$\begin{array}{lrr}2 \mathrm{~N} \mathrm{NaOH} & 100 & \mu \mathrm{l} \\ 10 \% \text { SDS (w/v) } & 50 & \mu \mathrm{l} \\ \text { Saccharose } & 0,2 \mathrm{~g} \\ \mathrm{H}_{2} \mathrm{O} \text { dest. } & \text { ad } 1 & \mathrm{ml}\end{array}$


2.4.2 Minipräparation von Plasmid-DNA (Birnboim und Doly, 1979, mod.)

1,5 $\mathrm{ml}$ Zellsuspension einer $5 \mathrm{ml}$-Kultur, welche in selektivem LB-Medium über Nacht bei $37^{\circ} \mathrm{C}$ angezogen wuchs, wurde $10 \mathrm{~min}$ bei $7000 \mathrm{Upm}$ abzentrifugiert und in $100 \mu \mathrm{l} \mathrm{P1-Puffer}$ resuspendiert. Der Zellaufschluß erfolgte mittels einer alkalischen Lyse durch Zugabe von $200 \mu \mathrm{l}$ P2-Lösung, fünfmaligem Umschwenken des E-Cups, sowie einer 5-minütigen Inkubation bei Raumtemperatur. Es schloß sich die Proteinfällung durch Zugabe von $150 \mu \mathrm{l}$ P3-Puffer (erneut $5 \times$ Umschwenken) und einer weiteren Inkubation von $15 \mathrm{~min}$ auf Eis an. Nach einem Zentrifugationsschritt (15 min, $13000 \mathrm{Upm}, 4^{\circ} \mathrm{C}$ ) wurde der Überstand $(400 \mu \mathrm{l})$ in ein neues E-Cup überführt (und einer Phenol/Chloroform/Isoamylalkohol Extraktion (2.3.2) unterworfen, falls eine besondere Reinheit erforderlich war) und die DNA mittels Isopropanol gefällt (2.3.3). Nach der Trocknung in der Vakuumzentrifuge konnte die DNA im gewünschten Volumen $\mathrm{H}_{2} \mathrm{O}_{\text {dest. }}$ oder TE-Puffer resuspendiert (meist $60 \mu \mathrm{l}$ ) und bei $-20^{\circ} \mathrm{C}$ gelagert werden.

\section{P1-Puffer:}

(resuspendieren)

EDTA $(10 \mathrm{mM}) \quad 0,74 \mathrm{~g}$
$\begin{array}{ll}\text { Tris- } \mathrm{HCl}(50 \mathrm{mM}) & 1,21 \mathrm{~g} \\ \mathrm{H}_{2} \mathrm{O} \text { dest. } \quad \text { ad } 200 \quad \mathrm{ml} & \\ \mathrm{pH} 8,0 & \end{array}$

$\mathrm{NaOH}(0,2 \mathrm{M})$

$8,0 \mathrm{~g}$

SDS

$10,0 \mathrm{~g}$

$\mathrm{H}_{2} \mathrm{O}$ dest.

ad $1000 \mathrm{ml}$

Kaliumacetat (3,2 M) 62,73 g

\section{P3-Puffer:}

(neutralisieren

und präzipitieren)
$\mathrm{H}_{2} \mathrm{O}$ dest. $\quad$ ad $200 \quad \mathrm{ml}$
$\mathrm{pH} 5,5$ mit Eisessig eingestellt

Um vor enzymatischen Modifikationen die Plasmid-DNA von mitgefällter RNA zu befreien, konnte RNase A-Lösung zugesetzt werden. Zunächst wurde eine RNaseStammlösung wie folgt hergestellt: RNase A wurde in einer Konzentration von $10 \mathrm{mg} / \mathrm{ml}$ in $10 \mathrm{mM}$ Tris- $\mathrm{HCl}(\mathrm{pH} 7,5) / 15 \mathrm{mM} \mathrm{NaCl}$ gelöst und dann das Gemisch für 15 min auf $90^{\circ} \mathrm{C}$ erhitzt. Nach Abkühlung auf RT konnte die Stammlösung bei $-20^{\circ} \mathrm{C}$ 
gelagert werden. Zur Herstellung der RNase-Lösung wurden $70 \mu$ der Stammlösung mit TE-Puffer auf $1 \mathrm{ml}$ aufgefüllt und anschließend bei $4^{\circ} \mathrm{C}$ gelagert.

\subsubsection{Plasmidisolierung durch „QIAprep Spin Miniprep“}

Dieser Plasmidisolierungskit von Qiagen ermöglichte die Präparation kleinerer Mengen hochreiner DNA (etwa $20 \mu \mathrm{g}$ aus 1,5 ml ÜN-Kultur von E. coli). Die Aufreinigung verlief, dem unter 2.4 .2 beschriebenden Prinzip folgend, nach Angaben des Herstellers.

\subsubsection{Isolierung von DNA-Fragmenten aus Agarosegelen}

Aus Agarosegelen konnten aufgetrennte DNA-Fragmente mit Hilfe eines kommerziell erhältlichen Extraktions-Kits (QiaQuick Gel Extraction Kit, Qiagen GmbH, Hilden) isoliert werden. Hierzu wurde das zu isolierende DNA-Fragment unter UV-Licht schnell mit dem Skalpell aus dem Gel ausgeschnitten und das Gewicht des Gelstückes bestimmt. Anschließend wurde das DNA-haltige Gelstück in 3 Vol. des QX1-Puffers bei $50^{\circ} \mathrm{C} 10 \mathrm{~min}$ lang geschmolzen und dann ein Gelvolumen Isopropanol hinzugefügt. Das Gemisch wurde auf die Qiaquick-Säule geladen und nach einer Zentrifugation (RT, 13000 Upm, 1 min) wurde der Durchfluß verworfen. Die Säule wurde dann mit 0,75 ml PE-Puffer gewaschen und erneut zentrifugiert. Zur vollständigen Entfernung des Waschpuffers wurde nach Verwerfung des Durchflusses nochmals zentrifugiert (RT, 13000 Upm, 1 min). Nach Überführung der Säule in ein neues $1,5 \mathrm{ml}$ Reaktionsgefäß erfolgte die Elution der DNA durch einminütige Inkubation mit 20-30 $\mu \mathrm{H}_{2} \mathrm{O}_{\text {MilliQ }}$ und einem weiteren Zentrifugationslauf.

\subsection{Enzymatische Modifikationen von DNA}

\subsubsection{Verdauung von DNA durch Restriktionsendonukleasen}

Die DNA-Lösungen wurden mit 1/10 Volumen des vom Hersteller empfohlenen 10-fach konzentrierten Restriktionspuffers und mit dem gewünschten Restriktionsenzym (2-20 U/ $\mu \mathrm{g}$ DNA) versetzt und für 2-6 h inkubiert. Bei Doppelverdauansätzen wurde entweder ein Puffer, in dem beide Enzyme gut schneiden, verwendet, oder es wurde zunächst das Enzym mit den niedrigeren Salzansprüchen eingesetzt und 
dann nach 3-stündiger Inkubation die Salzkonzentration durch Zugabe eines entsprechenden Volumens $1 \mathrm{M} \mathrm{NaCl}$ erhöht, das zweite Restriktionsenzym zugegeben und nach kurzem Mischen weiter inkubiert. Die Inkubationstemperatur betrug je nach eingesetztem Enzym $25^{\circ} \mathrm{C}, 30^{\circ} \mathrm{C}, 37^{\circ} \mathrm{C}$ oder $55^{\circ} \mathrm{C}$.

\subsubsection{Herstellung von glatten Enden („blunt ends“)}

Ligationen von Restriktionsfragmenten, welche keine kompatiblen Enden aufwiesen, wurden mit Hilfe des Klenow-Fragmentes der E. coli-DNA-Polymerase I ermöglicht. Die Auffüllreaktion der vorhandenen 5'-Überhänge mit Nukleotiden erfolgte direkt im Restriktionsansatz, welcher zur Hitzeinaktivierung des restlichen Restriktionsenzyms zuvor $10 \mathrm{~min}$ bei $70^{\circ} \mathrm{C}$ inkubiert worden war. Folgende Lösungen wurden miteinander gemischt:

$\begin{array}{crr}\text { DNA-Lösung } & 10 & \mu \mathrm{l} \\ \text { Klenow-Puffer } & 8 & \mu \mathrm{l} \\ \text { Klenow-Fragment }(2,5 \mathrm{U} / \mu \mathrm{l}) & 0,3 \mu \mathrm{l} \\ \text { Inkubation } 3 \min , 37^{\circ} \mathrm{C} & & \\ \mathrm{dNTP}-\mathrm{Mix}(0,4 \mathrm{mM}) & 2 & \mu \mathrm{l} \\ \text { Inkubation } 10 \mathrm{~min}, 37^{\circ} \mathrm{C} & & \end{array}$

Der Ansatz wurde einer Isopropanol-Fällung (2.3.3) unterzogen und konnte dann zur Ligation bzw. für den Verdau mit einem weiteren Enzym eingesetzt werden.

\subsubsection{Dephosphorylierung von DNA-Fragmenten}

Zur Vermeidung von Selbstligationen von restriktionsverdauter Vektor-DNA konnten die 5'-Phosphatgruppen enzymatisch mit alkalischer (shrimp) Phosphatase (Boehringer Mannheim $\mathrm{GmbH}$, Mannheim) abgespalten werden. Hierzu wurde der Verdauansatz mit $2 \mu \mathrm{l} 10$ x Puffer, 1,5 $\mu$ l Phosphatase und einer entsprechenden Menge $\mathrm{H}_{2} \mathrm{O}_{\text {dest. }}$ auf $20 \mu \mathrm{l}$ aufgefüllt und $30 \mathrm{~min}$ bei $37^{\circ} \mathrm{C}$ inkubiert. Es folgte die Zugabe von $1 \mu$ l Phosphatase und eine weitere 30-minütige Inkubation. Nach einer Hitzeinaktivierung für $10 \mathrm{~min}$ bei $75^{\circ} \mathrm{C}$ oder einer Phenol/Chloroform/IsoamylalkoholExtraktion mit anschließender Ethanolfällung (2.3.2, 2.3.3) konnte der Ansatz zur Ligation verwendet werden. 


\subsubsection{Ligation von DNA-Fragmenten}

Bei einer Ligation wird eine Phosphodiesterbindung zwischen doppelsträngigen DNA-Fragmenten gebildet, die mindestens ein freies 3'-Hydroxyende und 5'Phosphatende besitzen. Das Verhältnis von Insert-DNA zu Vektor-DNA lag zwischen $2: 1$ und $10: 1$. Vor der Ligation wurden die Restriktionsenzyme in den DNA-haltigen Lösungen durch eine Hitzebehandlung $\left(10 \mathrm{~min}, 70^{\circ} \mathrm{C}\right)$ inaktiviert. Der Ligationsansatz $(20 \mu \mathrm{l})$ wurde mit $1 / 10 \mathrm{Vol}$. eines zehnfach konzentrierten ATP-haltigen Ligationspuffers und mit 0,5 $\mu \mathrm{l}$ (1 Unit) T4-DNA-Ligase (Promega) versetzt. Ligationen von DNA-Fragmenten mit kohäsiven Enden erfolgten bei $16^{\circ} \mathrm{C}$ und solche mit stumpfen Enden (Zugabe von 0,1 Vol. 50 \%-igem (v/v) Polyethylenglykols (PEG) zur Erhöhung der Viskosität) bei Raumtemperatur, jeweils über Nacht. Die Ligationsansätze konnten ohne weitere Behandlung zur Transformation eingesetzt werden.

\subsection{Amplifikation von DNA-Fragmenten mit Hilfe der Poly- merase-Kettenreaktion (PCR)}

Bei der PCR wird ein DNA-Molekül (Template) in vitro amplifiziert. Falls erforderlich werden die zu amplifizierenden DNA-Bereiche mit neuen Restriktionsschnittstellen versehen, weshalb die Primer entsprechend der neuen Schnittsequenzen Fehlpaarungen zum DNA-Matrizenstrang aufweisen. Das zwischen den beiden Primern liegende DNA-Stück wird über folgendes, mehrfach zu durchlaufendes Zyklenschema amplifiziert:

1. Thermische Denaturierung der DNA

2. Hybridisierung der Oligonukleotid-Primer an die Zielsequenz bei optimaler Bindungstemperatur

3. Primerverlängerung durch eine thermostabile DNA-abhängige DNA-Polymerase

Die Annealing-Temperatur ist abhängig von der Länge und Zusammensetzung der Oligonukleotid-Primer. Je GC-reicher sie sind, umso höher liegt die Hybridisierungstemperatur. Es gilt folgende Näherung: $T_{D}\left({ }^{\circ} \mathrm{C}\right)=(2 \times[A+T]+4 \times[C+G])$, wobei $A, T$, $C$ und $G$ die Anzahl der jeweiligen Basen darstellen.

Zur Durchführung der PCR-Läufe wurden programmierbare Thermoblöcke (Primus 96 ${ }^{\text {plus }}$, MWG-Biotech) verwendet. Die verwendeten Primer wurden bei B\&G-Biotech 
GmbH (Freiburg) oder bei MWG-Biotech AG (Ebersberg) in Auftrag gegeben. Für die PCR wurden die Taq-Polymerase (Eigenherstellung) und die Pfu-Polymerase (Stratagene, Heidelberg), welche eine „proof reading“-Funktion besitzt, verwendet. Da die Reaktionsbedingungen stark von der verwendeten Polymerase, dem Primerpaar und der Template-DNA abhängen, sind sie jeweils in "Experimente und Ergebnisse“ aufgeführt. Die Reinigung des PCR-Amplifikats von Primern, Polymerase und evtl. Nebenprodukten erfolgte nach präparativer Agarose-Gelelektrophorese durch Ausschneiden der DNA aus dem Gel und Aufreinigung mit Hilfe eines Kits (siehe 2.4.4).

\subsection{Ortsspezifische Mutagenese}

Zur Einführung von Punktmutationen und zu gezielten Aminosäureaustauschen wurde der QuikChange ${ }^{T M}$ Site-Directed Mutagenesis Kit $\left(\right.$ Stratagene $^{\circledR}$ ) verwendet. Dem Kit liegt folgendes Prinzip zugrunde: Zwei synthetische Primer (mit der gewünschten Mutation in der Mitte) sind jeweils komplementär zu den antiparallelen DNA-Strängen des Vektors mit dem Zielinsert und werden mittels der PfuTurbo DNA Polymerase verlängert. Der Einbau der Oligonukleotid Primer erzeugt ein mutiertes Plasmid mit Strangbrüchen. Nach der PCR wird das parentale DNA-Template mittels der Dpnl-Endonuklease, die spezifisch für (halb-) methylierte DNA ist, abgedaut. Die DNA aus fast allen $E$. coli-Stämmen ist Dam-methyliert und dem Angriff durch die Nuklease ausgesetzt, so daß letztlich auch eine Selektion für mutierte, nichtmethylierte DNA erfolgt. Die verbleibende neue (mutierte) zirkuläre DNA wird in E. coli XL1-Blue transformiert und in den Zellen dann die Strangbrüche des mutierten Plasmides repariert.

Die eigentliche Durchführung erfolgte nach dem vom Hersteller beigefügten Protokoll.

\subsection{Transformationsverfahren}

\subsubsection{Hocheffiziente Transformation von E. coli (Inoue et al., 1990)}

\subsubsection{Präparation kompetenter Zellen für die Transformation}

Die Hauptkultur (250 ml SOB-Medium, in 1 I-Schikanekolben) wurde mit $1 \mathrm{ml}$ einer exponentiell wachsenden E. coli-LB-Vorkultur angeimpft und bei $18^{\circ} \mathrm{C}$ im Schüttel- 
wasserbad (Gyrotory, Modell G76, New Brunswick Scientific, Edison, N. Y., USA) bis $z u$ einer $\mathrm{OD}_{600}$ von 0,6-0,7 etwa $24 \mathrm{~h}$ angezogen. Nach 10-minütiger Abkühlung auf Eis wurden die Zellen durch Zentrifugation (10 min, 5000 Upm, $4{ }^{\circ} \mathrm{C}$, GSA-Rotor) geerntet, in $80 \mathrm{ml}$ eiskaltem TB-Puffer vorsichtig resuspendiert, weitere $10 \mathrm{~min}$ auf Eis gestellt und nochmals sedimentiert. Das Pellet wurde in $20 \mathrm{ml}$ kaltem TB-Puffer aufgenommen, mit 1,4 ml DMSO (Endkonzentration: $7 \%(\mathrm{v} / \mathrm{v})$ ) versetzt, sorgfältig gemischt, erneut $10 \mathrm{~min}$ auf Eis gestellt und als $200 \mu$-Aliquots in vorgekühlte Eppendorf-Reaktionsgefäße portioniert. Die Zellen wurden sofort in flüssigem Stickstoff schockgefroren und bei $-75^{\circ} \mathrm{C}$ gelagert.

\section{SOB-Medium:}

(Hanahan, 1983)

$\begin{array}{lc}\text { Trypton } & 2,0 \%(w / v) \\ \text { Hefeextrakt } & 0,5 \%(w / v) \\ \mathrm{NaCl} & 10 \mathrm{mM} \\ \mathrm{KCl} & 2,5 \mathrm{mM} \\ \mathrm{MgCl}_{2} & 10 \mathrm{mM} \\ \mathrm{MgSO}_{4} & 10 \mathrm{mM}\end{array}$

Die Magnesiumsalze wurden aus getrennt autoklavierten Stammlösungen (1 $\mathrm{M} \mathrm{MgCl}_{2} / 1 \mathrm{M} \mathrm{MgSO}_{4}$ ) zugegeben.

TB-Puffer:

$\begin{array}{lrl}\text { Pipes-Puffer } & 10 & \mathrm{mM} \\ \mathrm{MnCl}_{2} & 55 & \mathrm{mM} \text { (getrennt autoklaviert) } \\ \mathrm{CaCl}_{2} & 15 & \mathrm{mM} \\ \mathrm{KCl} & 250 & \mathrm{mM} \\ \mathrm{pH} 6,7 & & \end{array}$

\subsubsection{Transformation der kompetenten E. coli-Zellen}

Die eingefrorenen Zellen wurden im Eis aufgetaut, mit 10-150 ng DNA gemischt und zur Adsorption der DNA an die Zellen 30 min auf Eis inkubiert. Die Aufnahme der DNA erfolgte durch einen Hitzeschock bei $42^{\circ} \mathrm{C}$ für $45-60 \mathrm{~s}$. Nach Zugabe von $800 \mu \mathrm{l}$ LB-Medium wurde der Ansatz $1 \mathrm{~h}$ bei $37^{\circ} \mathrm{C}$ zur Ausprägung der Selektivmarker inkubiert. Anschließend wurden $100 \mu \mathrm{l}$ der Zellsuspension auf Agarplatten unter Selektivbedingungen ausplattiert und bei $37^{\circ} \mathrm{C}$ über Nacht inkubiert. 


\subsubsection{Der X-Gal-Test zur Selektion auf rekombinante E. coli-Klone}

Dieser Test wurde neben den plasmidkodierten Antibiotikaresistenzen zur Selektion rekombinanter Klone verwendet und basiert auf der Grundlage, daß die $\beta$-Galactosidase $\quad X$-Gal (5-Brom-4-Chlor-3-indolyl- $\beta$-D-galactopyranosid) enzymatisch spaltet und das Reaktionsprodukt durch Luftoxidation zu einem blauen Indigofarbstoff (5-Brom-4-Chlor-indigo) umgewandelt wird. Viele Plasmide, z. B. der pBluescriptReihe, enthalten neben dem Promotor- und Operatorbereich des lac-Operons auch das $5^{\prime}$-Ende des lacZ-Gens, welches für das $\alpha$-Peptid der $\beta$-Galactosidase kodiert. Dieses wiederum kann die (aufgrund einer aminoterminalen Deletion) verkürzte, inaktive $\beta$-Galactosidase von verschiedenen $E$. coli-Klonierungsstämmen ( $\mathrm{DH} 5 \alpha$, XL1-Blue) komplementieren, die nach der Induktion durch IPTG gebildet wird.

$100 \mu \mathrm{l}$ einer transformierten E. coli-Suspension wurden für diesen Test mit $25 \mu \mathrm{l}$ IPTG $(0,1 \mathrm{M})$ und $80 \mu \mathrm{l} 2 \%$-igem (w/v) X-Gal gemischt und auf selektiven Nährboden ausplattiert. Nach Wachstum konnten die Kolonien anhand ihrer Färbung unterschieden werden. Blaue Kolonien enthielten nur das religierte Plasmid, während bei weißen Klonen mit hoher Wahrscheinlichkeit eine Insertion in der Multiklonierungsstelle (MCS) des lacZ-Gens stattgefunden hatte, so daß entweder kein vollständiges Transkript mehr gebildet wurde (wenn die integrierte DNA einen Transkriptionsterminator trug) oder es zur Bildung eines Hybridproteins kam, welches keine funktionelle $\alpha$-Komplementation im Wirtsorganismus ermöglichte.

\subsubsection{Elektroporation von $E$. coli}

\subsubsection{Präparation von kompetenten Zellen}

Aus einer gut angewachsenen E. coli-Vorkultur wurden 500 ml LB-Medium 1-2 \%-ig (v/v) angeimpft und auf dem Rundschüttler bis zu einer $O_{600}$ von 0,5-0,6 inkubiert. Nach einer Abkühlung des Mediums in Eiswasser wurden die Zellen in sterilen GSAZentrifugenbechern geerntet (5000 Upm, $20 \mathrm{~min}, 4^{\circ} \mathrm{C}$ ), zweimal mit eiskaltem sterilem $\mathrm{H}_{2} \mathrm{O}_{\text {MilliQ }}$ vorsichtig, aber gründlich gewaschen und anschließend in $30 \mathrm{ml}$ eiskaltem $10 \%$-igem (v/v) Glycerin (steril) aufgenommen. Nach erneuter Zentrifugation (5000 Upm, $10 \mathrm{~min}, 4^{\circ} \mathrm{C}$ ) wurde das Volumen des Pellets abgeschätzt und schließlich mit dem gleichem Volumen $10 \%$-igen (v/v) Glycerins versetzt. Die Zellen wurden aliquotiert $(50 \mu \mathrm{l}$ bis $100 \mu \mathrm{l})$ und entweder sofort für eine Transformation genutzt oder bei $-75^{\circ} \mathrm{C}$ gelagert. 


\subsubsection{Transformation kompetenter Zellen durch Elektroporation}

Die eingefrorenen Zellen (2.8.3.1) wurden schonend auf Eis aufgetaut. Nach Zugabe der DNA-Lösung (50-500 ng) wurde der Ansatz in vorgekühlte sterile Elektroporationsküvetten pipettiert und für 10 min auf Eis inkubiert. Die Zellen wurden dann in einem Elektroporationsgerät (Gene-Pulser ${ }^{\circledR} I I$, Bio-Rad $\mathrm{GmbH}$, München) unter den folgenden Bedingungen elektroporiert:

Kapazität: $\quad 25 \mu \mathrm{Fd}$
Spannung: $\quad 2,5 \mathrm{kV}$
Widerstand: $200 \quad \Omega$

Die sich ergebenen Zeitkonstanten lagen zwischen 4,5 und 5,0 ms. Sofort nach erfolgter Elektroporation wurde $1 \mathrm{ml}$ LB-Medium zugesetzt und die Zellen für eine Stunde bei $37^{\circ} \mathrm{C}$ zur Expression der Selektionsmarker und der allgemeinen Regeneration auf dem Rotationsschüttler (Eigenbau) inkubiert. Danach erfolgte das Ausplattieren (20 - $100 \mu \mathrm{l})$ auf Selektivnährböden.

\subsection{Sequenzierung doppelsträngiger Plasmid-DNA}

Alle Sequenzierungen doppelsträngiger Plasmid-DNA wurden, nach Bereitstellung der entsprechenden hochreinen Plasmid-DNA (2.4.3), entweder vom Laboratorium für Genomanalyse (Institut für Mikrobiologie und Genetik, Göttingen) oder von der Firma SeqLab (Göttingen) mit den jeweiligen firmeninternen Verfahren durchgeführt.

\subsection{Standardtechniken für das Arbeiten mit Proteinen}

\subsubsection{Quantitative Proteinbestimmung}

Für eine quantitative Proteinbestimmung wurde der „Protein Assay Kit“ von BioRad, welcher auf der kolorimetrischen Methode von Bradford (1976, modifiziert) basiert, verwendet. Proteine und Peptide mit einer Molekularmasse $>3 \mathrm{kDa}$ bilden mit dem in saurer Lösung anionisch vorliegenden Farbstoff Coomassie Brilliant Blue G250 einen blauen Farbkomplex, der photometrisch bestimmt werden kann.

Mit der nach Angaben des Herstellers (Konzentrat-Verdünnung 1:5 mit $\mathrm{H}_{2} \mathrm{O}$ ) angefertigten Färbelösung wurde eine Eichgerade mit BSA im Bereich von 0-20 $\mathrm{gg}$ 
Protein/Ansatz unter folgenden Testbedingungen ermittelt: Probe mit $1 \mathrm{ml}$ Färbereagenz versetzen, gut mischen und für 10 min bei RT inkubieren. Nach nochmaligem Durchmischen erfolgte die Messung der OD bei $595 \mathrm{~nm}$ gegen eine Nullprobe ohne Protein.

\subsubsection{SDS-Polyacrylamidgelelektrophorese (SDS-PAGE)}

(mod. nach Laemmli, 1970)

Mit Hilfe des Detergenz SDS (Sodium-Dodecylsulfat) werden Tertiär- und Quartärstrukturen von Proteinen zerstört und diesen entsprechend ihrer Peptidkettenlänge eine äquivalente negative Ladung angelagert. Diese negative Ladung ermöglicht die Auftrennung von Proteinen entsprechend ihrer molekularen Masse im Polyacrylamidgel.

Für die Gelelektrophorese wurde eine Mini-Protean-II-Apparatur (BioRad, München) verwendet. Nach sorgfältiger Reinigung der Glasplattenpaare mit $\mathrm{H}_{2} \mathrm{O}$ und $70 \%$ igem (v/v) Ethanol, wurden diese mit den Spacern nach Angaben des Herstellers in den Gießstand eingesetzt. Dann wurde das $10 \%$-ige (v/v) Trenngel entsprechend dem unten stehendem Pipettierschema gegossen und mit $\mathrm{H}_{2} \mathrm{O}$ bidest. oder Ethanol $(70 \%(v / v))$ überschichtet. Nachdem das Trenngel polymerisiert war (deutliche Phasengrenze zwischen Gel und Überschichtung), wurde die Überschichtung entfernt, das Sammelgel auf das Trenngel gegossen und der Kamm luftblasenfrei eingesetzt. Vollständig auspolymerisierte Gele können vor Austrocknung geschützt mehrere Tage bei $4^{\circ} \mathrm{C}$ aufbewahrt werden.

Pipettierschema (für ein Gel):

\begin{tabular}{|c|c|c|}
\hline & Trenngel (10\%) & Sammelgel (4 \%) \\
\hline Trenngel-Stammlösung & $1 \mathrm{ml}$ & $0,48 \mathrm{ml}$ \\
\hline Sammelgel-Stammlösung & --- & $1,32 \mathrm{ml}$ \\
\hline $\mathrm{H}_{2} \mathrm{O}_{\text {bidest. }}$ & $2 \mathrm{ml}$ & $0,2 \mathrm{ml}$ \\
\hline Acrylamid-Stammlösung & $1 \mathrm{ml}$ & $15 \mu \mathrm{l}$ \\
\hline APS (10\%(w/v)) & $30 \mu \mathrm{l}$ & $2 \mu \mathrm{l}$ \\
\hline TEMED & $3 \mu \mathrm{l}$ & \\
\hline
\end{tabular}


Trenngel-Stammlösung:

Tris

SDS

$\mathrm{pH} 8,8$

Acrylamid-Stammlösung:

$40 \%(w / v)(A A)$

$10 \times$ Laufpuffer:

Tris $\quad 30 \mathrm{~g}$

SDS $\quad 10 \mathrm{~g}$

Glycin $\quad 144 \mathrm{~g}$

$\mathrm{H}_{2} \mathrm{O}_{\text {bidest. ad } 1000 \text { ml }}$

Der $\mathrm{pH}$-Wert wurde nicht eingestellt.
Sammelgel-Stammlösung:

Tris

$0,5 \mathrm{M}$

SDS

$0,4 \%(w / v)$

$\mathrm{pH} 6,8$

\section{$4 \times$ Probenpuffer:}

Glycerin

$7,5 \mathrm{ml}$

Tris

$0,4 \mathrm{~g}$

$\beta$-Mercaptoethanol 2,5 ml

SDS

$1,2 \mathrm{~g}$

Bromphenolblau $(0,2 \%) \quad 0,5 \mathrm{ml}$

$\mathrm{H}_{2} \mathrm{O}_{\text {bidest. }} \quad$ ad $50 \quad \mathrm{ml}$ Mit $\mathrm{HCl}_{\text {konz. }}$ auf $\mathrm{pH}$ 6,8 einstellen, aliquotieren und bei $-20^{\circ} \mathrm{C}$ lagern.

Elektrophorese:

Das SDS-Gel wurde in der Elektrophoreseapparatur fixiert und die obere und untere Kammer wurden mit 1 x Laufpuffer gefüllt. Die Geltaschen konnten mit bis zu $20 \mu \mathrm{l}$ zuvor bei $100^{\circ} \mathrm{C}$ für 5 min erhitzten Proben gefült werden, wobei ein Verhältnis von Probe zu SDS-Probenpuffer von 1:1 vorlag. Die Elektrophorese wurde bei einer konstanten Stromstärke von $25 \mathrm{~mA}$ für das Sammelgel und $35 \mathrm{~mA}$ für das Trenngel durchgeführt und dauerte 45-60 min.

\subsubsection{Färbung von Proteinen}

2.10.3.1 Coomassie-Färbung (Weber und Osborn, 1969, mod.)

Die SDS-Gele wurden nach Beendigung der Elektrophorese kurz mit $\mathrm{H}_{2} \mathrm{O}$ gespült und dann für $30 \mathrm{~min}$ in der Färbelösung auf einer Wippe gefärbt. Nach Spülen mit Wasser wurde das Gel in Entfärbelösung, welche mehrmals erneuert wurde, geschwenkt, bis der Hintergrund des Gels farblos war. Die fertigen SDS-Gele konnten danach luftblasenfrei zwischen 2 Lagen Cellophanfolie im Gel-Air-Dryer (BioRad, München) für eine Stunde getrocknet werden. 
Färbelösung:

Serva Blau G 250

Methanol, $100 \%(\mathrm{v} / \mathrm{v})$

Essigsäure, $100 \%(\mathrm{v} / \mathrm{v})$

$\mathrm{H}_{2} \mathrm{O}$ demin.

\section{Entfärbelösung:}

Methanol, $100 \%(\mathrm{v} / \mathrm{v}) \quad 330 \mathrm{ml}$

Essigsäure, $100 \%(\mathrm{v} / \mathrm{v}) \quad 100 \mathrm{ml}$

$\mathrm{H}_{2} \mathrm{O}_{\text {demin. }}$

ad $1000 \mathrm{ml}$

\subsubsection{Proteinfärbung mit Ponceau S Rot}

Diese Methode konnte zur schnellen, reversiblen Anfärbung von Proteinen auf Nitrocellulose-Blotmembranen genutzt werden. Hierbei wurde die geblottete Membran (siehe 2.11) 10 min mit Ponceau S gefärbt $[0,1 \%(w / v)$ Ponceau $S$ in $5 \%$ iger Trichloressigsäure (w/v)]. Nach dem Färbeschritt konnte die Membran durch Spülen unter Wasser dann langsam entfärbt werden.

\subsubsection{Größenbestimmung von Proteinen}

Die Bestimmung von Proteingrößen erfolgte nach Auftrennung im Polyacrylamidgel (2.10.2) anhand der Laufstrecken eines mitgelaufenen internen Standards. Als Größenstandard diente meist der "High Molecular Weight Standard Mixture" Stock No. SDS- 6H (Sigma), welcher aus folgenden sechs Proteinen besteht:

\section{Markerproteine:}

Myosin, Kaninchenmuskel

B - Galactosidase, E.coli

Phosphorylase b, Kaninchenmuskel

Albumin, Rind

Albumin, Hühnerei

Carboanhydrase, Rinder - Erythrocyten

\section{Molekularmasse [Da]}

205000

116000

97400

66000

45000

29000 


\subsubsection{Native Gelelektrophorese}

Pipettierschema (für ein Gel):

\begin{tabular}{|c|c|c|}
\hline & Trenngel $(7,5 \%)$ & Sammelgel (3 \%) \\
\hline Trenngel-Stammlösung & $1 \mathrm{ml}$ & --- \\
\hline Sammelgel-Stammlösung & --- & $0,38 \mathrm{ml}$ \\
\hline $\mathrm{H}_{2} \mathrm{O}_{\text {bidest. }}$ & $2,25 \mathrm{ml}$ & $1 \mathrm{ml}$ \\
\hline Acrylamid-Stammlösung & $0,75 \mathrm{ml}$ & $0,11 \mathrm{ml}$ \\
\hline APS $(10 \%(w / v))$ & $40 \mu \mathrm{l}$ & $10 \mu \mathrm{l}$ \\
\hline TEMED & $5 \mu \mathrm{l}$ & $3 \mu \mathrm{l}$ \\
\hline
\end{tabular}

Trenngel-Stammlösung (4x):

Tris $\quad 1,5 \mathrm{M}$

$\mathrm{pH} 8,0$

\section{Acrylamid-Stammlösung:}

$40 \%(w / v)(A A)$

\section{$10 \times$ Laufpuffer:}

Tris $250 \mathrm{mM}$

Glycin $\quad 1,92 \mathrm{mM}$

Der pH-Wert (etwa 8,8) wurde nicht eingestellt.

Sammelgel-Stammlösung (4x):

Tris

$0,5 \mathrm{M}$

$\mathrm{pH} 6,8$

\section{$5 \times$ Probenpuffer:}

Glycerin

Tris (1 M, pH 6,8) $3,1 \mathrm{ml}$

Bromphenolblau $1 \%$

ad $\mathrm{H}_{2} \mathrm{O}_{\text {bidest. }}$
$10 \mathrm{ml}$

\section{Elektrophorese:}

Das Nativ-Gel wurde in der Elektrophoreseapparatur fixiert und die obere und untere Kammer wurden mit $1 \times$ Laufpuffer gefüllt. Ein geeignetes Aliquot der Proteinprobe wurde mit $1 / 4$ Volumen $5 \times$ Nativ-Probenpuffer gemischt und in die Tasche pipettiert. Die Elektrophorese wurde bei einer konstanten Stromstärke von $15 \mathrm{~mA} / \mathrm{Gel}$ für etwa $2 \mathrm{~h}$ durchgeführt.

\subsubsection{Konzentrierung von Proteinen}

Um Proteinlösungen zu konzentrieren, wurden Mikrokonzentratoren (MACROSEP ${ }^{\mathrm{TM}}$, Pall Filtron, Karlstein) mit der Ausschlußgröße $30 \mathrm{kDa}$ verwendet. Dabei konnten Proteinlösungen von $12 \mathrm{ml}$ auf $1 \mathrm{ml}$ eingeengt werden. Die Zentrifugationsschritte erfolgten (5500 Upm, $4^{\circ} \mathrm{C}$, jeweils $1 \mathrm{~h}$ ) im SS-34-Rotor. 


\subsubsection{Umpufferung durch Diafiltration}

Der oben genannte Mikrokonzentrator wurde auch zur Umpufferung von Proteinlösungen verwendet. Dazu wurden die Proben mehrmals in den Konzentratoren eingeengt und in dem gewünschten Puffer aufgenommen.

\subsection{Western-Blot (Towbin et al., 1979)}

Nach der Auftrennung durch Polyacrylamid-Gelelektrophorese konnten Proteine für weitere immunologische Tests aus dem Gel auf eine Nitrocellulosemembran transferiert werden. Die Übertragung erfolgte dabei elektrophoretisch unter Verwendung einer Western-Blot-Kammer (Eigenbau) nach dem Semi-Dry-Verfahren. Das Whatmanpapier und eine Nitrocellulosemembran (Fa. Sartorius AG, Göttingen) wurden, nachdem sie auf Gelgröße zurechtgeschnitten waren, zusammen mit dem Gel in Transferpuffer gelegt. Anschließend wurden auf die Anodenplatte in folgender Reihenfolge 3 Lagen Whatmanpapier, die Nitrocellulosemembran, das Gel und wiederum 3 Lagen Whatmanpapier jeweils unter Vermeidung von Luftblasen aufgelegt. Nach der Entfernung überschüssigem Transferpuffers mittels saugfähigem Papiers legte man die Kathodenplatte auf und beschwerte die Apparatur. Die Proteine wurden bei konstanter Stromstärke mit $5 \mathrm{~mA} / \mathrm{cm}^{2}$ Membranfläche für 3045 min übertragen.

\begin{tabular}{llrl} 
Transferpuffer: & Tris $(125 \mathrm{mM})$ & 15,14 & $\mathrm{~g}$ \\
\hline & Glycin $(192 \mathrm{mM})$ & 14,40 & $\mathrm{~g}$ \\
& Methanol, $100 \%(\mathrm{v} / \mathrm{v}) 200$ & $\mathrm{ml}$ \\
& $\mathrm{H}_{2}$ Odest. $_{10}$ ad 1000 & $\mathrm{ml}$ \\
& $\mathrm{pH} 8,6$; Lagerung bei $4{ }^{\circ} \mathrm{C}$. &
\end{tabular}

\subsection{Immunologische Methoden}

\subsubsection{Herstellung von polyklonalen Antiseren gegen MTase}

Zur Herstellung polyklonaler Antiseren mit Anti-MTase-Antikörper wurde ein Kaninchen mit aufgereinigtem MTase-Protein immunisiert. Die Injektionen und die verschiedenen Blutungen wurden von der Firma BioScience (Göttingen) nach folgendem Protokoll durchgeführt: 
Injektionen: Tage 0, 21 und 49 (mit je $250 \mu \mathrm{g}$ des gereinigten Proteins).

Blutungen/Probenahmen: $\quad 5 \mathrm{ml}$ Präimmunserum

$$
\begin{array}{rl}
15 & \mathrm{ml} \text { 1. Blutung } \\
20 \mathrm{ml} 2 \text {. Blutung } \\
>50 \mathrm{ml} \text { Endblutung }
\end{array}
$$

Die Seren wurden nach Aliquotierung bei $-20^{\circ} \mathrm{C}$ und $-75^{\circ} \mathrm{C}$ gelagert.

\subsubsection{Dot Blot für immunologischen Nachweis}

Zur schnellen Überprüfung der Spezifität der polyklonalen Antikörper wurden 1-3 $\mu$ l der Proteinlösung direkt auf eine Nitrocellulosemembran pipettiert und getrocknet. Die weitere Behandlung der Membran erfolgte wie unter 2.12.3 beschrieben. Der 1. Antikörper (1. Blutung) wurde im Verhältnis 1:100 eingesetzt.

\subsubsection{Immundetektion von Proteinen mit alkalische Phosphatase- konjugierten Antikörpern}

Die Sichtbarmachung der auf einer Nitrocellulosemembran transferierten Proteine (2.11) mit den für sie spezifischen Antikörpern erfolgte mit Hilfe einer gekoppelten alkalischen Phosphatasereaktion. Die Membran wurde dabei zur Vermeidung unspezifischer Bindungen für $1 \mathrm{~h}$ bei RT mit einer wiederverwendbaren Blockierungslösung (TBST mit $3 \%(w / v)$ BSA) abgesättigt. Dann erfolgte die Bindung der polyklonalen Antikörper an ihr Substrat (TBST + 1. Antikörper (Endblutung), Verhältnis 1:2500; Inkubation $1 \mathrm{~h}$ ). Es folgten drei Waschschritte zu je 5 min in TBST zur Entfernung ungebundener Antikörper. Im nächsten Schritt wurde der sekundäre Antikörper (Anti-Kaninchen-Antikörper, lgG, mit alkalischer Phosphatase (SigmaAldrich Chemie $\mathrm{GmbH}$ ); Verhältnis 1:5000 in TBST) an die bereits gebundenen primären Anti-MTase-Antikörper durch eine 30-minütige Inkubation gekoppelt. Die Nitrocellulosemembran wurde dann $3 x$ in TBST (je 5 min) und $2 x$ in TBS (je 3 min) gewaschen. Anschließend erfolgte die Sichtbarmachung der Proteine durch Zugabe der Färbelösung. Die Farbreaktion konnte mittels $\mathrm{H}_{2} \mathrm{O}_{\text {demin. }}$ abgestoppt und die Membran im Dunkeln gelagert werden. 


\section{TBS:}

Tris- $\mathrm{HCl}$

$\mathrm{NaCl}$

$\mathrm{H}_{2} \mathrm{O}_{\text {demin. }} \quad$ ad $1000 \quad \mathrm{ml}$

$\mathrm{pH} 7,5$

\section{Puffer A:}

$\mathrm{NaCl}(100 \mathrm{mM})$

$5,84 \mathrm{~g}$

$\mathrm{MgCl}_{2}(5 \mathrm{mM})$

$1,02 \mathrm{~g}$

Tris $(100 \mathrm{mM}) \quad 12,11 \mathrm{~g}$

$\mathrm{H}_{2} \mathrm{O}_{\text {dest. }} \quad$ ad $1000 \quad \mathrm{ml}$

$\mathrm{pH} 9,5$; Lagerung des Puffers bei $4^{\circ} \mathrm{C}$.

\section{TBST:}

TBS mit 0,05\% (v/v) Tween 20

\section{Färbelösung:}

NBT-Stammlösung [50 mg/ml (w/v)] $66 \mu \mathrm{l}$ BCIP-Stammlösung $[50 \mathrm{mg} / \mathrm{ml}(\mathrm{w} / \mathrm{v})] 33 \mu \mathrm{l}$ Puffer A ad $10 \mathrm{ml}$ Lösung vor Gebrauch frisch ansetzen.

\subsection{Chromatographische Verfahren zur Produktanalyse}

\subsubsection{Dünnschicht-Chromatographie (TLC)}

Die Dünnschichtchromatographie ist eine Form der Verteilungschromatographie zwischen einer hydrophilen (stationären) und einer hydrophoben (mobilen) Phase. Mit dieser einfachen und schnellen Methode lassen sich Mono- und Oligosaccharide, wie sie bei hydrolytischer Spaltung oder bei Transferreaktionen auftreten, auftrennen und anhand eines geeigneten Standards bestimmen und detektieren. Als stationäre Phase dienten mit Kieselgel beschichtete Aluminium-Folien (Kieselgel $60 \quad \mathrm{~F}_{254}$, Merck). Als mobile Phase wurden folgende Laufmittel verwendet:

Laufmittel 1: 1- Propanol $60 \mathrm{ml}$ Ethylacetat $10 \mathrm{ml}$ $\mathrm{H}_{2} \mathrm{O}_{\text {bidest. }} \quad 30 \mathrm{ml}$ Laufzeit $\quad 2 \times 3 \mathrm{~h}$
Laufmittel 2: $\quad$ 1- Propanol $50 \mathrm{ml}$ Nitromethan $30 \mathrm{ml}$ $\mathrm{H}_{2} \mathrm{O}_{\text {bidest. }} \quad 20 \mathrm{ml}$ Laufzeit $1 \times 2 h$

Substratlösungen: $\quad 1 \%(w / v) \quad$ Entwicklungsreagenz:

Anilin $1 \mathrm{ml}$

Referenz $\mathrm{G}_{1}-\mathrm{G}_{7} \quad 0,1 \%(\mathrm{w} / \mathrm{v})$ Diphenylamin $1 \mathrm{~g}$ Aceton $100 \mathrm{ml}$ Lagerung dunkel bei $4^{\circ} \mathrm{C}$. 
lonenaustauscher: Serdolith ${ }^{\circledR}$ MB-3, $\quad$ Ortho Phosphorsäure: $\quad 85 \%$ \%(v/v) Mixed Bed Resin (Serva)

Der Testansatz (siehe 3.5.2, 3.5.6) wurde bei erforderlicher Temperatur für eine geeignete Zeit inkubiert und anschließend auf Eis gestellt. In der Zwischenzeit wurden die Dünnschichtplatten und die Kammer für den Lauf vorbereitet. $2 \mu$ Aliqots der Testansätze wurden entlang einer Linie $1 \mathrm{~cm}$ vom unteren Rand der DC-Platte strichförmig aufgetragen (Abstand der einzelnen Proben mind. 0,7 cm; Abstand zum Seitenrand der DC-Platte mind. 1,5 cm). Wurden Proben mehrmals aufgetragen, so mußten die Probenauftragsstriche zwischendurch mittels eines Föns gut getrocknet werden. Die Chromatographiekammer wurde mit Whatmanpapier ausgekleidet und die Schliffränder von Deckel und Kammer mit Vaseline gefettet. Anschließend wurden $100 \mathrm{ml}$ des jeweiligen Laufmittels über das Whatmanpapier in die Kammer gefüllt. Die trockene DC-Platte wurde dann in die gut equilibrierte DünnschichtKammer eingesetzt und entsprechend den Erfordernissen entwickelt, erneut getrocknet (Lagerung bei $-20^{\circ} \mathrm{C}$ in Alufolie möglich) und mit frisch hergestellter Sprühlösung (Entwicklungsreagenz + 1/10 Vol. Phosphorsäure) besprüht. Die besprühte Platte wurde sorgfältig in Alufolie eingewickelt und für 12 min bei $140^{\circ} \mathrm{C}$ inkubiert. Zur Aufbewahrung konnte die Platte anschließend in Schlauchfolie eingeschweißt werden.

\subsubsection{Hochleistungs-Flüssig-Chromatographie (HPLC)}

Die HPLC ist, wie die TLC, eine Form der Verteilungschromatographie zwischen einer stationären Phase (Trennsäule) und einer mobilen Phase (Laufmittel). Durch die verfügbaren Hochleistungs-Trennsäulen können Substanzgemische, deren Komponenten sich nur geringfügig in ihrer physikalischen oder chemischen Eigenschaften unterscheiden, schnell und mit hoher Auflösung analysiert werden. Die Proben wurden auf einem Dionex DX-500 HPLC-System analysiert. Dabei wurde eine CarboPac-100-Säule mit Vorsäule verwendet. Als Eluent diente $100 \mathrm{mM} \mathrm{NaOH}$

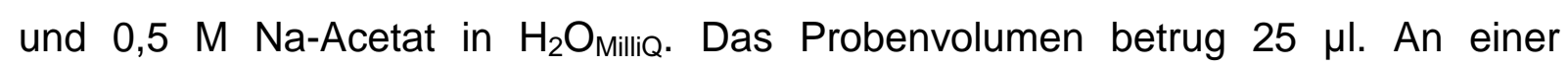
Goldelektrode wurden die Substanzen in obigen Eluenten, die einen hohen $\mathrm{pH}$-Wert aufweisen, oxidiert. Die dadurch entstehenden Signale wurden mittels eines ED 40Detektors (electrochemical detector) aufgefangen. Die Auswertung der Rohdaten erfolgte anschließend mit der Dionex-Software PeakNet, Version 5.01. 


\subsubsection{HPLC-Analyse der Stärkeumsetzung}

Nach entsprechenden Vorversuchen wurde folgendes Protokoll entwickelt:

Probenvorbereitung:

$0,25 \%(w / v)$ Substrat (hier: Maisstärke) wurden in $20 \mathrm{mM} \mathrm{Na}$-Acetat $\mathrm{pH} \mathrm{7,5}{ }^{\left(60^{\circ} \mathrm{C}\right)}$ durch Autoklavieren gelöst. Für Proben mit GTase wurden 20 U GTase-Rohextrakt $_{\text {Hitze }}$ pro $\mathrm{ml}$ Probenlösung zugesetzt und für $16 \mathrm{~h}$ bei $60^{\circ} \mathrm{C}$ schüttelnd inkubiert. Die Inaktivierung der GTase erfolgte durch eine sich anschließende Inkubation bei $100^{\circ} \mathrm{C}$ für $1 \mathrm{~h}$. Nach der Lyophilisierung der Probe wurde diese in $10 \mathrm{ml} 25 \mathrm{mM} \mathrm{Na}$ Acetat-Puffer $\mathrm{pH} \mathrm{4,5}$ resuspendiert, $400 \mathrm{U}$ Isoamylase (als Entzweigungsenzym für die Stärke) pro $\mathrm{ml}$ Probenvolumen zugesetzt und für $14 \mathrm{~h}$ bei $45^{\circ} \mathrm{C}$ schüttelnd inkubiert. Nach der Enzyminaktivierung bei $100^{\circ} \mathrm{C}$ für $5 \mathrm{~min}$ folgte erneut eine Lyophilisierung der Proben. Nun konnten bei Proben, die für die Inkubation mit Amyloglucosidase vorgesehen waren, $40 \mathrm{U}$ des Enzyms pro $\mathrm{ml}$ Probenvolumen (25 mM Na-Acetat-Puffer $\mathrm{pH} 4,5$ ) zugegeben und für $22 \mathrm{~h}$ bei $25^{\circ} \mathrm{C}$ inkubiert werden. Auch hier erfolgte dann die Hitzeinaktivierung der Amyloglucosidase durch Inkubation bei $100^{\circ} \mathrm{C}$ für 5 min und eine Lyophilisierung. Durch Inkubation mit Amyloglucosidase werden lineare Maltooligosaccharide bis zur Glucose abgebaut; zyklische Verbindungen bleiben bestehen.

Sämtliche Proben wurden dann in einer geeigneten Menge an $\mathrm{H}_{2} \mathrm{O}_{\text {MilliQ }}$ resuspendiert, für $15 \mathrm{~min}$ bei 15000 Upm (RT) zentrifugiert, um unlösliche Bestandteile abzutrennen, und schließlich $25 \mu$ des Überstandes zur Analyse mittels HPLC-PAD eingesetzt.

Die Identifizierung des Polymerisationsgrades der einzelnen „Peaks“ erfolgte durch Zugabe eines internen Standards (definiertes Maltooligosaccharid; z.B. Maltoheptaose) zu einer Probe direkt vor der HPLC-Analyse.

\subsection{Gewinnung und Reinigung von cytosolischen Pro- teinen}

Je nach Bedarf wurden die entsprechenden rekombinanten E. coli-Bakterienstämme in Maßstäben von $5 \mathrm{ml}$ bis zu 6 । unter den geeigneten Bedingungen angezogen, d. h. in der Regel bei $37^{\circ} \mathrm{C}$ unter Selektionsdruck und ständiger Belüftung für etwa 16-24 h. Gegebenenfalls wurde in der exponentiellen Wachstumsphase $\left(O_{600 \mathrm{~nm}}=\right.$ 0,5-0,9) mit einer definierten Menge IPTG induziert. 


\subsubsection{Präparation des Zellextraktes}

Entsprechend den weiteren Erfordernissen wurden die Zellen nach Ernte in geeigneten Puffern aufgenommen. Zellextrakte von E. coli, die anschließend einer säulenchromatographischen Reinigung unterworfen wurden, wurden i.d.R. in $20 \mathrm{mM}$ Tris- $\mathrm{Cl}$ pH 8,0 (RT) aufgenommen. Dieser Puffer diente dann auch als Waschpuffer.

\section{Zellaufschluß mit der French Pressure Cell}

- Zellen mit 7000 Upm (10-20 min) bei $4^{\circ} \mathrm{C}$ ernten, Überstand abnehmen

- Pellet in Waschpuffer resuspendieren und erneut zentrifugieren, Waschschritte bei Bedarf mehrmals wiederholen

- Bestimmung des Naßgewichts des Pellets und Zellen in etwa $1 \mathrm{ml}$ Puffer pro Gramm Naßgewicht gründlich resuspendieren

- Zellaufschluß in einer gekühlten Druckzelle (American Instrument Co., Silver Spring, USA) mit 6,9 MPa (1000 PSI); bei Bedarf mehrere Passagen; mikroskopische Kontrolle des Zellaufschlusses

- ggf. Zugabe einer Spatelspitze DNase und Inkubation bei RT für 10 min

- Zelltrümmer werden durch Zentrifugation (14000-16000 Upm; 20-30 min) entfernt; Überstand ist Protein-Rohextrakt (RE)

\section{Zellaufschluß durch Ultraschall}

Diese Methode wurde nur bei kleinen Volumina $(<3 \mathrm{ml})$ angewendet, um schnell Proteinextrakt zu gewinnen, so daß rasch variable Parameter überprüft und optimiert werden konnten.

- Zellen mit 10000 Upm für 10 min ernten und in geeignetem Waschpuffer resuspendieren (dicht gewachsene Kulturen konnten auch direkt zum Zellaufschluß eingesetzt werden)

- Aufschluß der Zellen (auf Eis) unter Verwendung einer Ultraschallsonde (Ultraschallprozessor UP 200s, Dr. Hielscher GmbH); Amplitude variabel, Cycle 0,5; 3-5 min; lichtmikroskopische Kontrolle

- Zelltrümmer hochtourig abzentrifugieren (13000 Upm, 15-30 min, $4^{\circ} \mathrm{C}$ )

- Überstand abheben (=Rohextrakt) 


\subsubsection{Abtrennung thermolabiler Proteine durch Hitzedenaturierung}

Zur Anreicherung eines thermostabilen heterologen Proteins aus dem Zellextrakt eines mesophilen Wirtes eignet sich ein Hitzeschritt, bei dem der überwiegende Teil der thermolabilen Wirtsproteine denaturiert und präzipitiert wird. Die optimale Dauer und Temperatur für die Hitzefällung sind durch Vorversuche zu bestimmen, da sie vom Volumen, $\mathrm{pH}$ und Proteinkonzentration des Zellextraktes abhängig sind. Zu beachten ist, daß sich Ergebnisse aus Experimenten mit E-Cups keinesfalls auf größere Volumina hochrechnen lassen, da sich Aufheizzeiten und effektive Temperatureinwirkungen ganz wesentlich unterscheiden. Durch Aliquotierung größerer Volumina in E-Cups, oder durch Simulierung der Testbedingungen durch Versenkung eines E-Cups in ein größeres Gefäß mit entsprechender Flüssigkeitsmenge an $\mathrm{H}_{2} \mathrm{O}$, lässt sich aber dieses Problem einfach umgehen. Nach einer entsprechenden Inkubationsdauer (i.d.R. 15-30 min) wird dann die Probe in Eis abgekühlt, zur Pelletierung des denaturierten Materials hochtourig zentrifugiert (16000-20000 Upm, $\left.30 \mathrm{~min}, 4^{\circ} \mathrm{C}\right)$ und der Überstand mit dem angereicherten Zielprotein abgehoben (=Rohextrakt $t_{\text {Hitze }}\left(\mathrm{RE}_{\text {Hitze }}\right)$ ).

\subsubsection{Fast Protein Liquid Chromatography (FPLC)}

\subsubsection{Geräte und Säulen}

Die verwendete FPLC-Anlage besteht aus folgenden Komponenten:

Geräte: Liquid Chromatography Controller LCC-500

$2 \times$ High Precision Pump P-500

In-line Mixer, Motor Valve MV-7

Uvicord S II Monitor und Fraction Collector Frac-100

Zweikanal-Laborschreiber

$10 \mathrm{ml}$ und $50 \mathrm{ml}$ Superloop, diverse Probenschleifen

Säulen:

SOURCE 15Q (50 ml)

Phenyl Sepharose HP XK 16/10

Superdex 200 prep grade XK 16/60

(Alle Komponenten von Pharmacia, Freiburg) 
Allgemeine Regeln beim Umgang mit der FPLC

- Proben vor dem Auftragen auf eine Säule immer durch Filtration (0,2 $\mu \mathrm{m}$ bzw. 0,45 $\mu \mathrm{m}$ Porenweite) oder hochtouriger Zentrifugation partikelfrei machen

- sämtliche Laufmittel und Puffer vor Gebrauch ebenfalls filtrieren

- individuelle Parameter der Säulen bezüglich der Bindungskapazität, optimaler Flußrate, Rückdruck, chemischer und physikalischer Stabilität sowie Regenerierung beachten (siehe Begleitblätter)

- Säulen in $20 \%$ (v/v) Ethanol lagern; direkte Umpufferung der Säulen von 20 \% $(\mathrm{v} / \mathrm{v})$ Ethanol zu einem salzhaltigen Eluenten oder umgekehrt vermeiden, dazwischen mit $\mathrm{H}_{2} \mathrm{O}_{\text {bidest. }}$ spülen

- alle Anschlüsse „drop to drop“ verbinden, um das Eindringen von Luft in das System zu vermeiden (besonders wichtig bei Gelfiltrationssäulen)

\subsubsection{Trennprinzipien}

\section{Ionenaustausch-Chromatographie}

\section{Prinzip}

Die Trennung beruht auf elektrostatischen Interaktionen zwischen den Proteinen und den funktionellen Gruppen des Gelmaterials: Geladene Gruppen auf der Oberfläche der Proteine treten mit entgegengesetzt geladenen Gruppen auf der Austauschermatrix in Wechselwirkung und führen so zu einer Bindung an die Säule, wobei die Bindungsstärke von den individuellen Ladungseigenschaften der einzelnen Polypeptide abhängt. Die Elution erfolgt durch Erhöhung der lonenstärke, die zu einer Schwächung der elektrostatischen Wechselwirkung zwischen Protein und Gelmaterial führt.

\section{Säule}

Bei dieser Chromatographie wurde der starke Anionenaustauscher SOURCE 15 Q in einer selbstgepackten XK 26/20-Säule (präparativ, 50 ml Säulenvolumen) verwendet. Die funktionelle Gruppe ist ein quartäres Amin, welches über einen hydrophilen Spacer an die Säulenmatrix gebunden ist. Die Proteinbindungskapazität beträgt etwa $25 \mathrm{mg}$ pro $\mathrm{ml}$ Gelbett, die empfohlene Flußrate wird mit 30-600 cm/h angegeben (maximaler Rückdruck: $5 \mathrm{MPa}$ ). 


\section{Methodik}

Die Säule wird zur Vorbereitung mit 2 Säulenvolumina (SV) Elutionspuffer B (= Hochsalzpuffer) gespült, um die funktionellen Gruppen mit Gegenionen abzusättigen, dann wird das Medium mit mindestens 8 SV Auftragungspuffer A (= Niedrigsalzpuffer) auf die Startbedingungen äquilibriert. Die Probe (in Puffer A) wird unter Niedrigsalzbedingungen auf die Säule aufgetragen und in einem ansteigenden Salzgradienten eluiert.

\section{Hydrophobe Interaktions-Chromatographie}

\section{Prinzip}

Diese Methode basiert auf der unterschiedlichen Oberflächenhydrophobizität der einzelnen Proteine. Durch Auftragung der Proteine in einem Puffer mit hoher lonenstärke entstehen starke Wechselwirkungen zwischen hydrophoben Oberflächenbereichen der Polypeptide und den hydrophoben Liganden der Säulenmatrix. Treibende Kraft für diese Wechselwirkung ist die Entropie, die durch die Aggregation unpolarer Gruppen in polarer Umgebung zunimmt. Die Elution erfolgt durch eine Verringerung der Polarität des Puffers. Dies kann durch eine Reduzierung der Ionenstärke, den Austausch des Salzes gegen eines mit geringerem Aussalzeffekt (Hofmeister-Serie) oder durch die Zugabe von unpolaren Agenzien (Harnstoff, Detergenzien, organische Lösungsmittel) erfolgen.

\section{Säule}

Es wurde mit einer Phenyl Sepharose HP XK 16/10 Fertigsäule mit 20 ml Säulenvolumen gearbeitet, bei der die Gelmatrix aus stark quervernetzten AgarosePartikeln besteht, die über ungeladene, chemisch stabile Etherbindungen mit PhenylResten derivatisiert sind. Die empfohlene Flußrate beträgt $50-150 \mathrm{~cm} / \mathrm{h}$ bei maximal 0,3 MPa Rückdruck.

\section{Methodik}

Zur Auftragung der Probe wird die Säule mit mindestens 2 SV auf HochsalzBedingungen äquilibriert. Die Probe muß sich ebenfalls in einem Milieu hoher lonenstärke befinden. Hierzu wird sie vorsichtig auf $5 \mathrm{M} \mathrm{NaCl}$ hochgesalzt, wobei darauf zu achten ist, daß ein Aussalzen des Proteins durch lokale 
Überkonzentrierung vermieden wird (portionierte Zugabe des $\mathrm{NaCl}$ unter ständigem Rühren). Die Elution erfolgt im absteigenden Salzgradienten, wobei evtl. mit $\mathrm{H}_{2} \mathrm{O}_{\text {bidest. }}$ nacheluiert werden muß, um stark hydrophobe Proteine wieder von der Säule zu lösen.

\section{Gelfiltration}

\section{Prinzip}

Bei dieser nicht-adsorptiven Methode erfolgt die Trennung der Proteine aufgrund ihrer Größe. Größere Moleküle steht ein vergleichsweise kleines Verteilungsvolumen in der jeweiligen Gelmatrix zur Verfügung, so daß sie früher als kleinere Proteine eluieren.

\section{Säule}

Für die Gelfiltration wurde eine Superdex 200 High Load 16/60 - Säule verwendet. Empfohlen wird für diese Säule eine Flußrate von $10-50 \mathrm{~cm} / \mathrm{h}$ bei maximal $0,3 \mathrm{MPa}$ Rückdruck.

\section{Molekularmassenbestimmung eines Proteins}

Da das Elutionsvolumen mit der Größe des jeweiligen Proteins korreliert, kann die Gelfiltration nicht nur als Reinigungsschritt, sondern auch zur Molekülmassenbestimmung herangezogen werden. Hierzu ermittelt man den Verteilungskoeffizienten $\mathrm{K}_{\mathrm{av}}$ eines Proteins nach folgender Gleichung:

$$
\mathbf{K}_{\mathrm{av}}=\left(\mathrm{V}_{\mathrm{e}}-\mathrm{V}_{\mathrm{o}}\right) /\left(\mathrm{V}_{\mathrm{t}}-\mathrm{V}_{\mathrm{o}}\right) \quad \begin{aligned}
& \mathrm{V}_{\mathrm{t}}=\text { gesamtes Säulenvolumen } \\
& \mathrm{V}_{\mathrm{o}}=\text { Ausschlußvolumen der Säule } \\
& \mathrm{V}_{\mathrm{e}}=\text { Elutionsvolumen des Proteins }
\end{aligned}
$$

Durch Kalibrierung der Gelfiltrationssäule mit Eichproteinen, Ermittlung des jeweiligen Verteilungskoeffizienten und Auftragung des dekadischen Logarithmus der Molekularmasse gegen den $\mathrm{K}_{\mathrm{av}}$-Wert erhält man eine Eichgerade, aus der man die Molekularmasse eines beliebigen Proteins anhand seines Verteilungskoeffizienten errechnen kann. 


\subsection{Enzymaktivitätstests}

\subsection{1 $\mathrm{I}_{2} / \mathrm{KI}$-Test zur Bestimmung von Transferaktivitäten}

Durch Einlagerung von lodmolekülen in die Zuckerhelix lassen sich $\alpha-1,4-O$ ligo- und Polyglucane mit Lugolscher Lösung anfärben. Die Farbentwicklung beginnt bei der Maltododecaose mit einer schwachrosa Färbung. Polysaccharide mit 30 Glucosidresten sind violett (Absorptionsmaximum um $510 \mathrm{~nm}$ ), Amylose ist mit einem Maximum bei 610-620 nm blau gefärbt (Thorn und Mohazzeb, 1990). Der I $\mathrm{I}_{2} / \mathrm{KI}$-Test wurde in zwei Varianten für die Maltosyltransferase bzw. für die 4- $\alpha$-Glucanotransferase eingesetzt.

\subsubsection{1 $\mathrm{I}_{2} / \mathrm{KI}$-Test zur Bestimmung der Maltosyltransferase-Aktivität}

Das Enzym wird mit einem Maltooligosaccharidgemisch, welches einen Polymerisationsgrad (DP) von 4-10 besitzt, inkubiert. Durch die Transferaktivität der Maltosyltransferase wird das Substratgemisch disproportioniert, wobei Produkte mit einem $\mathrm{DP} \geq 12$ entstehen, die sich mit Lugolscher Lösung anfärben lassen und bei $480 \mathrm{~nm}$ photometrisch messbar sind.

Substratlösung 2\% (w/v): Maltooligosaccharide-Mixture

(ICN Biochemicals, Cleveland)

$\mathrm{H}_{2} \mathrm{O}_{\text {bidest. }}$

ad $100 \mathrm{ml}$

Lösung sterilfiltrieren.

Mcllvaine-Puffer $\mathrm{pH} 6,5^{\left(75^{\circ} \mathrm{C}\right)}$ : Komponente A $0,2 \mathrm{M} \mathrm{Na}_{2} \mathrm{HPO}_{4}$ Komponente B $0,1 \mathrm{M}$ Zitronensäure Komponente $\mathrm{A}$ mit Komponente $\mathrm{B}$ bei $75^{\circ} \mathrm{C}$ auf $\mathrm{pH} \mathrm{6,5} \mathrm{titrieren.}$

I_/KI-Lösung:

Lugolsche Lösung (Sigma) 1 Vol. $\mathrm{H}_{2} \mathrm{O}_{\text {bidest. }}$ $4 \mathrm{Vol}$.

Vor Gebrauch in einer braunen, dicht schließenden Flasche frisch ansetzen. 
Testansatz:

$\begin{array}{ll}\text { Substratlösung } & 200 \mu \mathrm{l} \\ \text { Mcllvaine-Puffer pH 6,5 }{ }^{\left(75^{\circ} \mathrm{C}\right)} & 100 \mu \mathrm{l} \\ \text { Probe }+\mathrm{H}_{2} \mathrm{O}_{\text {bidest. }} & 100 \mu \mathrm{l}\end{array}$

Durchführung

- Präinkubation des Ansatz ohne Enzym für 10 min bei $75^{\circ} \mathrm{C}$

- Start der Reaktion durch Zugabe von Enzym; Inkubation bei $75^{\circ} \mathrm{C}$ für eine definierte Zeit

- $100 \mu \mathrm{l}$ Reaktionsansatz entnehmen und in $1 \mathrm{ml} \mathrm{I} / \mathrm{KI}$-Lösung pipettieren, mischen und zügig die Extinktion bei $480 \mathrm{~nm}$ gegen eine Nullprobe ohne Enzym messen (lod in verdünnter Lösung ist flüchtig und raucht relativ schnell aus)

\section{Quantifizierung}

Es handelt sich bei diesem Test um eine Gleichgewichtsreaktion, bei dem jedes Produkt gleichzeitig wieder Substrat ist. Im Verlauf der Inkubation entwickelt sich ein Gleichgewicht, welches zu einem gleichbleibenden Färbeverhalten mit lod führt. Allerdings findet in der Anfangsphase der Reaktion eine deutliche Verschiebung des in dem Testansatz vorliegenden Oligosaccharidgemisches von kurzkettigen zu längerkettigen ( $D P \geq 12) \alpha-1,4$-Glucanen statt. In dieser initialen Phase (bis zu einer $\mathrm{OD}_{480}$ von 1,0$)$ ist eine lineare Proportionalität zwischen Enzymaktivität und Farbintensität gegeben, die eine relative Quantifizierung erlaubt.

\subsubsection{2 $\mathrm{I}_{2} / \mathrm{KI}$-Test zur Bestimmung der $4-\alpha$-Glucanotransferase-Aktivität}

Hier wird die 4- $\alpha$-Glucanotransferase-Aktivität durch die Messung des Transfers von Glucanosylresten von einem langkettigen Donor auf Maltose als Akzeptor bestimmt. Dabei kommt es zu einer abnehmenden Anfärbbarkeit des Testansatzes mit lod (Liebl et al., 1992).

$20 \mathrm{mM}$ Tris- $\mathrm{Cl} \mathrm{pH} \mathrm{7,5^{(60^{ \circ } \mathrm { C } ) }}$ Tris

$\mathrm{H}_{2} \mathrm{O}_{\text {bidest. }}$ ad $1000 \mathrm{ml}$

Mit $\mathrm{HCl}$ bei $60^{\circ} \mathrm{C}$ auf $\mathrm{pH} 7,5$ einstellen.

Substratlösung $(0,05 \%(w / v))$ : Amylose

$2 \mathrm{~N} \mathrm{NaOH}$ ad $10 \mathrm{ml}$

Amylose vollständig lösen, dann neutralisieren mit $2 \mathrm{M} \mathrm{HCl}$ und verdünnen mit $20 \mathrm{mM}$ Tris- $\mathrm{Cl}, \mathrm{pH} 7,5^{\left(60^{\circ} \mathrm{C}\right)}$ ad $1000 \mathrm{ml}$ 
Maltoselösung:

Maltose

I 2 /KI-Lösung $(0,02 \%(v / v)): \quad$ Lugolsche Lösung

1 Vol.

$\mathrm{H}_{2} \mathrm{O}_{\text {bidest. }}$ 49 Vol.

Vor Gebrauch in einer braunen, dicht schließenden

Flasche frisch ansetzen.

Testansatz:

Maltoselösung

$25 \mu \mathrm{l}$

Probe

$x \mu l$

Substratlösung

ad $1000 \mu \mathrm{l}$

Durchführung

- Testansatz mischen und bei $60^{\circ} \mathrm{C}$ inkubieren.

- $\quad$ Zu den Zeitpunkten $\mathrm{t}_{0}$ min und $\mathrm{t}_{15}$ min je $100 \mu$ entnehmen und in $1 \mathrm{ml} \mathrm{I}_{2} / \mathrm{KI}$-Lösung $(0,02 \%(v / v))$ pipettieren.

- Messung der OD bei $620 \mathrm{~nm}$ gegen $\mathrm{H}_{2} \mathrm{O}_{\text {bidest. }}$ und Bildung der Differenz $\Delta \mathrm{E}_{620}$ zwischen den Extinktionen $\mathrm{E}_{620}\left(\mathrm{t}_{0 \mathrm{~min}}\right)$ und $\mathrm{E}_{620}\left(\mathrm{t}_{15 \mathrm{~min}}\right)$.

\section{Quantifizierung}

Für diesen Test gelten ähnliche Einschränkungen wie für den MaltosyltransferaseAktivitätstest, für ein $\Delta \mathrm{E}_{620}$ von $0,1-0,5$ besteht aber auch hier eine lineare Beziehung zur Enzymaktivität, so daß zumindest eine relative Quantifizierung möglich ist. Unitdefinition: $1 \mathrm{U}=\Delta \mathrm{E}_{620}$ pro $15 \mathrm{~min}$.

\subsubsection{Hydrolyse von para-Nitrophenyl-Substraten}

Para-Nitrophenyl (pNP)-Glycoside sind synthetische Testsubstrate für hydrolytische Enzyme. Durch die enzymatische Spaltung der arylglycosidischen Bindung wird p-Nitrophenol freigesetzt, das sich durch seine gelbe Färbung photometrisch bei $420 \mathrm{~nm}$ bestimmen läßt:

p-Nitrophenyl-Glycosid

p-Nitrophenol

$+\quad$ Zucker

(farblos)

(gelb) 


\section{Testansatz:}

Probe

Tris-Cl pH $7^{\left(60^{\circ} \mathrm{C}\right)}: \quad 0,5 \mathrm{M}$

$\mathrm{MnCl}_{2}$ :

$\mathrm{NAD}^{+}$:

Dithiothreitiol (DTT):1 $\mathrm{M}$ (Lagerung bei $4^{\circ} \mathrm{C}$ )

$\mathrm{H}_{2} \mathrm{O}_{\text {bidest. }}$ : $x \mu l$

$30 \mu \mathrm{l}$

$30 \mu \mathrm{l}$

$9 \mathrm{mM}$ (Lagerung bei $\left.4^{\circ} \mathrm{C}\right) \quad 30 \mu \mathrm{l}$

$15 \mu \mathrm{l}$

$185-\mathrm{x} \mu \mathrm{l}$

\section{Durchführung:}

- 5 min Präinkubation des Testansatzes bei $60^{\circ} \mathrm{C}$.

- Start durch Zugabe von $10 \mu \mathrm{l}$ p-Nitrophenyl- $\alpha$-D-glucopyranosid (0,1 M in DMSO, Lagerung bei $-20^{\circ} \mathrm{C}$ ) und Inkubation bei $60^{\circ} \mathrm{C}$ für eine definierte Zeit (Gelbfärbung).

- Abstoppen auf Eis durch Zugabe von $20 \mu$ I EDTA $(0,5 \mathrm{M}$; pH 8,0) und Farbintensivierung durch Alkalisierung.

- Zugabe von $680 \mu \mathrm{H}_{2} \mathrm{O}_{\text {bidest. }}$ und Bestimmung der Extinktion bei $420 \mathrm{~nm}$ gegen eine Negativkontrolle ohne Enzym.

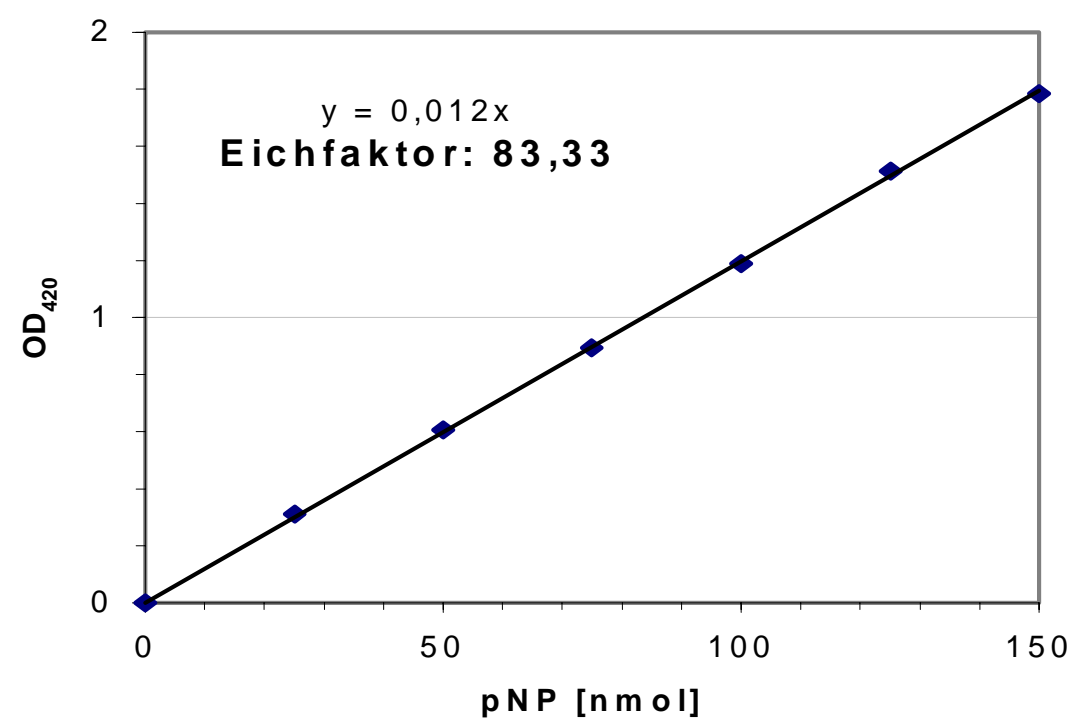

Abb. 7: Eichgerade für den pNP- $\alpha$-D-glucosid-Test. Die Eichgerade wurde unter Testbedingungen mit einer 2,5 mM p-Nitrophenol-Standardlösung im Bereich von 0-150 nmol p-Nitrophenol durchgeführt $(\rightarrow$ Der molare Extinktions-Koeffizient von pNP unter diesen Bedingungen ist $\left.12000 \mathrm{M}^{-1} \mathrm{~cm}^{-1}\right)$. 


\section{Quantifizierung}

Durch Multiplikation des erhaltenen Extinktionswertes mit dem reziproken Wert des ermittelten Steigungsfaktors erhält man die Menge an p-Nitrophenol (in $\mu$ mol), die im Test freigesetzt wurde. Eine Unit entspricht der Enzymaktivität, die 1 mmol p-Nitrophenol in 1 min freisetzt.

\subsubsection{Enzymaktivitätstest auf Agarplatten}

Zur Identifizierung $\alpha$-Glucosidase positiver Klone nach der Transformation wurde das künstliche Substrat 4-Methylumbelliferyl- $\alpha$-D-glucosid verwendet, dessen Hydrolyseprodukt 4-Methylumbelliferon durch Fluoreszenz bei $366 \mathrm{~nm}$ nachgewiesen werden kann.

\section{Inkubationslösung:}

$\begin{array}{lr}0,5 \mathrm{M} \mathrm{Tris-Cl} \mathrm{pH} 7^{\left(60^{\circ} \mathrm{C}\right)} & 50 \mu \mathrm{l} \\ 10 \mathrm{mM} \mathrm{MnCl}_{2} & 50 \mu \mathrm{l} \\ 9 \mathrm{mM} \mathrm{NAD}^{+} & 50 \mu \mathrm{l} \\ 1 \mathrm{M} \mathrm{DTT}^{1} \mathrm{M} \mathrm{MU}^{-} \alpha \text {-D-glucosid (in DMSO) } & 25 \mu \mathrm{l} \\ \mathrm{H}_{2} \mathrm{O}_{\text {bidest. }} & 300 \mu \mathrm{l}\end{array}$

Durchführung

- Strichförmiges Animpfen der Transformanten auf LB-Agarplatten und Inkubation (unter Selektionsdruck) bei $37^{\circ} \mathrm{C}$ über Nacht.

- Präinkubation der Aktivitätsplatte bei $60^{\circ} \mathrm{C}$ im Wasserbad/Trockenschrank.

- Auflegen eines mit Inkubationslösung getränkten Membranfilters und weitere Inkubation bei $60^{\circ} \mathrm{C}$ (15 min).

- Detektion positiver Klone unter UV-Licht (366 nm).

\subsubsection{DNSA-Test zur Bestimmung reduzierender Zucker}

Bei der Hydrolyse polymerer Zucker werden kleinere Bruchstücke bzw. Monomere gebildet, wodurch sich die Zahl der reduzierenden Enden vervielfacht. In Gegenwart von Phenol und Natriumsulfit wird DNSA durch freie Halbacetalgruppen zur 3-Amino5-nitrosalicylsäure reduziert. Diese Reaktion bedingt eine zunehmende Braunfärbung des Testansatzes, die proportional zur Anzahl an reduzierenden Enden ist und photometrisch bei $575 \mathrm{~nm}$ quantifiziert werden kann. 
3,5-Dinitrosalicylsäure (gelb)

DNSA-Reagenz:

$\underset{\text { Phenol, } \mathrm{Na}_{2} \mathrm{SO}_{3}}{\stackrel{100^{\circ} \mathrm{C}, 15 \mathrm{~min}}{\longrightarrow}}$

3-Amino-5-nitrosalicylsäure

(braun)
Dinitrosalicylsäure

Phenol

$\mathrm{Na}_{2} \mathrm{SO}_{3}$

K-Na-Tartrat

$\mathrm{NaOH}$

$\mathrm{H}_{2} \mathrm{O}_{\text {bidest. }}$

Komponente A

Komponente $B$

Komponente A mit Komponente $\mathrm{B}$ bei $75^{\circ} \mathrm{C}$ auf $\mathrm{pH} 6,5$ titrieren

lösliche Substrate

$1 \%(\mathrm{w} / \mathrm{v})$ in $\mathrm{H}_{2} \mathrm{O}_{\text {bidest. }}$

unlösliche Substrate

\section{Testansatz:}

- lösliche Substrate

$$
\begin{aligned}
& \text { Substratlösung }(1 \%(\mathrm{w} / \mathrm{v})) \\
& \text { Mcllvaine, } \mathrm{pH} 6,5^{\left(75^{\circ} \mathrm{C}\right)} \\
& \text { Probe }+\mathrm{H}_{2} \mathrm{O}_{\text {bidest. }}
\end{aligned}
$$$$
250 \mu \mathrm{l}
$$$$
100 \mu \mathrm{l}
$$$$
150 \mu \mathrm{l}
$$

- unlösliche Substrate

Substratlösung (2\% (w/v))

$375 \mu l$

Mcllvaine, $\mathrm{pH} 6,5^{\left(75^{\circ} \mathrm{C}\right)}$

Probe $+\mathrm{H}_{2} \mathrm{O}_{\text {bidest. }}$ $225 \mu \mathrm{l}$

Durchführung

- Präinkubation des Testansatzes ohne Enzym für 10 min bei $75^{\circ} \mathrm{C}$.

- Start der Reaktion durch Zugabe von Enzym; Inkubation für eine definierte Zeit bei $75^{\circ} \mathrm{C}$.

- bei unlöslichen Substraten: Substrat abzentrifugieren, $500 \mu \mathrm{l}$ Überstand entnehmen und in ein neues E-Cup überführen.

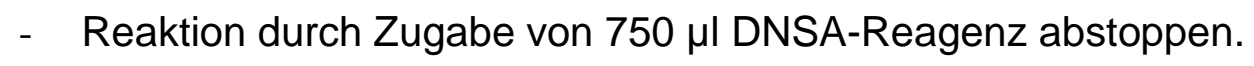

- Ansatz 15 min bei $100^{\circ} \mathrm{C}$ inkubieren, anschließend auf Eis abkühlen.

- $\quad$ OD bei $575 \mathrm{~nm}$ gegen eine Nullprobe ohne Enzym messen. 


\section{Quantifizierung}

Zur Quantifizierung der hydrolytischen Aktivität wird für jedes polymere Substrat eine Eichgerade mit variablen Mengen des entsprechenden Monomers (für Glucane also eine Eichgerade mit Glucose) unter Testbedingungen erstellt. 1 Unit entspricht der Enzymaktivität, die $1 \mu \mathrm{mol}$ reduzierende Enden (Glucose-Äquivalente) in $1 \mathrm{~min}$ erzeugt.

\subsection{Charakterisierung von Enzymen}

\subsubsection{Cofaktor-Abhängigkeit der Aktivität}

Die Experimente für die $\alpha$-Glucosidasen wurden mit dem in 2.15.2 beschriebenen Standard-Test durchgeführt. Die Konzentrationen der eingesetzten Cofaktoren betrugen für $\mathrm{NAD}^{+} 0,9 \mathrm{mM}$, für $\mathrm{MnCl}_{2} 1 \mathrm{mM}$ und für DTT $50 \mathrm{mM}$. Zur Ermittlung des Effektes (der Konzentration) eines Cofaktors auf die enzymatische Aktivität der $\alpha$-Glucosidase wurden die beiden anderen jeweils in ihren optimalen Konzentrationsverhältnissen zugesetzt.

\subsubsection{Reduzierende Agenzien}

Der stimulierende Effekt von DTT legte nahe, daß ein reduzierendes Agenz für die $\alpha$-Glucosidase-Aktivität benötigt wurde. Aus diesem Grunde wurde das DTT aus dem Standard-Test entfernt und durch variable Konzentrationen von 2-Mercaptoethanol oder L-Cystein ersetzt. Da L-Cystein leicht eine Änderung des pH-Wertes im Testansatz bewirken kann, wurde es in einem geeignetem Puffer gelöst und der $\mathrm{pH}$ Wert der Testansätze bei den verschiedenen L-Cystein-Konzentrationen auf seine Konstanz hin überprüft.

\subsubsection{Einfluß verschiedener Salze auf die Aktivität}

Der Effekt verschiedener zweiwertiger Kationen auf die Aktivität der $\alpha$-Glucosidase wurde zunächst ebenfalls im Standard-Test bestimmt. Da verschiedene Salze eine Eigenfärbung aufweisen, wird jeder Ansatz gegen einen eigenen Nullwert mit dem entsprechenden Salz gemessen. Angegeben wird schließlich die relative Aktivität (in Prozent), bezogen auf einen Referenzansatz ohne Additiv. Da einige Metalle unter Standard-Testbedingungen vermutlich durch Reduktion durch DTT ausfallen, wurde

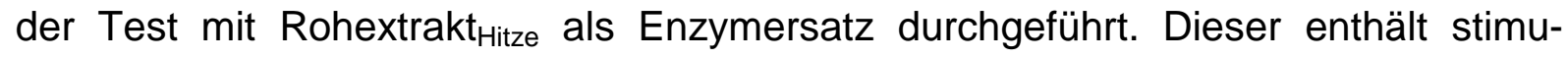


lierende Komponenten zwar nur in suboptimalen Konzentrationen; man kann aber auf die Zugabe von DTT verzichten und dennoch den aktivierenden Effekt verschiedener Salze zeigen.

\subsubsection{Nukleotide}

Die Aktivität der $\alpha$-Glucosidase wurde wiederum im Standard-Test bestimmt. Alle eingesetzten Testsubstrate wurden in einer Endkonzentration von $1 \mathrm{mM}$ zum Test hinzugefügt. Wegen der Eigenfärbung von FMN / FAD wurde wie im Abschnitt (2.16.1.2) verfahren.

\subsubsection{Enzymkinetik}

Für die Charakterisierung enzymkatalysierter Reaktionen spielen die MichaelisMenten-Parameter $K_{m}$ und $v_{\max }$ eine grundlegende Rolle. Die erforderlichen Messungen der initialen Reaktionsgeschwindigkeit in Abhängigkeit von der Substratkonzentration erfolgte durch enzymatische Tests. Hierbei wurden zur Vermeidung von Meßfehlern durch Aufheiz- und Abkühlzeiten alle Inkubationsansätze vor Enzymzugabe 5-10 min vorgeheizt; der Reaktionsstop erfolgte auf Eis. Um alle Ansätze unter identischen Bedingungen zu inkubieren, wurden sie im Abstand von 20-30 sec zeitlich versetzt bearbeitet. Für den Fall, daß ein Enzym in stark verdünnten Lösungen nur eine begrenzte Stabilität aufweist, wurden Enzymverdünnungen erst unmittelbar vor der Verwendung hergestellt. Es wurden Mehrfachmessungen durchgeführt, um statistisch erfaßbare Werte zu erhalten. Als Inkubationszeit wurde derjenige Zeitpunkt gewählt, an dem die erste Zunahme an Produkt zu verzeichnen war (Anfangskinetik).

\subsubsection{Kinetik der $\alpha$-Glucosidase}

\section{Synthetische Substrate}

- Verwendung des Standard-Testes (2.15.2): Präinkubation für 5 min; Inkubationsdauer: 3 min; Abstoppung auf Eis; Eichfaktor für pNP = 83,33 (2.15.2)

\section{Maltooligosaccharide als Substrate}

- Verwendung einer zweistufigen Reaktion (siehe 3.2.3): Die von der Hexokinase benötigten zweiwertigen Metallionen werden von $\mathrm{MnCl}_{2}$ aus dem Ansatz I 
geliefert; anstelle von NADP konnte das NAD aus der ersten Reaktion genutzt werden.

- Nach der zweiten Reaktion darf nicht mehr gemischt werden, da sonst das gebildete NADH wieder oxidiert wird!

- Es wurde im $70 \mu \mathrm{l}-\mathrm{Maßstab}$ mit einer Quarz-Küvette $\left(\mathrm{OD}_{340}\right)$ gearbeitet. Dieses relativ kleine Testvolumen bedingt allerdings größere Meßfehler.

- Eine Eichgerade wurde mit Glucose (Bereich 0 - $55 \mathrm{nmol}$ ) erstellt. Der Eichfaktor war 12,56. 1 Unit entspricht der Zunahme der Zuckerkonzentration um $1 \mu \mathrm{mol}$ pro $\min$.

\section{Ermittlung der Bindungskonstante $K_{d}$}

Durch ortsspezifische Mutagenese wurde der N-Terminus der $\alpha$-Glucosidase mutiert. Der erhoffte Effekt, nämlich die Beeinträchtigung der NAD+-Bindung, sollte durch Bestimmung der Bindungskonstanten $K_{d}$ experimentell gezeigt werden. Hierzu wurden deshalb in einem modifizierten Standard-Test mit $p$-Nitrophenyl- $\alpha-D-$ glucopyranosid als Substrat die $\mathrm{NAD}^{+}$-Konzentrationen so lange variiert (siehe 3.2.5), bis schließlich ein Plateau in einer Michaelis-Menten-Auftragung erreicht wurde. Um optimale Inkubationszeiten (7-10 min) zu gewährleisten, wurden die eingesetzten Enzymkonzentrationen entsprechend angepaßt.

\subsubsection{Einfluß potentieller metabolischer Regulatoren und Kinetik der Inhibi- tion}

\section{$\alpha$-Glucosidase}

Um eine mögliche Regulation des Enzyms durch Intermediate des Kohlenhydratmetabolismus zu überprüfen, werden geeignete Verbindungen im Standard-Test (Inkubation: $60^{\circ} \mathrm{C}$ für $15 \mathrm{~min}$ ) zugesetzt.

Additive (effektive Konzentration: $10 \mathrm{mM}$; Verbindungen wurden in 0,5 M Tris- $\mathrm{Cl}$

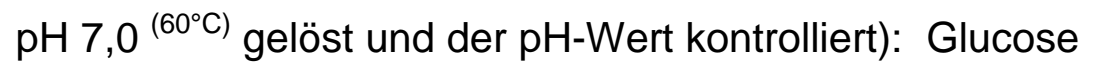

Glucose-6-Phosphat

Fructose-6-Phosphat

Fructose-1,6-Diphosphat

Pyruvat

Die Aktivität wird mit einem Referenzansatz ohne Additiv verglichen. 
Für Fructose-1,6-Diphosphat wurde der Inhibitortyp ermittelt. Hierzu wurde die Enzymaktivität in Abhängigkeit unterschiedlicher Inhibitor- und Substratkonzentrationen bestimmt. Zuerst wird die Enzymaktivität bei unterschiedlichen Substratkonzentrationen und gleichbleibender Inhibitorkonzentration bestimmt. Anschließend verändert man die Inhibitorkonzentration und mißt die Enzymaktivität bei steigender Substratkonzentration. Zur Ermittlung des Hemmtyps wird ein Lineweaver-BurkDiagramm erstellt.

Um bei den Messungen einen konstanten pH-Wert zu erhalten, mußte Fructose-1,6Diphosphat in Tris-Puffer gelöst werden. Da sich in Abhängigkeit der zugegebenen Menge an Inhibitor zum Testansatz auch die Konzentration an Tris-Puffer veränderte, wurde für alle gemessenen Inhibitor-Konzentrationen individuelle Eichgeraden für pNP erstellt und folgende Eichfaktoren ermittelt:

$$
\begin{array}{ll}
\text { ohne F-1,6-DP }=83,33 & 25 \mathrm{mM} \mathrm{F-1,6-DP}=91,74 \\
6,25 \mathrm{mM} \mathrm{F-1,6-DP}=86,21 & 50 \mathrm{mM} \mathrm{F-1,6-DP}=104,17 \\
12,5 \mathrm{mM} \mathrm{F-1,6-DP}=86,96 &
\end{array}
$$

\section{Maltosyltransferase}

Zur Untersuchung des Einflusses potentieller (phosphathaltiger) Regulatoren auf die MTase-Aktivität wurden verschiedene Substrate (siehe 3.4.6) im $\mathrm{I}_{2} / \mathrm{KI}$-Test eingesetzt.

\begin{tabular}{|llrl|}
\hline Testansatz: & Substratlösung $(2 \%)$ & 200 & $\mu \mathrm{l}$ \\
& Mcllvaine $\mathrm{pH} 6,5^{\left(75^{\circ} \mathrm{C}\right)}$ & 100 & $\mu \mathrm{l}$ \\
& Additiv & 40 & $\mu \mathrm{l}(\mathrm{EK} .: 10 \mathrm{mM})$ \\
& $\mathrm{H}_{2} \mathrm{O}_{\text {bidest. }}$ & $53,53 \mu \mathrm{l}$ \\
& MTase & $6,47 \mu \mathrm{l}(6 \mu \mathrm{g})$ \\
Inkubation: & $75^{\circ} \mathrm{C}$ für $10 \mathrm{~min}$ & \\
\hline
\end{tabular}

Gegebenenfalls wurden die Additive in Puffer gelöst, um einen konstanten $\mathrm{pH}$-Wert zu garantieren.

Für Glucose-1,6-Diphosphat (in 0,5 M Tris-Cl pH 7,0 ${ }^{\left(75^{\circ} \mathrm{C}\right)}$ ) wurde zusätzlich die Abhängigkeit der Aktivität der MTase für den Konzentrationsbereich von $0-10 \mathrm{mM}$ ermittelt. 


\subsubsection{Temperaturabhängigkeit der Aktivität}

Der Einfluß der Temperatur auf die Aktivität der Mutante V110R wurde mit dem $\mathrm{I}_{2} / \mathrm{KI}$ Test (siehe 2.15.1.1) bei Inkubationstemperaturen von $30^{\circ} \mathrm{C}-95^{\circ} \mathrm{C}$ gemessen. Im Test wurde der Mcllvaine-Puffer verwendet, der einen sehr niedrigen TemperaturKoeffizienten aufweist $\left(\Delta \mathrm{pH}=0,002 /{ }^{\circ} \mathrm{C}\right)$. Um dennoch $\mathrm{pH}$-Effekte auf die Aktivität $\mathrm{zu}$ vermeiden, wurde der Puffer für jeden Testansatz bei der jeweiligen Inkubationstemperatur eingestellt.

Die thermische Inaktivierung eines Enzyms ist zeitabhängig und somit ist auch die Bestimmung des Temperaturoptimums zeitabhängig. Um den Effekt der thermischen Inaktivierung möglichst zu reduzieren, wurde die Inkubationszeit des Testes auf 10 min begrenzt.

\subsubsection{Thermische Inaktivierung}

Um die Abnahme der Enzymaktivität in Abhängigkeit von Inkubationstemperatur und -zeit zu verfolgen, wurde für jede Temperatur ein ausreichend großer Ansatz zusammenpipettiert, der das Enzym in optimalem Puffer (Mcllvaine pH 6,5; eingestellt bei der entsprechenden Temperatur) enthält. Der Pool wird dann auf eine geeignete Anzahl von E-Cups aufgeteilt, die sukzessive in entsprechenden Zeitabständen in einen PCR-Heizblock (bietet größere Temperaturgenauigkeit gegenüber Wasserbädern oder Trockenschränken) gestellt wurden, wobei die am längsten zu inkubierende Probe als erstes eingesetzt wurde. Der Vorteil dieser Methode besteht darin, daß die Bestimmung der Restaktivität in einem einzigen Meßdurchgang erfolgen kann. Letztlich wird die verbliebene Restaktivität (in Prozent) bezogen auf einen Referenzansatz ohne Präinkubation angegeben.

Bei der Bestimmung der Thermoinaktivierung der Mutante V110R wurde zusätzlich noch ein Ansatz in einem Gradienten PCR-Heizblock (Eppendorf Mastercycler gradient) durchgeführt. Hier konnten gleichzeitig in einem Heizblock für die Temperaturen $73,4^{\circ} \mathrm{C}, 73,5^{\circ} \mathrm{C}, 73,8^{\circ} \mathrm{C}, 74,3^{\circ} \mathrm{C}, 75,0^{\circ} \mathrm{C}, 75,9^{\circ} \mathrm{C}, 76,7^{\circ} \mathrm{C}, 77,5^{\circ} \mathrm{C}$, $78,3^{\circ} \mathrm{C}, 78,9^{\circ} \mathrm{C}, 79,3^{\circ} \mathrm{C}$ und $79,5^{\circ} \mathrm{C}$ die Präinkubation für die Zeitdauer von $2 \mathrm{~h}$ durchgeführt werden. 


\subsection{Zentrifugationen}

Für alle molekularbiologischen und proteinchemischen Arbeiten wurden je nach Lösungs- bzw. Kulturvolumen unterschiedliche Zentrifugen und Rotoren genutzt. Sofern nicht anders angegeben, wurden Volumina bis $2 \mathrm{ml}$ in einer Biofuge fresco (Kühlzentrifuge) oder Biofuge pico der Fa. Heraeus, (Osterode/Harz) zentrifugiert. Volumina, die oberhalb $2 \mathrm{ml}$ lagen, wurden in einer Sorvall RC5C oder Sorvall RC2B-Zentrifuge der Fa. Du Pont (Bad Homburg) mit den Rotoren SS-34, GSA oder GS-3 zentrifugiert.

\subsection{Chemikalien, Biochemikalien und Enzyme}

Sofern nicht anders angegeben wurden Chemikalien der Firmen Merck AG (Darmstadt), Fluka Chemie AG (Neu-Ulm) oder Riedel-de Haen (Hannover) mit den Reinheitsgraden „pro analysis“ oder „reinst“ verwendet.

Restriktionsenzyme wurden von den Firmen Gibco BRL (Eggenstein), MBI Fermentas (St. Leon-Rot), New England Biolabs (Frankfurt am Main), Amersham Pharmacia Biotech (Freiburg) und USB (jetzt Amersham Pharmacia Biotech) bezogen.

Weitere Verbrauchsmaterialien:

Aldrich-Chemie $\mathrm{GmbH}$, (Steinheim)

Biomol Feinchemikalien, Hamburg

Boehringer Mannheim, Mannheim

Fluka Feinchemikalien GmbH, Neu-Ulm

GERBU Biotechnik, Gaiberg

MBI Fermentas, Wilna, Litauen

Merck, Darmstadt

Oxoid, Basingstoke, England

Promega (Vertrieb durch die Serva $\mathrm{GmbH}$ ) siehe Sigma

BCIP, NBT, IPTG, Ampicillin, Brom-

phenolblau, TEMED, 40\% Acrylamide

$4 x$ cryst. Mix 37,5 : 1

Lysozym, DNase I, RNase A,

Glycerin, Indol, D(+)-Sucrose

Acrylamide M-BIS (30 \%-ige (w/v)

Stammlösung 19:1

DNA-Größenstandard (1 kB-Leiter)

Proteinase $\mathrm{K}$

Bacteriological Agar No.1, Hefeextrakt, Trypton 
Qiagen, Hilden

QIAprep Spin Miniprep Kit, QIAquick

Gel Extraction Kit

Roth $\mathrm{GmbH} \&$ Co, Karlsruhe Isoamylalkohol, Phenol, Tris, $\mathrm{NaOH}$

Schleicher \& Schuell, Dassel

3 MM Whatman Filterpapier, Membranfilter

Serva Feinbiochemika GmbH, Heidelberg Bromphenolblau, EDTA, Ethidiumbromid, Rinderserumalbumin (Fraktion V), SDS, Serva Blau G250, Tween 20, Glycerin

Sigma-Aldrich Chemie, Deisenhofen Anti-Kaninchen-Immunglobulin-AP, Ficoll 400, BSA, Coomassie ${ }^{\circledR}$ Brilliant Blue G250, Mono- und Polysaccharide 


\section{EXPERIMENTE UND ERGEBNISSE}

\subsection{Klonierung der $\alpha$-Glucosidasen agIB aus T. maritima und agIA aus T. neapolitana}

Die Isolierung und Analyse des agIA-Gens aus T. maritima (Bibel et al., 1998) führte zur Aufdeckung eines ungewöhnlichen Bedürfnisses des rekombinanten Proteins für die Cofaktoren $\mathrm{NAD}^{+}$und $\mathrm{Mn}^{2+}$, sowie für reduzierende Bedingungen (Raasch et al., 2000). Dies waren ausreichende Gründe, um das stromaufwärts gelegene aglB (T. maritima) und das homologe Gen aglA aus T. neapolitana (Identität: 90\%; Ähnlichkeit: $97 \%$ auf Aminosäuresequenzebene) zu klonieren und so die Voraussetzungen für den Vergleich der verschiedenen Eigenschaften der drei $\alpha$-Glucosidasen zu schaffen.

\subsubsection{Klonierung von aglB aus $T$. maritima in E. coli}

Die Isolierung von agIB erfolgte mit Hilfe von Amplifikation durch PCR. Die verwendeten Primer waren 29 bzw. 30 bp lang und enthielten für die Klonierung geeignete Restriktionsschnittstellen (Tab. 4).

Tab. 4: Verwendete Primer für die PCR

\begin{tabular}{ccc}
\hline Bezeichnung & Primer-Sequenz $^{\text {a) }}\left(5^{`} \rightarrow 3^{`}\right)$ & Schnittstelle \\
\hline TM 1835a & GGTGAACATATGATGTACCCGATGCCGTC & Ndel \\
TM 1835b & ATGACTCGAGTCAAACTCTCTTGTACAATC & Xhol \\
\hline
\end{tabular}

${ }^{a)}$ : die eingefügte Schnittstelle ist jeweils unterstrichen

\section{PCR-Ansatz:}

\begin{tabular}{|lll|}
\hline TM 1835a $(100 \mathrm{pmol} / \mu \mathrm{l})$ & 0,5 & $\mu \mathrm{l}$ \\
TM 1835b $(100 \mathrm{pmol} / \mu \mathrm{l})$ & 0,5 & $\mu \mathrm{l}$ \\
Matrizen-DNA $(0,2 \mu \mathrm{g} / \mu \mathrm{l})^{\mathrm{b})}$ & 0,5 & $\mu \mathrm{l}$ \\
dNTP-Lösung (je 10 mM) & 4 & $\mu \mathrm{l}$ \\
Pfu-Puffer (10x) & 5 & $\mu \mathrm{l}$ \\
DMSO & 5 & $\mu \mathrm{l}$ \\
$\mathrm{H}_{2} \mathrm{O}$ & 34 & $\mu \mathrm{l}$ \\
Pfu-Polymerase $(9 \mathrm{U} / \mu \mathrm{l})$ & 1 & $\mu \mathrm{l}$ \\
\hline
\end{tabular}

PCR-Bedingungen:

\begin{tabular}{|lllc|}
\hline Erste Denaturierung: & $95^{\circ} \mathrm{C}, 5$ & $\mathrm{~min}$ \\
32 Zyklen: & & & \\
\hline 1.) Denaturierung: & $94^{\circ} \mathrm{C}$, & 45 & $\mathrm{~s}$ \\
2.) Primer-Anlagerung: & $38^{\circ} \mathrm{C}$, & 90 & $\mathrm{~s}$ \\
3.) Synthese: & $72^{\circ} \mathrm{C}$, & 2 & $\mathrm{~min}$ \\
Letzter Syntheseschritt: & $72^{\circ} \mathrm{C}$, & 10 & $\mathrm{~min}$ \\
\hline
\end{tabular}

b) chromosomale Gesamt-DNA aus T. maritima MSB8 wurde freundlicherweise von W. Liebl zur Verfügung gestellt. 
Der PCR-Ansatz wurde bei den angegebenen Bedingungen inkubiert, das 1,4 kb PCR-Produkt aus dem Agarose-Gel extrahiert (2.4.4), mit dem EcoRV geschnittenen pBSK $^{+}$-Vektor ligiert und in E.coli DH5 $\alpha$ transformiert. Nach Blau-Weiß-Screening wurde ein Klon mit korrekt inseriertem PCR-Fragment ausgewählt und unter

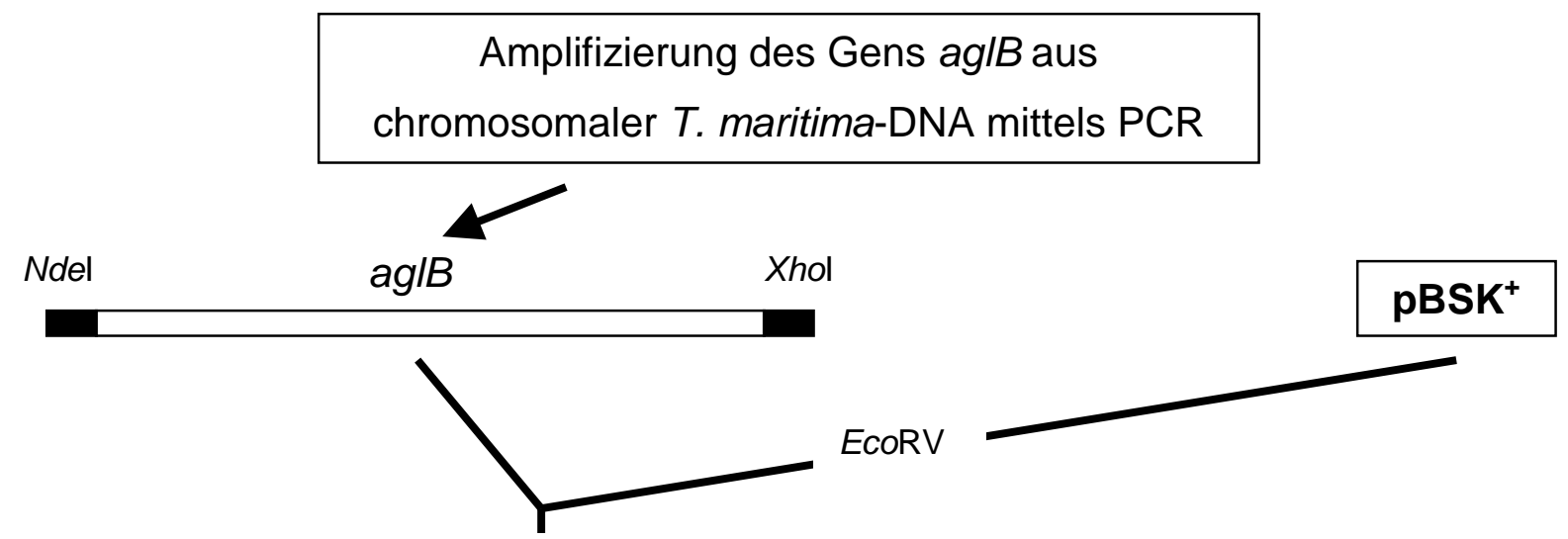

Ligation stumpfer Enden

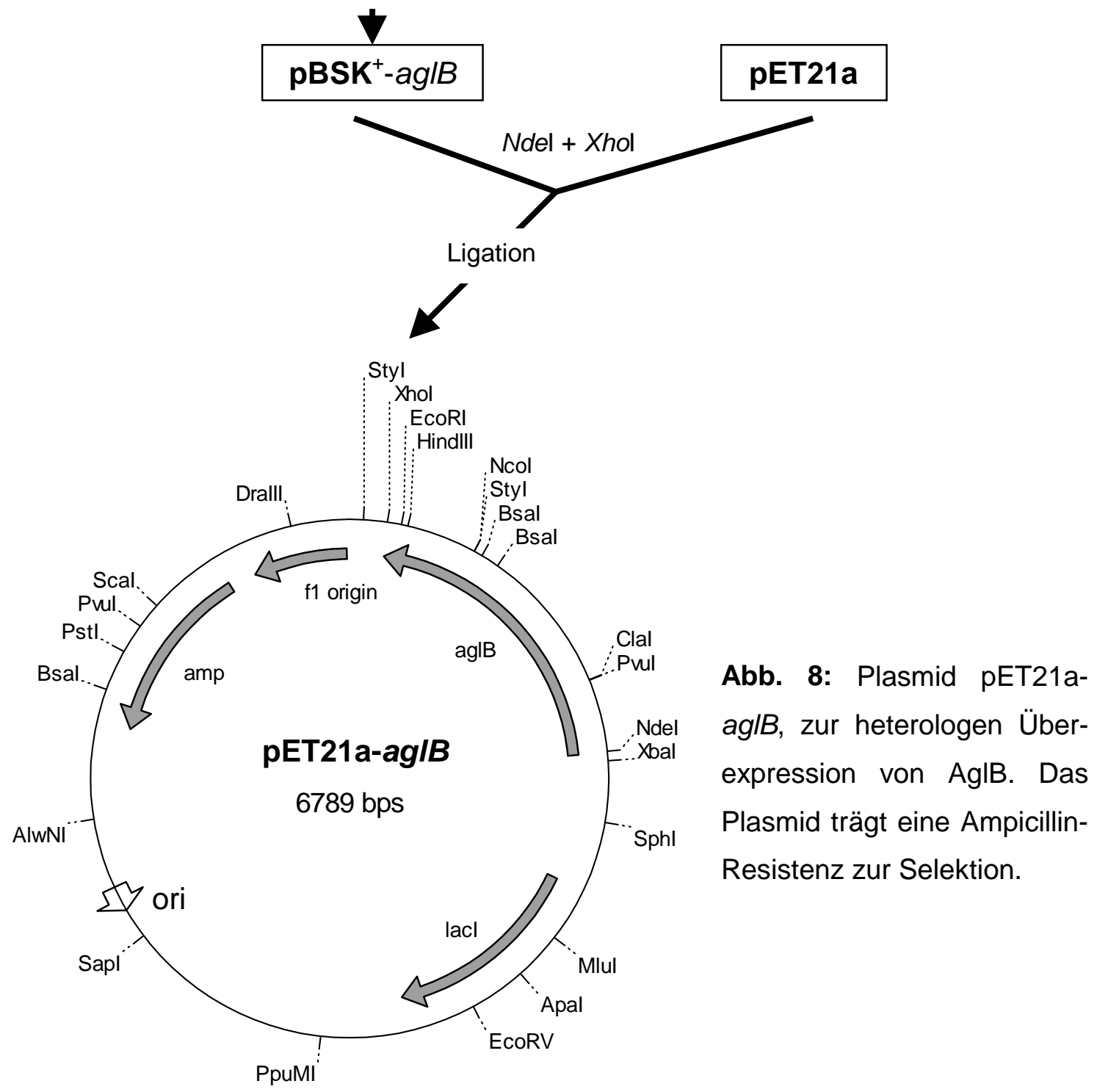


Verwendung der neu eingebauten Schnittstellen Ndel/Xhol in den Vektor pET21a kloniert (Abb. 8). Dieses neue Plasmid pET21a-aglB wurde zur heterologen Expression in den Stamm E. coli BL21 (DE3) elektroporiert. AglB (473 As; 55 kDa) zeigte Aktivität gegenüber Cyclodextrinen und para-Nitrophenyl- $\alpha$-D-Maltosid und wurde im Rahmen einer noch nicht abgeschlossenen Diplomarbeit (Veith, 2001) gereinigt und weiter charakterisiert.

\subsubsection{Klonierung von agIA aus T. neapolitana in E. coli}

Aus einer T. neapolitana Z2706-MC24 Plasmidgenbank in E. coli lagen zwei überlappende Klone E. coli XL1-Blue-M1 bzw. -M2 vor, die beide $\alpha$-GlucosidaseAktivität zeigten. Bei beiden Klonen lag agIA auf jeweils größeren DNA-Fragmenten im pUC18-Vektor vor.

Zur Herstellung eines agIA-exprimierenden Subklones (Abb. 9) wurde aus pM2 ein 2390 bp-Fragment mittels EcoRI-Verdau herausgeschnitten, in den ebenso geschnittenen Expressionsvektor pJF118ut ligiert und in E. coli JM83 transformiert. Der Enzymaktivitätstest auf einer Agarplatte mit 4-Methylumbelliferyl- $\alpha$-D-glycosid als Substrat (2.15.3) sowie enzymatische Kontrollverdauungen (2.5.1) ergaben, daß mit E. coli JM83 (pJF118ut-agIA) ein korrekter Subklon mit $\alpha$-Glucosidase-Aktivität vorlag.

\subsubsection{Heterologe Expression, Reinigung und erste Charakterisierung von AglA (T. neapolitana)}

Nach entsprechenden Vorversuchen wurde für die Reinigung der $\alpha$-Glucosidase ( $T$. neapolitana) im präparativen Maßstab ein Kulturvolumen von 5 I ( $5 \times 1$ I in LB LBmp $_{\text {Amp }}$ angeimpft, bei einer $\mathrm{OD}_{600}$ von 0,5 - 0,6 mit 0,5 mM (Endkonzentration) IPTG induziert und für $20 \mathrm{~h}$ bei $37^{\circ} \mathrm{C}$ unter kräftiger Belüftung inkubiert. Die Zellen (Naßgewicht: 12,8 g) wurden anschließend geerntet, mit $20 \mathrm{mM}$ Tris- $\mathrm{Cl}$ pH 8 gewaschen und in etwa $1 \mathrm{ml}$ Puffer pro Gramm Zell-Naßgewicht gründlich resuspendiert. Der Zellaufschluß erfolgte in der French Pressure Cell (6,9 MPa). Nach Abzentrifugation der Zelltrümmer (13000 Upm, 15 min) wurde der geklärte Rohextrakt aliquotiert $(0,6 \mathrm{ml})$, für $15 \mathrm{~min}$ bei $85^{\circ} \mathrm{C}$ inkubiert und zur raschen Abkühlung auf Eis gestellt. Bei diesem Schritt erfolgt eine erste Anreicherung des thermostabilen rekombinanten Enzyms durch die Hitzefällung, bei welcher der überwiegende Teil der mesophilen Wirtsproteine präzipitiert. Durch hochtourige Zentrifugation wurde das präzipitierte 
Material abgetrennt. Der Überstand der Aliquots wurde vereinigt und einem weiteren Reinigungsschritt durch Anionenaustauschchromatographie unterworfen.
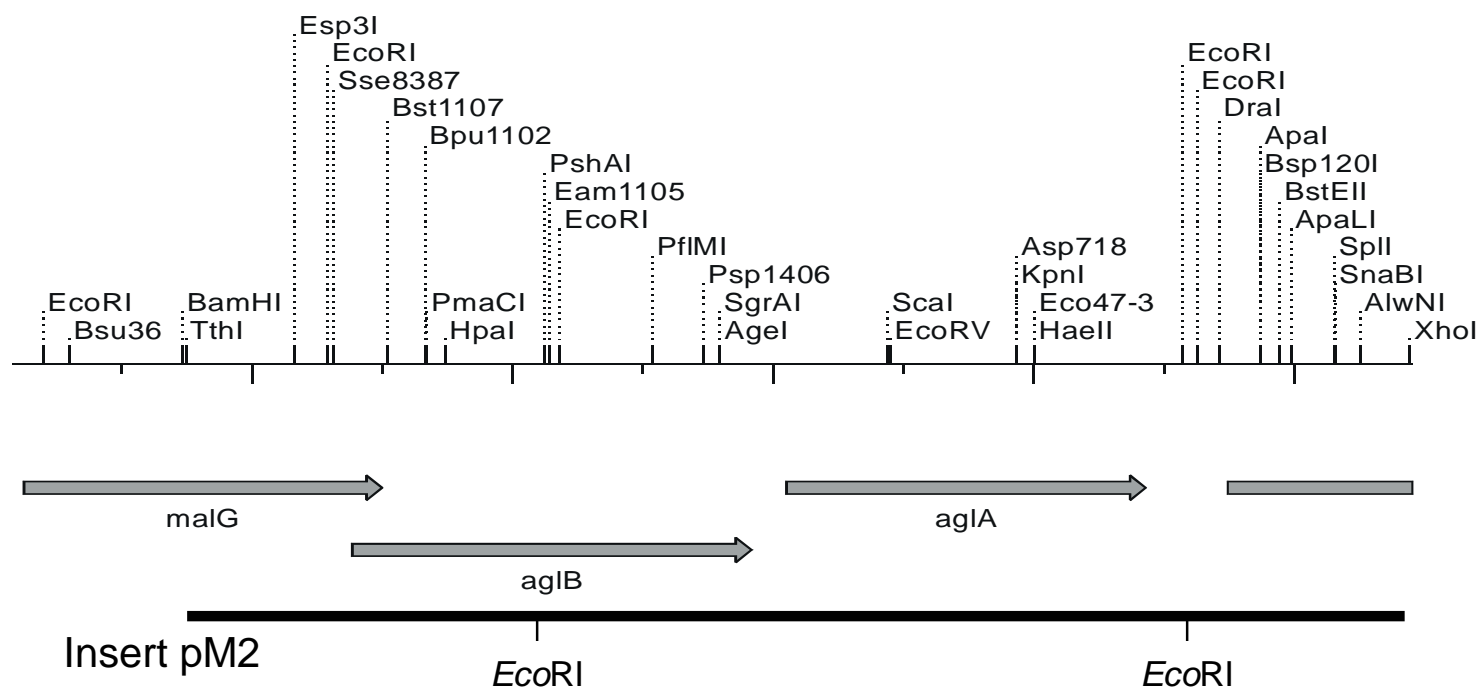

(Sau3A partial)

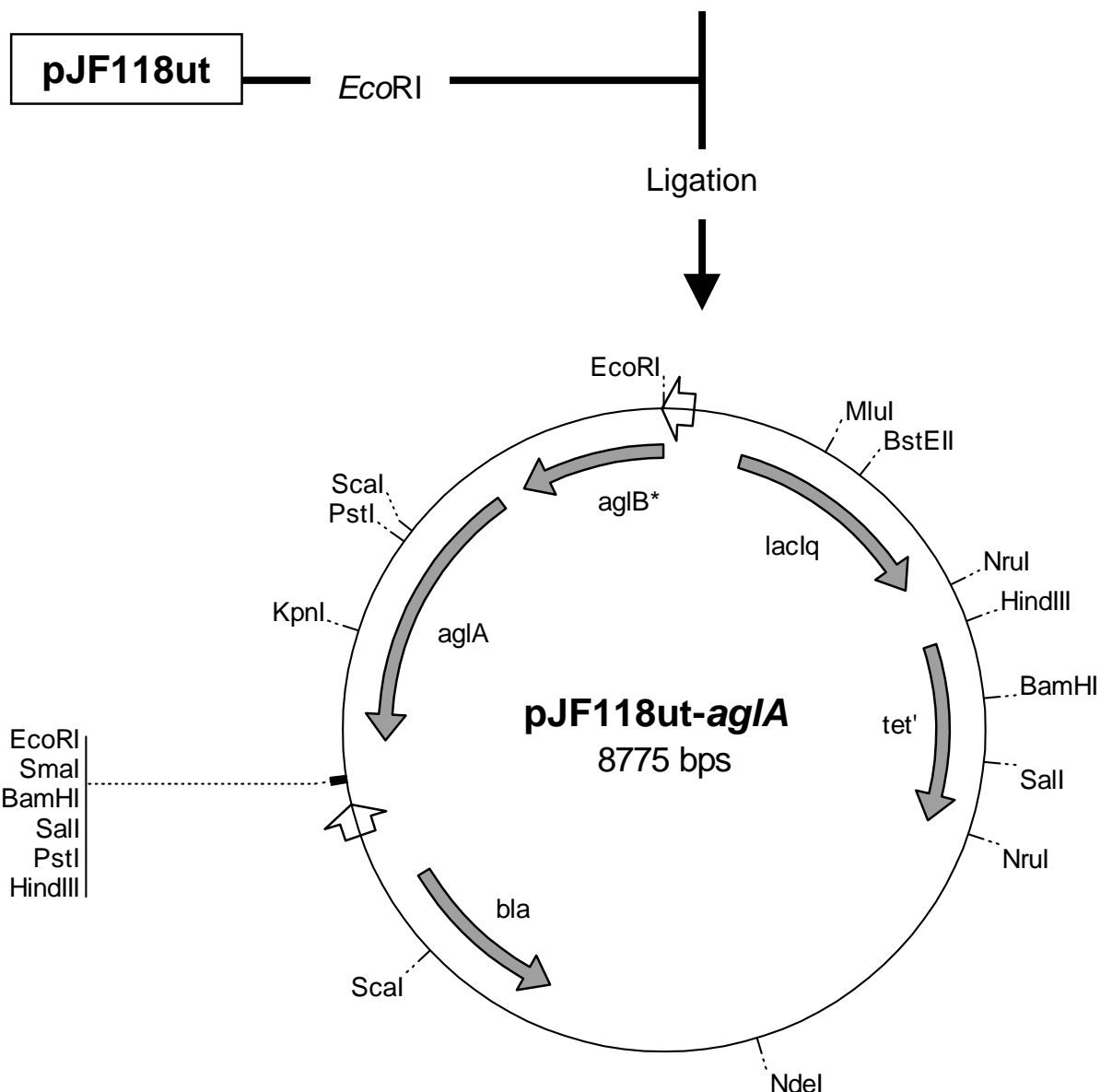

Abb. 9: Konstruktion des AglA Expressionsplasmides pJF118ut-aglA. Die lineare Restriktionskarte zeigt das DNA-Insert pM2 mit einem unvollständigen Gencluster für Enzyme der Stärke/Maltodextrin-Verwertung aus T. neapolitana, welches im pUC18-Vektor kloniert vorlag. " $A g I B$ ist in pJF118ut-agIA nur unvollständig kloniert. 


\section{Anionenaustauschchromatographie}

Für diesen Reinigungsschritt wurde der hitzegefällte Rohextrakt durch Sterilfiltration partikelfrei gemacht.

\section{Parameter}

$\begin{array}{ll}\text { Medium } & : \text { Source } 15 \mathrm{Q} \\ \text { Säule } & : \text { XK } 26 \\ \text { Säulenvolumen } & : 50 \mathrm{ml} \\ \text { Puffer A } & : 20 \mathrm{mM} \text { Tris-Cl pH 8 } \\ \text { Puffer B } & : 20 \mathrm{mM} \text { Tris-Cl pH } 8,1 \mathrm{M} \mathrm{NaCl} \\ \text { Flußrate } & : 10 \mathrm{ml} / \mathrm{min} \\ \text { Fraktion } & : 10 \mathrm{ml} \\ \text { Equilibrierung } & : 2 \text { SV Puffer B, 10 SV Puffer A } \\ \text { Gradient } & : \text { siehe Elutionsprofil }\end{array}$

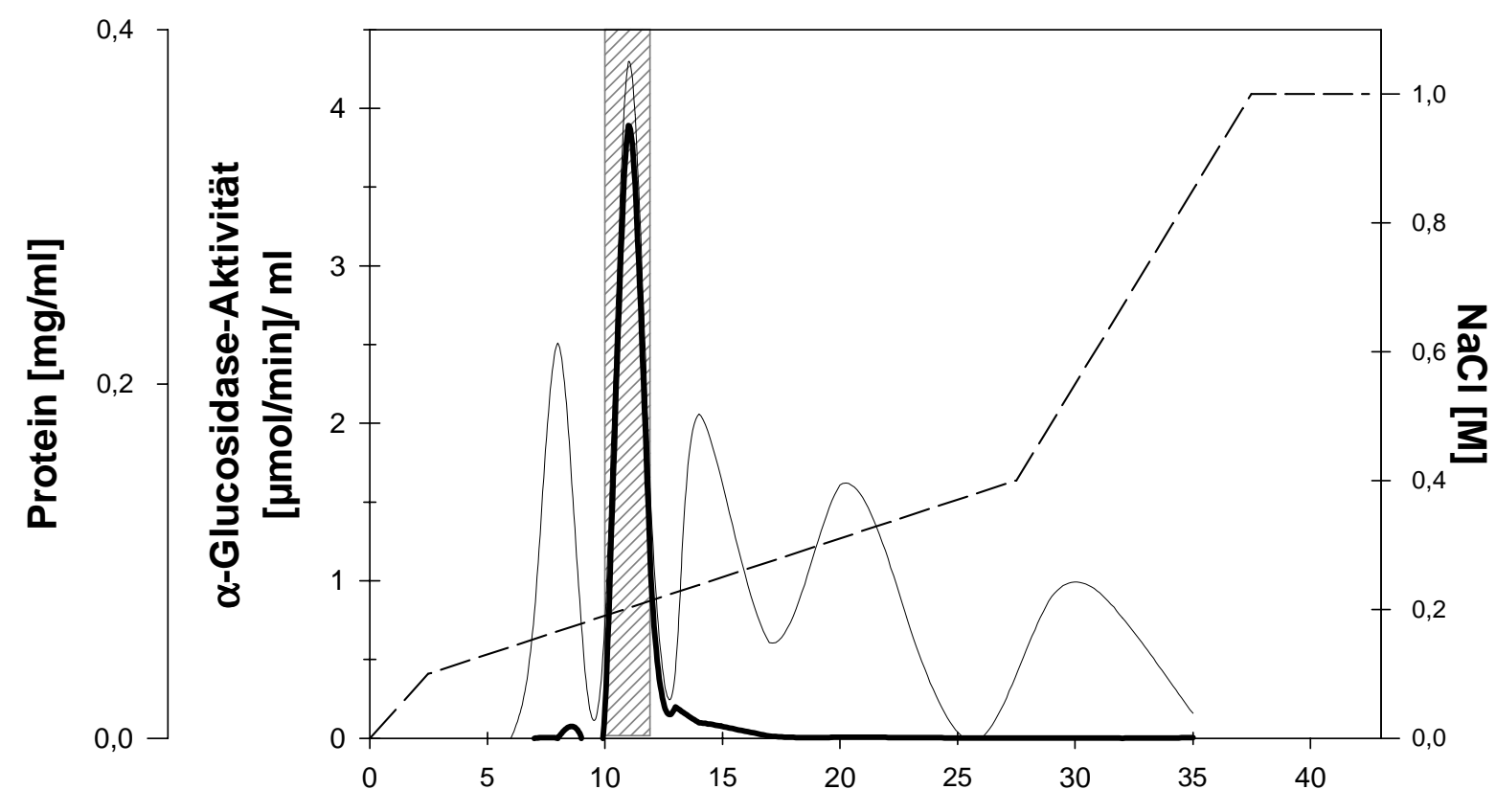

Fraktion

Abb. 10: Chromatogramm des SOURCE 15 Q-Säulenlaufes zur Reinigung der rekombinant exprimierten $\alpha$-Glucosidase. Die durchgezogene dünne Linie stellt den Verlauf der Proteinkonzentration, die durchgezogene dicke Linie den Verlauf der in den Fraktionen gemessenen Aktivität und die gestrichelte Linie den NaCl-Gradienten dar. Die gepoolten Fraktionen (10-12) sind grau hinterlegt.

Die Fraktionen wurden auf den Proteingehalt und auf $\alpha$-Glucosidase-Aktivität hin analysiert, Abb. 10 zeigt das Chromatogramm dieses Reinigungsschrittes. Die aktiven Fraktionen wurden nach Kontrolle im SDS-Polyacrylamidgel vereinigt und

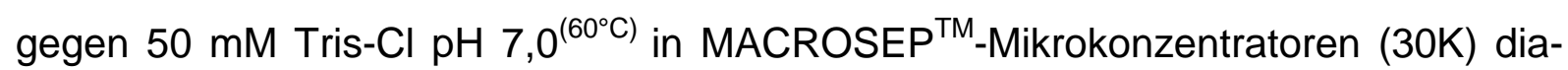


lysiert und eingeengt. Abb. 11 zeigt eine SDS-PAGE mit den Reinigungschritten der oben dargestellten zweistufigen Präparation.

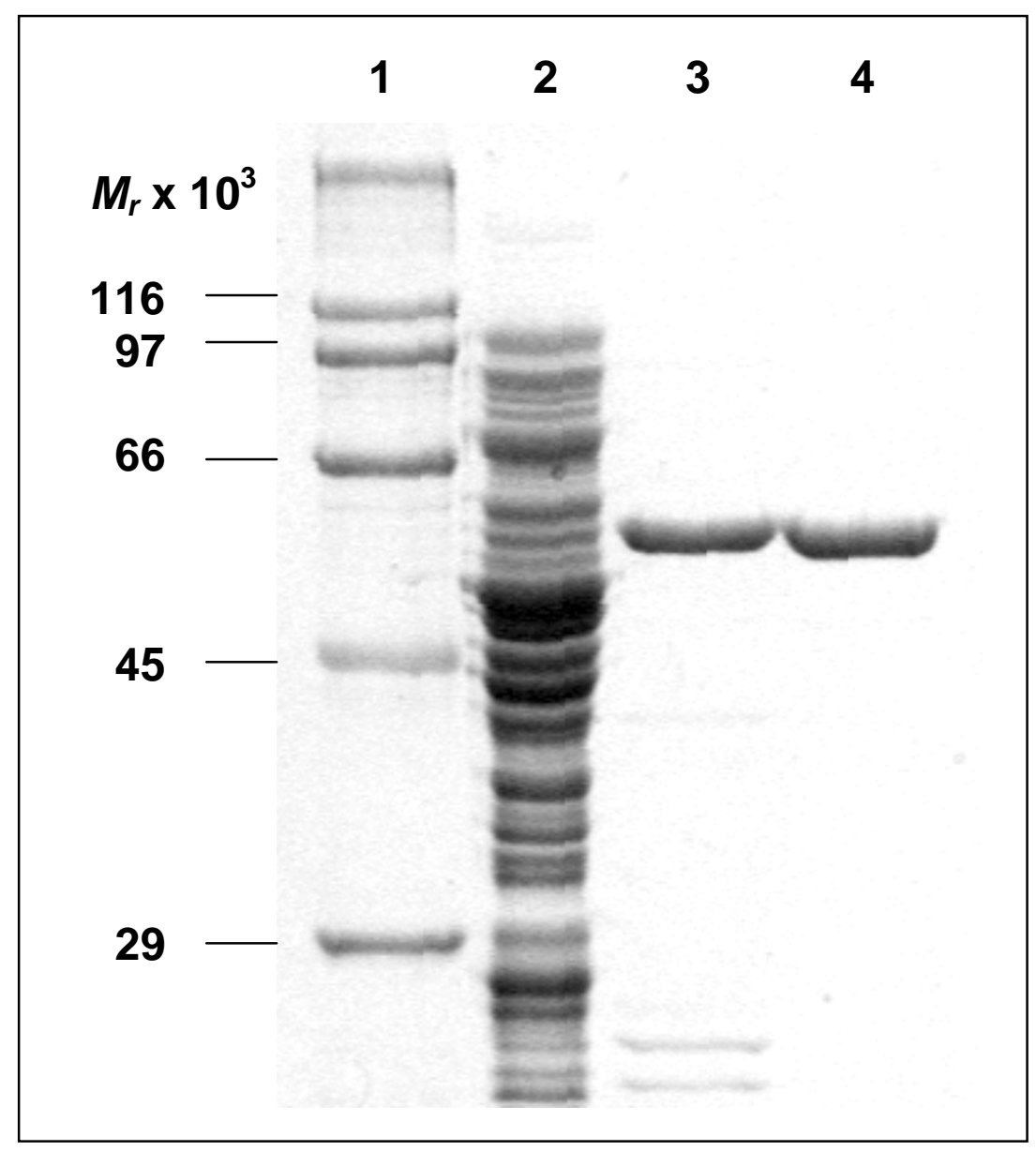

Abb. 11: SDS-PAGE der Reinigungsschritte der rekombinanten $\alpha$-Glucosidase ( $T$. neapolitana)

Spur 1: Molekularmassenstandard Spur 3: Rohextrakt hitzedenaturiert $15 \mathrm{~min} / 85^{\circ} \mathrm{C}$ Spur 2: E. coli JM83/pJF118ut-agIA RE Spur 4: SOURCE 15 Q-Pool

Da bei der Aufreinigung der $\alpha$-Glucosidase aus T. maritima eine Abhängigkeit der enzymatischen Aktivität von $\mathrm{NAD}^{+}, \mathrm{Mn}^{2+}$ und DTT gezeigt werden konnte (Raasch et al., 2000), wurde nun untersucht, ob diese Cofaktoren auch für das sehr ähnliche Enzym aus T. neapolitana entsprechende Funktionen übernehmen. In Abb. 12 ist gezeigt, bei welchen Konzentrationen jeweils eine maximale spezifische Aktivität der $\alpha$-Glucosidase gemessen werden konnte.

Die Messungen wurden mit dem p-Nitrophenyl- $\alpha$-D-glucosid Enzymtest mit jeweils $1 \mu \mathrm{g}$ gereinigtem Enzym durchgeführt. Um die höchste enzymatische Aktivität zu 
erhalten, waren Cofaktor-Konzentrationen von 0,9 mM NAD ${ }^{+}, 1 \mathrm{mM} \mathrm{MnCl}_{2}$ und 50-60 mM DTT erforderlich.
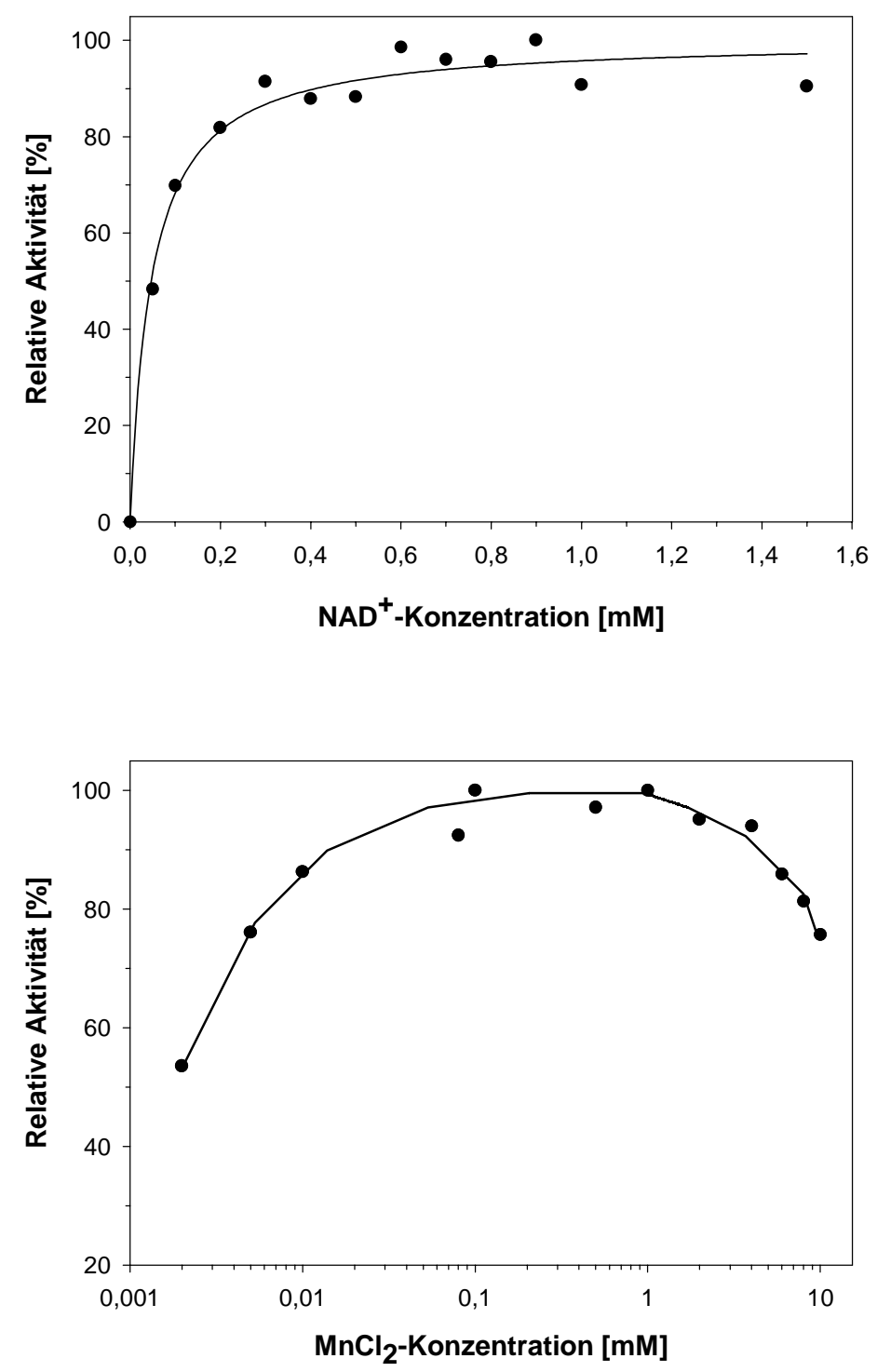

Abb. 12: Effekt der Konzentration von $\mathrm{NAD}^{+}$, $\mathrm{MnCl}_{2}$ und DTT auf die Aktivität von gereinigtem AgIA ( $T$. neapolitana). Zur Messung wurde die Konzentration des jeweiligen Parameters variiert, während die beiden anderen Cofaktoren in optimaler Konzentration zugesetzt wurden.

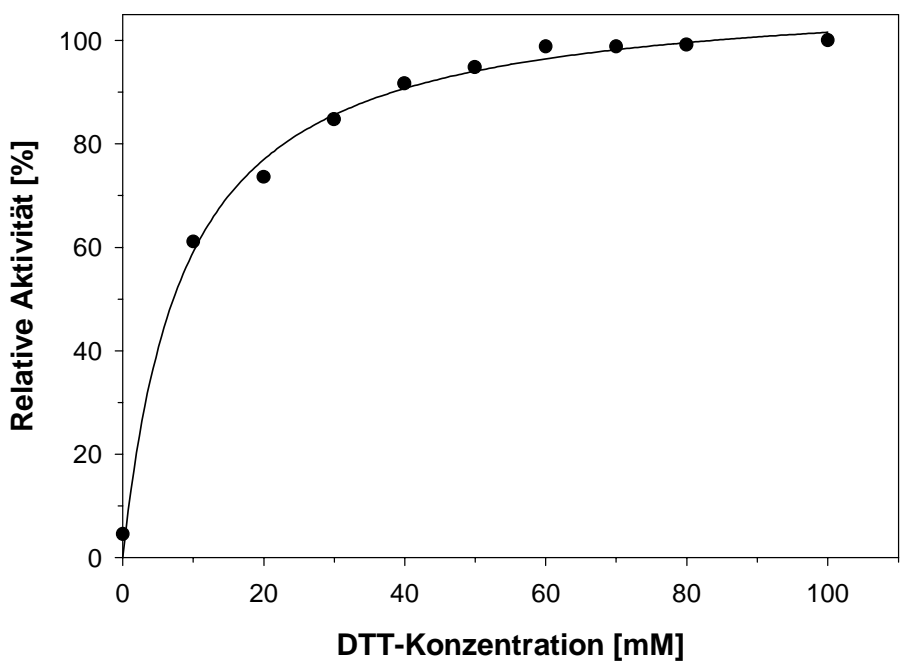


Zur Untersuchung der Bedeutung der einzelnen Cofaktoren für die Aktivität von AgIA ( $T$. neapolitana), wurde in einem weiteren Experiment die Zusammensetzung der aktivierenden Komponenten variiert (Abb. 13)

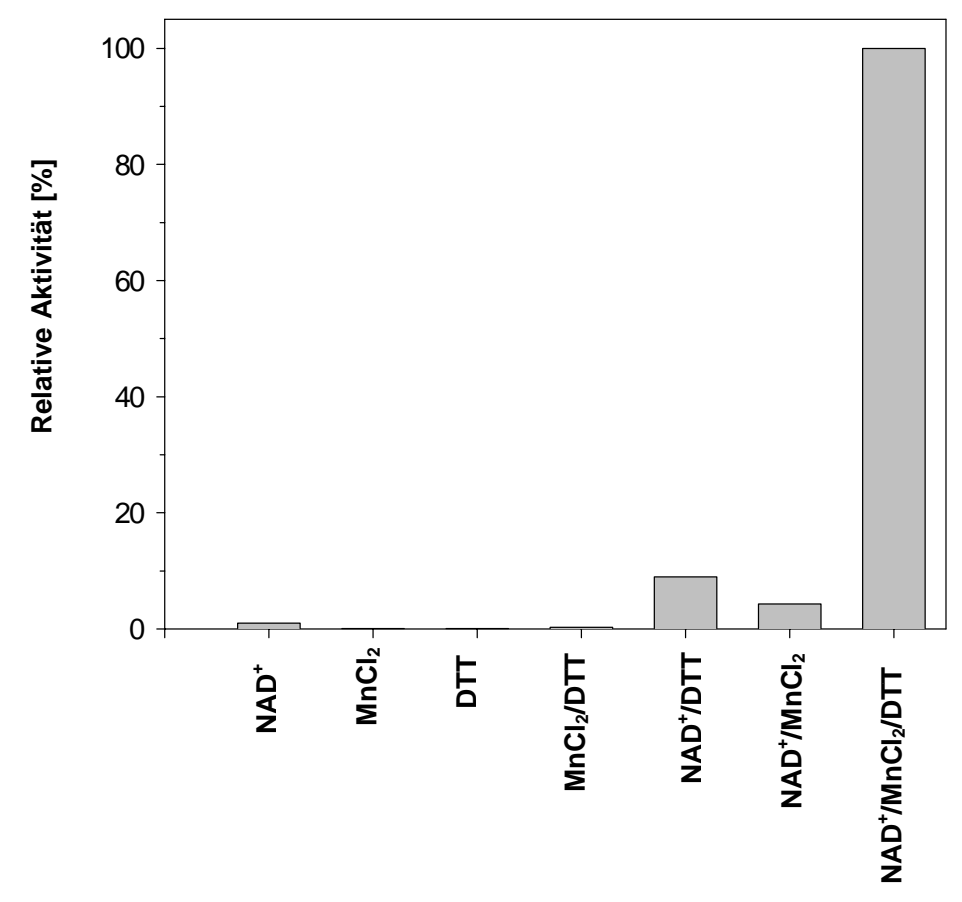

Abb. 13: Effekt der Anwesenheit von $\mathrm{NAD}^{+}$, $\mathrm{MnCl}_{2}$ und DTT auf die Aktivität von gereinigtem AgIA ( $T$. neapolitana). Die Konzentrationen der Cofaktoren betrugen für $\mathrm{NAD}^{+}$0,9 mM, für $\mathrm{MnCl}_{2}$ $1 \mathrm{mM}$ und für DTT 50 $\mathrm{mM}$.

Für die volle enzymatische Aktivität war die gemeinsame Anwesenheit aller drei Cofaktoren notwendig. Fehlte auch nur eine der drei Komponenten $\mathrm{MnCl}_{2}$, DTT oder $\mathrm{NAD}^{+}$, so wurden nur noch $9 \%, 4,3 \%$ bzw. 0,3\% der maximalen Aktivität erzielt. Bei Anwesenheit nur eines Aktivators sank die enzymatische Aktivität auf unter $1 \%$ ab. Beim Ansatz mit $\mathrm{NAD}^{+} / \mathrm{DTT}$ ist die relativ hohe Aktivität vermutlich auf Kontaminationen dieser Chemikalien mit $\mathrm{Mn}^{2+}$-Ionen zurückzuführen.

Da die Aufreinigung und die Analyse des Bedürfnisses des Enzyms für Cofaktoren weitgehend mit den Ergebnissen übereinstimmten, welche für die $\alpha$-Glucosidase aus T. maritima ermittelt worden waren, erfolgten die weiterführenden Experimente mit AgIA (T. maritima). 


\subsection{Thermotoga maritima AgIA, eine extrem thermostabile $\mathrm{NAD}^{+}-, \mathrm{Mn}^{2+}$ - und thiolabhängige $\alpha$-Glucosidase (Raasch et al., 2000)}

Die Isolierung und Reinigung von AglA aus T. maritima (im folgenden nur als AglA bezeichnet) und die Identifizierung der für die Aktivität notwendigen Faktoren, erforderte mehrere Jahre und stellte sich als schwieriger und zeitaufwendiger Prozeß heraus (Goßlar, 1992; Bibel, 1994; Schanzer, 1996). Trotzdem sollen in der Folge nur die Ergebnisse ausführlicher dargestellt werden, die im Rahmen dieser Dissertation neu hinzu gewonnen wurden. Ältere Daten werden nur dort in knapper Form wiedergegeben, wo sie zu einem besseren Gesamtverständnis beitragen.

\subsubsection{Sequenzanalyse von aglA}

Im Rahmen der Konstruktion von agIA-Mutanten, auf die später noch näher eingegangen wird, fiel auf, daß bei PCR-Klonierungen mit Primern, die aus der Orginalsequenz (Bibel et al., 1998) abgeleitet worden waren, keine Klone erhalten wurden, die thermostabile $\alpha$-Glucosidase-Aktivitäten aufwiesen. Der Vergleich der Orginalsequenz mit Sequenzdaten, die im Rahmen der Genomsequenzierung von T. maritima erhalten wurden (Datenbank TIGR, Nelson et al., 1999), ergab einen Sequenzierungsfehler in der Orginalsequenz. Dieser bewirkt, daß der ORF, welcher für AglA kodiert, 21 Aminosäuren länger ist, als von Bibel et al. (1998) ursprünglich veröffentlicht wurde und erklärt somit auch die Thermolabilität der zunächst erzeugten Klone ${ }^{1}$.

Weiterhin zeigte der Sequenzvergleich, daß agIA in einem Gen-Cluster lokalisiert ist, welches für Enzyme kodiert, die an der Umsetzung und am Abbau von Stärke/ Maltooligosacchariden beteiligt sind (Abb. 14). Das Cluster beinhaltet folgende Gene: $\operatorname{amy} A(\leftarrow)$-malE $(\rightarrow)$-malF $(\rightarrow)$-malG $(\rightarrow)$-aglB $(\rightarrow)$-aglA $(\rightarrow)$. Amy $A$ und malE wurden bereits früher beschrieben (Liebl et al., 1997) bzw. sind Gegenstand laufender Arbeiten (Fütterer, persönl. Mitteilung). Das Gen aglB wurde im Rahmen dieser Arbeit kloniert (3.1.1).

\footnotetext{
1) Postuliert man an der gleichen Stelle in der veröffentlichten agIA ( $T$. neapolitana)-Sequenz auch einen Sequenzierungsfehler, so vergrößert sich dessen kodierender Leserahmen ebenfalls um 21 Aminosäuren.
} 
Der AglA-kodierende Leserahmen translatiert in ein Polypeptid bestehend aus 480 Aminosäuren mit einer berechneten Molekularmasse von 55046 Da. Fünf Nukleotide stromaufwärts befindet sich eine mögliche Ribosomen-Bindestelle (5'...GGAGGTG...-3'), welche genau komplementär zum 3'-Ende der $16 \mathrm{~S}$ rRNAs von T. maritima (3'-UCUUUCCUCCACU...5') und E. coli (3'-AUUCCUCCACU...5') ist. Ein $\mathrm{G}+\mathrm{C}$-reiches „inverted repeat" (5'-...AAAGGGGCCTGAAAGGCCCCTTT...-3') 12 bp stromabwärts der kodierenden Sequenz könnte ein Signal für einen Transkriptionsstop darstellen.

Die auf Ähnlichkeiten der Aminosäuresequenz basierende Klassifizierung der Glycosylhydrolasen (Henrissat, 1991; Henrissat und Bairoch, 1993) führte zur Zuordnung von AglA zu der Familie 4. Weitere Vertreter dieser Familie sind $\alpha$-Galactosidasen, Phospho- $\beta$-Glucosidasen und Phospho- $\alpha$-Glucosidasen.

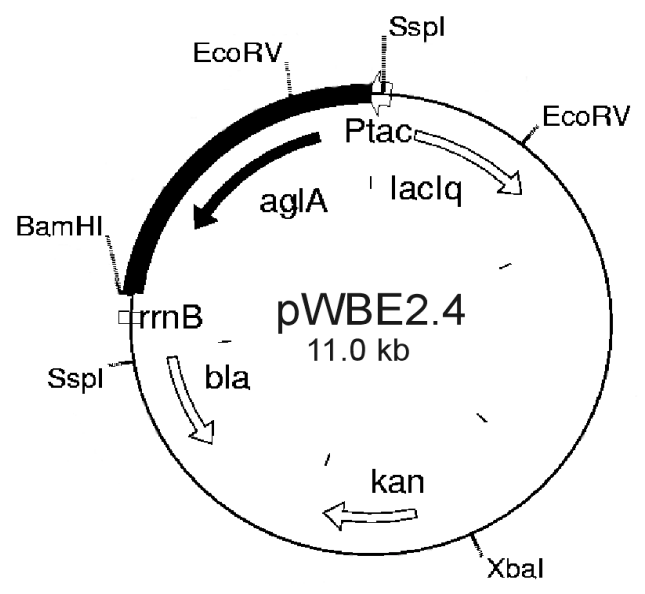

Abb. 14: Schematische Darstellung einer Region des T. maritima MSB8 Chromosoms mit einem Gen-Cluster, welches für Enzyme der Stärke/Maltodextrin-Umsetzung kodiert.

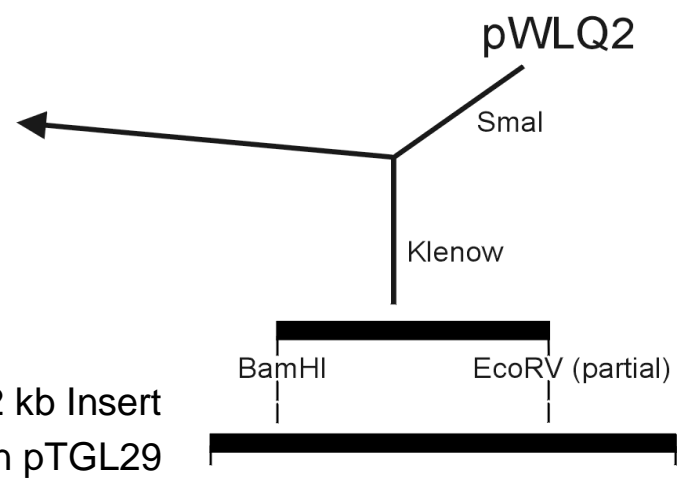

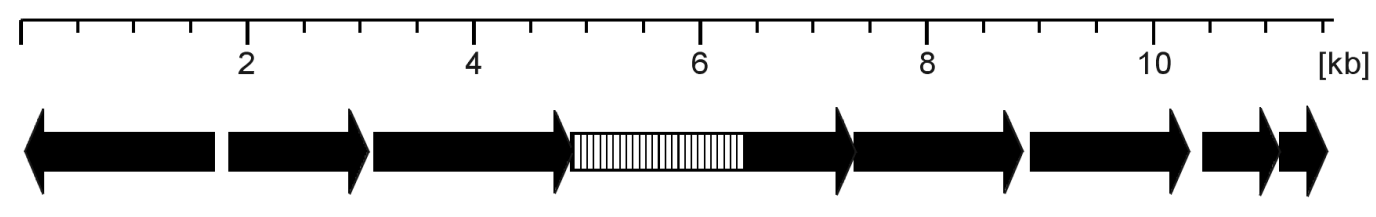

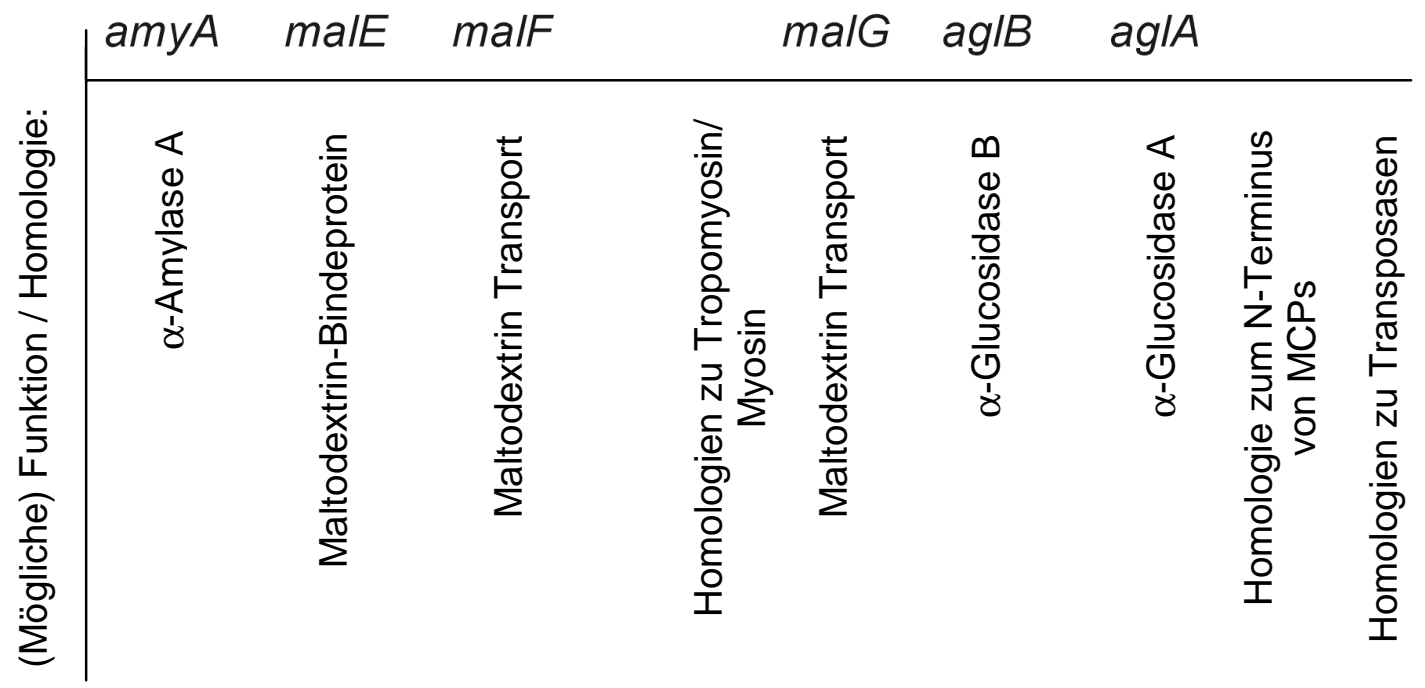




\subsubsection{Einfluß von Cofaktoren auf die Aktivität des rekombinanten Proteins}

Wie bereits erwähnt, traten bei der heterologen Expression mit anschließender chromatographischer Aufreinigung Probleme in der Gestalt auf, daß zunächst keine enzymatische Aktivität festzustellen war. Dies war ein Hinweis darauf, daß bei der Reinigung des Enzyms Aktivatoren verloren wurden. Analog wie oben für AglA ( T. neapolitana) beschrieben, benötigt auch die $\alpha$-Glucosidase aus $T$. maritima zur Entfaltung ihrer vollen Aktivität drei Cofaktoren: Maximale enzymatische Aktivität konnte mit 0,9 mM NAD, $1 \mathrm{mM} \mathrm{MnCl} 2$ und reduzierenden Bedingungen (wenn nicht anders erwähnt: $50 \mathrm{mM}$ DTT) erreicht werden. Mit diesen Konzentrationen wurde auch ein optimierter Standard-Test erstellt, mit dessen Hilfe die weitere Enzymcharakterisierung erfolgte. Fehlte auch nur einer dieser Komponenten im Test, so fiel die Aktivität auf weniger als 2,5\% der maximal möglichen ab.

\subsubsection{Reduzierende Agenzien}

Die stimulierende Wirkung von DTT war ein Hinweis darauf, daß ein reduzierendes Agens für die $\alpha$-Glucosidase-Aktivität benötigt wurde. Ein möglicher Substituent für DTT war 2-Mercaptoethanol. Bei Konzentrationen von $600 \mathrm{mM}$ oder mehr wurde maximale Aktivität gemessen (Abb. 15).

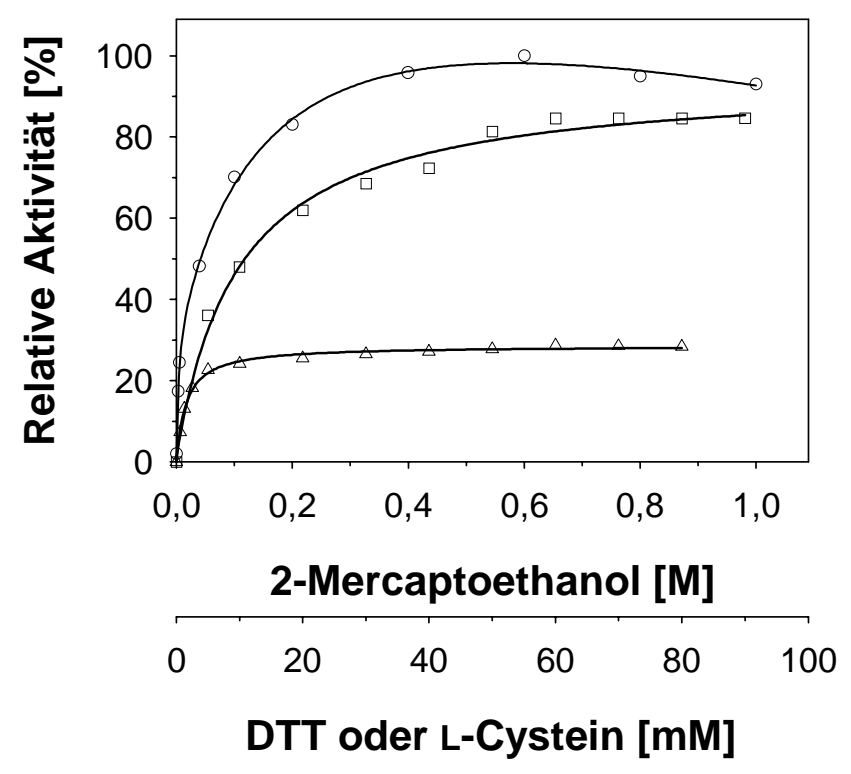

Abb. 15: Effekt von reduzierenden Agenzien auf die Aktivität von gereinigtem AglA. Zunehmende Konzentrationen von DTT ( ), 2-Mercaptoethanol $(\mathrm{O})$ oder L-Cystein $(\Delta)$ wurden zum Standard-Test mit den Cofaktoren $\mathrm{NAD}^{+}$und $\mathrm{MnCl}_{2}$ hinzugegeben.

Der Ersatz von DTT durch L-Cystein führte ebenso zu einer Aktivitätssteigerung. Ein maximaler Effekt wurde bei einer Konzentration von 60 mM L-Cystein gemessen. Die 
mit DTT gemessene maximale Aktivität war jedoch dreimal höher als mit L-Cystein. Die überraschend hohe Konzentration von DTT $(50 \mathrm{mM})$, 2-Mercaptoethanol (600 mM) oder L-Cystein $(60 \mathrm{mM})$ für die Aktivierung von AglA ließ die Frage aufkommen, ob neben der reduzierenden Wirkung dieser Komponenten andere Eigenschaften der Substanzen eine Rolle bei der Aktivierung des Enzyms spielen. Aus diesem Grund wurden strukturell ähnliche, aber nicht-thiolische Komponenten als Substituenten eingesetzt: DTT wurde teilweise durch Erythritol oder Glycerin ersetzt, und 1,2-Ethandiol und Ethanol wurden als Ersatz für 2-Mercaptoethanol getestet. Für dieses Experiment wurde folgender Testansatz verwendet:

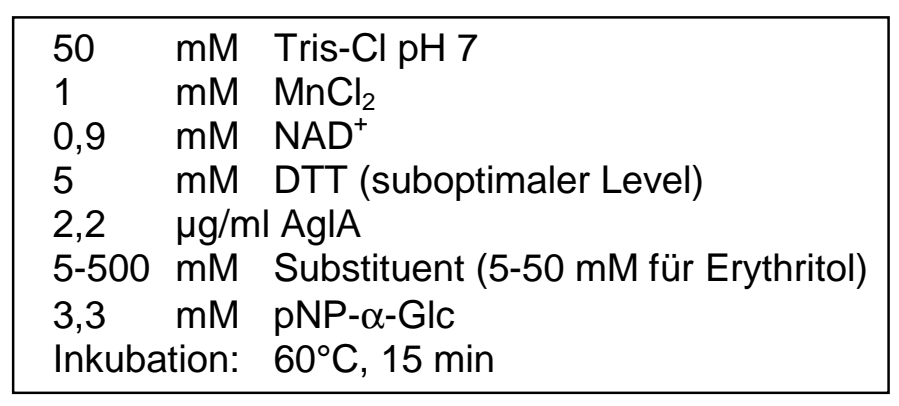

Es war nicht möglich, die DTT-Konzentration durch teilweisen Ersatz mit einer der oben aufgeführten Komponenten zu senken, ohne dabei gleichzeitig enzymatischen Aktivitätsverlust hinnehmen zu müssen. Es bleibt daher auch weiterhin unklar, warum derart hohe Konzentrationen an reduzierenden Agenzien für die maximale Aktivierung des Enzyms notwendig sind.

\subsubsection{Einfluß divalenter Metallionen}

Der Effekt verschiedener zweiwertiger Metallionen auf die Aktivität von AglA ist in Tab. 5 zusammengefasst. Bei der Anwesenheit von 0,9 mM NAD ${ }^{+}$und $50 \mathrm{mM}$ DTT konnte der stimulierende Effekt von $\mathrm{Mn}^{2+}$ auf gereinigtes, rekombinantes AglA bestätigt werden. Wegen einer Trübung des Testansatzes (verursacht in Verbindung mit selbst geringen Konzentrationen von 5 mM DTT) war es jedoch nicht möglich, Aussagen über Effekte durch $\mathrm{Fe}^{2+}, \mathrm{Co}^{2+}$ oder $\mathrm{Ni}^{2+}$ zu treffen. Um dieses Problem zu umgehen, wurde hitzedenaturierter $\left(85^{\circ} \mathrm{C}, 15 \mathrm{~min}\right)$ Rohextrakt (dieser enthält stimulierende Komponenten in suboptimalen Konzentrationen) als Enzymquelle eingesetzt. Dadurch konnte die Zugabe von DTT zum Testansatz vermieden und der aktivierende Effekt von $\mathrm{Co}^{2+}$ und $\mathrm{Ni}^{2+}$ gezeigt werden. 
Tab. 5: Effekt divalenter Metallionen auf die Aktivität von rekombinantem AglA

Additive (1 mM)

Relative Aktivität (\%):

\begin{tabular}{|c|c|c|}
\hline & Gereinigtes AglA & $\begin{array}{l}\text { JM83(pWBE2.4) Rohextrakt mit } \\
\text { AglA Aktivität a) }\end{array}$ \\
\hline & Testbedingungen: & Testbedingungen: \\
\hline & 50 mM Tris- $\mathrm{HCl} \mathrm{pH7}$ & $50 \mathrm{mM}$ Tris- $\mathrm{HCl} \mathrm{pH} 7$ \\
\hline & $0.9 \mathrm{mM} \mathrm{NAD}^{+}$ & $0.9 \mathrm{mM} \mathrm{NAD}^{+}$ \\
\hline & $50 \mathrm{mM}$ DTT & ohne DTT \\
\hline ohne & 0 & 13 \\
\hline $\mathrm{Mg}^{2+}$ & 1,1 & 13 \\
\hline $\mathrm{Ca}^{2+}$ & 3,1 & 15 \\
\hline $\mathrm{Sr}^{2+}$ & 0,2 & 13 \\
\hline $\mathrm{Ba}^{2+}$ & 0,2 & 13 \\
\hline $\mathrm{Mn}^{2+}$ & $100^{b)}$ & $100^{b)}$ \\
\hline $\mathrm{Fe}^{2+}$ & n. d. ${ }^{c)}$ & n. d. \\
\hline $\mathrm{Co}^{2+}$ & n. d. & 59 \\
\hline $\mathrm{Ni}^{2+}$ & n. d. & 25 \\
\hline $\mathrm{Cu}^{2+}$ & 0,1 & 5,4 \\
\hline $\mathrm{Zn}^{2+}$ & 3,1 & 14 \\
\hline
\end{tabular}

a) Das hohe Basisniveau der AglA-Aktivität in dieser Versuchsreihe wird durch die Anwesenheit suboptimaler Mengen aktivierender Komponenten ( $\mathrm{NAD}^{+}$, Metallionen, reduzierende Substanzen) im Rohextrakt verursacht.

b) Die spezifischen Aktivitäten für gereinigtes AglA und Rohextrakt mit AglA-Aktivität betrugen $8,5 \mathrm{U} / \mathrm{mg}$ bzw. $2,8 \mathrm{U} / \mathrm{mg}$.

c) n.d., durch Unverträglichkeiten der Metallionen mit den Testbedingungen konnten keine Daten erhoben werden.

\subsubsection{Nukleotide}

$\mathrm{Da}$ auf die ortsspezifische Mutagenese der potentiellen NAD+-Bindestelle später noch im Detail eingegangen wird, sei an dieser Stelle nur erwähnt, daß bei allen Experimenten mit niedermolekularen Substanzen sich lediglich $\mathrm{NAD}^{+}$(s.0., 100\%) und in weitaus geringerem Maße NADP $(11,7 \%)$ stimulierend auf die Aktivität von AgIA auswirkten. NADH, NADPH, ATP, ADP, dATP, cAMP, FAD und FMN bewirkten keine Aktivierung von AglA. 
Es wurde desweiteren versucht, mittels eines Wellenlängenscans, der einen Wellenlängenbereich von 200 bis 400 nm umfasste, die typischen Maxima bei 260 bzw. $340 \mathrm{~nm}$ und damit eine mögliche AglA-katalysierte Bildung von NADH aus NAD ${ }^{+}$ (260 nm: Absorptionsmaximums des Adeninringes) nachzuweisen. Ein wie für die Positivkontrolle NADH ermitteltes Auftreten eines Maximums bei $340 \mathrm{~nm}$ war nicht festzustellen. Dies schließt allerdings nicht aus, daß NADH in sehr geringem Maße (z.B. als katalytisches Intermediat während des Reaktionszyklus) gebildet werden könnte und diese Bildung sich lediglich einer nicht ausreichend sensitiven Meßmethode entzog.

\subsubsection{Gelfiltrationsstudien und kinetische Parameter der Substrathydrolyse}

Die relative Größe des gereinigten AgIA wurde durch SDS-PAGE mit 58 kDa bestimmt (nicht gezeigt) und liegt damit etwas höher, als aus der Primärstruktur rechnerisch abgeleitet worden war (55 kDa). Um Aufschluß über die Molekularmasse des nativen Enzyms und damit Hinweise auf eine mögliche Oligomerisierung des Proteins zu erhalten, wurde eine analytische Gelfiltration durchgeführt. Die Kalibrierung der Säule mit 6 Eichproteinen fand unter identischen Bedingungen statt.

$\begin{array}{ll}\text { Parameter } & \\ \text { Medium } & : \text { Superdex } 200 \text { prep grade } \\ \text { Säule } & : \text { HiLoad 16/60 } \\ \text { Säulenvolumen }: & 121 \mathrm{ml} \\ \text { Laufmittel } & : 50 \mathrm{mM} \text { Tris-Cl pH7, } 150 \mathrm{mM} \mathrm{NaCl} \\ \text { Flußrate } & : 1 \mathrm{ml} / \mathrm{min} \\ \text { Fraktion } & : 1 \mathrm{ml} \\ \text { AglA } & : 0,2 \mathrm{mg}\end{array}$

In Abb. 16 ist die mit den Kalibrierungsdaten erstellte Regressionsgerade, die für die Analyse der $\alpha$-Glucosidase verwendet wurde, wiedergegeben. 


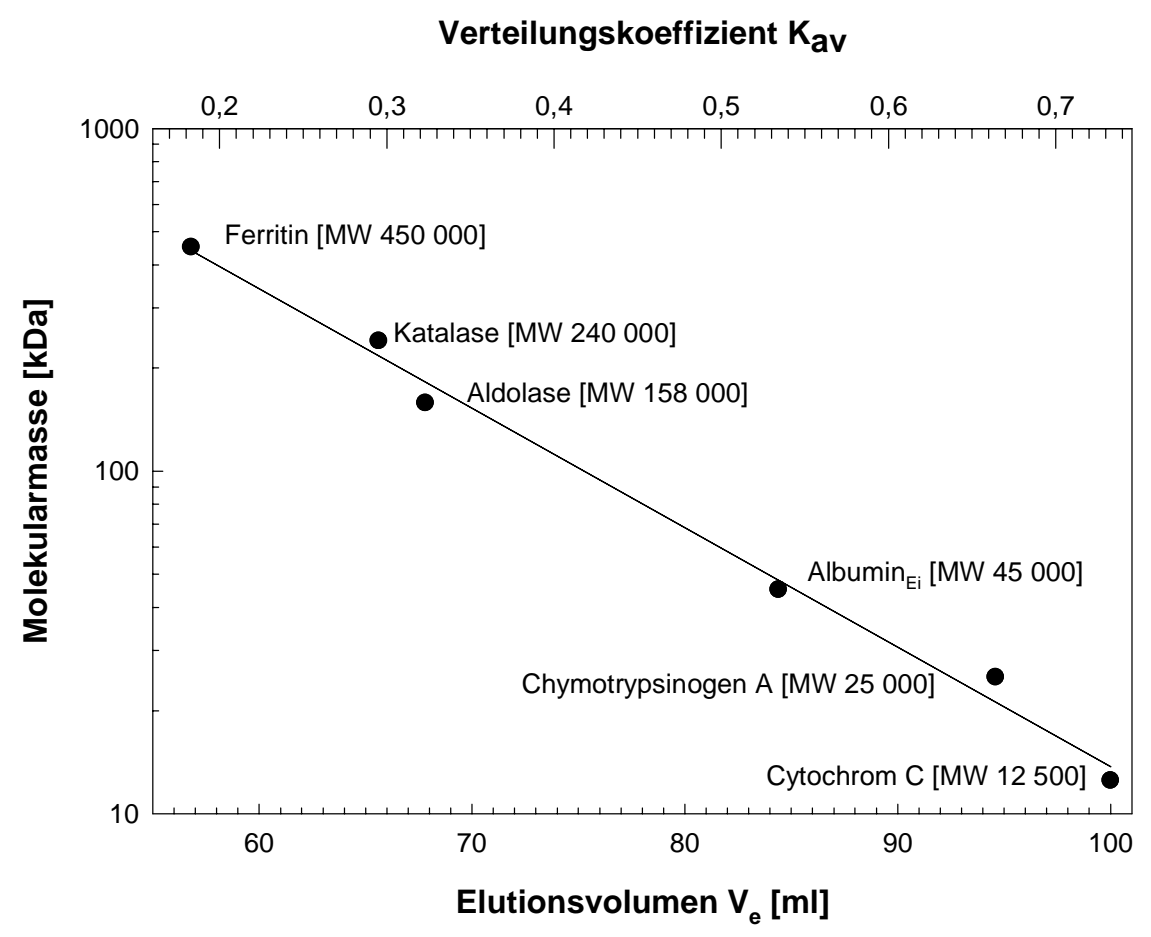

Abb. 16: Eichgerade für die analytische Gelfiltration mit einer Superdex 200 pg HiLoad 16/60-Säule

Es gilt: $\mathrm{K}_{\mathrm{av}}=\left(\mathrm{V}_{\mathrm{e}}-\mathrm{V}_{\mathrm{o}}\right) /\left(\mathrm{V}_{\mathrm{t}}-\mathrm{V}_{\mathrm{o}}\right)$ mit $\mathrm{V}_{\mathrm{o}}: 42,4 \mathrm{ml}$ und $\mathrm{V}_{\mathrm{t}}: 121 \mathrm{ml}$

Für die $\alpha$-Glucosidase wurde ein Elutionsvolumen $V_{\mathrm{e}}$ von $74 \mathrm{ml}$ ermittelt; mit der aus der Regressionsgeraden abgeleiteten Formel

$$
\log \mathrm{MW}[\mathrm{kDa}]=3,145-2,74 \times \mathrm{K}_{\mathrm{av}}
$$

errechnete sich daher für das native Enzym eine Molekularmasse von $110 \mathrm{kDa}$. Ähnliche Resultate (102 - $120 \mathrm{kDa}$ ) ergaben sich, wenn Gelfiltrationsexperimente in Gegenwart von $1 \mathrm{mM} \mathrm{MnCl}_{2}, 4 \mathrm{mM} \mathrm{MnCl}$, 0,9 mM NAD', $50 \mathrm{mM}$ DTT oder $1 \mathrm{mM}$ EDTA unter ansonsten identischen Bedingungen durchgeführt wurden. Diese Ergebnisse legen nahe, daß es sich bei AglA in seiner aktiven Form um ein Homodimer, bestehend aus 2 identischen 55-kDa Untereinheiten, handelt.

Die Tatsache, daß AglA p-Nitrophenol sowohl aus pNP- $\alpha$-D-Glucosid als auch aus pNP- $\alpha$-D-Galactosid freisetzen kann, zeigt, daß AglA im Hinblick auf die Konfiguration an der C-4 Position des Glyconrestes des Substrates nicht spezifisch 
ist (Tab. 6). Die relativen Aktivitäten, die mit diesen Substraten bestimmt wurden (bei einer Substratkonzentration von $10 \mathrm{mM}$ und $60^{\circ} \mathrm{C}$ ) waren $100 \mathrm{bzw}$. $114 \%$. Die $\mathrm{K}_{\mathrm{m}}{ }^{-}$ Werte, welche aus Eadie-Hofstee Auftragungen (mit Substratkonzentrationen zwischen 0,01 und $50 \mathrm{mM}$ ) bestimmt worden waren, zeigten eine leicht höhere Affinität für das Glucosid-Substrat.

Tab. 6: Kinetische Parameter der Substrathydrolyse durch rekombinantes AgIA.

\begin{tabular}{lcccc}
\hline Substrat & $\begin{array}{c}v_{\max } \\
{\left[\mu \mathrm{mol} \times \mathrm{min}^{-1} \times \mathrm{mg}^{-1}\right]}\end{array}$ & $\begin{array}{c}K_{\mathrm{m}} \\
{[\mathrm{mM}]}\end{array}$ & \multicolumn{1}{c}{$\begin{array}{c}\left.k_{\mathrm{cat}}{ }^{\mathrm{a}}{ }^{-1}\right] \\
{\left[\mathrm{s}^{-1}\right]}\end{array}$} & $\begin{array}{c}v_{\text {max }} / K_{\mathrm{m}}{ }^{\mathrm{b}} \\
{\left[\mathrm{ml} \times \mathrm{min}^{-1} \times \mathrm{mg}^{-1}\right]}\end{array}$ \\
\hline pNP- $\alpha$-D-Glucosid & 9,94 & 0,23 & 9,12 & 43,22 \\
pNP- $\alpha$-D-Galactosid & 11,42 & 0,53 & 10,48 & 21,55 \\
\hline Maltose & 5,48 & 2,90 & 5,03 & 1,89 \\
Maltotriose & 0,38 & 2,28 & 0,35 & 0,17 \\
Maltotetraose & 0,16 & 2,96 & 0,15 & 0,05 \\
\hline
\end{tabular}

Die Ermittlung der kinetischen Parameter erfolgte aus Regressionsgeraden, die durch die Meßpunkte einer Eadie-Hofstee-Auftragung gelegt wurden.

a) Die molekulare Aktivität $k_{\text {cat }}$ gibt die Anzahl der hydrolytischen Reaktionen wieder, die ein Enzym-Molekül pro Sekunde durchführt.

${ }^{b)}$ Katalytische Effizienz, mit $v_{\max }=\mathrm{E}_{0} \times k_{\text {cat }}$

Die Bestimmung der kinetischen Daten für die Umsetzung der Maltooligosaccharide (Tab. 6) erfolgte nach folgendem Schema, mit Substratkonzentrationen von 0,2-50 mM für Maltose und 1-50 mM für Maltotriose bzw. -tetraose:

\begin{tabular}{|c|c|c|}
\hline Reaktion & Enzyme & Ansatz \\
\hline $\begin{array}{l}\text { Maltooligosaccharid } \rightarrow \text { Glucose } \\
\text { Glucose }+ \text { ATP } \rightarrow \text { Glu-6-P + ADP }\end{array}$ & $\alpha$-Glucosidase & $\mathbf{I}$ \\
\hline Glu-6-P + NAD $\rightarrow$ 6-P-Gluconat + NADH & Hexokinase / Glu-6-P-DH & II \\
\hline
\end{tabular}

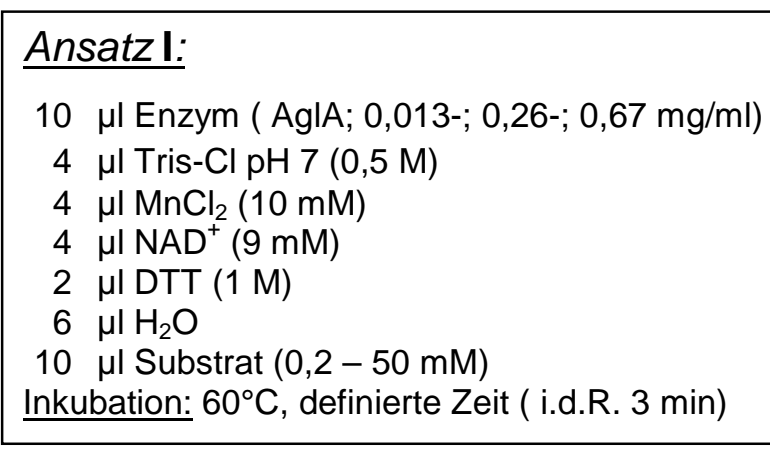

Ansatz II: (Ansatz I + folgende Additive) $5 \mu \mathrm{l}$ ATP $(50 \mathrm{mM})$

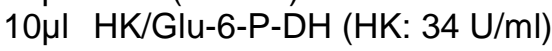

$15 \mu \mathrm{l} \quad \mathrm{H}_{2} \mathrm{O}$ (Glu-6-P-DH: $\left.17 \mathrm{U} / \mathrm{ml}\right)$ Inkubation: RT, definierte Zeit (20 min) 
Gemessen wurde in einer $70 \mu \mathrm{l}$ fassenden Quarzküvette die Absorptionszunahme bei $340 \mathrm{~nm}$ (NADH-Bildung). Die molekulare Aktivität von AglA nimmt mit zunehmenden Polymerisationsgrad des Substrates ab. Dieses Ergebnis stimmt mit einer früheren dünnschichtchromatographischen Analyse überein (Schanzer, 1996).

\subsubsection{Ortsspezifische Mutagenese der potentiellen $\mathrm{NAD}^{+}$-Bindungsstelle und eines konservierten Cysteinrestes}

Eine Computer-gestützte Analyse der Aminosäuresequenz im N-terminalen Bereich bei Vertreten der Familie 4 der Glycosylhydrolasen lieferte ein potentielles NAD+Bindemotiv bei allen untersuchten Enzymen (Abb. 17). Diese Domäne zeigt eine $\beta \alpha \beta$-Struktur mit einem Glycin-reichen Loop zwischen dem ersten $\beta$-Faltblatt und der Dinukleotid-Binde-Helix. Unabhängig von unseren Arbeiten postulierten auch Thompson et al. (1998) diesen Bereich als NAD(H)-Bindestelle. Die AglA-Aminosäuresequenz ...-GAGSAV-.. zeigt Ähnlichkeiten zum sog. „Rossmann-fold“ (GXGXXG) und deutet auf das Vorhandensein einer hier unvollständigen bzw. variierten Fingerprint-Region hin (Rossmann et al., 1975; Bellamacina, 1996). Interessanterweise ist das in dieser Struktur dem zweiten Glycin folgende Serin bei allen Vertreten der Familie 4 vorhanden. Weitere Übereinstimmungen, die auf die NAD+Bindestelle in der oben beschriebenen Region hindeuten, sind:

- hydrophober Kern, bestehend aus kleinen hydrophoben Aminosäuren (z.B. Valin)

- konservierte, negativ geladene Aminosäure am C-Terminus des $\beta B$-Faltblattes (Aspartat)

- konservierte, positiv geladene Aminosäure am N-Terminus des $\beta A$-Faltblattes (Lysin)

Die oben angeführten Hinweise auf die $\mathrm{NAD}^{+}$-Bindestelle sollten nun experimentell bestätigt werden, indem die hochkonservierten Aminosäuren ...-G(X)GS-... durch eine ortsspezifischen Mutagenese jeweils gegen Alanin mittels PCR ausgetauscht wurden. Erwartet wurde, daß die entsprechenden Mutanten in ihrer $\mathrm{NAD}^{+}$-Bindung beeinträchtigt und deshalb die Aktivität der $\alpha$-Glucosidase abnehmen würde.

Auch das in der Familie 4 hochkonservierte Cystein 174 wurde im Rahmen dieser Mutagenesestudien durch ein Serin ausgetauscht, um zu zeigen, daß es für die Aktivität von AglA von entscheidender Bedeutung ist. 


\section{potentielles NAD+-Bindemotiv}

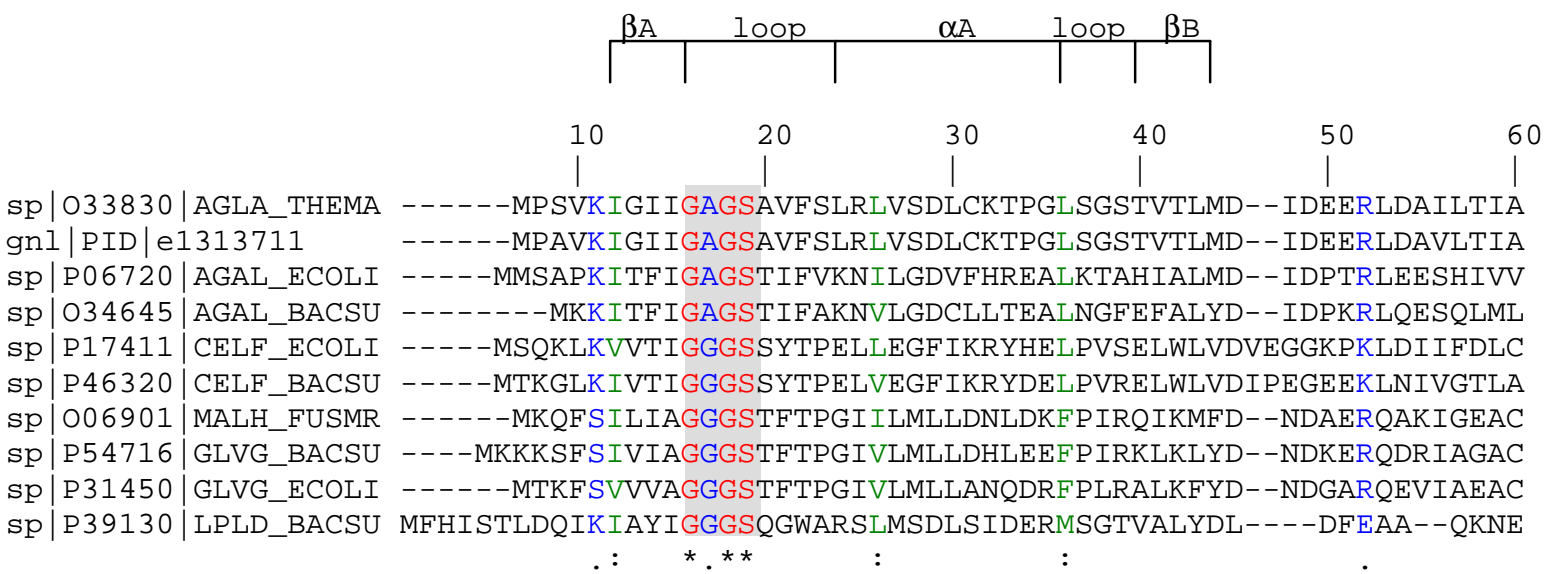

Abb. 17: Alignment der Aminosäuresequenzen des N-terminalen Bereiches von Proteinen der Familie 4 der Glycosylhydrolasen

* hochkonservierte Aminosäuren; Die Sequenzen wurden mit CLUSTALW (1.74) verglichen. AGLA_THEMA (Bibel et al., 1998): $\alpha$-Glucosidase (T. maritima); gnl: $\alpha$-Glucosidase (T. neapolitana); AGAL_ECOLI (Liljeström und Liljeström, 1987): $\alpha$-Galactosidase (E. coll); AGLA_BACSU (Lapidus et al., 1997): $\alpha$-Galactosidase (Bacillus subtilis); CELF_ECOLI (Parker und Hall, 1990): 6-Phospho- $\beta$ Glucosidase (E. coll); CELF_BACSU (Tobisch et al., 1997): putative 6-Phospho- $\beta$-Glucosidase (Bacillus subtilis); MALH-FUSMR (Bouma et al., 1997): 6-Phospho- $\alpha$-D-Glucosidase ( $F$. mortiferum); GLVG_BACSU (Yamamoto et al., 1996): 6-Phospho- $\alpha$-Glucosidase (Bacillus subtilis); GLVG_ECOLI (Reizer et al., 1994): 6-Phospho- $\alpha$-Glucosidase (E. coll); LPLD_BACSU: nichtcharakterisierte Glycosylhydrolase (Bacillus subtilis)

In Tab. 7 sind die verwendeten Primer mit den entsprechenden Basenaustauschen zusammengestellt.

Tab. 7: Verwendete Primer für die PCR

\begin{tabular}{clc}
\hline Bezeichnung & \multicolumn{1}{c}{ Primer-Sequenz $^{\text {a) }}\left(5{ }^{`} \rightarrow 3{ }^{`}\right)$} & $\begin{array}{c}\text { Schnittstelle / } \\
\text { Austausch }\end{array}$ \\
\hline Glu1 & GGAGGAATTCATGCCATCTGTGAAGATCGG & EcoRI \\
& TA & \\
G10A & GGAGGAATTCATGCCATCTGTGAAGATCGG & EcoRI \\
& TATCATCGCTGCGGGGAGC & GGT $\rightarrow$ GCT \\
G12A & GGAGGAATTCATGCCATCTGTGAAGATCGG & EcoRI \\
& TATCATCGGTGCGGCGAGCGCGGTG & GGG $\rightarrow$ GCG \\
& GGAGGAATTCATGCCATCTGTGAAGATCGG & EcoRI \\
& TATCATCGGTGCGGGGGCCGCGGTGTTTTC & AGC $\rightarrow$ GCC
\end{tabular}


C174S GTAGTGTCCATGGCTGAATCCCACTGC

$\mathrm{NcOl}$

$\mathrm{GCA} \rightarrow \mathrm{GCT}$

TM1834b

CAGAAGCTTTCATCTCTTCAGATAATGTTTC

HindIII CG

a): Die eingefügte Schnittstelle ist jeweils unterstrichen; Basenaustausche sind fett hervorgehoben.

\section{PCR-Ansatz:}

\begin{tabular}{|lll|}
\hline Primer 1 $(100 \mathrm{pmol} / \mu \mathrm{l})$ & 1,25 & $\mu \mathrm{l}$ \\
Primer 2 $(100 \mathrm{pmol} / \mu \mathrm{l})$ & 1,25 & $\mu \mathrm{l}$ \\
pWBE2.4 & 0,25 & $\mu \mathrm{l}$ \\
dNTP-Lösung (je 10 mM) & 4 & $\mu \mathrm{l}$ \\
Pfu-Puffer (10x) & 5 & $\mu \mathrm{l}$ \\
DMSO & 5 & $\mu \mathrm{l}$ \\
$\mathrm{H}_{2} \mathrm{O}$ & 33 & $\mu \mathrm{l}$ \\
Pfu-Polymerase $(9 \mathrm{U} / \mu \mathrm{l})$ & 0,5 & $\mu \mathrm{l}$ \\
\hline
\end{tabular}

PCR-Bedingungen:

\begin{tabular}{|lllc|}
\hline $\begin{array}{l}\text { Erste Denaturierung: } \\
\text { 32 Zyklen: }\end{array}$ & $94^{\circ} \mathrm{C}$, & 5 & $\mathrm{~min}$ \\
\hline 1.) Denaturierung: & $94^{\circ} \mathrm{C}$, & 45 & $\mathrm{~s}$ \\
2.) Primer-Anlagerung: & $38^{\circ} \mathrm{C}$, & 45 & $\mathrm{~s}$ \\
3.) Synthese: & $72^{\circ} \mathrm{C}$, & 2 & $\mathrm{~min}$ \\
Letzter Syntheseschritt: & $72^{\circ} \mathrm{C}$, & 10 & $\mathrm{~min}$ \\
\hline
\end{tabular}

Es wurden fünf PCR-Ansätze mit folgenden Primerkombinationen verwendet:
1) Glu 1+ TM1834b
2) $\mathrm{G} 10 \mathrm{~A}+\mathrm{TM} 1834 \mathrm{~b}$
3) $G 12 A+T M 1834 b$
4) $S 13 A+T M 1834 b$
5) Glu1 + C174S

Die PCR-Ansätze wurden bei den angegebenen Bedingungen inkubiert, die PCRProdukte aus dem Agarose-Gel extrahiert, mit EcoRV geschnittenem pBSK ${ }^{+}$-Vektor ligiert und in E. coli XL1-Blue transformiert. Nach Blau-Weiß-Screening wurde je ein Klon der Ansätze 1-4 mit korrekt inseriertem PCR-Fragment ausgewählt und unter Verwendung der neu eingebauten Schnittstellen EcoRI/Hindlll in den Vektor pET21a kloniert (Abb. 18). Die neuen Konstrukte pET21a-agIA, pET21a-G10A, pET21a-G12A und pET21a-S13A wurden zur heterologen Expression in den Stamm E. coli BL21 (DE3) elektroporiert.

Zur Konstruktion von pET21a-C174S wurden die Plasmide pET21a-(Glu1+ TM1834b) und pBSK ${ }^{+}$-(Glu1 + C174S) jeweils mit EcoRI/Ncol verdaut, die benötigten DNA-Fragmente aus dem Agarose-Gel extrahiert, religiert und zur heterologen Expression in E. coli BL21(DE3) elektroporiert. 
Amplifizierung des Gens aglA aus dem Plasmid pWBE2.4 (siehe 3.2.1) mit mutagenen Oligonukleotid-Primern durch PCR

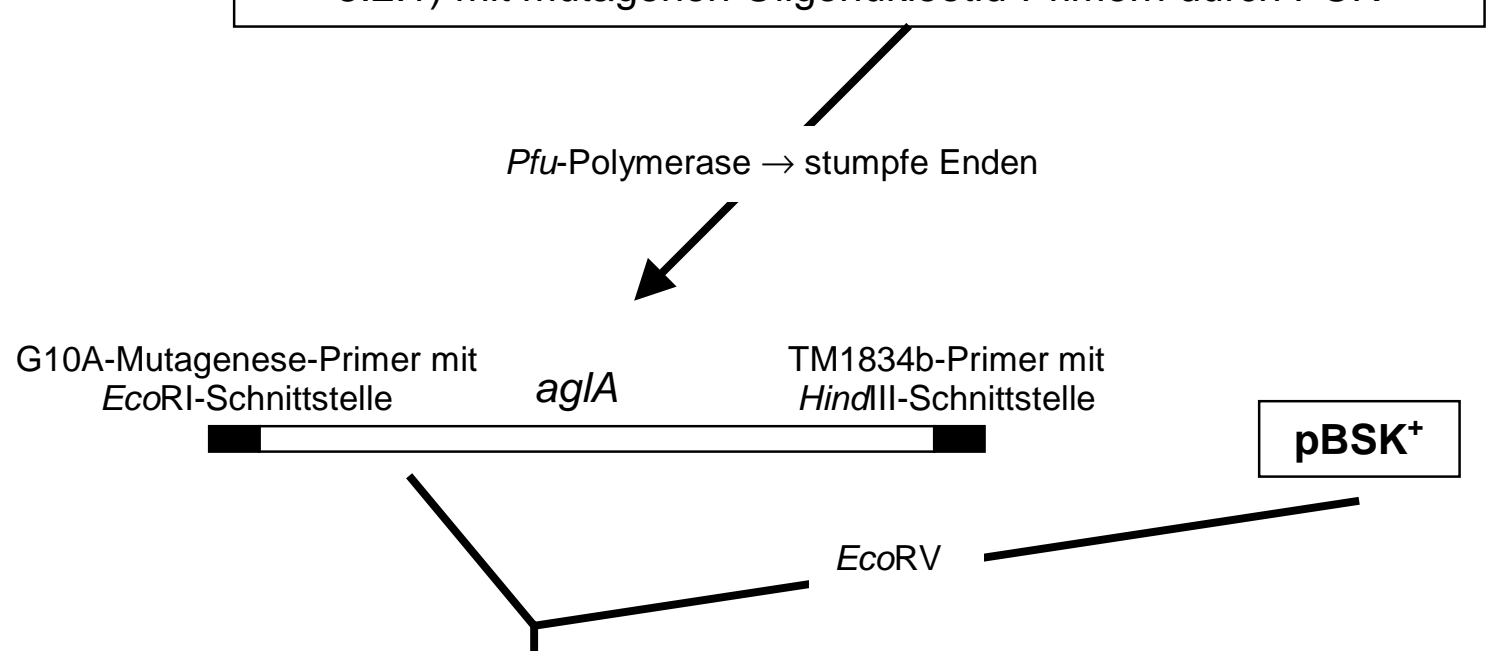

Ligation stumpfer Enden

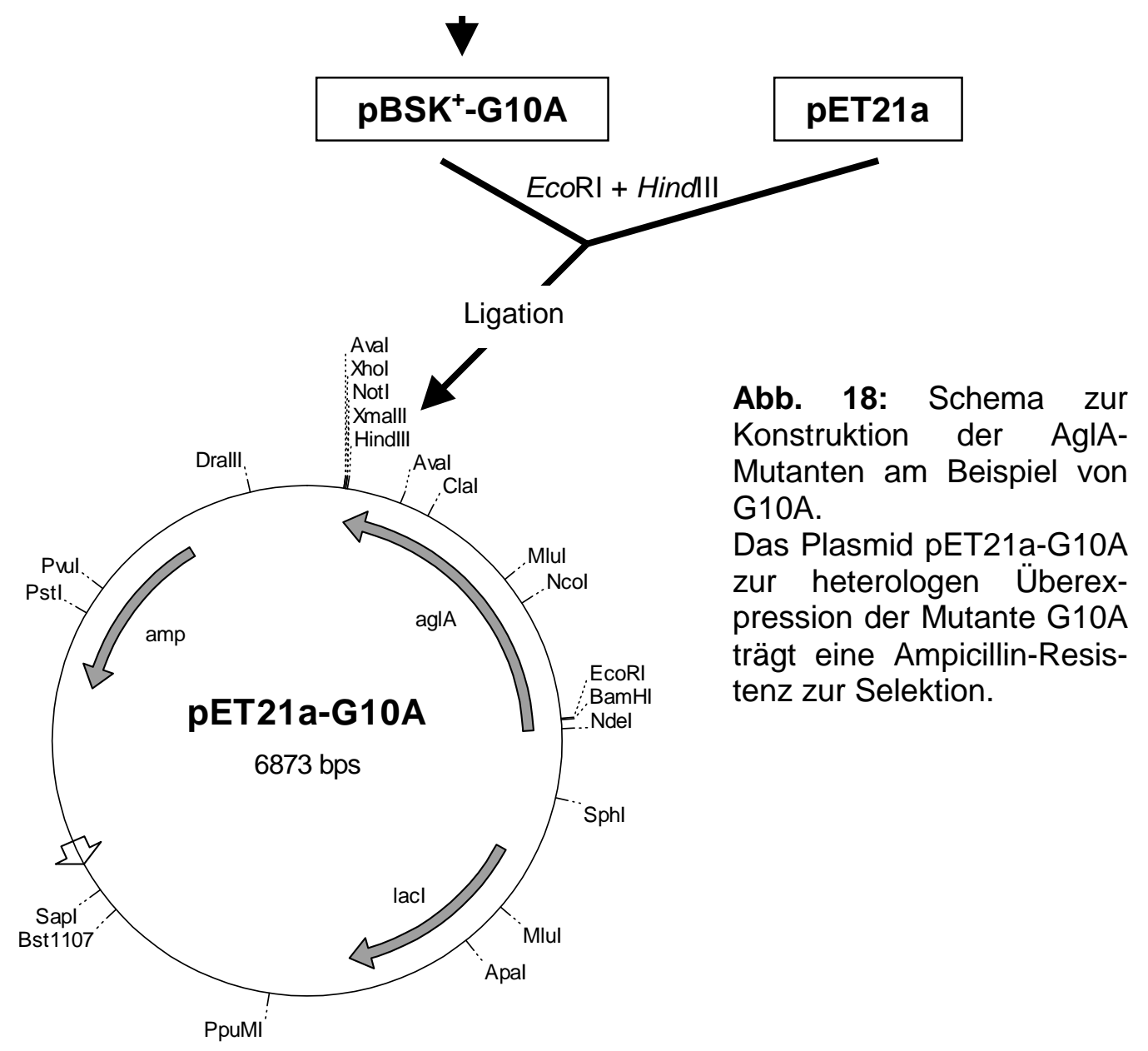

Zur Kontrolle der korrekten Mutagenese wurden alle neu erzeugten Mutanten von der Firma SEQLAB (Göttingen) sequenziert und die gewünschten Basenaustausche und die damit verbundenen Aminosäureänderungen bestätigt. 


\subsubsection{Expression und Reinigung der AgIA-Mutanten sowie Kinetik der NAD ${ }^{+}-$ Bindung}

Für die Reinigung der $\alpha$-Glucosidase bzw. der neuen Mutanten wurden Kulturvolumina von je 2 I (LB-Amp) 3\%-ig angeimpft, bei einer $\mathrm{OD}_{600}$ von 0,5 - 0,6 mit 0,3 mM IPTG induziert und für $5 \mathrm{~h}$ bei $37^{\circ} \mathrm{C}$ und unter kräftiger Belüftung inkubiert. Die Zellen wurden anschließend geerntet, mit 20 mM Tris- $\mathrm{Cl}$ pH 8 gewaschen und in etwa $1 \mathrm{ml}$ Puffer pro Gramm Zell-Naßgewicht gründlich resuspendiert. Der Zellaufschluß wurde mittels einer French Pressure Cell (6,9 $\mathrm{MPa}$ ) durchgeführt. Der Hitzefällungsschritt erfolgte in SS34-Röhrchen für $15 \mathrm{~min}$ bei $75^{\circ} \mathrm{C}$ und einer raschen Abkühlung auf Eis. Durch hochtourige Zentrifugation (16000 Upm, 30 min) wurde das präzipitierte Material abgetrennt und der Überstand einem weiteren Reinigungsschritt durch Anionenaustauschchromatographie unterworfen.

\section{Parameter}

$\begin{array}{ll}\text { Medium } & : \text { Source } 15 \mathrm{Q} \\ \text { Säule } & : \text { XK } 26 \\ \text { Säulenvolumen } & : 50 \mathrm{ml} \\ \text { Puffer A } & : 20 \mathrm{mM} \text { Tris-Cl pH } 8 \\ \text { Puffer B } & : 20 \mathrm{mM} \text { Tris-Cl pH } 8,1 \mathrm{M} \mathrm{NaCl} \\ \text { Flußrate } & : 10 \mathrm{ml} / \mathrm{min} \\ \text { Fraktion } & : 10 \mathrm{ml} \\ \text { Equilibrierung } & : 2 \text { SV Puffer B, 10 SV Puffer A } \\ \text { Gradient } & : \text { siehe nebenstehendes Schema }\end{array}$

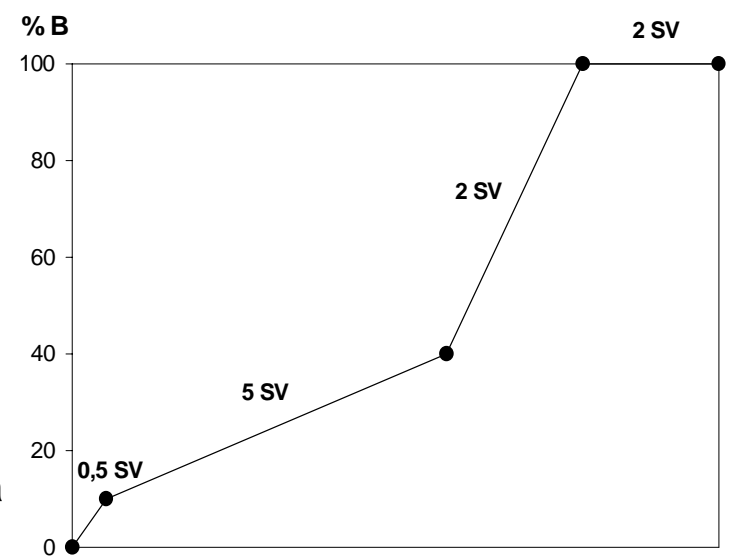

Die Fraktionen wurden auf den Proteingehalt hin analysiert. Nach zusätzlicher Kontrolle im SDS-Polyacrylamidgel wurden die Fraktionen mit den geringsten Kontaminationen vereinigt und gegen $20 \mathrm{mM}$ Tris- $\mathrm{Cl} \mathrm{pH} 7,5^{\left(60^{\circ} \mathrm{C}\right)}$ in MACROSEPMikrokonzentratoren (30K) dialysiert und eingeengt. Abb. 19 zeigt ein SDS-PAGETrenngel (10\%) mit aufgereinigten AgIA bzw. AglA-Mutanten. Interessanterweise ist die in allen anderen Spuren auftretende Kontaminationsbande (bei etwa $40 \mathrm{kDa}$ ) bei der Mutante pET21a-C174S nicht mehr sichtbar. 


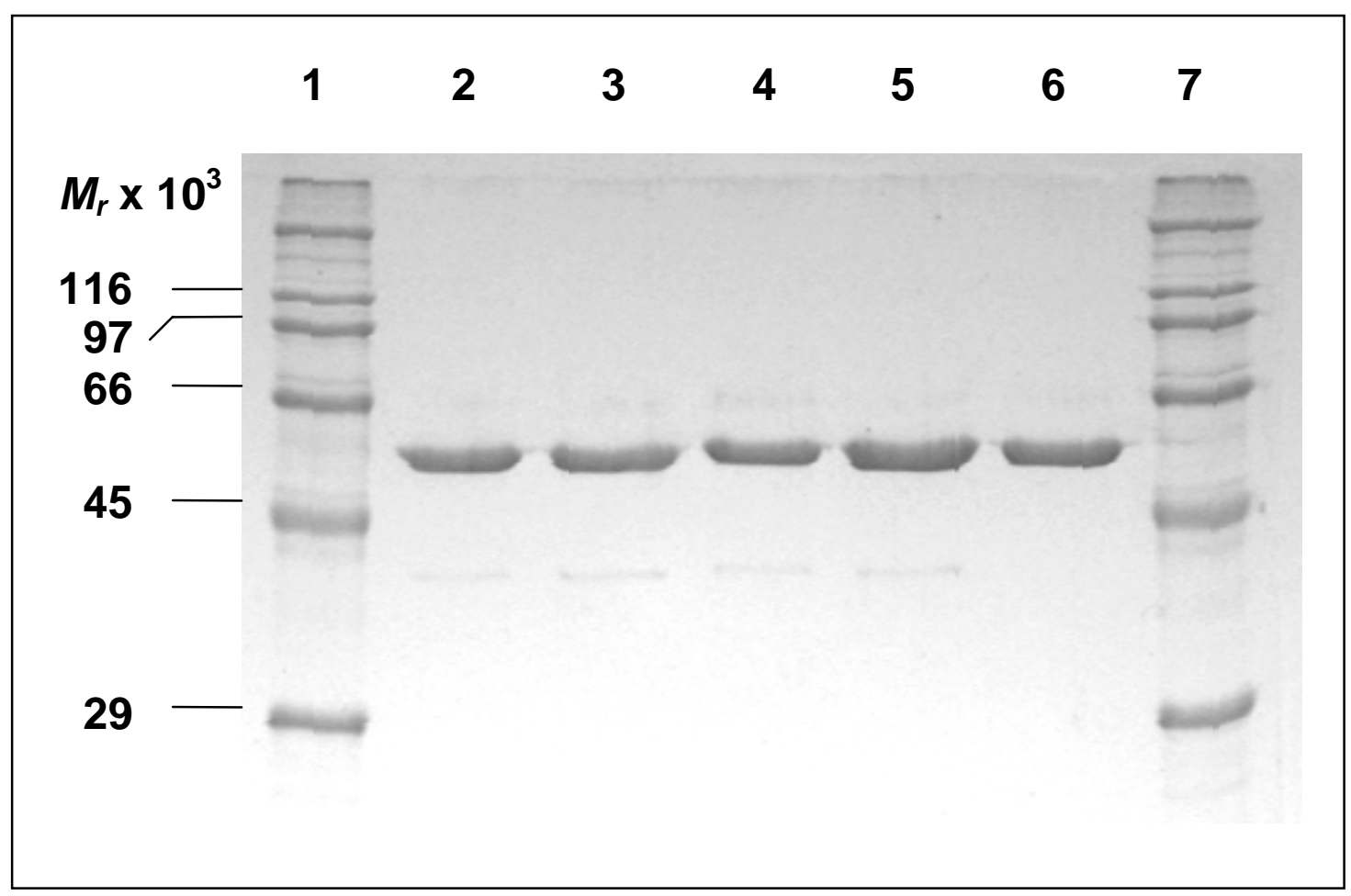

Abb. 19: SDS-PAGE der aufgereinigten rekombinanten $\alpha$-Glucosidase und der anderen AglA-Mutanten

Spur 1 und 7: Molekularmassenstandard

Spur 2: pET21a-AgIA

Spur 3: pET21a-G10A
Spur 4: pET21a-G12A

Spur 5: pET21a-S13A

Spur 6: pET21a-C174S

Mit der so aufgereinigten Wildtyp- $\alpha$-Glucosidase AgIA und den AgIA-Mutationsderivaten wurde der Effekt der Aminosäureaustausche auf die enzymatische $\alpha$-Glucosidase-Aktivität zunächst im Standard-Test überprüft (Abb. 20).

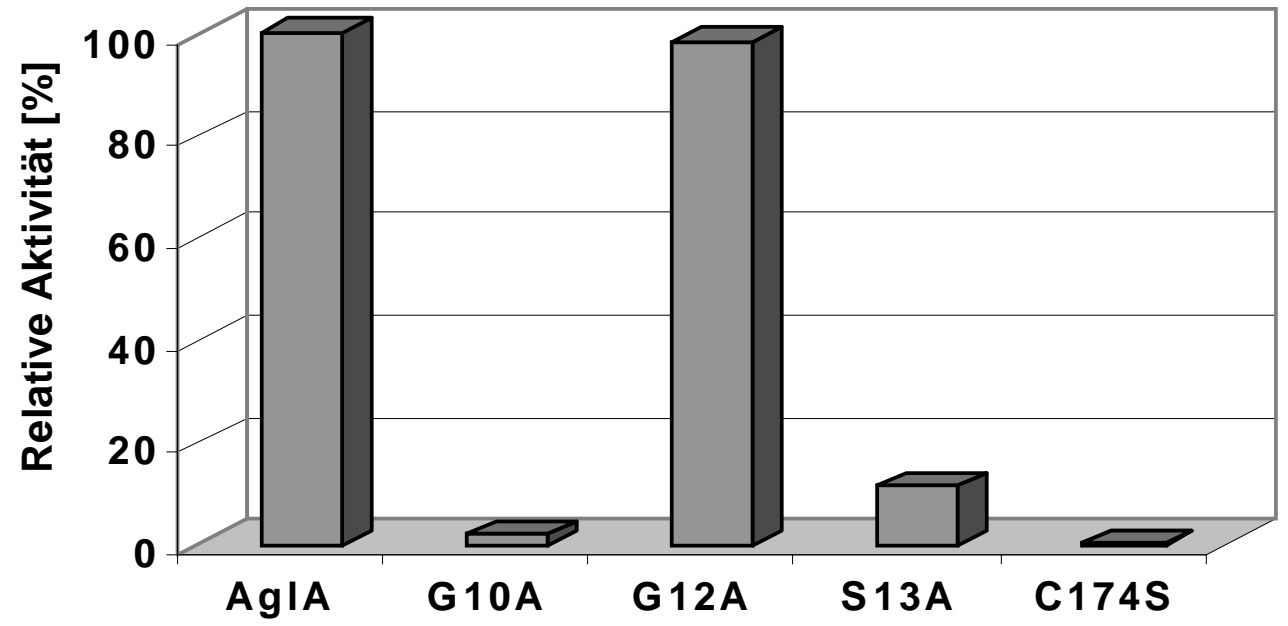

Abb. 20: Effekt der Einführung von Punktmutationen auf die Glucosidase-Aktivität gemessen im Standard-Test 
Während sich bei der Mutante G12A keine signifikante Veränderung in der Aktivität zeigte, führte der Aminosäureaustausch zu Alanin bei G10A und S13A zur deutlichen Aktivitätsabnahme auf 2 bzw. 11\% gegenüber AglA.

Mit C174S war keine enzymatische Aktivität mehr meßbar, was als eindeutiges Zeichen für die Wichtigkeit diese Aminosäure gewertet werden kann.

Zur Bestimmung der Affinität der Mutanten zu NAD ${ }^{+}$wurde nun die Bindungskonstante $K_{d}$ bestimmt.

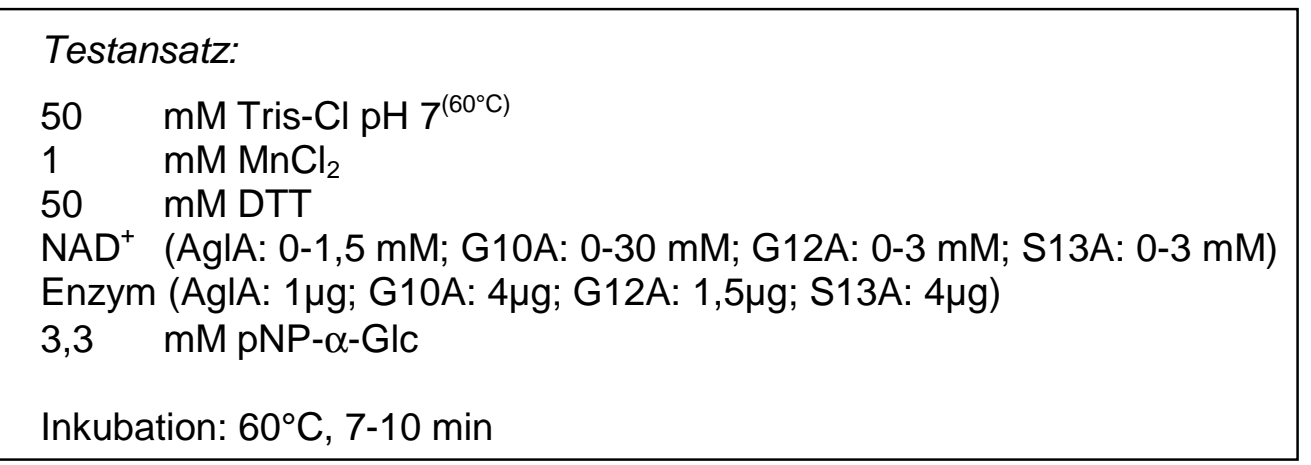

Die Auswertung erfolgte durch graphische Auftragung der Meßwerte nach den Methoden von Michaelis-Menten, Lineweaver-Burk und Eadie-Hofstee. Abb. 21 zeigt exemplarisch die Ergebnisse, die für die Mutante G12A ermittelt wurden.

Michaelis-Menten
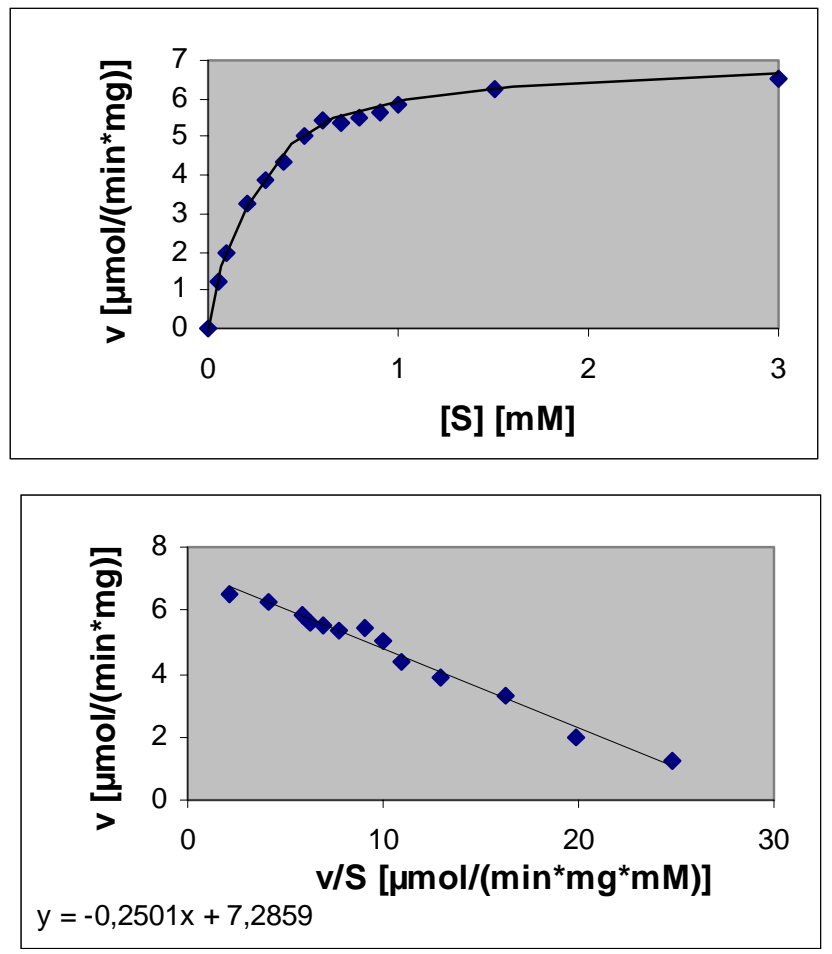

\section{Lineweaver-Burk}

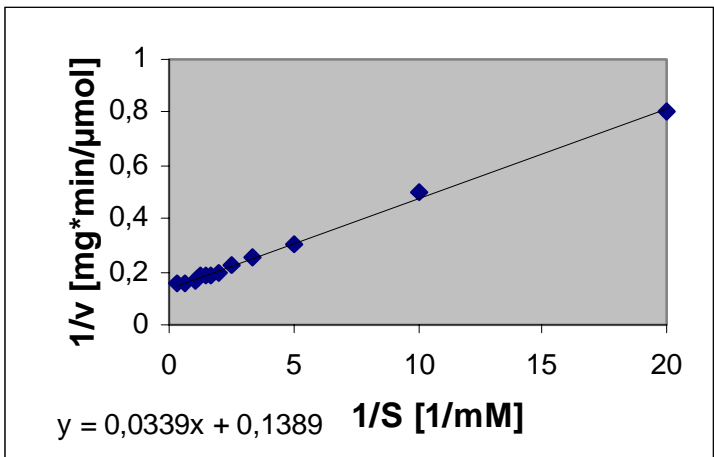

\section{Eadie-Hofstee}

Abb. 21: Graphische Auftragung der Meßwerte nach den Methoden von Michaelis-Menten, Lineweaver-Burk und Eadie-Hofstee am Beispiel von G12A $[S]=\left[N^{+} D^{+}\right]$ 
Die Ergebnisse sind tabellarisch in Tab. 8 angegeben. Gemäß den Ergebnissen, die in Abb. 20 dargestellt sind, nimmt der $K_{\mathrm{d}}$-Wert in folgender Reihenfolge zu (d. h. die Affinität zu NAD nimmt ab): AgIA $<$ G12A $<$ S13A $<$ G10A. Die damit nachgewiesene Beeinträchtigung der $\mathrm{NAD}^{+}$-Bindung durch Mutagenese im $\mathrm{N}$-Terminus von $\mathrm{AgIA}$ untermauert die These, daß es sich hierbei wirklich um die $N A D^{+}$-Binderegion handelt.

Tab. 8: Kinetik der $N A D^{+}$-Bindung durch AglA und dessen Mutanten

\begin{tabular}{ccccc}
\hline & \multicolumn{2}{c}{ Lineweaver-Burk } & \multicolumn{2}{c}{ Eadie-Hofstee } \\
& $K_{\mathrm{d}}[\mathrm{mM}]$ & $\begin{array}{c}v_{\max } \\
{\left[\mu \mathrm{mol} /\left(\mathrm{min}^{*} \mathrm{mg}\right)\right]}\end{array}$ & $K_{\mathrm{d}}[\mathrm{mM}]$ & $\begin{array}{c}v_{\max } \\
{\left[\mu \mathrm{mol} /\left(\mathrm{min}^{*} \mathrm{mg}\right]\right.}\end{array}$ \\
\hline AglA & 0,04 & 5,36 & 0,03 & 5,28 \\
G10A & 18,12 & 3,86 & 12,18 & 2,94 \\
S13A & 0,63 & 1,76 & 0,45 & 1,46 \\
G12A & 0,24 & 7,20 & 0,25 & 7,29
\end{tabular}

\subsubsection{Kinetik der Inhibition durch Fructose-1,6-Diphosphat}

Im Rahmen einer ersten Untersuchung zur Regulation der $\alpha$-Glucosidase konnte nur Fructose-1,6-Diphosphat als mäßiger Inhibitor identifiziert werden. Mit Glucose, Glucose-6-Phosphat, Fructose-6-Phosphat oder Pyruvat (Endkonzentration: jeweils $10 \mathrm{mM}$ ) wurde keine signifikante Beeinträchtigung der Enzymaktivität festgestellt. Je nach Angriff der Hemmsubstanz am Enzym unterscheidet man zwischen kompetitiver, unkompetitiver und nicht kompetitiver Hemmung. Der Inhibitionstyp kann dadurch ermittelt werden, daß das Enzym in Anwesenheit verschiedener Hemmstoffkonzentrationen inkubiert wird. Bei doppelt reziproker Auftragung der ermittelten Reaktionsgeschwindigkeiten [v] gegen die Substratkonzentration [S] im LineweaverBurk-Diagramm trafen sich die Regressionsgeraden nahezu in einem Schnittpunkt auf der Abzisse. Dieses deutet auf eine nicht-kompetitive Hemmung hin, bei welcher der $K_{\mathrm{m}}$-Wert konstant bleibt, während $v_{\max }$ sich verringert (Tab. 9). Es ist aber nicht ganz auszuschließen, daß es sich um eine gemischte (nicht-kompetitive) Hemmung handeln könnte. 


\begin{tabular}{|c|c|}
\hline \multicolumn{2}{|c|}{ Testansatz: } \\
\hline $50 \mathrm{mM}$ & Tris-Cl $\mathrm{pH} 7^{\left(60^{\circ} \mathrm{C}\right)}$ \\
\hline $\mathrm{mM}$ & $\mathrm{MnCl}_{2}$ \\
\hline $0,9 \mathrm{mM}$ & $\mathrm{NAD}^{+}$ \\
\hline $50 \mathrm{mM}$ & DTT \\
\hline $\begin{array}{l}\text { pNP- } \alpha-G l c \\
\text { Fru-1,6-PP }\end{array}$ & $\begin{array}{l}0,05-10 \mathrm{mM} \\
0-50 \mathrm{mM}\end{array}$ \\
\hline $\begin{array}{l}\text { Enzym } \\
\text { Inkubation: }\end{array}$ & $1,89 \mu \mathrm{g}$ \\
\hline
\end{tabular}

Tab. 9: Kinetik der Inhibition durch Fructose-1,6-Diphosphat

\begin{tabular}{ccccc}
\hline & \multicolumn{2}{c}{ Lineweaver-Burk } & \multicolumn{2}{c}{ Eadie-Hofstee } \\
& $K_{\mathrm{m}}[\mathrm{mM}]$ & $v_{\max }$ & $K_{\mathrm{m}}[\mathrm{mM}]$ & $v_{\max }$ \\
& & {$\left[\mu \mathrm{mol} /\left(\mathrm{min}^{*} \mathrm{mg}\right)\right]$} & & {$\left[\mu \mathrm{mol} /\left(\mathrm{min}^{*} \mathrm{mg}\right]\right.$} \\
\hline Ohne F-1,6-DP & 0,29 & 10,21 & 0,24 & 9,43 \\
6,25 mM F-1,6-DP & 0,22 & 8,57 & 0,20 & 8,16 \\
12,5 mM F-1,6-DP & 0,22 & 7,91 & 0,21 & 7,72 \\
25 mM F-1,6-DP & 0,22 & 6,52 & 0,22 & 6,52 \\
50 mM F-1,6-DP & 0,30 & 4,82 & 0,34 & 5,10 \\
Mittelwert & 0,25 & & 0,24 & \\
\hline
\end{tabular}

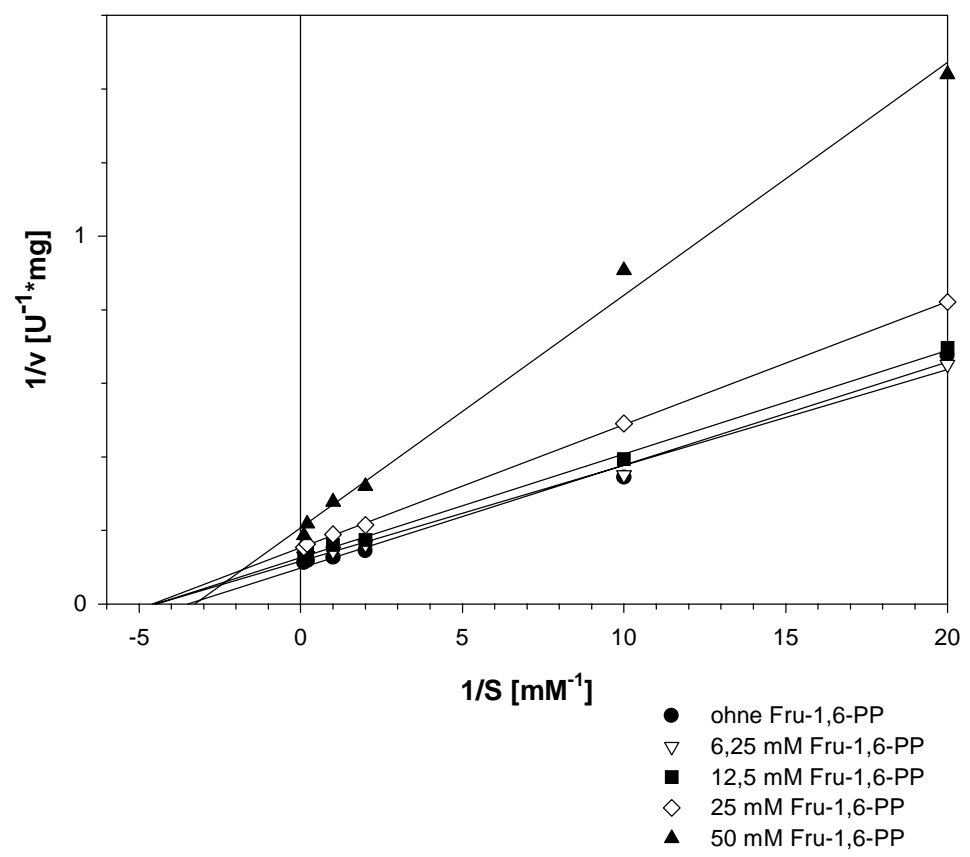

Abb. 22: Lineweaver-Burk-Diagramm der nicht-kompetitiven AglA Inhibition durch Fructose-1,6-Diphosphat 
Trägt man in einem Sekundärdiagramm die Inhibitorkonzentration [I] gegen die Steigung der Geraden im Lineweaver-Burk-Diagramm $\left(=K_{\mathrm{m}} / V_{\max }\right)$ auf, ergibt der Schnittpunkt der extrapolierten Regressionsgeraden mit der Abzisse die Inhibitorkonstante $K_{\mathrm{i}}$. Für Fructose-1,6-Diphosphat wurde dieser Wert mit $65 \mathrm{mM}$ bestimmt (Abb. 23). Die physiologische Signifikanz dieses sehr hohen Wertes ist jedoch fragwürdig.

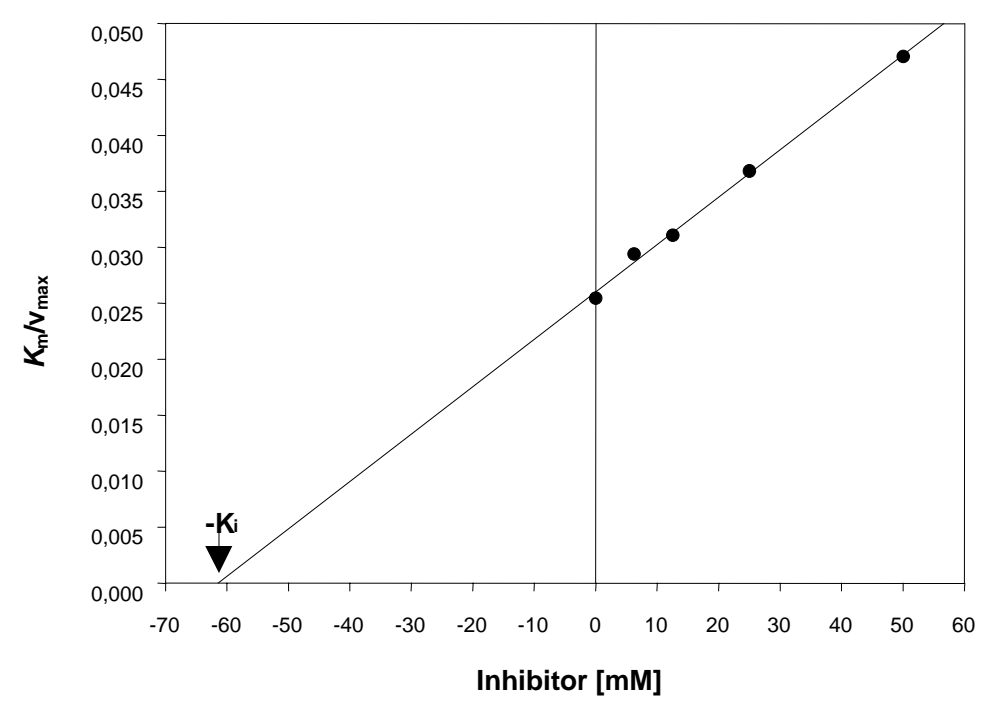

Abb. 23: Bestimmung der Inhibitorkonstanten $K_{\mathrm{i}}$ für Fructose-1,6-Diphosphat mittels Sekundärdiagramm 


\subsection{Optimierung der heterologen Überexpression der GTase in $E$. coli und vereinfachte, hocheffiziente Auf- reinigung des rekombinanten Proteins}

Trotz des Vorliegens einiger Strategien und Erfahrungen (Liebl et al., 1992; Huber, 1994; Meissner, 1997) gelang es bisher nicht, stabile Proteinkristalle zu erhalten, mit deren Hilfe eine Röntgenstrukturanalyse durchgeführt und damit die Aufklärung der räumlichen Struktur der $4-\alpha-$ Glucanotransferase erreicht werden konnte (Liebl, persönl. Mitteilung). Eine wichtige Voraussetzung für diese Experimente ist die Gewinnung großer Mengen an Enzym in ausreichender Qualität und in angemessener Zeit. Aus diesem Grund wurde das Verfahren der heterologen Expression und der chromatographischen Aufreinigung optimiert und vereinfacht.

\subsubsection{Klonierung von $m g t A$ in den Expressionsvektor pET21c}

Zunächst wurde eine Umklonierung des $m g t A$ Gens aus dem Plasmid pTAM1 (einem auf pSU1-basierenden Plasmid mit $m g t A$ als Teil eines 2,6-kB Fragmentes chromosomaler T. maritima MSB8 DNA; Liebl et al., 1992) in den Überexpressionsvektor pET21c mittels PCR vorgenommen (Ludwig, persönl. Mitteilung). Die Primer und die PCR-Bedingungen waren:

Tab. 10: Verwendete Primer für die PCR

\begin{tabular}{clc}
\hline Bezeichnung & \multicolumn{1}{c}{ Primer-Sequenz $^{\mathrm{a})}\left(5^{\prime} \rightarrow 3^{\prime}\right)$} & Schnittstelle \\
\hline GTASE-V & CCCGTTCCATATGATAGGCTATCAGATCTAC & Ndel \\
GTASE-R & TCACCGTCATCCTTTCGG & \\
\hline
\end{tabular}

a): Die eingefügte Schnittstelle ist unterstrichen.

\section{PCR-Ansatz:}

\begin{tabular}{|lll|}
\hline GTASE-V $(50 \mathrm{pmol} / \mu \mathrm{l})$ & 1,0 & $\mu \mathrm{l}$ \\
GTASE-R $(50 \mathrm{pmol} / \mu \mathrm{l})$ & 1,0 & $\mu \mathrm{l}$ \\
pTAM1-DNA & 1,5 & $\mu \mathrm{l}$ \\
dNTP-Lösung (je $10 \mathrm{mM})$ & 3 & $\mu \mathrm{l}$ \\
Pfu-Puffer (10x) & 10 & $\mu \mathrm{l}$ \\
$\mathrm{H}_{2} \mathrm{O}$ & 82,5 & $\mu \mathrm{l}$ \\
Pfu-Polymerase $(9 \mathrm{U} / \mu \mathrm{l})$ & 1 & $\mu \mathrm{l}$ \\
Flüssigwachs & 70 & $\mu \mathrm{l}$ \\
\hline
\end{tabular}

PCR-Bedingungen:

\begin{tabular}{|llll|}
\hline $\begin{array}{l}\text { Erste Denaturierung: } \\
\text { 30 Zyklen: }\end{array}$ & $94^{\circ} \mathrm{C}$, & 45 & $\mathrm{~s}$ \\
\hline 1.) Denaturierung: & $94^{\circ} \mathrm{C}$, & 45 & $\mathrm{~s}$ \\
2.) Primer-Anlagerung: & $51^{\circ} \mathrm{C}$, & 45 & $\mathrm{~s}$ \\
3.) Synthese: & $72^{\circ} \mathrm{C}$, & 2 & $\mathrm{~min}$ \\
Letzter Syntheseschritt: & $72^{\circ} \mathrm{C}$, & 10 & $\mathrm{~min}$ \\
\hline
\end{tabular}




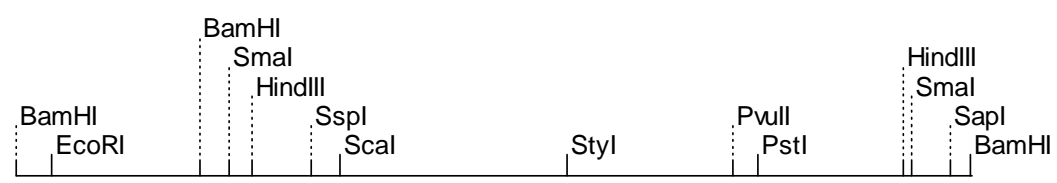

2,6 kB chromosomales T. maritima DNA-Insert des Plasmides pTAM1

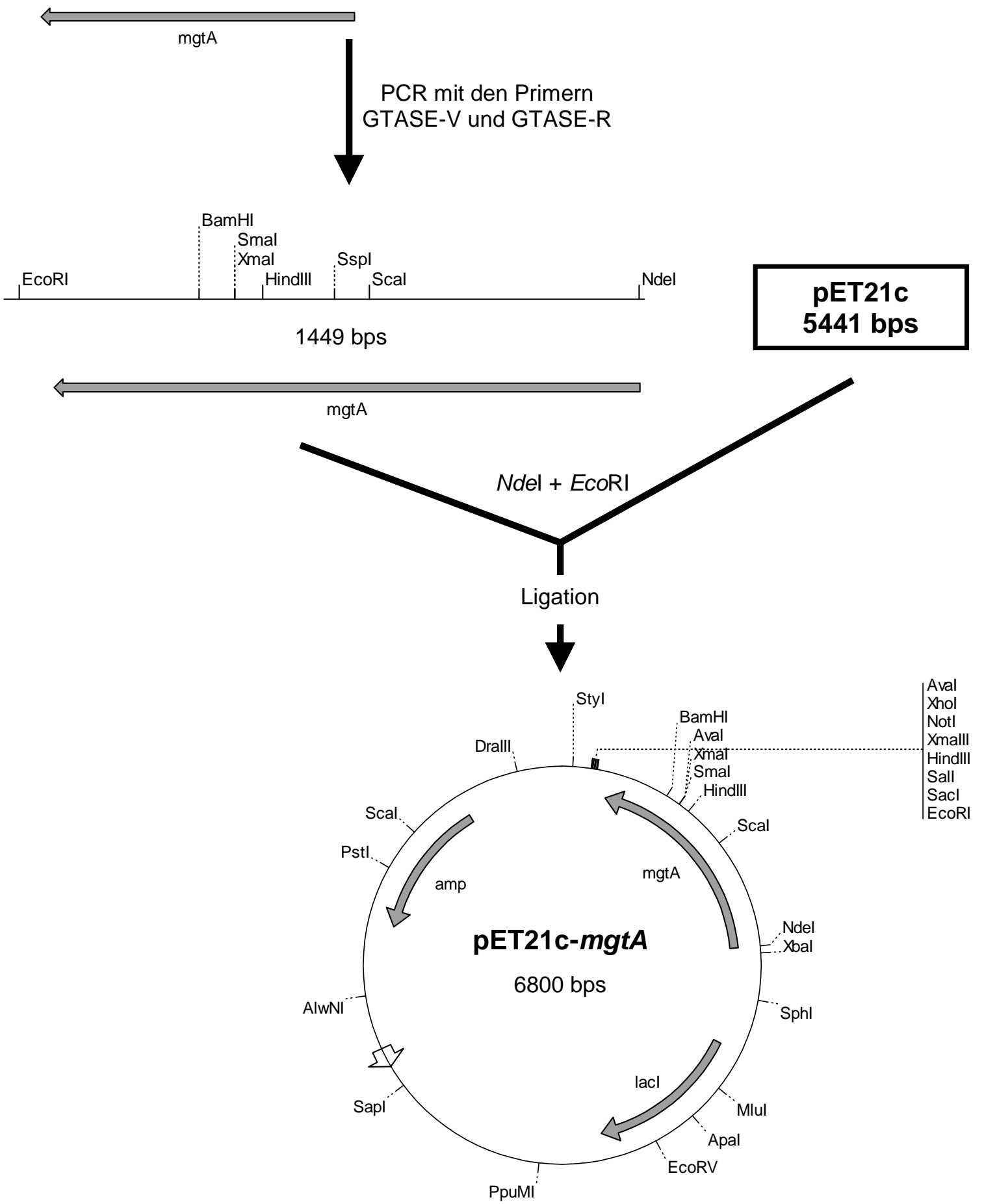

Abb. 24: Konstruktion des GTase Expressionsplasmides pET21c-mgtA. Das Plasmid trägt ein Ampicillin-Resistenzgen zur Selektion. $m g t A=$ GTase-Gen 
Der PCR-Ansatz wurde bei den angegebenen Bedingungen inkubiert, das entsprechende 1,4 kb PCR-Produkt aus dem Agarose-Gel extrahiert, mit Ndel+ EcoRI geschnitten und durch Phenol-Chloroform-Extraktion und Ethanol-Fällung gereinigt. Es folgte die Ligation in den Ndel+EcoRI geschnittenen Vektor pET21c (Abb. 24), die Transformation in E. coli Xl1-Blue und letztlich die Elektroporation in E. coli BL21 (DE3). Korrekte Klone mit dem neuen Konstrukt pET21c-mgtA wurden durch einen Aktivitätstest auf Stärke-(IPTG)-haltigen Agarplatten identifiziert und isoliert. Bei $37^{\circ} \mathrm{C}$ über Nacht gewachsene aktive Klone bilden nach Inkubation der Agarplatte bei $60^{\circ} \mathrm{C}$ für $4 \mathrm{~h}$ und anschließender Überschichtung mit Lugol'scher Lösung helle Höfe um die jeweilige Kolonien.

\subsubsection{Expression und Reinigung der rekombinanten 4- $\alpha$-Glucanotransferase}

Zur Gewinnung des Ausgangsmaterials für die Reinigung wurde E. coli BL21 (DE3) / pET21c- $m g t A$ in 5 I LB Amp -Medium bei $37^{\circ} \mathrm{C}$ geschüttelt. In der exponentiellen Wachstumsphase $\left(\mathrm{OD}_{600 \mathrm{~nm}}=0,6-0,9\right)$ erfolgte die Induktion mit 0,1 mM IPTG und eine weitere Inkubation für 3,5 h. Anschließend wurden die Zellen geerntet (GSA, 7000 Upm, $20 \mathrm{~min}, 4^{\circ} \mathrm{C}$ ), einmal mit $20 \mathrm{mM}$ Tris- $\mathrm{Cl} \mathrm{pH} 8$ gewaschen und in $1 \mathrm{ml}$ TrisPuffer pro Gramm Naßgewicht (hier: 10,3 g) resuspendiert. Der Zellaufschluß erfolgte in der French Pressure Cell (2x). Es folgte ein Zentrifugationsschritt (SS34, $14000 \mathrm{Upm}, 30 \mathrm{~min}$ ), die Hitzefällung bei $70^{\circ} \mathrm{C}$ für $20 \mathrm{~min}$ und eine weitere Zentrifugation. Der so geklärte hitzegefällte Rohextrakt wurde zur weiteren chromatographischen Aufreinigung eingesetzt.

\section{Parameter}

$\begin{array}{ll}\text { Medium } & \text { : Source } 15 \mathrm{Q} \\ \text { Säule } & \text { : XK } 26 \\ \text { Säulenvolumen }: 50 \mathrm{ml} \\ \text { Puffer A } & : 20 \mathrm{mM} \text { Tris-Cl pH } 8 \\ \text { Puffer B } & : 20 \mathrm{mM} \text { Tris-Cl pH } 8,1 \mathrm{M} \mathrm{NaCl} \\ \text { Flußrate } & : 10 \mathrm{ml} / \mathrm{min} \\ \text { Fraktion } & : 10 \mathrm{ml} \\ \text { Equilibrierung } & : 2 \text { SV Puffer B, } 10 \text { SV Puffer A } \\ \text { Gradient } & \text { : siehe nebenstehendes Schema }\end{array}$

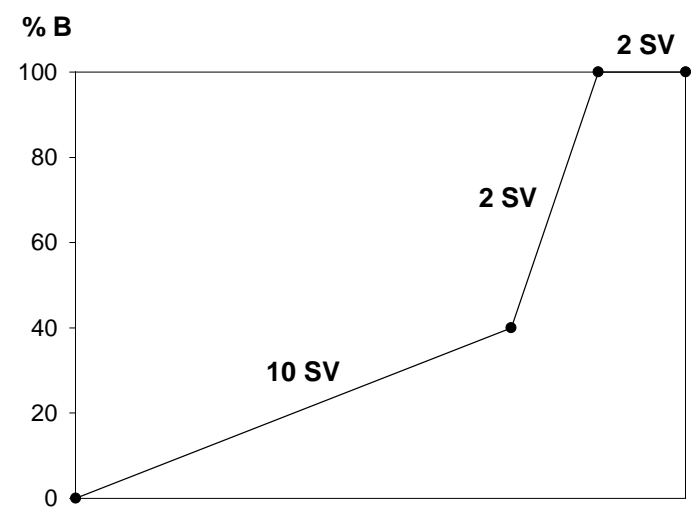

Die Fraktionen wurden auf den Proteingehalt und mit dem $\mathrm{I}_{2} / \mathrm{KI}$-Test qualitativ auf 4- $\alpha$-Glucanotransferase-Aktivität hin analysiert. Nach zusätzlicher Kontrolle im SDSPolyacrylamidgel wurden die Fraktionen, die keine Kontaminationsbanden aufwiesen 
(Fraktionen: 20-24), vereinigt und gegen $20 \mathrm{mM}$ Tris- $\mathrm{Cl} \mathrm{pH} 8$ in MACROSEPMikrokonzentratoren $(30 \mathrm{~K})$ dialysiert und eingeengt. Abb. 25 zeigt eine SDS-PAGE (10\%) mit den Reinigungsschritten der oben dargestellten zweistufigen Präparation.

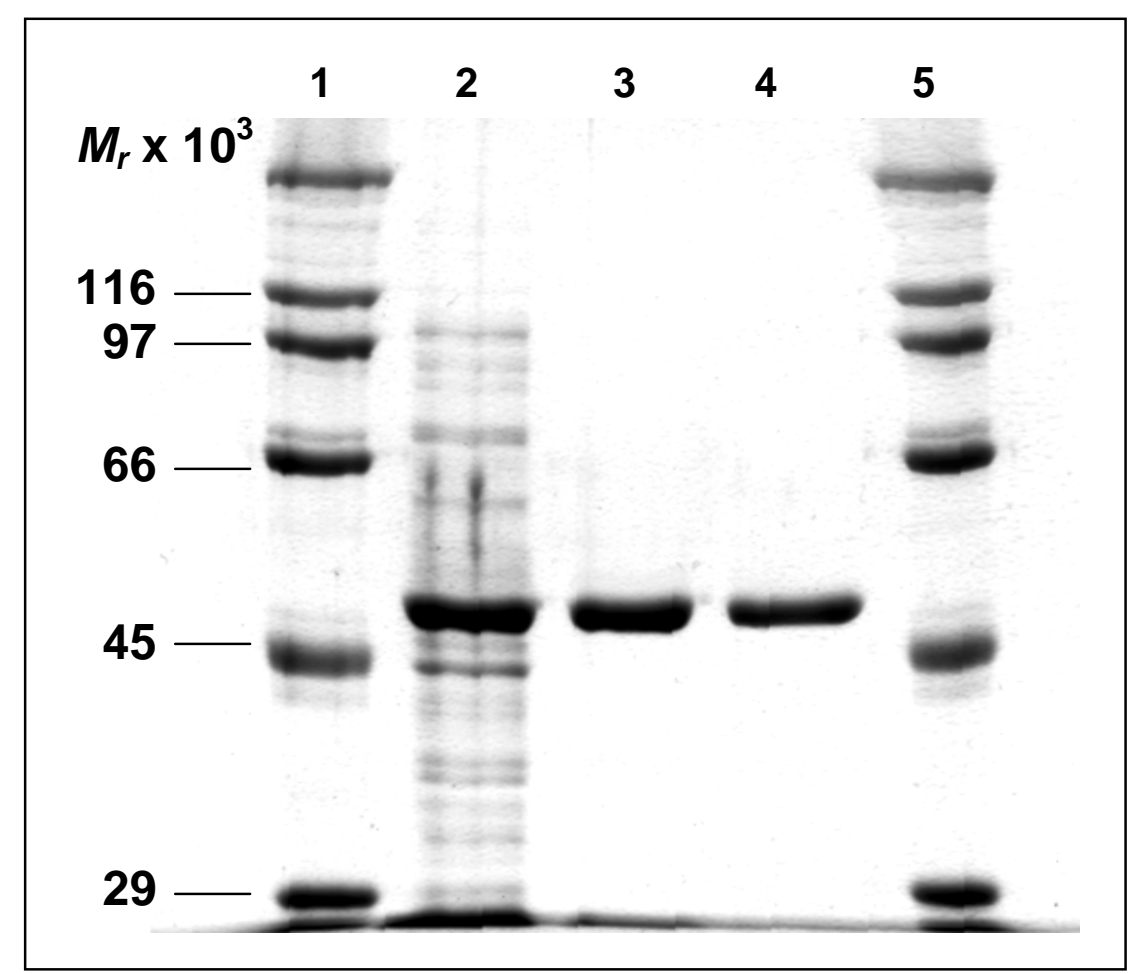

Abb. 25: SDS-PAGE-Trenngel (10\%) der Reinigungsschritte der rekombinanten GTase

Spur 1 und 5: Molekularmassenstandard

Spur 2: E. coli BI21(DE3) pET21c-mgtA Rohextrakt

Spur 3: Rohextrakt hitzedenaturiert, $20 \mathrm{~min} / 70^{\circ} \mathrm{C}$

Spur 4: SOURCE 15 Q-Pool, dialysiert

Tab. 11: Bilanzierung der Reinigung der 4- $\alpha$-Glucanotransferase

\begin{tabular}{lccccc}
\hline $\begin{array}{l}\text { Reinigungs- } \\
\text { schritt }\end{array}$ & $\begin{array}{c}\text { Protein } \\
(\mathrm{mg})\end{array}$ & $\begin{array}{c}\text { Gesamt- } \\
\text { aktivität }(\mathrm{U})\end{array}$ & $\begin{array}{c}\text { Spez.Aktivität } \\
(\mathrm{U} / \mathrm{mg})\end{array}$ & $\begin{array}{c}\text { Anreicherungs- } \\
\text { faktor }\end{array}$ & $\begin{array}{c}\text { Ausbeute } \\
(\%)\end{array}$ \\
\hline Zellextrakt & 789,9 & 131312 & 166 & 0 & 100 \\
Hitzefällung & 75,8 & 68351 & 901 & 5,4 & 52 \\
Source 15Q & 27,8 & 32745 & 1178 & 7,1 & 25 \\
\hline
\end{tabular}

Aus 5 I Kulturmedium konnten durch die beschriebenen Reinigungsschritte 27,8 mg hochreines, kristallisationstaugliches Enzym gewonnen werden (Tab. 11). Ausgehend von einem Naßgewicht der Zellen von 10,3 g aus 5 I Medium läßt sich berechnen, daß 2,7 mg GTase/g Zellen bzw. 5,6 mg GTase/l Medium gereinigt werden 
konnten. Berücksichtigt man eine 25\%-ige Ausbeute bei annähernd 100\%-iger Reinheit, so folgt, daß 10,8 mg GTase/g E. coli-Zellen bzw. 22,4 mg GTase/l Medium gebildet wurde. Dies wiederum entspricht etwa 14\% des E. coli-Proteins.

Im Vergleich zu früheren Reinigungen (Liebl et al., 1992; Huber, 1994) konnte somit der Reinheitsgrad, der sich in der spezifischen Aktivität wiederspiegelt, nochmals um das 1,65-fache gesteigert bzw. das Volumen des Ausgangsmedium um das 3,1fache reduziert werden, um dieselbe Menge an homogener GTase zu erhalten.

Zum Nachweis der extrem schwachen hydrolytischen Aktivität wurde gereinigte

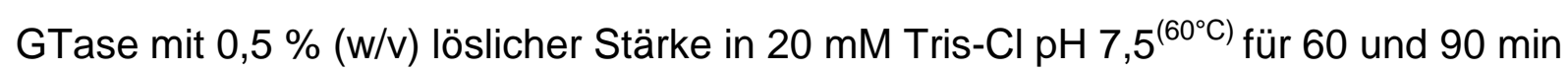
bei $60^{\circ} \mathrm{C}$ inkubiert und anschließend im DNSA-Test vermessen. Es wurde für die Hydrolyse eine spezifische Aktivität von $0,016 \mathrm{U} / \mathrm{mg}$ bestimmt.

\subsubsection{HPLC-Analyse der Stärkeumsetzung}

Die GTase greift polymere Substrate wie Stärke oder Amylose in der Weise an, daß auch nach längerer Inkubation im $\mathrm{I}_{2} / \mathrm{KI}$-Test nur eine Verfärbung von blau nach violett bis rot eintritt und nicht eine Verfärbung nach gelb, wie es bei einer Kombination von Stärke und Maltose der Fall ist (Liebl et al., 1992). Der Effekt der GTase-Aktivität auf die Kettenlängenverteilung der Maisstärke wurde deshalb mittels einer HPLC-PADAnalyse untersucht. Bei der Detektion durch gepulste Amperometrie können Kohlenhydrate bis in den picomolaren Bereich (hier: Auflösung bis DP 40; Abb. 26 A) nachgewiesen werden. Dabei werden die Kohlenhydrate an der Oberfläche der Goldoder Arbeitselektrode oxidiert und der resultierende Strom (Stromstärke/Zeit = Ladung [C]), der proportional zur Probenkonzentration ist, gemessen. Dann wird das Potential weiter erhöht, um die Goldelektrode zu oxidieren und von Kohlehydratprodukten zu reinigen. Ein drittes Potential reduziert das Goldoxid an der Elektrodenoberfläche wieder zu Gold und damit steht die Elektrode für eine weitere Messung zur Verfügung.

In Abb. 26 ist die Veränderung der Kettenlängenverteilung von Maisstärke nach Inkubation mit der GTase dargestellt. Die Durchführung und Probenvorbereitung ist im Kapitel 2.13.3 beschrieben. Generell läßt sich eine Abnahme hin zu kürzeren Kettenlängen feststellen, wobei die häufigsten Kettenlängen einen Polymerisationsgrad von 4-6 und 13-15 aufweisen (B). 

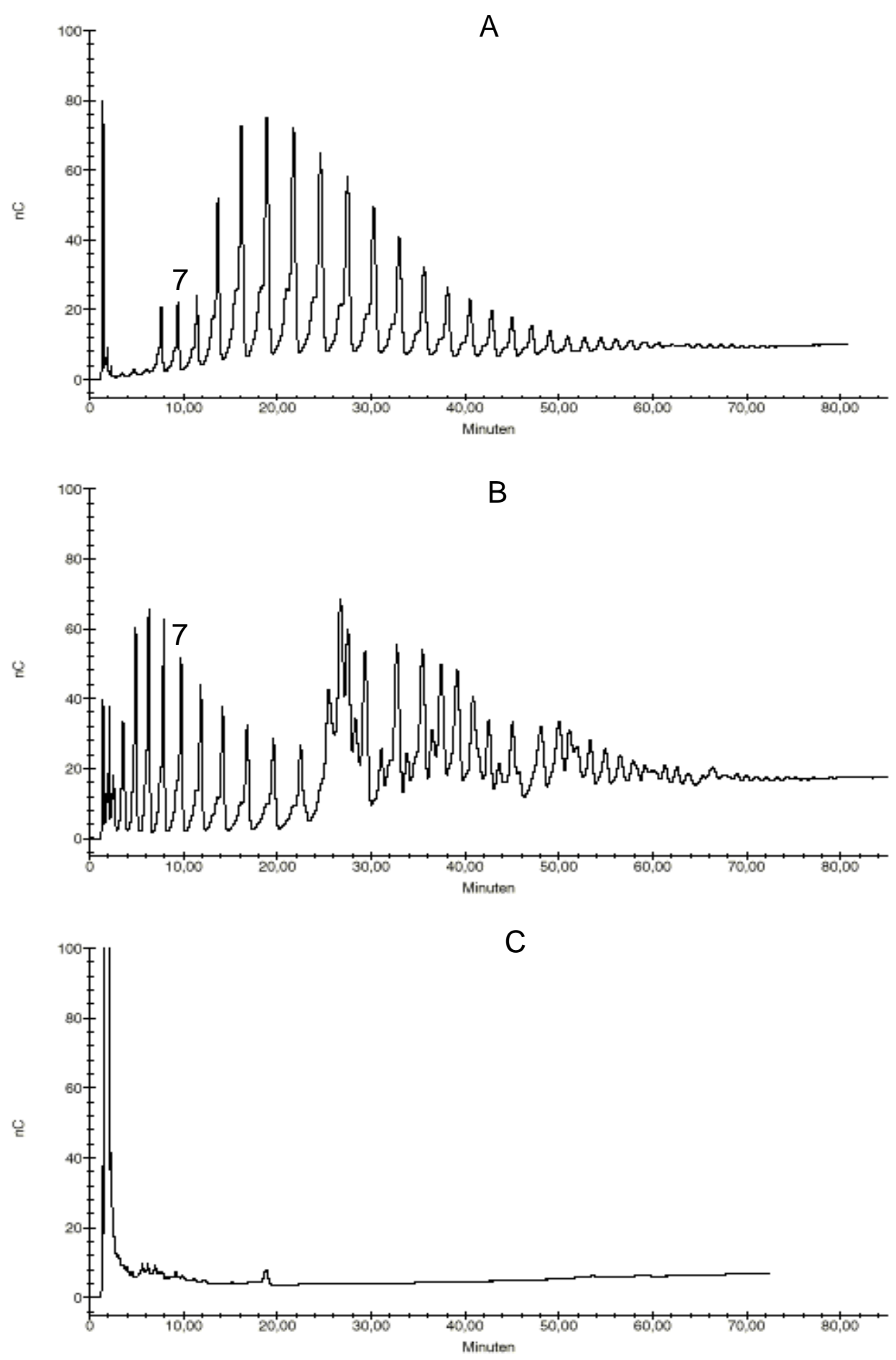

Abb. 26: Analyse des Effektes der GTase Aktivität auf die Kettenlängenverteilung von Maisstärke mittels HPAE-PAD ( $\mathrm{nC}=$ Ladung)
A) Maisstärke ohne GTase-Inkubation
B) Maisstärke nach Inkubation mit GTase-Rohextrakt
C) Maisstärke nach Inkubation mit GTase-Rohextrakt und Amyloglucosidase

Alle Proben wurden mit Isoamylase als Entzweigungsenzym inkubiert. Die Nummer (7) gibt den Grad der Polymerisierung des jeweiligen „Peaks“ an. Probenvorbereitung: siehe Material und Methoden, Kapitel 2.13.3. 
Da nach einer Inkubation mit Amyloglucosidase hauptsächlich nur noch ein GlucosePeak auftritt (C), kann man davon ausgehen, daß es sich bei den „unregelmäßigen“ Peaks (ab DP 13) nicht um zyklische Verbindungen handelt. Damit bestätigt diese Methode die Aussage, die kolorimetrisch durch lodfärbung mit dem $\mathrm{I}_{2} / \mathrm{KI}$-Test bereits getroffen wurde. Die häufige Kettenlängenverteilung bei den Polymerisationsgraden 13-15 kann somit für die auftretende rot-violette Färbung verantwortlich gemacht werden. Ob bei der Stärkeumsetzung durch die GTase ein Transfer von der Amylose auf Amylopektin oder umgekehrt erfolgt, läßt sich aus dieser Analyse allerdings nicht ableiten.

\subsubsection{Inhibitoren der GTase im Hinblick auf die Strukturanalyse}

Wie bereits erwähnt, waren bisherige Bemühungen zur Kristallisation und Röntgenstrukturanalyse erfolglos. Mit dem in dieser Arbeit beschriebenen Protokoll zur Expression und Aufreinigung der GTase ist es nun möglich, schnell und in ausreichender Menge kristallisationsfähiges Protein zu isolieren. In Kooperation mit der Arbeitsgruppe um Prof. Dr. D.W. Rice (Sheffield, UK) ist es gelungen erste Beugungsstudien mit definierten Mustern, d.h. erste röntgenkristallographische Daten der GTase zu erhalten (Roujeinikova, persönl. Mitteilung). Um Rückschlüsse auf den Aufbau des aktiven Zentrums zu erhalten, bietet sich neben der Verwendung von Maltooligosacchariden auch die Kokristallisation der GTase mit Inhibitoren bekannter Struktur an. Ein solcher Inhibitor stellt $\beta$-Cyclodextrin ( $\beta-C D)$ dar, der in einer früheren Arbeit als kompetitiver Inhibitor der GTase beschrieben wurde (Huber, 1994).

In Abb. 27 ist eine Inhibitorstudie mit der GTase dargestellt, bei der neben dem erwähnten $\beta$-Cyclodextrin auch $\alpha$ - und $\gamma$-Cyclodextrin, sowie Acarbose verwendet wurde. Acarbose ist ein Pseudotetrasaccharid (ungesättigter Cyclit, der $\alpha$-pseudo-Nglycosidisch mit 4-Amino-4,6-didesoxy-D-Glucose verknüpft, die ihrerseits $\alpha$-glycosidisch mit Maltose verbunden ist), das von Actinomyceten gebildet wird und als $\alpha$-Glucosidase-Hemmer fungiert.

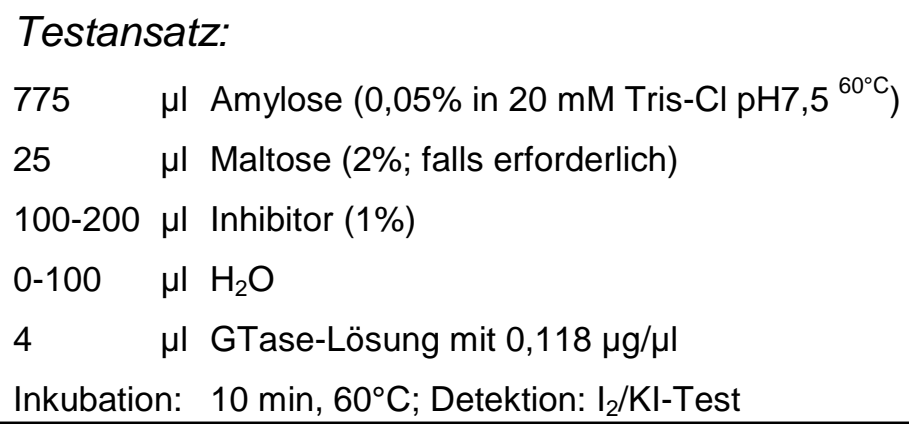




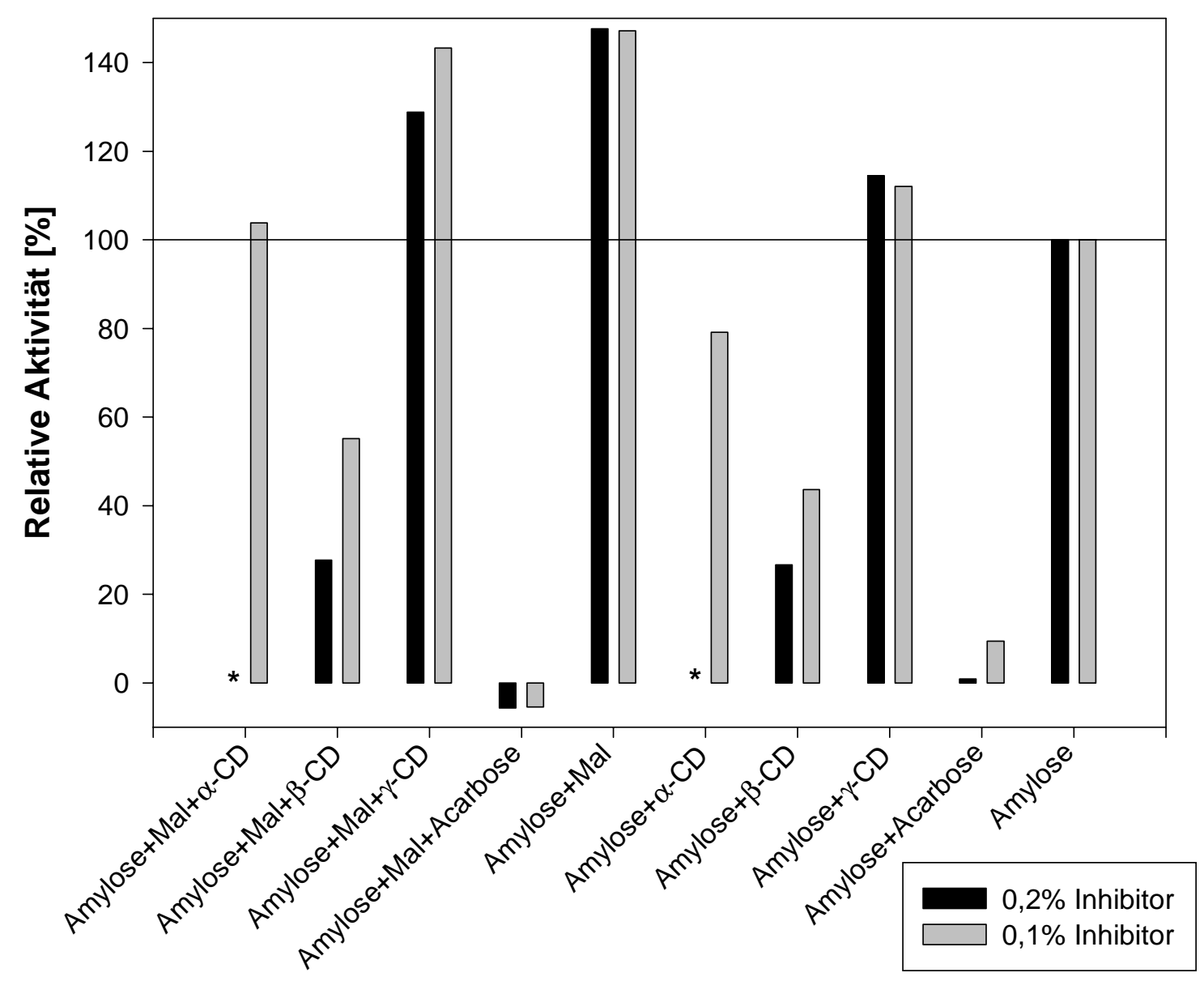

Abb. 27: Inhibitorstudie der GTase mit $\alpha-, \beta-, \gamma$-Cyclodextrin (CD) und Acarbose mit und ohne den Effektor Maltose (Mal)

${ }^{*}$ n.d.: $\alpha-C D$ setzt in der eingesetzten Konzentration die $\mathrm{OD}_{620}$ bereits vor Zugabe der GTase so stark herab, daß eine Messung nicht möglich war. Dies trifft im geringen Maße auch für Acarbose zu und erklärt die negativen Werte im Ansatz Amylose+Mal+Acarbose.

Vergleicht man die Ansätze mit und ohne Maltose, so zeigt sich deutlich, daß durch Maltosezugabe die GTase-Aktivität scheinbar gesteigert wird. $\gamma-C D$ und $\alpha-C D$ haben keinen bzw. nur geringen Einfluß auf die Aktivität. $\beta$-CD hemmt in An- als auch in Abwesenheit von Maltose das Enzym deutlich. Durch Acarbose wird die GTase sowohl mit als auch ohne Maltosezusatz annähernd vollständig gehemmt. Die Analyse per Dünnschichtchromatographie ergab, analog zu den Ergebnissen von Meissner (1997) zur MTase, ein negatives Ergebnis im Donor- (Acarbose, Maltose und GTase im Ansatz) und Disproportionierungs-Versuch (nur Acarbose und GTase im Ansatz), aber ein positives Resultat im Akzeptor-spezifischen Experiment (Acarbose, Amylose und GTase im Ansatz). Da Acarbose nicht von der GTase 
umgesetzt wird, kann es als Inhibitor mit bekannter Struktur zur Kokristallisation mit der GTase eingesetzt werden.

\subsection{Aufklärung der Proteinstruktur der rekombinanten Maltosyltransferase (MmtA) aus T. maritima (Roujei- nikova et al., 2001)}

Auch für dieses Enzym gilt die Feststellung, daß nur Ergebnisse, die im Rahmen dieser Arbeit bzw. in Kooperation mit der Arbeitsgruppe von Prof. Dr. Rice neu gewonnen wurden, hier ausführlicher dargestellt werden. Für darüber hinausgehende Details sei auf die angegebene aktuelle Literatur verwiesen. Ältere Ergebnisse (Meissner, 1997; Meissner und Liebl, 1998) werden nur dort erwähnt, wo sie zum besseren Verständnis beitragen.

\subsubsection{Reinigung und Kristallisation des rekombinanten Proteins (Burke et al., 2000)}

Nach der biochemischen Charakterisierung der ungewöhnlichen Eigenschaften der Maltodextrin Glycosyltransferase (MTase; Meissner, 1997) und ersten Kristallisationsexperimenten, sollte nun die räumliche Struktur des Enzyms aufgeklärt werden, um einerseits die molekulare Basis der einzigartigen Transferspezifität aufzudecken und um andererseits die Voraussetzung für eine vergleichende Analyse mit anderen Glycosyltransferasen, insbesondere mit der GTase, zu schaffen. Die Experimente zur Röntgenstrukturanalyse wurden in Kooperation mit der Arbeitsgruppe von Prof. Dr. D.W. Rice (Sheffield, UK) durchgeführt.

Die heterolog in E. coli JM83 überproduzierte MTase aus T. maritima wurde nach einem Reinigungsschema von Meissner (1997) isoliert (Abb. 28).

Es konnten so aus 4 I Kulturvolumen $27 \mathrm{mg}$ hochreines Protein gewonnen werden. Mit dieser Proteincharge wurden anschließend mittels der „hanging drop“-Technik innerhalb von 2-3 Tagen stäbchenförmige Kristalle mit den Maßen 0,25 x 0,25 x 1,5 $\mathrm{mm}$ erhalten (Burke et al., 2000). Hierzu wurde ein $3 \mu$-Aliquot der Proteinlösung (18 mg/ml) mit dem gleichen Volumen einer Reservoirlösung gemischt, die aus 0,350,40 $\mathrm{M} \mathrm{NH}_{4} \mathrm{H}_{2} \mathrm{PO}_{4}, \mathrm{pH} 4,7-4,8$ (mittels $\left(\mathrm{NH}_{4}\right)_{2} \mathrm{HPO}_{4}$ ) bestand. Die Beugungsmuster wurden letztlich von tiefgekühlten Kristallen bis zu einer Auflösung von 2,4 $\AA$ erhalten. 


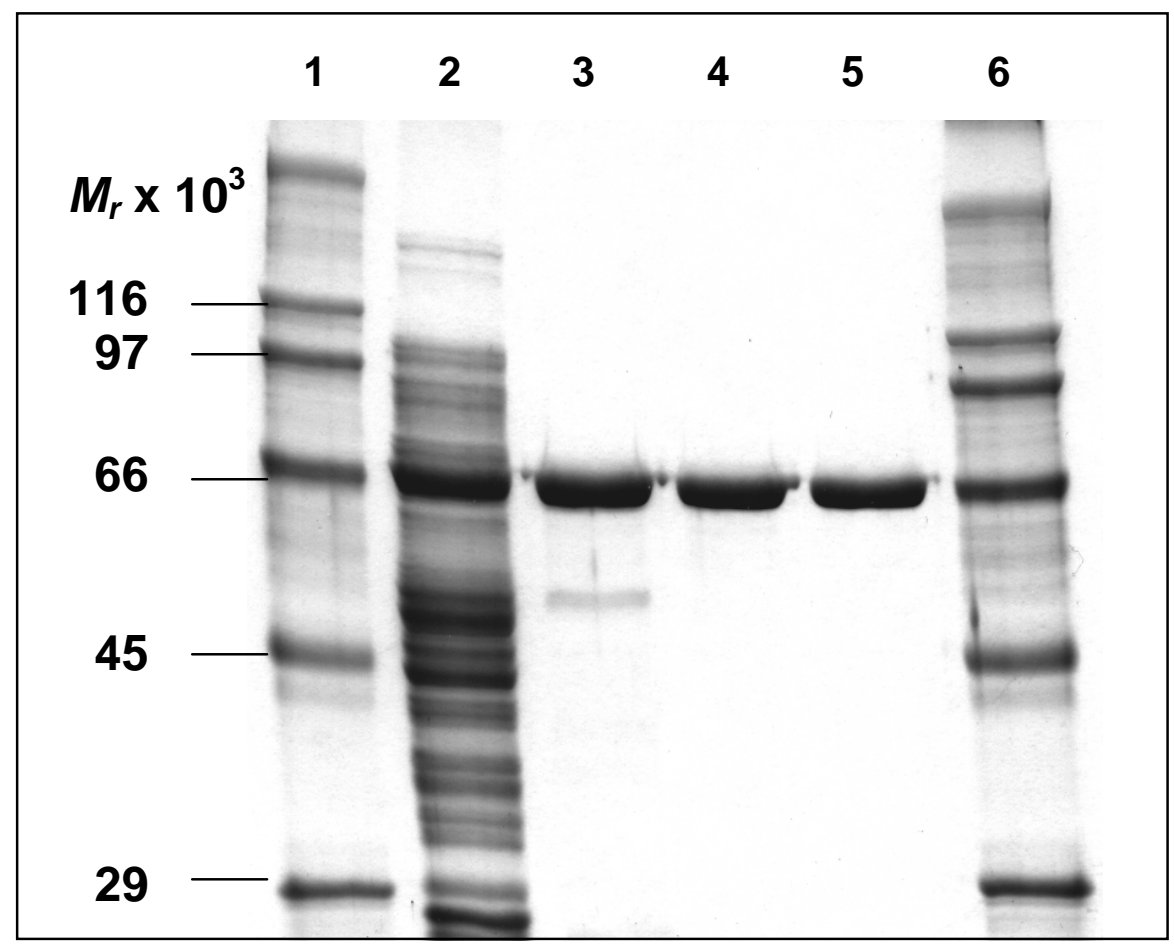

Abb. 28: SDS-PAGE der Reinigungsschritte einer dreistufigen MaltosyltransferasePräparation

Spur 1: Molekularmassenstandard

Spur 2: E. coli JM83-pTAA3-Rohextrakt

Spur 3: Rohextrakt hitzedenaturiert, $15 \mathrm{~min} / 75^{\circ} \mathrm{C}$
Spur 4: SOURCE 15 Q-Pool

Spur 5: Phenyl Sepharose HP-Pool

Spur 6: Molekularmassenstandard

\subsubsection{Gelfiltrationsstudie}

Zur Lösung der räumlichen Struktur eines Proteins ist die Kenntnis des Oligomerisierungsgrades hilfreich. Um diesen in Erfahrung zu bringen, kann man die Nativ-Molekularmasse des jeweiligen Enzyms durch analytische Gelfiltration bestimmen. Frühere Messungen mit hitzegefälltem Rohextrakt wiesen darauf hin, daß die native MTase als ein Komplex mit mehr als 450 kDa existiert (Meissner, 1997). Da die Oligomerisierung eines Enzyms aber oftmals von der Reinheit der verwendeten Probe und vom Salzgehalt des verwendeten Puffersystems abhängig ist, wurde erneut eine Gelfiltration, diesmal mit 0,3 mg hochreiner MTase, durchgeführt. Die Analyse mittels der Superdex 200 HiLoad 16/60 Säule ergab sowohl mit 50 mM Tris-Cl pH 7 (neutral), $150 \mathrm{mM} \mathrm{NaCl}$ als auch mit Mcllvaine-Puffer pH 4,8 (sauer) eine dimere Quartärstruktur des nativen Enzyms (bestimmte Molekularmasse: 130$140 \mathrm{kDa}$ ). Diese Ergebnisse wurden kürzlich von der Sheffielder-Arbeitsgruppe bestätigt (Liebl, persönl. Mitteilung). 


\subsubsection{Maltosebindung und Lokalisierung der putativen aktiven Aminosäuren}

Frühere vergleichende Sequenzstudien der MTase mit anderen Vertretern der $\alpha$-Amylase-Familie ergaben, daß die Reste Asp 385, Glu 414 und Asp 468 konserviert vorliegen und vermutlich die katalytisch aktiven Seitenketten der MTase darstellen. Mittels Strukturanalyse konnten diese Reste am C-terminalen Ende der

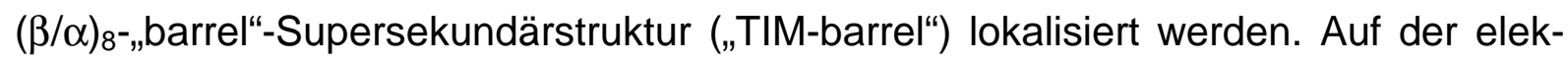
trostatischen Potential-Oberfläche der MTase ist die Tasche mit dem aktiven Zentrum als eine negativ geladene Region zu erkennen (Abb. 29), welche in einer tiefen Spalte am C-terminalen Ende des „barrels“ liegt.
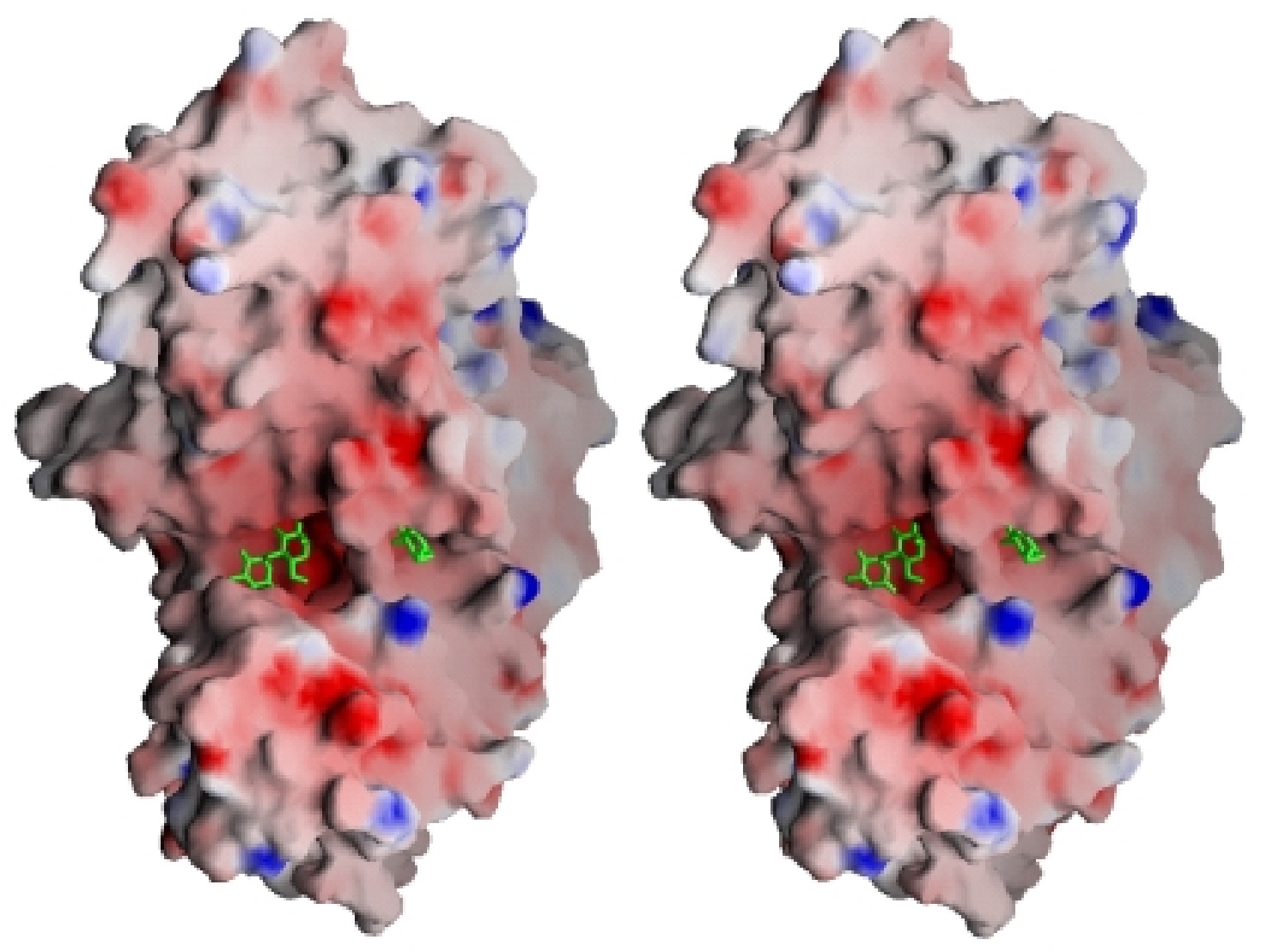

Abb. 29: GRASP-Darstellung (Nicholls et al., 1991) der elektrostatischen Ladungsverteilung auf der molekularen MTase-Oberfläche. Eingezeichnet ist das, in der negativ geladenen Tasche des aktiven Zentrums gebundene, Maltose-Molekül und der nicht-reduzierende EndGlycosylrest des zweiten Maltose-Moleküls, welches in einer benachbarten Tasche gebunden wird (Roujeinikova et al., 2001).

Da Maltose nicht als Substrat durch die MTase umgesetzt wird, konnte es zur Kokristallisation verwendet werden. Die Kristalle, die erhalten wurden, konnten bis zu 
einer Genauigkeit von 2,1 $\AA$ strukturell aufgelöst werden. Je Untereinheit wurden zwei Maltose-Bindestellen identifiziert (Abb. 29). Die erste Maltose-Bindestelle ist im Bereich des aktiven Zentrums lokalisiert und stell die gemeinsame Substrat/ Substratanaloga-Bindestelle für komplexierte $\alpha$-Amylasen und verwandte Enzyme dar. Die zwei Pyranosen der Maltose besetzen dabei die "subsites“ -2 und -1 (,subsites“ = „Unterbindungsregionen“ für Monosaccharidyl-Einheiten des oligo- oder polymeren Substratmoleküls; Nomenklatur: siehe Davies et al., 1997). Es wird postuliert, daß die Transferreaktion der MTase über ein kovalentes Maltosyl-EnzymIntermediat verläuft, bei der die vom Substrat abgespaltene Maltosyl-Einheit in diesen „subsites“ festgelegt wird.

Die zweite Maltose-Bindestelle befindet sich in einer Tasche auf der Enzymoberfläche, die in einer Entfernung von $10 \AA$ zum aktiven Zentrum liegt. Diese Nähe legt eine regulatorische Funktion nahe oder aber deutet auf die Möglichkeit der Bindung verzweigter Substrate hin.

\subsubsection{MTase als Dimer}

Gelfiltrationsstudien zeigten, daß die MTase sowohl in neutraler als auch in saurer Lösung als Dimer vorliegt (siehe 3.4.2). Die Analyse der Kristallstruktur und die Anordnung der MTase-Moleküle im Kristall stützen diese Aussage. Abb. 30 zeigt die Anordnung der Monomere der nativen MTase. Die Untereinheiten werden durch mehrere hydrophobe Kontakte miteinander verbunden, bei denen die beteiligten Reste aus 3 (N, A, B) der 4 MTase Domänen stammen. Insbesondere die Seitenketten von Ile19, Val110, Leu111 und Phe113 des einen Monomers ergeben zusammen mit den Seitenketten Leu148, Phe149, Val226, Leu229, Leu289, Val293 und lle299 des anderen Monomers ein hydrophobes Cluster an der dimeren Nahtstelle. Zusätzliche Analysen ergaben, daß die Schleife $\beta 5 / \alpha 6$ mit Lys151 des einen Monomers durch Kontakte zur Schleife $\beta 4 / \alpha 5$ des anderen Monomers stabilisiert wird. Lys151 wird anhand der Strukturanalyse als entscheidend für die Erkennung des nicht-reduzierenden Substratendes betrachtet und ist möglicherweise für den exo-agierenden Enzymmechanismus der MTase mitverantwortlich. Die Seitenkette des Lys151 bildet eine sterische Barriere an der Stelle, wo sich die "subsite“ -3 in anderen homologen Enzymen befindet und verhindert vermutlich deshalb die Abspaltung längerer Zuckereinheiten vom Substrat. 

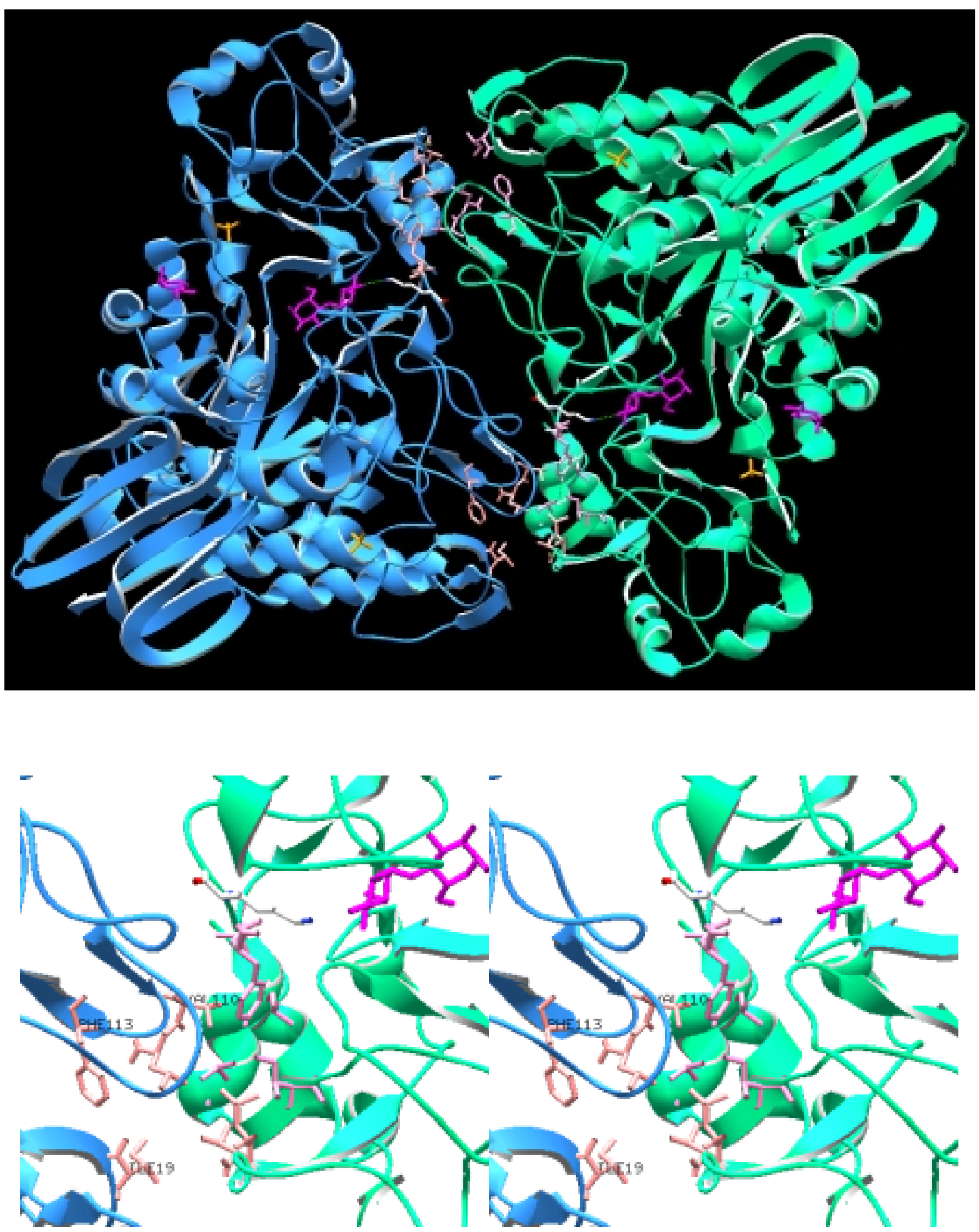

Abb. 30: Kristallstruktur des MTase-Dimers

Die beiden monomeren Untereinheiten sind in blau und in grün dargestellt. Das aktive Zentrum ist durch das violette Maltosemolekül gekennzeichnet und der Glycosylrest der zweiten Maltose ist ebenfalls violett wiedergegeben. Phosphat-lonen sind in gelb gehalten. Zwei symmetrische hydrophobe Cluster sind an der dimeren Nahtstelle (siehe Text) dargestellt, wobei die beteiligten Aminosäuren detailliert herausgearbeitet wurden. Die Aminosäure Lys151 ist in weiß gehalten. In der unteren Abbildung ist die Stereoansicht eines 
hydrophoben Clusters bestehend aus 11 Resten und ein aktives Zentrum detailliert gezeigt (Liebl, persönl. Mitteilung).

\subsubsection{Molekulare Basis der Transferaktivität}

Bei den Resten, die an der Bildung der "subsite“ -1 der Maltosebindestelle beteiligt sind, sind fünf (Tyr158, Arg383 und die katalytisch wirkenden Asp385, Glu414 und Asp468) hochkonserviert in der $\alpha$-Amylase-Familie. Die ebenso konservierte dreidimensionale Anordnung (Abb. 31) dieser an der Katalyse beteiligten Aminosäuren legt nahe, daß die katalytischen Eigenschaften der MTase denen anderer Vertreter der $\alpha$-Amylase-Familie ähnelt. Es wird postuliert, daß Glu414 als eine katalytische Säure/Base und Asp385 als Nukleophil fungiert. Der dritte katalytische Rest Asp468 interagiert über Wasserstoffbrückenbindungen mit den O2- und O3-Hydroxyl-Gruppen der -1 Glucoseeinheit. Daher bietet sich funktionell eine Rolle bei der Substraterkennung an.
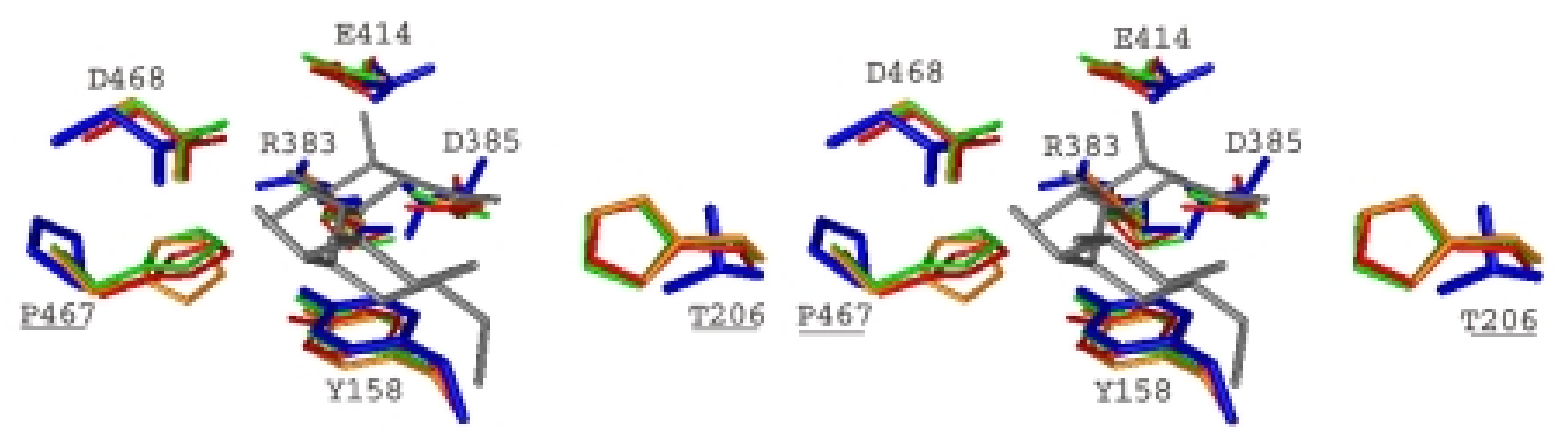

Abb. 31: Stereoansicht der Überlagerung konservierter Reste des aktiven Zentrums der TAKA-Amylase A (grün), Bacillus circulans CGTase (orange) und B. cereus Oligo-1,6Glucosidase (rot), sowie der entsprechenden Reste der MTase (blau). Das MTase MaltoseMolekül ist mit grauen Linien in den „subsites“ -2 (unten) und -1 (oben) eingezeichnet.

Der MTase fehlen zwei Histidine, die bei anderen Vertretern der Familie 13 hochkonserviert sind, dort beide Seiten der "subsite“ -1 (entsprechend His122/ His296 in der TAKA-Amylase; Thr206/Pro467 in der MTase) flankieren und zumindest bei der Barley-Amylase (Sögaard et al., 1993) den katalytischen Übergangszustand stabilisieren. Außerdem belegen Wasserstoffbrücken die Beteiligung an der Substratbindung. Legt man einen gemeinsamen katalytischen Mechanismus zugrunde, so scheint die Anwesenheit von Thr206 und Pro467 an den entsprechenden Positionen in der MTase eine mögliche Erklärung für die spezifische TransglycosylierungsAktivität des Enzyms zu liefern. 


\subsubsection{Einfluß potentieller metabolischer Regulatoren auf die Aktivität}

$\mathrm{Da}$ in der Kristallstruktur (Abb. 30) Phosphationen identifiziert werden konnten, wurde der Einfluß potentieller phosphathaltiger Regulatoren auf die MTase-Aktivität überprüft (Abb. 32). Dabei hatten aber weder die bereits von Meissner (1997) getesteten Substanzen wie Glucose-1-Phosphat, Glucose-6-Phosphat, Fructose-6Phosphat und Fructose-1,6-Bisphosphat noch ATP, ADP, cAMP, NADP und AcetylPhosphat oder die phosphatfreien Pyruvat und L-Glucose signifikanten Einfluß auf die Reaktionsstärke der MTase. Phosphoenolpyruvat interferierte mit dem Standard$\mathrm{I}_{2} / \mathrm{KI}$-Test und konnte (im Gegensatz zu Meissner, 1997) deshalb nicht bestimmt werden. Einzig Glucose-1,6-Diphosphat (10 mM) reduzierte die Aktivität auf 55-65\% (Abb. 32 und 33) signifikant. Um Interferenzen des Testes mit unerwarteten Spaltprodukten auszuschließen, wurde eine Dünnschichtchromatographie mit Glucose1,6-Diphosphat durchgeführt. Es konnte keine „Kontamination“ durch Glucose detektiert werden, die ansonsten die Inhibition der MTase erklären würde.

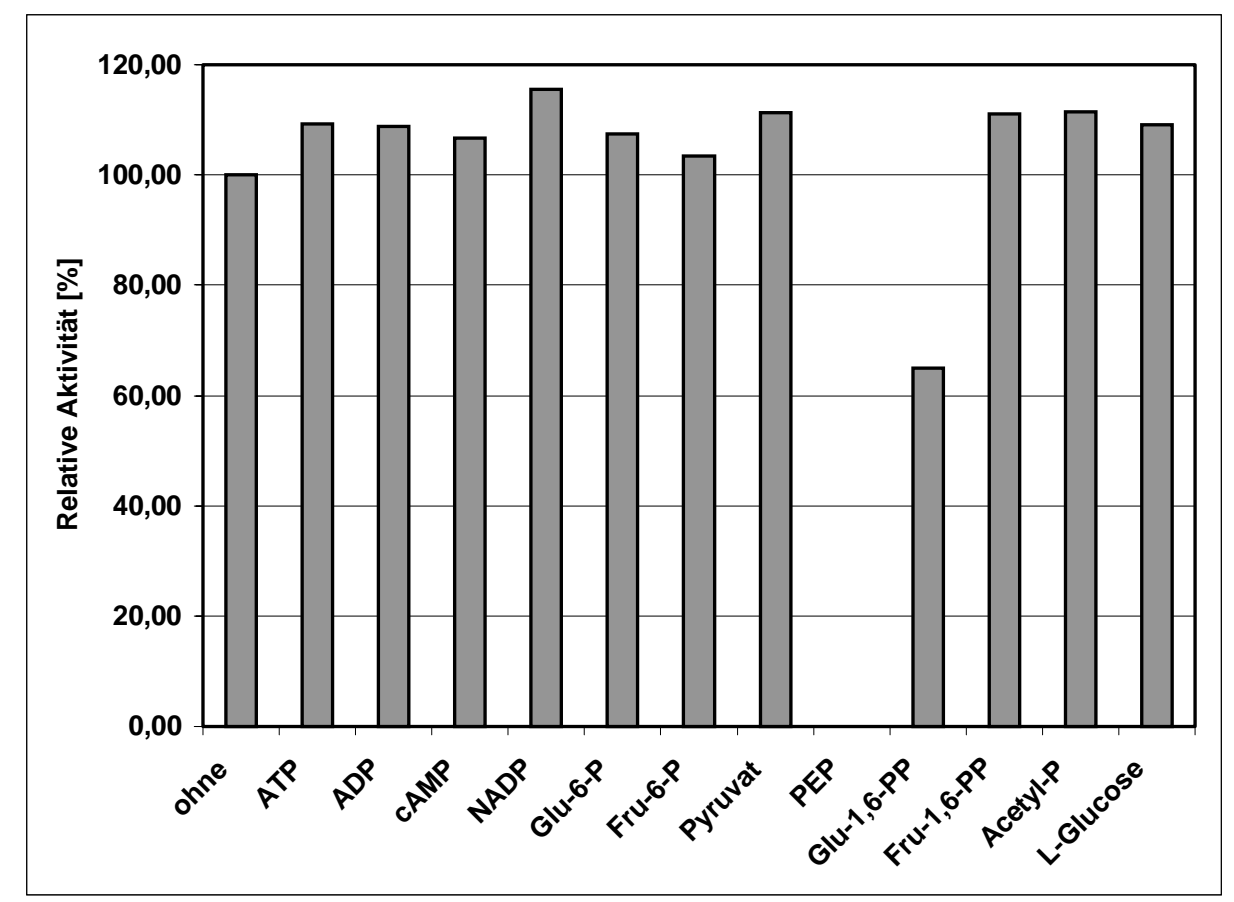

Abb. 32: Beeinflussung der enzymatischen Aktivität der MTase durch verschiedene (phosphathaltige) Substanzen 


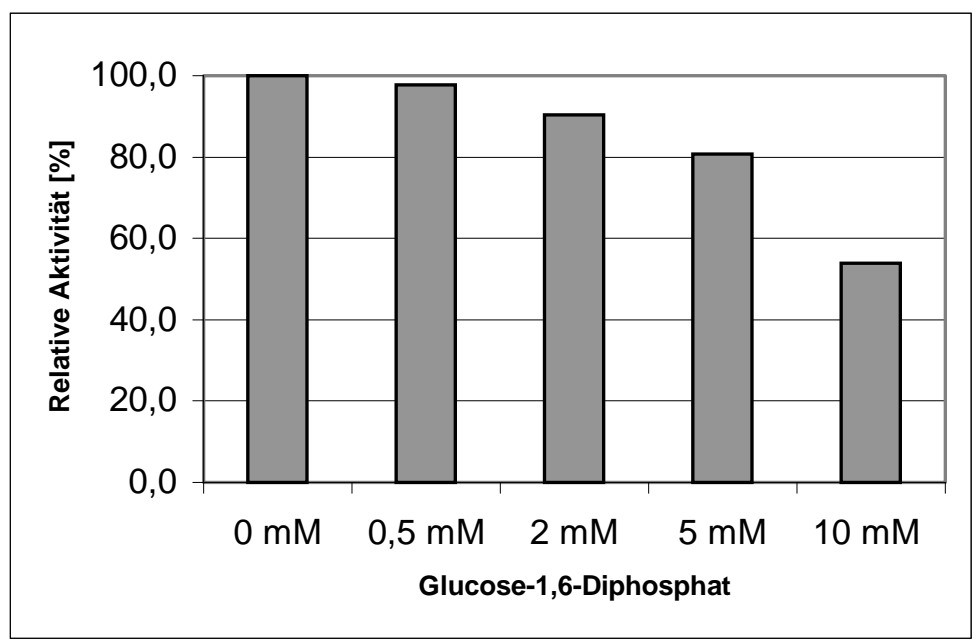

Abb. 33: Abhängigkeit der enzymatischen Aktivität der MTase von der Glucose-1,6Diphosphat-Konzentration

\subsection{Gezielte ortsspezifische Mutagenese von $m m t A$ und Austausch strukturell bedeutender Aminosäuren}

Für die folgenden Mutagenesen zum Aminosäureaustausch wurde der Quik Change $^{\mathrm{TM}}$ Site-Directed Mutagenesis Kit (Stratagene) verwendet (Prinzip: siehe Material und Methoden, Kap.: 2.7). Die Mutagenese-Effizienz ist dabei stark von der Größe des parentalen DNA-Plasmides abhängig. Aus diesem Grunde wurde die MTase zunächst aus dem 8,5 kB großen pTAA3-Plasmid subkloniert, wobei zur Einführung einer Ndel-Schnittstelle ein Basenaustausch $(G \rightarrow A)$ im Startcodon der Originalsequenz erforderlich war.

Tab. 12: Verwendete Primer für die PCR

\begin{tabular}{ccc}
\hline Bezeichnung & \multicolumn{1}{c}{ Primer-Sequenz $^{\text {a) }}\left(5^{\prime} \rightarrow 3^{\prime}\right)$} & Schnittstelle \\
\hline MTase a & GATCATATGCTTTTGAGAGAGATAAAC & Ndel \\
MTase b & GAAAGCTTCTTACTCCTGTACAACAAGAGC & Hindlll \\
\hline
\end{tabular}

a): Die eingefügte Schnittstelle ist jeweils unterstrichen, der Basenaustausch ist fett hervorgehoben. 
PCR-Ansatz:

\begin{tabular}{|lll|}
\hline MTase a $(100 \mathrm{pmol} / \mu \mathrm{l})$ & 1,25 & $\mu \mathrm{l}$ \\
MTase b $(100 \mathrm{pmol} / \mu \mathrm{l})$ & 1,25 & $\mu \mathrm{l}$ \\
pTAA3 & 4 & $\mu \mathrm{l}$ \\
dNTP-Lösung (je 10 mM) & 4 & $\mu \mathrm{l}$ \\
Pfu-Puffer (10x) & 5 & $\mu \mathrm{l}$ \\
DMSO & 5 & $\mu \mathrm{l}$ \\
$\mathrm{H}_{2} \mathrm{O}$ & 28,5 & $\mu \mathrm{l}$ \\
Pfu-Polymerase $(9 \mathrm{U} / \mu \mathrm{l})$ & 1 & $\mu \mathrm{l}$ \\
\hline
\end{tabular}

\section{PCR-Bedingungen:}

Erste Denaturierung: $\quad 94^{\circ} \mathrm{C}, 5 \mathrm{~min}$ 32 Zyklen:

1.) Denaturierung: $\quad 94^{\circ} \mathrm{C}, 45 \mathrm{~s}$

2.) Primer-Anlagerung: $38^{\circ} \mathrm{C}, \quad 45 \mathrm{~s}$

3.) Synthese: $\quad 72^{\circ} \mathrm{C}, 2 \mathrm{~min}$ Letzter Syntheseschritt: $72^{\circ} \mathrm{C}, 10 \mathrm{~min}$

Der PCR-Ansatz wurde bei den angegebenen Bedingungen inkubiert, das PCRProdukt aus dem Agarose-Gel extrahiert, mit EcoRV geschnittenem pBSK+-Vektor ligiert und in E. coli XL1-Blue transformiert. Nach Blau-Weiß-Screening wurde ein Klon mit korrekt inseriertem PCR-Fragment ausgewählt und dieses unter Verwendung der neu eingebauten Schnittstellen Ndel/Hindll in den Vektor pET21a kloniert. Das neue Konstrukt pET21a-mmtA (Abb. 34) wurde zur heterologen Expression in den Stamm E. coli BL21 (DE3) elektroporiert.

\subsubsection{Mutagenese der katalytisch aktiven Aminosäuren}

Zunächst sollte das aktive Zentrum ausgeschaltet werden, bei dem Glu414 als eine katalytische Säure/Base und Asp385 als Nukleophil fungiert. Deshalb wurden Glutamat durch Glutamin bzw. Aspartat durch Asparagin ersetzt. Ziel war es, Kristalle und deren Röntgenstruktur zu erhalten, bei denen ein höherkettiges Maltooligosaccharid-Substrat im aktiven Zentrum gebunden ist und was somit den Zustand des Enzyms vor der eigentlichen Substratspaltung repräsentiert.

Tab. 13: Verwendete Primer für die PCR

\begin{tabular}{clc}
\hline Bezeichnung & \multicolumn{1}{c}{ Primer-Sequenz $^{\mathrm{a})}\left(5^{\prime} \rightarrow 3^{`}\right)$} & Austausch \\
\hline Asp 385a & CGGTGCAAGACTCAATATGGGGCACGC & GAT $\rightarrow$ AAT \\
Asp 385b & GCGTGCCCCATATTGAGTCTTGCACCG & ATC $\rightarrow$ ATT \\
Glu 414a & GTGATGATCGCACAGGAGCTGGACATGG & GAG $\rightarrow$ CAG \\
Glu 414b & CCATGTCCAGCTCCTGTGCGATCATCAC & CTC $\rightarrow$ CTG \\
\hline
\end{tabular}

a): Die Basenaustausche sind jeweils fett hervorgehoben. 
Es wurden zwei PCR-Ansätze mit folgenden Primerkombinationen verwendet:
1) Asp 385a + Asp 385b
2) Glu $414 a+$ Glu $414 b$

Als parentales DNA-Plasmid diente das oben erwähnte $4,9 \mathrm{kB}$ große $\mathrm{pBSK}^{+}-m m t A$ Plasmid.

\section{PCR-Ansatz:}

\begin{tabular}{|c|c|}
\hline Primer $1(125 \mathrm{ng} / \mu \mathrm{l})$ & $1 \mu$ \\
\hline Primer $2(125 \mathrm{ng} / \mu \mathrm{l})$ & $1 \mu$ \\
\hline $\mathrm{pBSK}^{+}-m m t A$ & $2 \mu$ \\
\hline dNTP-Lösung & $1 \mu$ \\
\hline Reaktions-Puffer (10x) & $5 \mu$ \\
\hline $\mathrm{H}_{2} \mathrm{O}$ & $39 \mu$ \\
\hline Pfu-Turbo $(2,5 \mathrm{U} / \mu \mathrm{l})$ & $1 \mu$ \\
\hline
\end{tabular}

\section{PCR-Bedingungen:}

\begin{tabular}{|lllc|}
\hline $\begin{array}{l}\text { Erste Denaturierung: } \\
\text { 16 Zyklen: }\end{array}$ & $95^{\circ} \mathrm{C}, 30$ & $\mathrm{~s}$ \\
\hline 1.) Denaturierung: & $95^{\circ} \mathrm{C}, 30$ & $\mathrm{~s}$ \\
2.) Primer-Anlagerung: & $55^{\circ} \mathrm{C}, 1$ & $\mathrm{~min}$ \\
3.) Synthese: & $68^{\circ} \mathrm{C}, 12,5$ & $\mathrm{~min}$ \\
\hline
\end{tabular}

Der PCR-Ansatz wurde bei den angegebenen Bedingungen inkubiert und anschließend zum Verdau der parentalen dsDNA mit $1 \mu \mathrm{l} D p n \mathrm{l}(10 \mathrm{U} / \mu \mathrm{l})$ bei $37^{\circ} \mathrm{C}$ für eine Stunde versetzt. Es folgte die Transformation in E.coli XL1-Blue. Unter Verwendung der Schnittstellen Ndel+Hindlll wurde dann in den Vektor pET21a umkloniert (Abb. 34). Die neuen Konstrukte pET21a-D385N und pET21a-E414Q wurden zur heterologen Expression in den Stamm E. coli BL21 (DE3) elektroporiert. Zur Kontrolle (auf Grund der zu erwarteten Inaktivierung gab es keine andere Selektionsmöglichkeit der Klone) wurden die neuen Konstrukte durch Sequenzierung überprüft und die Korrektheit der Mutagenese bestätigt.

Bei der Reinigung und der Kristallisation wurde wie bei der MTase (3.4.1) verfahren. Allerdings zeigten sich bei der Aktivitätskontrolle im Standard- $\mathrm{I}_{2} / \mathrm{KI}-\mathrm{Test}$ bereits geringe Restaktivitäten $(<0,3 \%$, Tab. 18), die auch mittels einer dünnschichtchromatischen Analyse (Substratverdau über Nacht) visuell sichtbar gemacht werden konnten (Abb. 41). Leider bestätigte sich dieses Ergebnis auch durch die Röntgenstrukturanalyse (Liebl, persönl. Mitteilung). Die verbliebene Restaktivität bei den „active site"-Mutanten (=Austausch der katalytisch aktiven Aminosäuren) reichte aus, um mindestens eine Donorsubstrat-Spaltung während des Kristallisationsvorganges stattfinden zu lassen, so daß im aktiven Zentrum wiederum nur der Zustand nach der Substratspaltung mit eingelagertem Maltosylrest vorlag.

Abb. 34 (folgende Seite): Konstruktion von pET21a-mmtA und schematische Darstellung der ortsspezifischen Mutagenese am Beispiel von pET21a-D385N 
Amplifizierung des Gens $m m t A$ aus dem Plasmid pTAA3 $(\approx 8,5 \mathrm{kB}$; Meissner, 1997) durch PCR

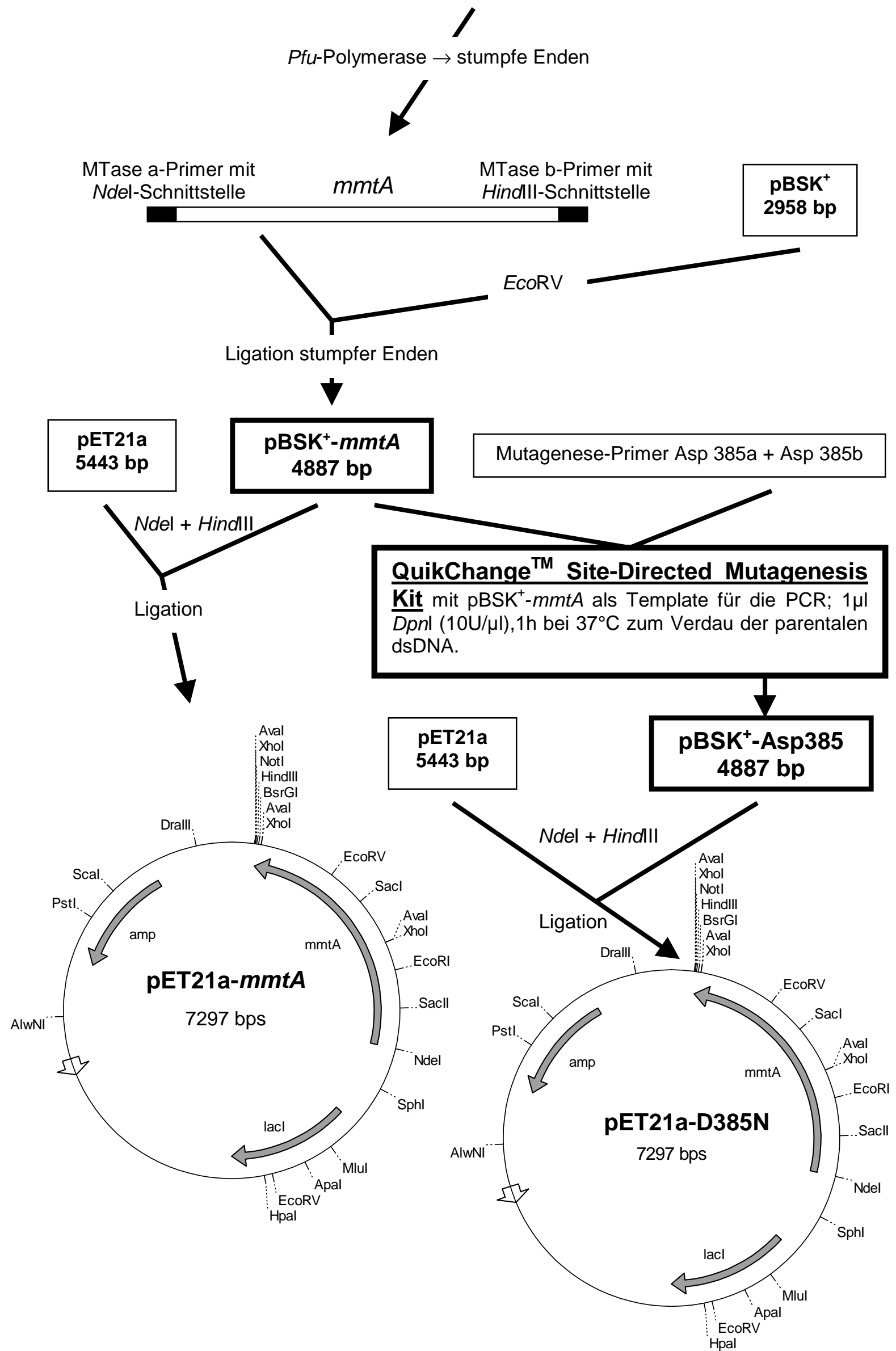




\subsubsection{Versuche zur Modifizierung der Transfereigenschaften und zur Erhöhung der hydrolytischen Aktivität der MTase}

Um die Ausführungen zu den möglichen Funktionen einiger strukturell wichtiger Aminosäuren $(3.4 .4,3.4 .5)$ experimentell zu belegen, wurden weitere Aminosäuren ausgetauscht. In Tab. 14 sind die betroffenen Aminosäuren und die möglichen Auswirkungen auf die Funktion zusammengefasst.

Tab. 14: Gezielte Aminosäureaustausche bei der MTase und potentielle Auswirkungen auf die Funktion

\begin{tabular}{lll}
\hline Aminosäure & Austausch gegen & \multicolumn{1}{c}{ möglicher veränderter Phänotyp } \\
\hline Lysin (K) 151 & Alanin (A) & Aktivität; Transferspezifität; Dimerisierung? \\
Threonin (T) 206 & Histidin (H) & gesteigerte Aktivität? \\
Threonin (T) 466 & Asparagin (N) & Transfer $\rightarrow$ Hydrolyse (siehe Diskussion!) \\
Prolin (P) 467 & Histidin (H) & gesteigerte Aktivität? \\
Aspartat (D) 317 & Alanin (A) & Aktivität; Transferspezifität? \\
\hline
\end{tabular}

Tab. 15: Verwendete Primer für die PCR

\begin{tabular}{lll}
\hline Bezeichnung & \multicolumn{1}{c}{ Primer-Sequenz $^{\text {a) }}\left(5^{`} \rightarrow 3^{`}\right)$} & Austausch \\
\hline Lys 151a & GATCTCTTCAAGGCGGGAGACGCTCCTTC & AAG $\rightarrow$ GCG \\
Lys 151b & GAAGGAGCGTCTCCCGCCTTGAAGAGATC & CTT $\rightarrow$ CGC \\
Thr 206a & GATTTCATTCCGAGACACGCCGCCAGAGACTC & ACG $\rightarrow$ CAC \\
Thr 206b & GAGTCTCTGGCGGCGTGTCTCGGAATGAAATC & CGT $\rightarrow$ GTG \\
Thr 466a & GCCTCCGTTGAAACCCCGACACACCG & ACT $\rightarrow$ AAC \\
Thr 466b & CGGTGTGTCGGGGTTTCAACGGAGGC & AGT $\rightarrow$ GTT \\
Pro 467a & CTCCGTTGAAACTCACGACACACCGCG & CCC $\rightarrow$ CAC \\
Pro 467b & CGCGGTGTGTCGTGAGTTTCAACGGAG & GGG $\rightarrow$ GTG \\
D317Aa & CCCACGTGGGACGCTGTCACGTTCTTG & GAT $\rightarrow$ GCT \\
D317Ab & CAAGAACGTGACAGCGTCCCACGTGGG & ATC $\rightarrow$ AGC
\end{tabular}

a): Die Basenaustausche sind jeweils fett hervorgehoben.

Es wurden fünf PCR-Ansätze mit folgenden Primerkombinationen verwendet:
1) Lys $151 a$ + Lys $151 b$
2) Thr 206a + Thr 206b
3) Thr $466 a+\operatorname{Thr} 466 b$
4) Pro $467 a+$ Pro 467b
5) $\mathrm{D} 317 \mathrm{Aa}+\mathrm{D} 317 \mathrm{Ab}$ 
Die PCR-Bedingungen, weitere Klonierungsschritte, Sequenzkontrolle und die Aufreinigung der MTase-Mutanten erfolgte analog der Mutagenese der katalytisch aktiven Aminosäuren (3.5.1).

Zur Konstruktion der Doppelmutante pET21a-T206H/P467H wurde wie folgt vorgegangen: Die bei einem Zwischenschritt der Mutagenese erhaltenen Plasmide $\mathrm{pBSK}^{+}-\mathrm{T} 206 \mathrm{H}$ und $\mathrm{pBSK}^{+}-\mathrm{P} 467 \mathrm{H}$ wurden jeweils Ndel+EcoRV verdaut, die entsprechenden DNA-Fragmente aus einem Agarose-Gel isoliert, religiert und in E. coli XI1-Blue transformiert. Danach folgte die Umklonierung in pET21 a (Ndel+HindllI) und die Elektroporation in E. coli BL21 (DE3). Die Doppelmutante pET21 a-K151A/ D317A ließ sich folgendermaßen klonieren: Die Plasmide pET21a-K151A und pET21a-D317A wurden EcoRI+Hindll verdaut, die entsprechenden DNA-Fragmente aus einem Agarose-Gel isoliert, religiert und in E. coli BL21 (DE3) elektroporiert.

Abb. 35 zeigt den Aufreinigungserfolg (Reinigungsprozedur analog wie bei der MTase) der neuen MTase-Mutanten und die Bestätigung durch Western-BlotAnalyse mit in dieser Arbeit erzeugten Anti-MTase-Antikörpern (Kaninchen-Serum).

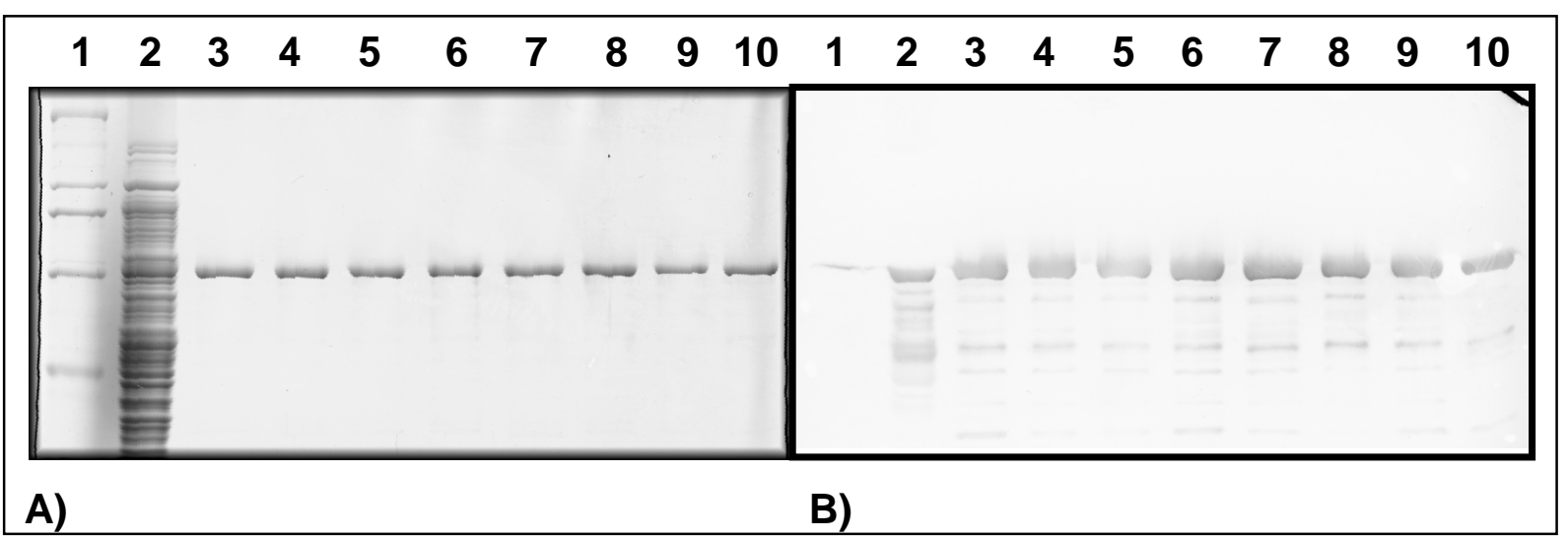

Abb. 35: Gereinigte MTase-Mutanten und Überprüfung durch Western-Blot-Analyse

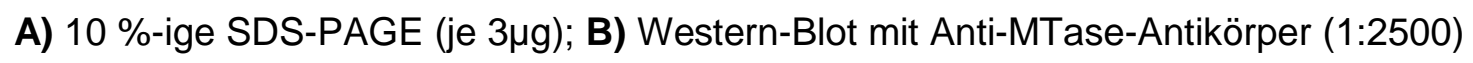

Spur 1: Molekularmassenstandard (205, 116, 97, 66, $45 \mathrm{kDa})$

Spur 2: pET21 a-mmtA-Rohextrakt

Spur 3: pET21 a- $m m t A$, gereinigt

Spur 4: pET21 a-K151A, gereinigt

Spur 5: pET21 a-T206H, gereinigt

Spur 6: pET21 a-D385N, gereinigt
Spur 7: pET21 a-E414Q, gereinigt Spur 8: pET21 a-T466N, gereinigt Spur 9: pET21 a-P467H, gereinigt Spur 10: pET21 a-T206H/P467H, gereinigt 


\begin{tabular}{|lrl|}
\hline \multicolumn{2}{l}{$\begin{array}{l}\text { Reaktionsparameter } \\
\text { Ansatz: }\end{array}$} & Dünnschichtparameter \\
$0,5 \mathrm{M}$ Tris-Cl pH7 ${ }^{\left(75^{\circ} \mathrm{C}\right)}$ & $4 \mu \mathrm{l}$ & Entsalzung der Proben: ja \\
Maltooligosaccharid $1 \%$ & $10 \mu \mathrm{l}$ & Auftragung Standard: $2 \mu \mathrm{l}(14 \mu \mathrm{g})$ \\
$\mathrm{H}_{2} \mathrm{O}$ & $23,6 \mu \mathrm{l}$ & Auftragung Proben: $4,5 \mu \mathrm{l}(11 \mu \mathrm{g})$ \\
Enzym & $1,4 \mu \mathrm{g}$ & Laufmittel:1-Propanol/Ethylacetat $/ \mathrm{H}_{2} \mathrm{O}$ \\
Inkubation: $\quad 40 \mathrm{~min}$ bei $75^{\circ} \mathrm{C}$ & Entwicklung: $2 \times 4,5 \mathrm{~h}$ \\
\hline
\end{tabular}

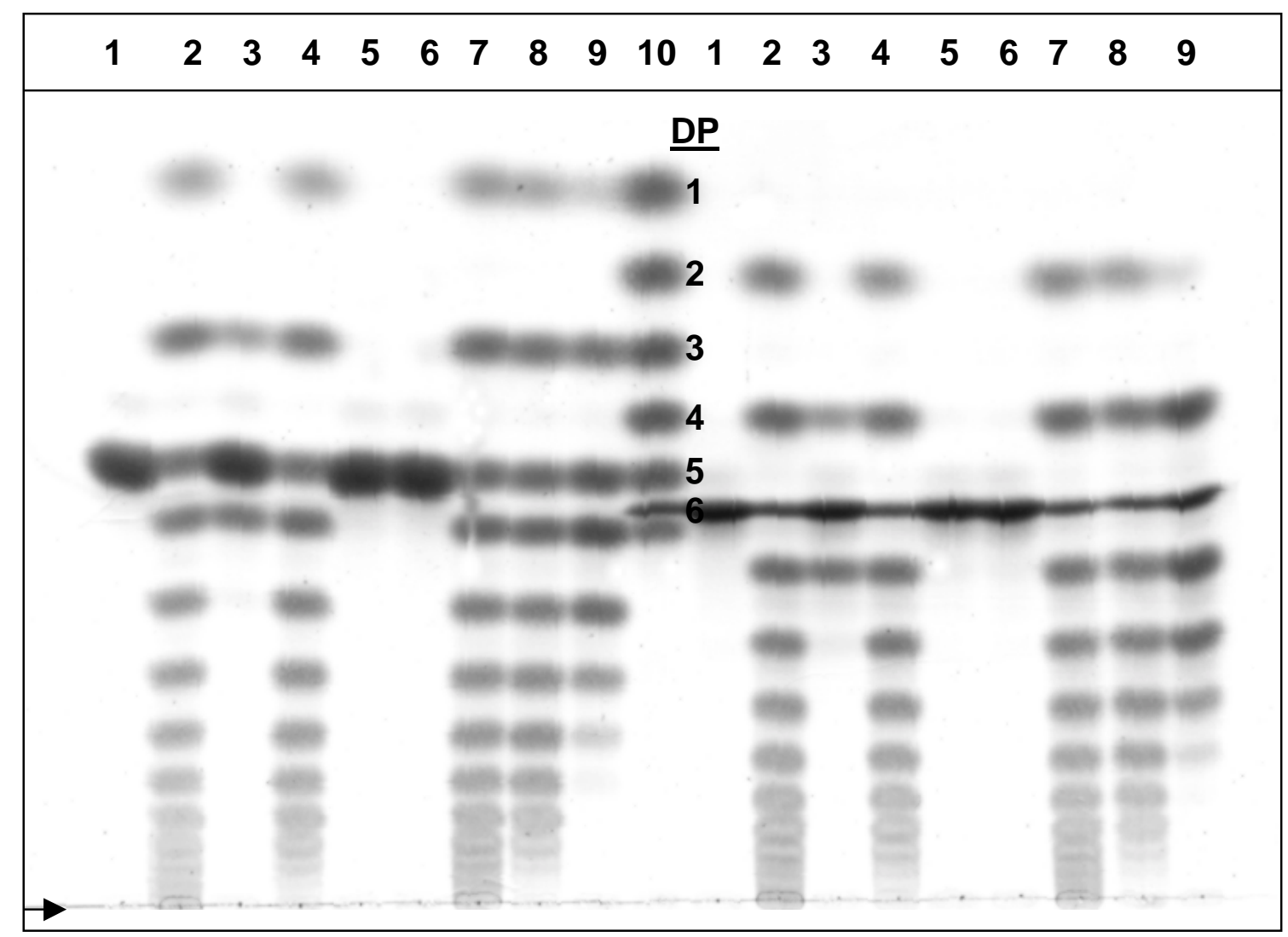

Abb. 36: Dünnschichtchromatographische (DC-) Analyse der Reaktionsprodukte von Maltopentaose und Maltohexaose nach Inkubation $\left(75^{\circ} \mathrm{C}, 40 \mathrm{~min}\right)$ mit MTase/MTase-Mutanten. (Der Pfeil markiert die Auftragslinie; DP = Polymerisationsgrad)

Spur 1: Pentaose bzw. Hexaose - Enzym

Spur 6: Pentaose bzw. Hexaose + E414Q

Spur 2: Pentaose bzw. Hexaose + MTase Spur 7: Pentaose bzw. Hexaose + T466N

Spur 3: Pentaose bzw. Hexaose + K151A Spur 8: Pentaose bzw. Hexaose + P467H

Spur 4: Pentaose bzw. Hexaose + T206H Spur 9: Pentaose bzw. Hexaose + T206H/P467H

Spur 5: Pentaose bzw. Hexaose + D385N Spur 10: Standard G1-G7

Das Produktmuster zeigt, daß die Transferspezifität in keinem Fall verändert worden war. Je nach Substrat wurden Produktspektren mit ausschließlich geradzahligen oder ausschließlich ungeradzahligen Polymerisationsgrad erhalten. Dies trifft auch für 
D317A und für die Doppelmutante K151A/D317A zu (vgl. auch Abb. 41). Bei der hier relativ kurzen Inkubationszeit zeigt sich bei den „active site“-Mutanten keine Produktbildung. Die Verringerung der enzymatischen Aktivität einiger Mutanten, spiegelt sich bei dieser DC-Analyse durch „unvollständige“ Produktbildung wieder (siehe K151A; T206H/P467H). Setzt man mehr Enzym in den Test ein, bzw. verlängert die Inkubationszeiten, so zeigt sich auch bei diesen Mutanten das vollständige Produktmuster (nicht dargestellt). Für die im $\mathrm{I}_{2} / \mathrm{KI}$-Test bzw. DNSA-Test gemessenen enzymatischen Aktivitäten sei auf das Kapitel „Transfer- und HydrolyseAktivitäten der MTase-Mutanten im Vergleich“ (3.5.6) verwiesen. Im folgenden wurde nun der Oligomerisierungsgrad einiger MTase-Mutanten untersucht.

\subsubsection{Die Mutante V110R}

Zunächst wurden die Mutanten V110R und A230R nach dem bewährten Protokoll konstruiert. Hierbei wurde also jeweils eine hydrophobe gegen eine hydrophile Aminosäure ersetzt. Für die Doppelmutante V110R/A230R wurde analog zur Doppelmutante K151A/D317A verfahren, d. h. pET21a-V110R und pET21a-A230R wurden jeweils mit $E c o R I+H i n d l l l$ verdaut, die entsprechenden DNA-Fragmente aus einem Agarose-Gel isoliert, religiert und in E. coli BL21 (DE3) elektroporiert. Auch diese neuen Konstrukte wurden exprimiert und aufgereinigt (nicht gezeigt). Bei dem Schritt der hydrophoben Interaktionschromatographie (Phenyl-Sepharose-Säule) fiel dabei auf, daß die Proteine nicht gleichzeitig, sondern zu unterschiedlichen Elutionszeiten (absteigender Salzgradient) eluierten. Die MTase eluierte bei einer höheren Salzkonzentration als V110R und A230R. Die Doppelmutante V110R/ A230R eluierte im Vergleich dazu bei der geringsten Salzkonzentration. Dies wurde als erster Hinweis auf Unterschiede in der Oberfächenhydrophobizität der einzelnen Proteine gewertet.

Tab. 16: Verwendete Primer für die PCR

\begin{tabular}{ccc}
\hline Bezeichnung & \multicolumn{1}{c}{ Primer-Sequenz $^{\text {a) }}\left(5^{`} \rightarrow 3^{`}\right)$} & Austausch \\
\hline V110Ra & GAAGAGAACGACCGTCTTGGTTTCAGA & GTT $\rightarrow$ CGT \\
V110Rb & TCTGAAACCAAGACGGTCGTTCTCTTC & AAC $\rightarrow$ ACG \\
A230Ra & GTGGAGGAACTCCGTGATTACACTCC & GCG $\rightarrow$ CGT \\
A230Rb & GGAGTGTAATCACGGAGTTCCTCCAC & CGC $\rightarrow$ ACG
\end{tabular}

a): Die Basenaustausche sind jeweils fett hervorgehoben. 


\subsubsection{Nachweis der Monomerisierung durch Gelfiltration und Nativ-PAGE}

Die Nativ-Molekularmasse einiger MTase-Mutanten wurde mittels analytischer Gelfiltration (50 mM Tris-Cl pH 7, $150 \mathrm{mM} \mathrm{NaCl}$ ) bestimmt. Die Ergebnisse und der jeweils abgeleitete Oligomerisierungsgrad sind in Tab. 17 zusammengefasst.

Tab. 17: Molekularmasse und Oligomerisierungsgrad verschiedener Mutanten

\begin{tabular}{ccc}
\hline Enzym & Molekularmasse $(\mathrm{kDa})$ & Oligomerisierungsgrad \\
\hline MTase & $139 \pm 10$ & Dimer \\
K151A & $139 \pm 10$ & Dimer \\
K151A/D317A & $139 \pm 10$ & Dimer \\
V110R & $65 \pm 5$ & Monomer \\
A230R & $139 \pm 10$ & Dimer \\
V110R/A230R & $65 \pm 5$ & Monomer \\
\hline
\end{tabular}

Eine weitere Bestätigung der Monomerisierung von V110R und der Doppelmutante V110R/A230R wurde durch eine Nativ-PAGE (Abb. 37) erhalten. Nimmt man die MTase als dimeren Standard, so zeigen V110R und V110R/A230R ein im Vergleich schnelleres Laufverhalten.

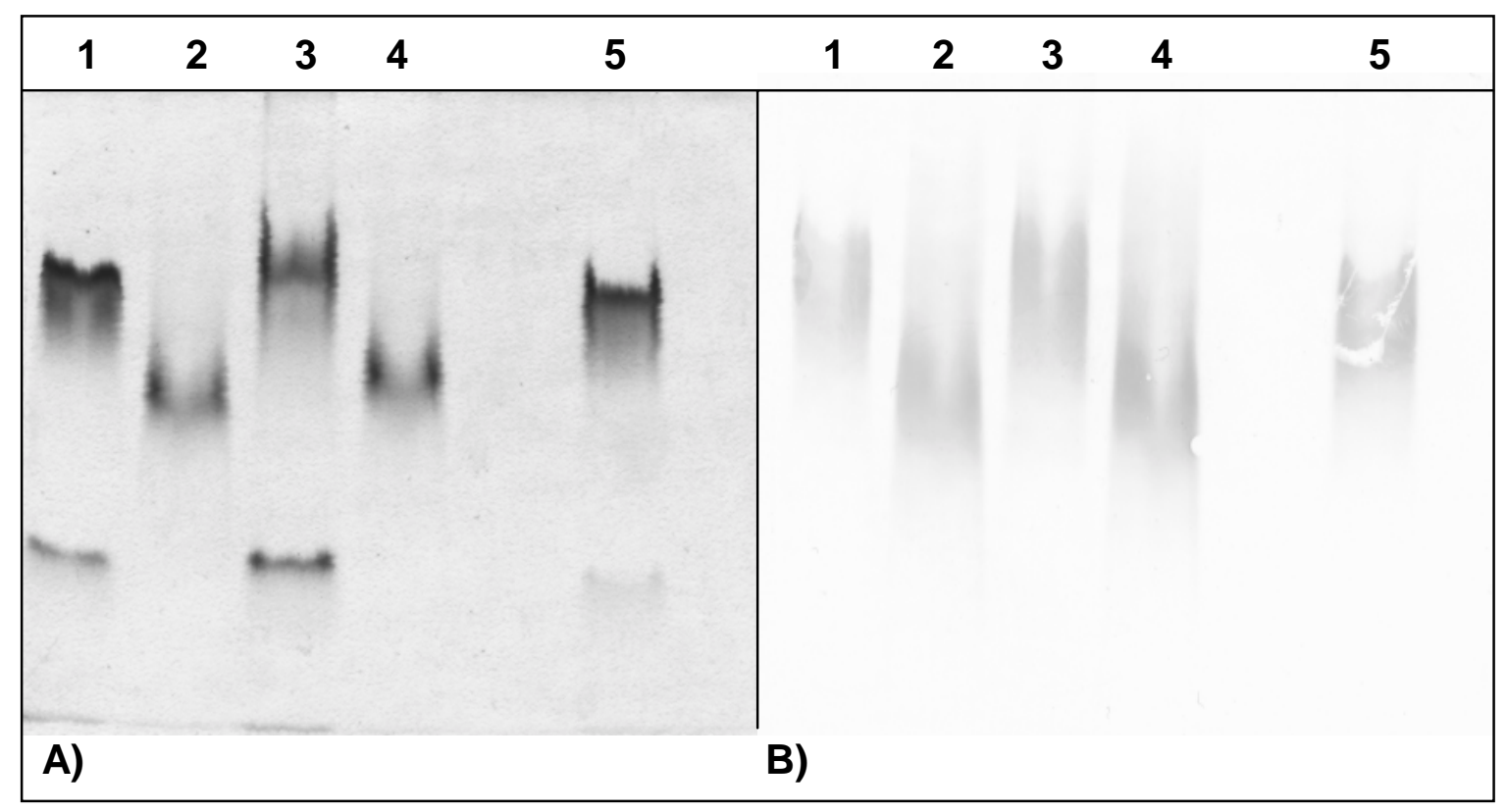

Abb. 37: Native Gelelektrophorese und Kontrolle durch Western-Blot-Analyse A) 7,5\%-ige Nativ-PAGE (je 2 $\mu$ g); B) Western-Blot mit Anti-MTase-Antikörper (1:2500) 
Da die Mutante A230R einen dimeren Charakter aufweist, kann man davon ausgehen, daß die Monomerisierung der Doppelmutante V110R/A230R von der V110R-Mutation verursacht wird.

\subsubsection{Temperaturabhängigkeit der Aktivität und thermische Inaktivierung}

Die Oligomerisierung von monomer aktiven Proteinen wird als eine der Möglichkeiten zur thermischen Stabilisierung von Proteinen diskutiert. Zur Untersuchung des Abhängigkeitsverhältnisses der Oligomerisierung zur Thermostabilität, wurde die Mutante V110R im Hinblick auf die Temperaturabhängigkeit der Aktivität analysiert und Experimente zur thermischen Inaktivierung durchgeführt.

\section{Reaktionsparameter:}

Ansatz: Maltooligosaccharid-Mix 2\% $100 \mu \mathrm{l}$

$$
\begin{array}{lr}
\text { Mcllvaine pH 6,5 } & 50 \mu \mathrm{l} \\
\mathrm{H}_{2} \mathrm{O}_{\text {bidest. }} & 42,4 \mu \mathrm{l} \\
\text { V110R }(0,79 \mu \mathrm{g} / \mu \mathrm{l}) & 7,6 \mu \mathrm{l}
\end{array}
$$

Inkubation: 10 min bei der jeweiligen Temperatur

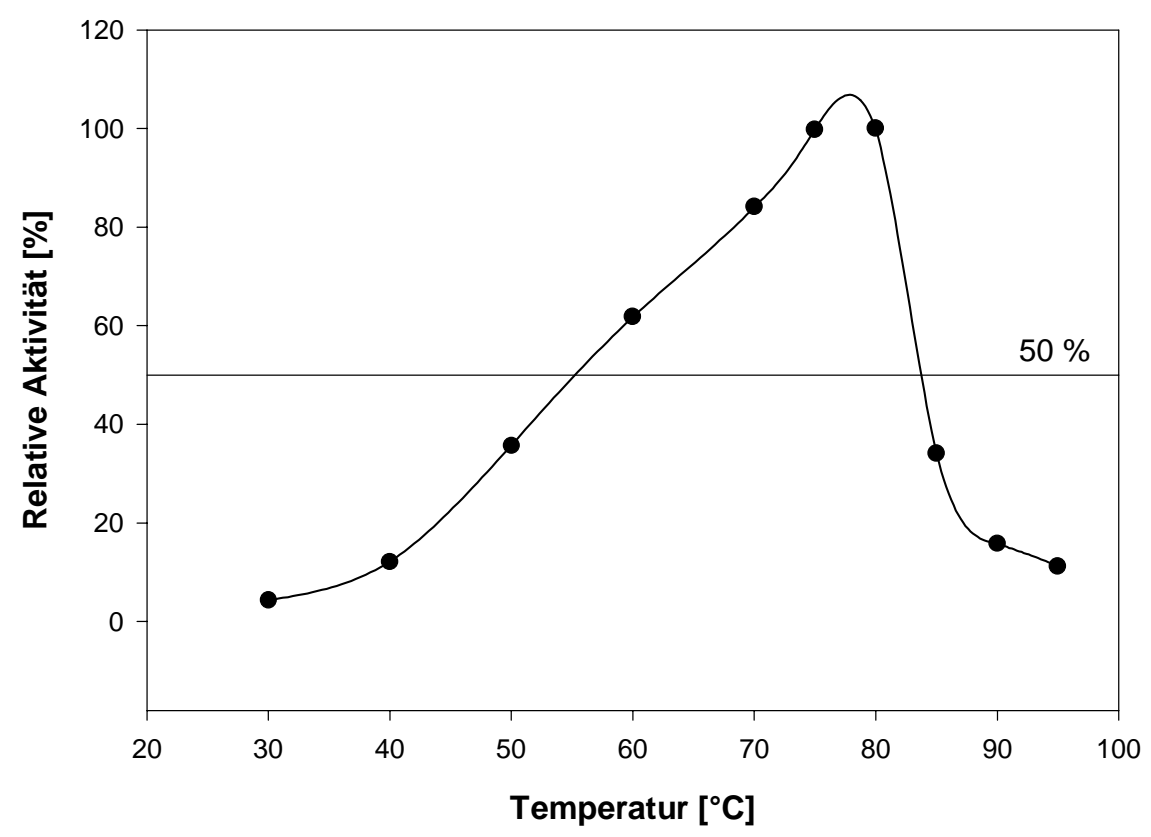

Abb. 38: Abhängigkeit der enzymatischen Aktivität von V110R von der Inkubationstemperatur. Dargestellt ist die relative Aktivität bezogen auf den höchsten Meßwert der Versuchsreihe. 
Die gemessene Reaktionsstärke ist bei einer Temperatur von $75-80^{\circ} \mathrm{C}$ am höchsten und fällt oberhalb dieser Werte schnell ab; 50 \% oder mehr relative Aktivität werden in dem Bereich von $55-83^{\circ} \mathrm{C}$ entfaltet (Abb. 38). Damit liegen die Werte für V110R um $10^{\circ} \mathrm{C}$ niedriger, als für die MTase bestimmt worden war (Meissner, 1997).

Die thermische Inaktivierung von V110R und von der MTase (Kontrolle) wurde in Abhängigkeit von Temperatur und Dauer der Exposition verfolgt (Abb. 39). Da sich der Temperaturbereich, in dem sich die Thermoinaktivierung für V110R abspielte, als sehr eng erwies, wurde die Präinkubation im PCR-Heizblock durchgeführt, der eine größere Temperaturgenauigkeit bietet.

\begin{tabular}{|lrlr|}
\hline Versuchsparameter: & \multicolumn{3}{l}{} \\
Präinkubationsansatz: & & Reaktionsansatz: \\
MTase $(1,17 \mu \mathrm{g} / \mu \mathrm{l}) /$ & & Maltooligosaccharid-Mix $2 \%$ & $100 \mu \mathrm{l}$ \\
$\mathrm{V} 110 \mathrm{R}(0,81 \mu \mathrm{g} / \mu \mathrm{l})$ & $6,8 \mu \mathrm{g}$ & Mcllvaine $\mathrm{pH} 6,5^{\left(75^{\circ} \mathrm{C}\right)}$ & $50 \mu \mathrm{l}$ \\
$\mathrm{Mcllvaine} \mathrm{pH} 6,5$ & $4 \mu \mathrm{l}$ & $\mathrm{H}_{2} \mathrm{O}_{\text {bidest. }}$ & $45 \mu \mathrm{l}$ \\
$\mathrm{H}_{2} \mathrm{O}_{\text {bidest. }}$ & ad $20 \mu \mathrm{l}$ & Präinkubationsansatz & $5 \mu \mathrm{l}$ \\
& & Inkubation: 15 min bei $75^{\circ} \mathrm{C}$ \\
\hline
\end{tabular}

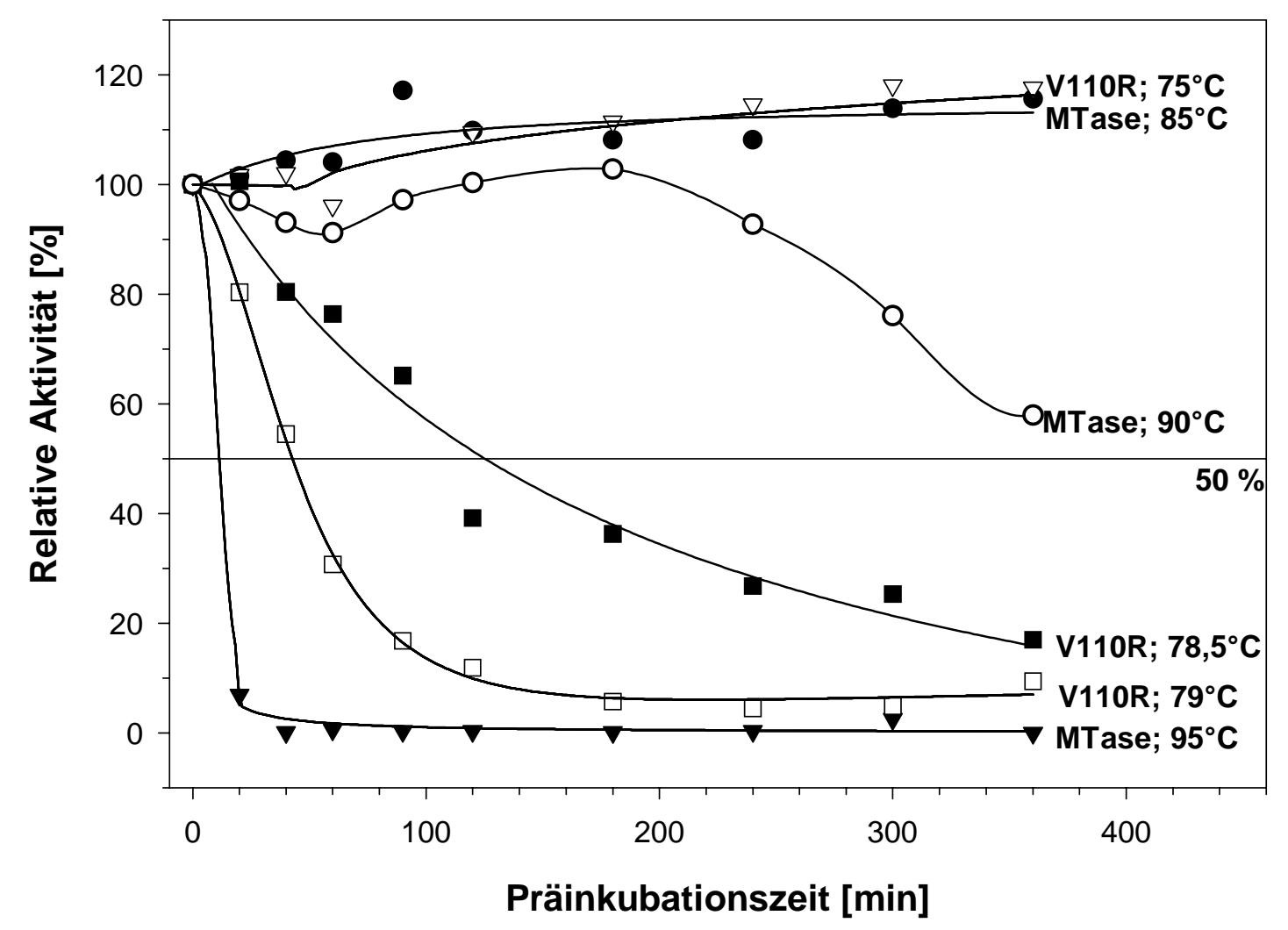

Abb. 39: Verlauf der thermischen Inaktivierung der MTase und V110R in Abhängigkeit von Temperatur und Inkubationszeit. 
Es ist deutlich eine Abnahme der thermischen Stabilität der Monomer-Mutante gegenüber der dimeren MTase festzustellen. Im dargestellten Inkubationszeitraum sind MTase und V110R bei $85^{\circ} \mathrm{C}$ bzw. $75^{\circ} \mathrm{C}$ stabil. V110R wurde bereits bei nur $79^{\circ} \mathrm{C}$ mit einer Halbwertszeit von etwa 40 min relativ rasch inaktiviert. Die Dimerisierung der Maltosyltransferase scheint somit ein ganz entscheidender Faktor bei der thermischen Stabilität des Enzyms darzustellen.

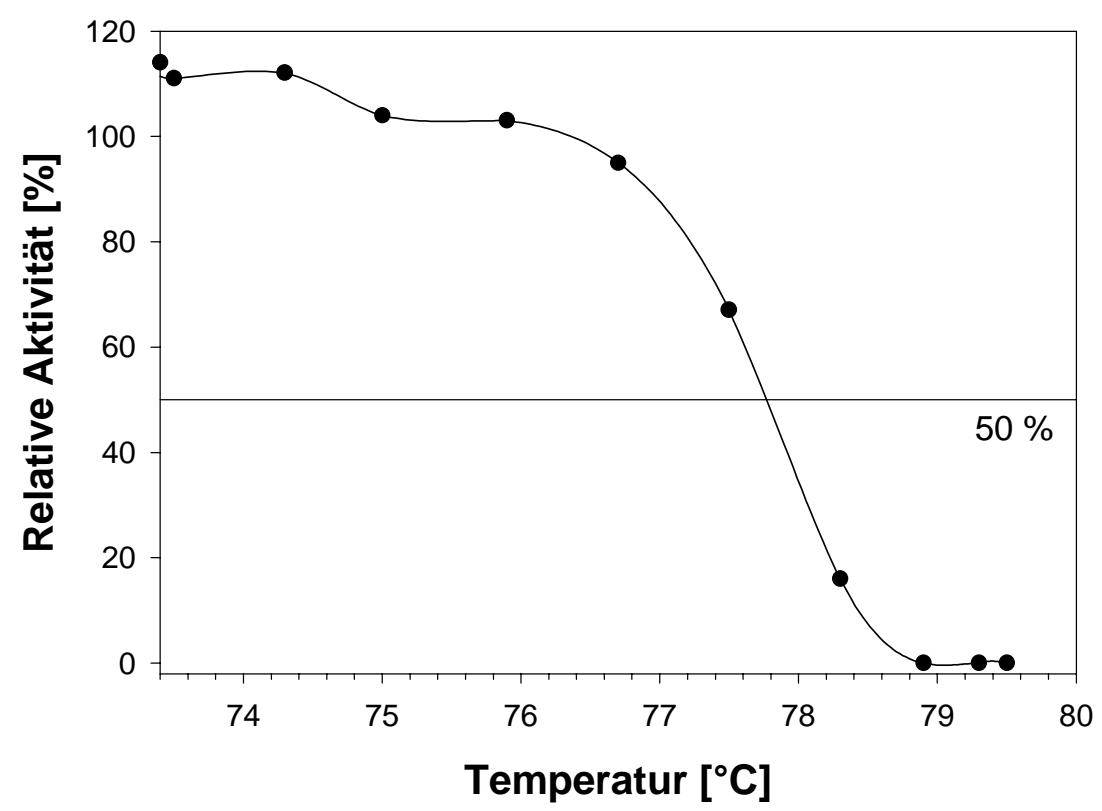

Abb. 40: Verlauf der thermischen Inaktivierung von V110R in Abhängigkeit von der Temperatur (Präinkubationszeit: 2 h; Inkubator: Gradienten-PCR)

Zur Bestätigung der oben gemachten Aussagen wurde die Thermoinaktivierung für V110R für die Präinkubationszeit von $2 \mathrm{~h}$ in einem Gradienten-PCR-Heizblock wiederholt (Abb. 40). Bei diesem Heizblock konnte der Temperaturbereich, in dem die Thermoinaktivierung erfolgte, auf $2^{\circ} \mathrm{C}\left(76,6-78,6^{\circ} \mathrm{C}\right)$ eingegrenzt werden.

\subsubsection{Transfer- und Hydrolyse-Aktivitäten der MTase-Mutanten im Vergleich}

Bei ersten Versuchen mit Maltooligosacchariden als Substrate fiel bei den Produktspektren der dünnschichtchromatographischen Analyse mit V110R und V110R/A230R auf, daß bei ungeradzahligem Substrat stets auch geradzahlige (neben ungeradzahligen) Produkte erhalten wurden. Das geradzahlige Substrat lieferte hingegen nur geradzahlige Produkte. Aus dieser Beobachtung konnte geschlossen werden, daß neben der Maltosyl-Transferaktivität die hydrolytische 
Aktivität eine gesteigerte Rolle spielen mußte. Das Substrat muß aus mindestens drei Glucoseeinheiten bestehen ( $\geq$ Maltotriose), damit es umgesetzt wird.

Abb. 41 zeigt die enzymatische Umsetzung von Maltoheptaose mit allen konstruierten MTase-Mutanten. Auf Grund der langen Inkubationszeit $\left(14 \mathrm{~h}, 75^{\circ} \mathrm{C}\right)$, sind neben den Transfer- auch die Hydrolyse-Produkte bei einigen Mutanten teilweise sichtbar. Auch die Stärke der enzymatische Aktivität der Mutanten spiegelt sich in der Dünnschicht-Chromatographie (DC) wieder. Je niedriger die Aktivität, desto weniger Produktspots sind zu erkennen (siehe z. B. „active-site“-Mutanten). Bei der Inkubation der MTase-Mutanten mit Maltohexaose als Substrat traten nur ausschließlich geradzahlige Produkte in der DC-Analyse auf (nicht gezeigt).

\begin{tabular}{|lrl|}
\hline \multicolumn{2}{l}{ Reaktionsparameter } & Dünnschichtparameter \\
Ansatz: & \\
$0,5 \mathrm{M}$ Tris-Cl pH7 ${ }^{\left(75^{\circ} \mathrm{C}\right)}$ & $4 \mu \mathrm{l}$ & Entsalzung der Proben: ja \\
Maltooligosaccharid $1 \%$ & $10 \mu \mathrm{l}$ & Auftragung Standard: $2 \mu \mathrm{l}(14 \mu \mathrm{g})$ \\
$\mathrm{H}_{2} \mathrm{O}$ & $26-\mathrm{X} \mathrm{\mu l}$ & Auftragung Proben: $6 \mu \mathrm{l}(15 \mu \mathrm{g})$ \\
Enzym & $1,5 \mu \mathrm{g}$ & Laufmittel:1-Propanol/Ethylacetat/ $/ \mathrm{H}_{2} \mathrm{O}$ \\
Inkubation: & $14 \mathrm{~h}$ bei $75^{\circ} \mathrm{C}$ & Entwicklung: $2 \times 4,5 \mathrm{~h}$ \\
\hline
\end{tabular}

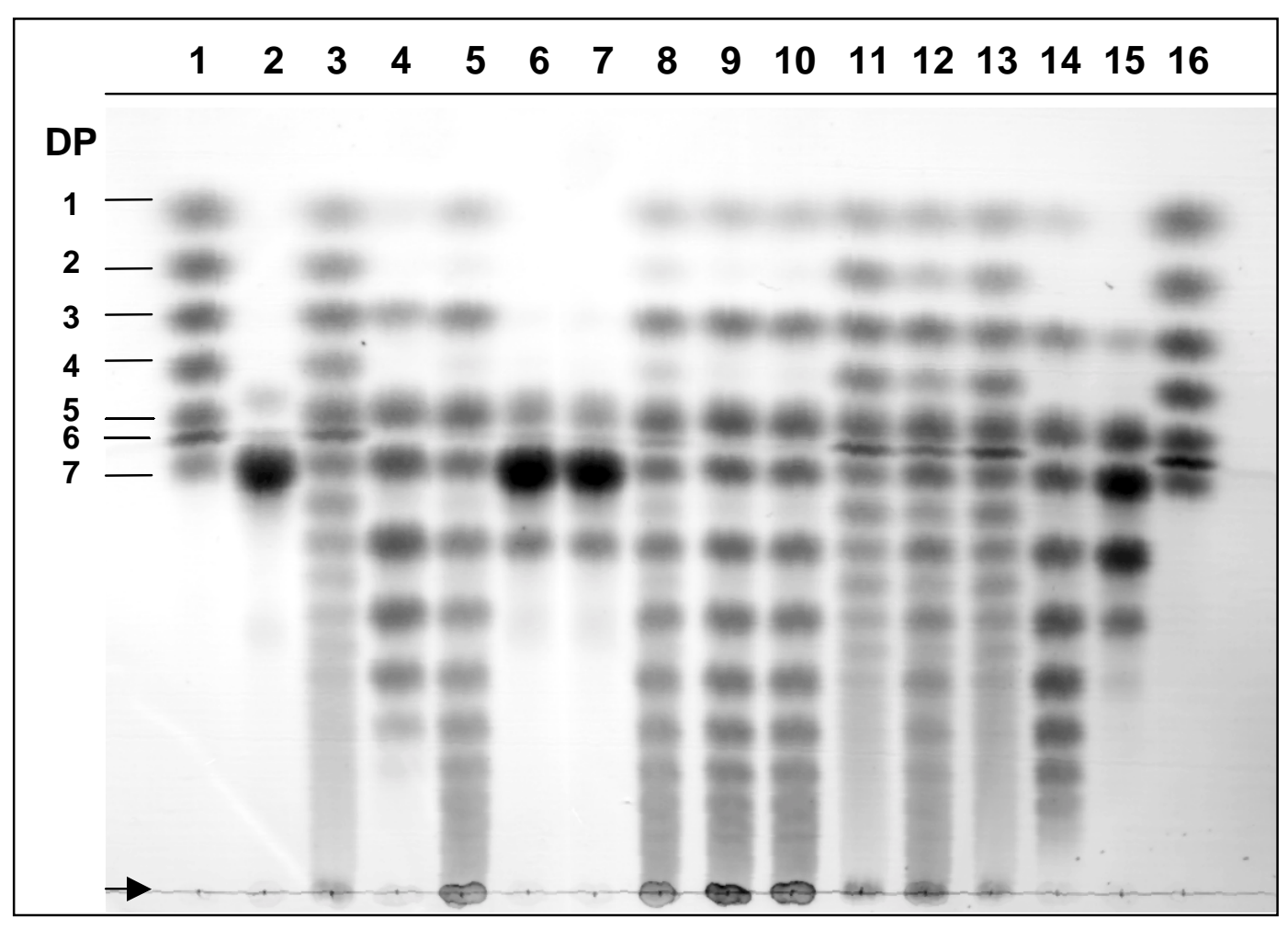

Abb. 41: Dünnschichtchromatographische Analyse der Reaktionsprodukte von Maltoheptaose nach Inkubation $\left(75^{\circ} \mathrm{C}, 14 \mathrm{~h}\right)$ mit MTase/MTase-Mutanten. (Der Pfeil markiert die Auftragslinie.) 

1: Standard $\mathrm{G}_{1}-\mathrm{G}_{7}$
6: Heptaose + D385N
11: Heptaose + V110R
2: Heptaose (-Enzym)
7: Heptaose + E414Q
12: Heptaose + A230R
3: Heptaose + MTase
8: Heptaose $+\mathrm{T} 466 \mathrm{~N}$
13: Heptaose + V110R/A230R
4: Heptaose + K151 A
9: Heptaose $+\mathrm{P} 467 \mathrm{H}$
14: Heptaose + D317A
5: Heptaose $+\mathrm{T} 206 \mathrm{H}$
10: Heptaose $+\mathrm{T} 206 \mathrm{H} / \mathrm{P} 467 \mathrm{H}$
15: Heptaose + K151A/D317A

Die Transfer- und die hydrolytische Aktivität aller Mutanten wurde nun auch quantitativ erfaßt. Die Messung der Transfer-Aktivität erfolgte mittels des Standard$\mathrm{I}_{2} / \mathrm{KI}$-Testes und die Bestimmung der hydrolytischen Aktivität durch Anwendung des DNSA-Testes.

In Abb. 42 und Tab. 18 sind die Transfer- und Hydrolyse-Aktivitäten aller MTaseMutanten einander gegenüber gestellt. Die Aktivitäten wurden relativ zur Transfer-

\begin{tabular}{|lr|}
\hline I 2 /KI-Test: & \\
Mcllvaine pH 6,5 ${ }^{\left(75^{\circ} \mathrm{C}\right)}$ & $100 \mu \mathrm{l}$ \\
Maltooligosaccharid-Mix $2 \%$ & $200 \mu \mathrm{l}$ \\
$\mathrm{H}_{2} \mathrm{O}_{\text {bidest. }}$ & $100-\mathrm{X} \mu \mathrm{l}$ \\
Enzym & $6 \mu \mathrm{g}$ \\
Inkubation: & 10 min bei $75^{\circ} \mathrm{C}$ \\
\hline
\end{tabular}

\begin{tabular}{|lr|}
\hline DNSA-Test: & \\
Mcllvaine pH 6,5 ${ }^{\left(75^{\circ} \mathrm{C}\right)}$ & $100 \mu \mathrm{l}$ \\
lösliche Stärke $1 \%$ & $250 \mu \mathrm{l}$ \\
$\mathrm{H}_{2} \mathrm{O}_{\text {bidest. }}$ & $150-\mathrm{X} \mu \mathrm{l}$ \\
Enzym & $6 \mu \mathrm{g}$ \\
Inkubation: & $6 \mathrm{~h}$ bei $75^{\circ} \mathrm{C}$ \\
\hline
\end{tabular}

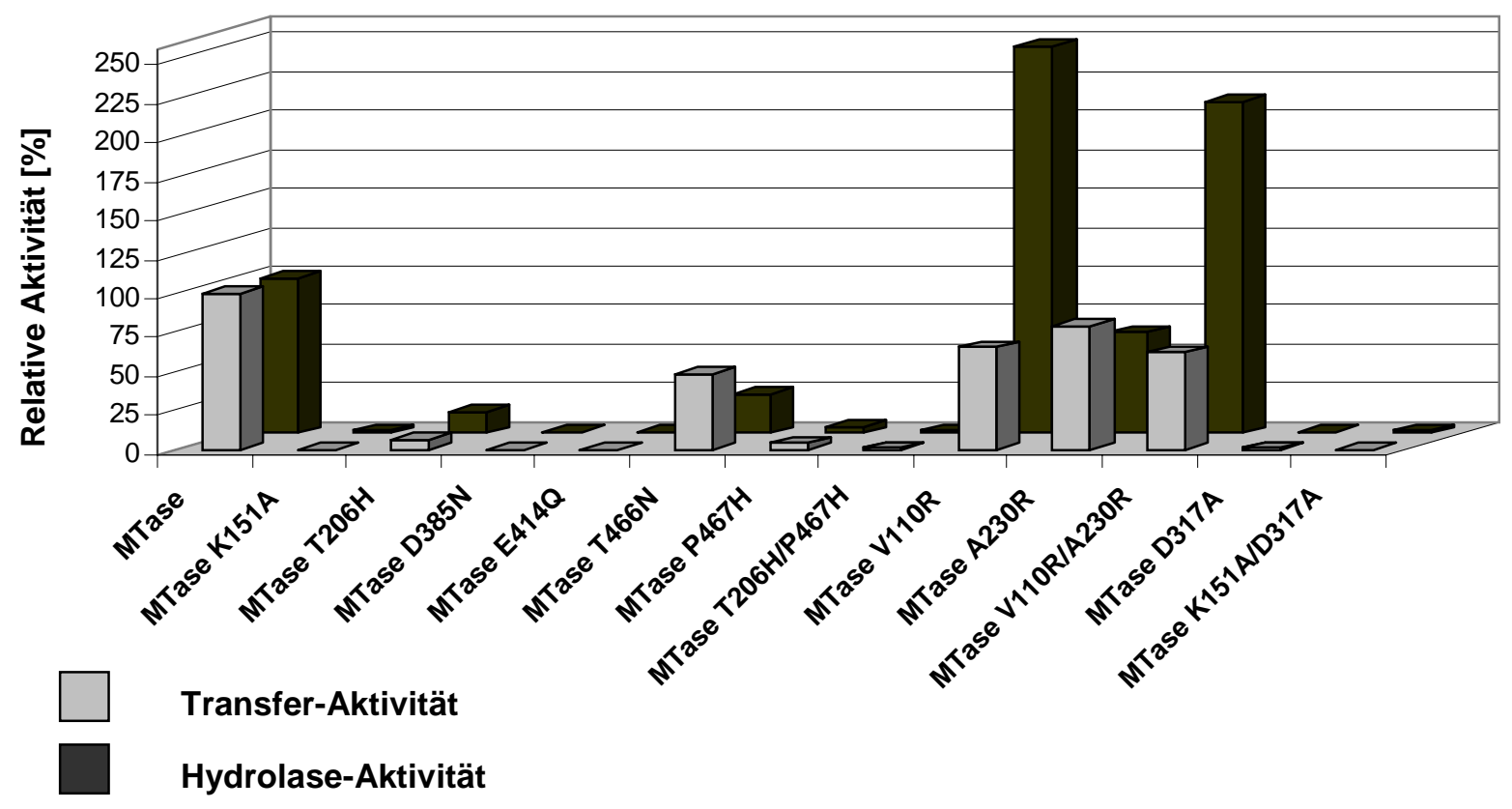

Abb. 42: Relative Transfer- und Hydrolyse-Aktivitäten der MTase-Mutanten im Vergleich (bezogen auf die MTase; Erläuterungen siehe Text) 
Tab. 18: Vergleich der relativen Transfer- und Hydrolyse-Aktivitäten

\begin{tabular}{lccc}
\hline Mutanten & $\begin{array}{c}\mathrm{I}_{2} / \text { KI-Test } \\
{[\%]}\end{array}$ & $\begin{array}{c}\text { DNSA-Test } \\
{[\%]}\end{array}$ & $\begin{array}{c}\text { relative Hydrolyse/ } \\
\text { relativer Transfer }\end{array}$ \\
\hline MTase & 100 & $100^{\mathrm{a})}$ & 1,0 \\
MTase K151A & 0 & 1,4 & n.d. $)$ \\
MTase T206H & 7 & 13,6 & 1,9 \\
MTase D385N & 0,3 & 0,8 & n.d. \\
MTase E414Q & 0,1 & 1,1 & n.d. \\
MTase T466N & 49 & 24,7 & 0,5 \\
MTase P467H & 4,2 & 3,8 & 0,9 \\
MTase T206H/P467H & 0,6 & 1,9 & n.d. \\
MTase V110R & 65,5 & 248,6 & 3,8 \\
MTase A230R & 79 & 64,8 & 0,8 \\
MTase V110R/A230R & 62,5 & 212,8 & 3,4 \\
MTase D317A & 0,6 & 0,9 & n.d. \\
MTase K151A/D317A & 0,3 & 1,7 & n.d.
\end{tabular}

a) Für die MTase wurde eine spezifische hydrolytische Aktivität von 0,27 U/mg bestimmt.

b) n.d., der Quotient aus hydrolytischer und Transfer-Aktivität wurde nicht gebildet, da die gemessenen Aktivitäten im Grenzbereich der verwendeten kolorimetrischen Enzymaktivitätstests liegen. In diesem Bereich ist die Quotientenbildung auf Grund der relativ großen Meßungenauigkeiten nicht mehr sinnvoll.

bzw. Hydrolyse-Aktivität der Wildtyp-MTase (jeweils $100 \%$ gesetzt) dargestellt. Für die Wildtyp-MTase wurde eine spezifische hydrolytische Aktivität von $0,27 \mathrm{U} / \mathrm{mg}$ bestimmt. Die im $\mathrm{I}_{2} / \mathrm{KI}$-Test bestimmte Transferaktivität kann nicht quantitativ angegeben werden. Mit anderen Testmethoden liegt die Transferaktivität für die MTase jedoch um $0,5-3 \times 10^{3} \mathrm{U} / \mathrm{mg}$ (je nach eingesetzten Substraten; siehe Meissner, 1997).

Alle Mutanten, deren Funktionen im Bereich des aktiven Zentrums (z.B. D385N, E414Q) und bei der Substraterkennung / -bindung (z.B. K151A, D317A, P467H) eine wesentliche Rolle zu spielen scheinen, sind sowohl in ihrer Transfer- als auch in ihrer hydrolytischen Aktivität stark eingeschränkt. Keiner dieser Mutanten erreicht mehr $5 \%$ der Aktivität des Wildtypes. T206H zeigt im Hydrolyse/Transfer-Verhältnis eine um 1,9 gesteigerte hydrolytische Aktivität, wobei allerdings die relativen Aktivitäten im 
Vergleich zur MTase erheblich gesunken sind. Die deutlichste Veränderung beim Vergleich Hydrolyse/Transfer ist bei den Monomer-Mutanten zu beobachten. Bei der Doppelmutante V110R/A230R ist die hydrolytische Aktivität gegenüber der Transferaktivität (relativ zum Hydrolyse/Transfer-Verhältnis bei der Wildtyp-MTase) um das 3,4-fache, bei V110R gar um das 3,8-fache gesteigert. Diese Mutanten sind in ihrer Transferaktivität zudem nur in geringerem Maße beeinträchtigt (relative Aktivitäten: 62,5 bzw. 65,5\%). Die Einführung eines Asparagins anstelle von Threonin bei der Aminosäureposition 466 bewirkte keine Erhöhung des Hydrolyse/Transfer-Verhältnisses: Bei dieser Mutante ist die Transferrate, relativ zum Verhältnis bei der WildtypMTase, doppelt so hoch wie die hydrolytische Aktivität. 


\section{DISKUSSION}

Glucosidasen (O-Glycosid Hydrolasen, EC 3.2.1.-) bilden eine weitverbreitete Enzymgruppe mit signifikanter biochemischer, biomedizinischer und industrieller $\mathrm{Be}$ deutung. Sie katalysieren die Hydrolyse der glycosidischen Bindungen in Oligo- und Polysacchariden. Die IUB-MB (International Union of Biochemistry and Molecular Biology) Enzym-Nomenklatur der Glycosylhydrolasen basiert auf der Substratspezifität und dabei gelegentlich auf dem molekularem Mechanismus, berücksichtigt aber nicht strukturelle Aspekte dieser Enzyme. Deshalb wurde vor einigen Jahren eine Klassifizierung der Glycosylhydrolasen auf Grundlage der Ähnlichkeiten in der Aminosäuresequenz vorgeschlagen (Henrissat, 1991; Henrissat und Bairoch, 1993; Henrissat und Davies, 1997). Wegen der direkten Beziehung zwischen Sequenz und Faltungseigenschaften bietet eine solche Klassifizierung folgende Vorteile: (1) Den strukturellen Eigenschaften der Enzyme wird besser Rechnung getragen als das durch die Substratspezifität möglich wäre. (2) Es werden evolutionäre Beziehungen zwischen Enzymen unterschiedlicher Substratspezifität aufgezeigt. (3) Informationen über den Reaktionsmechanismus sind leicht auf andere Mitglieder derselben Familie übertragbar. Zur Zeit gibt es 70 verschiedene Familien der Glycosylhydrolasen. Ausgehend von Aminosäuresequenzvergleichen der $\alpha$-Glucosidase AgIA und der Maltosyltransferase aus T. maritima erfolgte die Zuordnung dieser Enzyme zu der Familie 4 bzw. zu der Familie 13 ( $\alpha$-Amylase-Familie) der Glycosylhydrolasen (Bibel et al., 1998; Meissner, 1997).

\section{1 $\alpha$-Glucosidasen von T. maritima}

Die Genomsequenzierung von T. maritima (Nelson et al., 1999) ergab, daß $54 \%$ der 1877 offenen Leserahmen eine mögliche Funktion zugeordnet werden konnte, während 46 \% (863 ORFs) mit unbekannter Funktionalität weiterer Untersuchungen bedürfen. Viele der T. maritima ORFs kodieren für Enzyme, die am Abbau von Zuckern und pflanzlichen Polysacchariden beteiligt sind. Im folgenden soll der Schwerpunkt der Diskussion zunächst bei den $\alpha$-Glucosidasen liegen.

\subsubsection{Genetischer Kontext der $\alpha$-Glucosidasen agIA und aglB}

Der Vergleich von agIA und seinen umgebenden Sequenzen (Sequenzdaten vom Genomsequenzierungsprojekt, Datenbank des „Institute of Genome Research“ TIGR, 
Rockville, MD, USA) ergab, daß das Gen in einem Gen-Cluster für die Stärke/Maltodextrin-Umsetzung in $T$. maritima lokalisiert ist. Hier ist aglA eines von mehreren Genen (malE-malF-malG-aglB-aglA) für Maltodextrin-Transport und -Hydrolyse. Die Gene für zwei amylolytische Enzyme, die bereits früher beschrieben wurden (Liebl et al., 1997), namentlich das Maltodextrin Bindeprotein MalE und die $\alpha$-Amylase AmyA, gehören ebenfalls dem Cluster an. AmyA ist stromaufwärts von malE divergent lokalisiert. In einem Abstand von nur fünf Leserahmen von amyA befindet sich ein weiteres in unserer Arbeitsgruppe bearbeitetes Gen pulA, welches für eine Pullulanase kodiert (Kriegshäuser und Liebl, 2000). Die intergenische Region zwischen malE und malF enthält ein G/C-reiches "inverted repeat" (5'-AAGAGGGGGACTTTTCCCCCTCTT-3'), welches bei der Regulation des Levels der MalE-Produktion in Relation zum Level der MalF und MalG-Synthese eine wichtige Rolle spielen könnte. Für E. coli ist bekannt, daß MalF und MalG in stöchiometrischen Mengen benötigt werden, während MalE in 100-fachem Überschuß produziert wird (Boos und Lucht, 1996). Die Sequenzdaten weisen deutlich darauf hin, daß T. maritima über ein E. coli-ähnliches (periplasmatisches) Bindeprotein abhängiges ABC-Transportsystem für die Maltodextrin-Aufnahme verfügt. Obwohl die Existenz von Porinen in der Zellhülle von T. maritima bereits nachgewiesen wurde (Rachel et al., 1990), ist es bisher nicht geklärt, ob Thermotoga in Analogie zu LamB (Maltoporin, $\lambda$-Rezeptor) in der äußeren Membran von E. coli eine spezifische Diffusionspore für Maltodextrine in seiner "Toga“ enthält. In diesem Zusammenhang fällt auf, daß T. maritima neben dem oben beschriebenen System noch über ein zweites malEFG Gen-Cluster (TM1202-TM1204, Nelson et al., 1999) verfügt. Die genaue Rolle dieses Clusters muß erst noch analysiert werden. Ein Bindeprotein-abhängiger $\mathrm{ABC}$-Transporter für Maltose und Trehalose wurde auch im hyperthermophilen Archaeon Thermococcus litoralis identifiziert (Horlacher et al., 1998). Da beide Organismen (T. maritima und Tc. litoralis) sehr ursprüngliche Vertreter im phylogenetischen Stammbaum darstellen, kann man spekulieren, daß die hochaffinen Transportsysteme und ihre genetische Anordnung auf dem Chromosom (malE-malF-ma/G) sehr früh in der Evolution etabliert wurden.

Überraschenderweise gehört AglA aus T. maritima nicht wie andere typische $\alpha$-Glucosidasen zur umfangreichen $\alpha$-Amylase Familie (Familie 13 der Glycosylhydrolasen), sondern zeigt geringe Homologien (Identität: $\approx 26 \%$ ) zur Melibiase MelA aus E. coli und einem putativen Enzym aus B. subtilis. Weiterhin gab es Ähnlich- 
keiten mit 6-Phospho- $\beta$-Glucosidasen (CelF aus E. coli/B. subtilis) und 6-Phospho- $\alpha-$ Glucosidasen aus Fusobacterium mortiferum und Bacillus subtilis, die alle Vertreter der Familie 4 darstellen. Die zweite stromaufwärts von AglA gelegene $\alpha$-Glucosidase AgIB ist eine Cyclodextrinase und gehört zur $\alpha$-Amylase-Familie. Die Eigenschaften dieses Enzyms, d.h. die biochemische Charakterisierung und die Analyse des Substratprofils wurde von Veith (2001) ermittelt.

\subsubsection{Weitere Glucosidasen in T. maritima}

Die Sequenzierung des T. maritima Genoms (Nelson et al., 1999) führte zur Identifizierung weiterer putativer $\alpha$-Glucosidasen (TM0434: 1410 bp, 470 As, 55 kDa; TM0752: 1413 bp, 471 As, 55 kDa; TM1068: 1398 bp, 466 As, 54 kDa; TM1281: 1245 bp, 415 As, 48 kDa), die alle der Familie 4 der Glycosylhydrolasen zugeordnet wurden. TM0434 und TM1068 stellen eine Genduplikation dar (Identität auf AsEbene: 98,5 \%) und weisen mit TM0752 eine gemeinsame Identität von $61 \%$ auf. Nimmt man beim MULTALIN-oder CLUSTALW-Alignment noch AgIA (TM1834) hinzu, so beträgt die Identität der vier Proteine untereinander immerhin noch $39 \%$. Interessanterweise fehlen, im Gegensatz zu den $\alpha$-Glucosidasen AgIA aus T. maritima und $T$. neapolitana, bei allen drei noch nicht näher charakterisierten putativen $\alpha$-Glucosidasen inmitten der Proteinsequenz 16 Aminosäuren (As 325-340 bei AGLA_THEMA, Abb. 43). Dies könnte auf einen fundamentalen Unterschied zu AgIA hindeuten, z.B. hinsichtlich der Substratspezifität. Während TM0434, TM0752 und TM1068 vermutlich homologe $\alpha$-Glucosidasen zu AgIA darstellen, handelt es sich bei TM1281 um eine putative 6-Phospho- $\beta$-Glucosidase. Die entsprechenden Gene konnten bereits heterolog in E. coli kloniert und zum Teil exprimiert werden (nicht gezeigt). Allerdings wurden bisher noch keine enzymatischen Aktivitäten zugeordnet, wobei die Gründe hierfür noch im Detail geklärt werden müssen. Eventuell wurde bisher mit falschen Substraten gearbeitet oder die Proteine haben sich bei der heterologen Expression falsch gefaltet. Möglicherweise handelt es sich teilweise aber auch um kryptische Gene, die erst nach einer entsprechenden Mutation im Genom aktiviert werden. E. coli K12 beispielsweise verfügt über ein cel-(Cellobiose-Verwertung) Operon, welches im Wildtyp-Stamm nicht exprimiert wird (Parker und Hall, 1990). Es erscheint allerdings nicht plausibel, warum das T. maritima Genom gleich mehrere stillgelegte $\alpha$-Glucosidase-Gene haben sollte, da deren Replikation vom energetischen Gesichtspunkt her betrachtet für die Zelle ungünstig wäre. 
AGLA_THEMA AGLA_THENEO TM0 434 TM1068

TM0752

TM1281

GLVG_BACSU MALH_FUSMR AGAL_ECOLI LPLD_BACSU Consensus Prim.cons.

AGLA_THEMA AGLA_THENEO TM0 434 TM1 068 TM0752

TM1281 GLVG_BACSU MALH_FUSMR AGAL_ECOLI LPLD_BACSU Consensus Prim.cons.

AGLA_THEMA AGLA_THENEO TM0 434

TM1068

TM0752

TM1281

GLVG_BACSU

MALH_FUSMR

AGAL ECOLI

LPLD_BACSU

Consensus

Prim.cons.

AGLA_THEMA AGLA THENEO TM0 434 TM1 068

TM0 752

TM1281

GLVG_BACSU MALH_FUSMR AGAL_ECOLI LPLD_BACSU Consensus Prim.cons.

AGLA_THEMA AGLA_THENEO TM0 434 TM1068 TM0752

TM1281 GLVG_BACSU MALH_FUSMR AGAL_ECOLI LPLD_BACSU Consensus Prim.cons. $\begin{array}{ccccccc}10 & 20 & 30 & 40 & 50 & 60 & 70 \\ \mid & \mid & \mid & \mid & 80\end{array}$ ------MPAVKIGI IGAGSAVF SLRLVSDLCKTPGLS--GSTVTLMD IDEERLDAVLTIAKKYVEEVGADLKFEKTTSVD -------MPT IVFVGAGSVRYT I KLVGDLAKTPDLY--GSRLVLMD IDEERLKATY I LVTKYLRELNAEYTVEQTT SLE --------MPTIVFVGAGSVRYTIKLVGDLAKTPDLY--GSRLVLMD IDEERLKATY ILVTKYLRELNAEYTVEQTTSLE -------MKI S I I GA GSVRFALOLVGD IAOTEELSREDTH I YMMDVHERRLNASY I LARKYVEE LNSPVK IVKT S SLD -MRIAVIGGGSSYTPELVKGLIDISEDVR--IDEVIFYDIDEEKQKIVVDFVKRLVKDR---FKVLISDTFE --------MRIAVIGGGSSYTPELVKGLLDISEDVR--IDEVIFYDIDEEKQKIVVDFVKRLVKDR---FKVLISDTF ------MKOF S I L IAGGGS TF TP GI I LMLLDNLDKFP---IROI KMF DNDAEROAKI GEACA I LLKEKAPOIKF SYSTNPE ----MMSAPKITF I GA GST IFVKNI LGDVF HREALK--TAHIALMD IDP TRLEESHIVVRKLMD SAGASGKI TCHTQQK MFHISTLDQIKIAYIGGGSQGWARSLMSDLS IDERM---SGTVALYDLDFEAAQKNEVIGNH---SGNGRWRYEAVSTLK $\mathrm{kI} \quad \mathrm{iGgGS}$ gdl e $l$ DiD er e $k$ t MFHI23M2 4PKIVI IGAGS2RFPL3LVGDL2KTEDLSREGSTV4 LMD IDEERL2AIYI2VKKYV2ELNAD3KFEKTTSLE

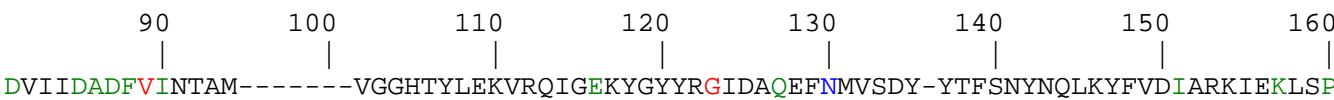
EAIADADFVINTAM-------VGGHTYLEKVRRISEKYGYYRG IDAQEFNMVSDY-YTF SNYNQLKYFVD IARKIERLSP EALEGADFVINTAL-YRAP GHEDGYVHYE IMREVGERHGYYRG IDSQELNMVSDY-YTLSNYNHLKMS LDIAKAVEKIAP EALEGADFVINTAL-YRAP GHEDGYVHYE IMREVGERHGYYRG IDSQELNMVSDY-YTLSNYNHLKMS LD IAKAVEKIAP EAIDGADF I INTAYPYDPRYHDSGSQRWDEVTKVGEKHGYYRG IDSQELNMVSTYTYVLSSYPDMKLALEIAEKMKKMAP GAVVDAKYVIFQFR----------PGGLKGREN-DEGIPLKYGLIGQ--ETTGVG-GF SAALRAFP IVEEYVDTVRKTSEAFTDVDFVMAH IR---------VGKYAMRAL-DEQIP LKYGVVGQ--ETCGP G-GIAYGMRS I GGVLEI LDYMEKYSP EAFTD IDFVMAH IR----------VGKYPMREL-DEKIP LRHGVVGQ--ETCGP G-GIAYGMRS IGGVIGLIDYMEKYSP EALEDADFVVVAFQ---------IGGYEPCTVTDFEVCKRHGLEQTIADTLGP G-GIMRALRT IP HLWQICEDMTEVCP KALSAAD IVI IS I L---------P GS LDDMEV-DVHLP ERCG IYQSVGD TVGP G-GI IRGLRAVP IFAE IARA IRDYAP eA dadfVi $g$ de $p \quad G$ q \#t gpg gi $r$ ei $k$ EALEDADFVINTA2PYRAPGH22G4G4YE33R3VDEK2GYYRGID2QELN2V222T22LSNYR4LK42L2IA22MEKYSP

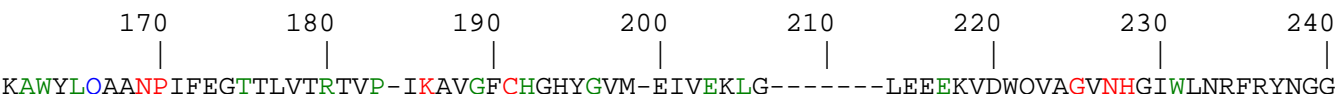
KAWYSAAANPVFEGTTLVTRTVP-IKAVGFCHGHYGVM-EI IEKLG------LERKQVDWQVAGVNHG IWLNRFRYNGE NAWILQTANPVFEITQLVKRLTK-AKIVGFCHGYAHVF-HLAKVLG-------VEPEELDWQVAGVNHAIWMNRFRCRGE NAWILOTANPVFEITOLVKRLTK-AKIVGFCHGYAHVF-HLAKVLG-------VEPEELDWOVAGVNHAIWMNRFRCRGE KAYLMQTANPVFEITQAVRRWTG-ANIVGFCHGVAGVY-EVFEKLD-------LDPEEVDWQVAGVNHG IWLNRFRYRGE NAT IVNF TNP S GH I TEFVRNYLEYEKF I GLCNVP INF IRE I AEMF S-------ARLEDVF LKYYGLNHLSF IEKVFVK-G DAWMLNYSNPAAIVAEATRRLRPNSKI LNICDMPVG IEDRMAQILG------LSSRKEMKVRYYGLNHFGWWTS IQDQEG NAWMLNYSNPAA IVAEATRRLRP NSKVLNICDMP I G IEVRMAE I LG------LESRKDMD IMYYGLNHF GWWKSVRDKQG DA TMLNYVNPMAMNTWAMYARYPH IKOVGLCHSVQGT----AEELARDLNIDPAT---LRYRCA G INHMAFYLELERKTA ESWVINYTNPMSVCTRVLYKVFP GIKA I GCCHEVF GTQKLLAEMVTERLGIEVPRRED IRVNVLGINHFTWITKASYRH I

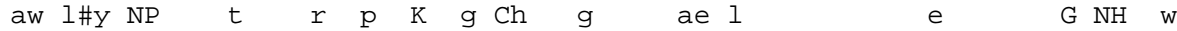
NAW2 LNYANPVFE I T22VRRLTPNIKIVGFCHG2AGV34E2AEKLG22L2 I 2 LLEREEVDWQVAGVNH2 IWLNRFRYRG2 $\begin{array}{rrrrrrr}250 & 260 & 270 & 280 & 290 & 300 & 310\end{array}$ N--AYP LLDKWIEEKSKDWKPENPFNDQLSPAAIDMYRFYGVMP I GD TVRNSSWRYHRDLETKKKWYGEPWGGADSEIGW D--AYPLIPRWISEKSKDWKPENPFNDQLSPAAIDMYKFYGVMP I GDTVRNASWRYHRDLETKKRWYGEPWGGADSEIGW D--LYPKLDEWIEENASRWEP KNPWDVDF SPAAIDMYRFYGMYP IGD TVRSGTWKYHYDLETKKRWYGK-FGGIDNEVER D--LYPKLDEWIEENASRWEPKNPWDVDF SPAAIDMYRFYGMYP IGDTVRSGTWKYHYDLETKKRWYGK-FGG IDNEVER D--AYP LLDEWIEKKLPEWEPKNPWD TQMSPAAMDMYKFYGMLP IGD TVRNGSWKYHYNLETKKKWF GK-FGGIDNEVER E-DVTEKVFENLKLKLSNIP DEDFP----TWFYD SVRL----------IVNPYLRYY--LMEKKMFKK--------ISTHE N-DLMPKLKEHVSOYGYI-PKTEAEAVEASWNDTFAKARDVOAADPDTLPNTYLOYY--LFPDDMVKK-------SNPNH N-DLMPKLREHVSQYGYVVPKGDNQHTEASWNDTFAKAKDVLALDP TT LPNTYLKYY--LFPDYVVEH-------SNKEY DGSYVNLYPELLAAY-EAGQAP KPNI-HGNTRCQ-NIVRYEMF KKLGYFVTESSEHFAEYTPWF I KP G-------REDLI D--LLP IFREF SAHYGESGYELEGECWRD SVFCSAHRVAFDLFETYGAIPAAGDRHLAEF LP GPYLK--------QPEVW

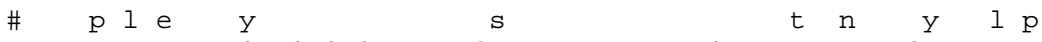
DGDLYPKLDEWIEE2GS2W2P 2NPWDVQ3SPAAIDMYRFYGM4P IGDTVRNGSW2YHYDLETKKRWYGKPFGGIDSEVE2 \begin{tabular}{ccccccc|}
330 & 340 & 350 & 360 & 370 & 380 & 390
\end{tabular} KWYQDTLGKVTD I TKKVAKF I KENP ALKLSD LGSVLGKDLSEKQFVLEVEKI LDPEKKSGEQH I SF HDALLNDNRSRFVI PKFYESLREQRKRLMELAKEVEKDPTIELTK----------------VWPEVFTTGSESVEQH IPF INALVNDKKARLVI PKFYESLREQRKRLMELAKEVEKDPT IELTK---------------VWPEVFT TGSESVEQH IPF INALVNDKKARLVL PKFHEQLRRARERL IKLAEEVQQNP GMKLTE----------------EHPE IFPKGKLSGEQH IPF INAIANNKRVRLFL LRAREVMK-IEKELFEKYRTAV-EIPEELT--------------------KRGGSMYST--AAAHLIRDLETDEGKIHIV TRANEVMEGREAF IF SQCDMITREQSSENS-------------------EIKIDDHAS--Y IVDLARAIAYNTGERMLI TRANEVMDGREKFVFGECEKVVKNOSSEGC--------------------ALHIDEHAS--Y IVDLARAIAFNTKEKMLI ERYKVP LDEYPKRCVEQLANWHKELEEYKK------------------ASRID IKP SREYAST IMNAIWTGEP SVIYG KFHLTP ISFRKQDRAEKRQETERLIVQQRG-------------------VAE---KASGEEGVNI IAALLGLGELVTNV
$r \quad e$
$\mathrm{K} \quad \mathrm{e}$
$S$ e $i$ al

2R33EVLRER2KRLFELAKEVEKNP S3ELT2LGSVLGKDLSEKQFVLE2PEIF ID2KASGEQH IPF INAL2NDKKARLVL 
AGLA_THEMA AGLA_THENEO TM0 434 TM1068

TM0752

TM1281

GLVG_BACSU MALH_FUSMR AGAL_ECOLI LPLD BACSU Consensus Prim.cons.

AGLA_THEMA AGLA_THENEO TM0 434

TM1 068

TM0752

TM1281

GLVG_BACSU

MALH_FUSMR

AGAL_ECOLI

LPLD_BACSU

Consensus

Prim.cons.

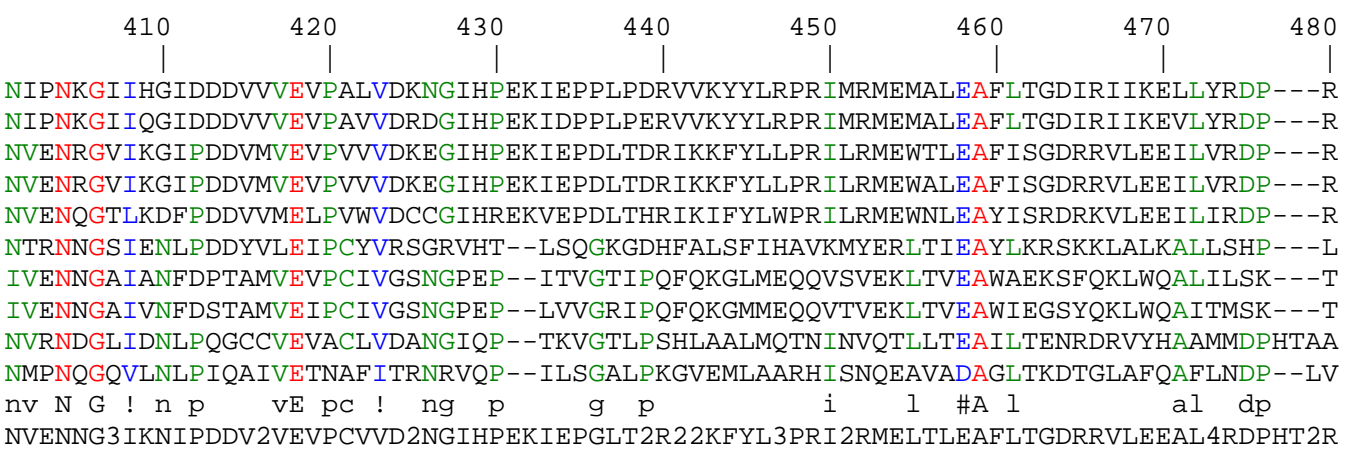

\begin{tabular}{cc|}
490 & 500 \\
TKSDEQVEKVIEEILALPENEEMRKHYLKR---
\end{tabular}

TKSDEQVER-

TRSYEQAVAVIDD I LNLPFNEEMKKHYSKVGKN

TRSYEQAVAVIDD I LNLPFNEEMKKHYGS----

TKSYEQIVQVLDE IFNLPFNEELRRYYKEKL--

GPDVEDAKDLLEEILEANREYVKLG--------

VPNARVARLILEDLVEANKDFWPELDQSPTRIS

VP SAKVAKDILDDLIEANKEYWPVLK--------

VLGIDE IYALVDDLIAAHGDWLPGWLHR-----

QIDRSDAEQLFNDMLQCIMQS--------_---

a \#\# a \#

T2SYEQA2AVLDD IL22PFNEE22KHYSK 4322

Abb. 43: Alignment der Aminosäuresequenzen von Proteinen der Familie 4 der Glycosylhydrolasen mittels MULTALIN. \#: konservierte Positionen von NDQEBZ; ! : konservierte Positionen von IV; AGLA_THEMA (Nelson et al., 1999): $\alpha$-Glucosidase (T. maritima); AGLA_THENEO: $\alpha$-Glucosidase (T. neapolitana); TM0434, TM1068, TM0752 (Nelson et al., 1999): putative $\alpha$-Glucosidasen (T. maritima); TM1281 (Nelson et al., 1999): putative 6-Phospho- $\beta$-Glucosidase (T. maritima); GLVG_BACSU (Yamamoto et al., 1996): 6-Phospho- $\alpha$ Glucosidase (Bacillus subtilis); MALH_FUSMR (Bouma et al., 1997): 6-Phospho- $\alpha$-DGlucosidase (F. mortiferum); AGAL_ECOLI (Liljeström und Liljeström, 1987): $\alpha$-Galactosidase (E. coli); LPLD_BACSU: nichtcharakterisierte Glycosylhydrolase (Bacillus subtilis)

\subsection{Cofaktor-Abhängigkeit von AglA und anderen Enzy- men der Glycosylhydrolase - Familie 4}

Die ersten Versuche der Aufreinigung der heterolog exprimierten rekombinanten $\alpha$-Glucosidase aus T. maritima scheiterten an einem drastischen Verlust der Enzymaktivität während der chromatographischen Aufreinigungsschritte (Bibel, 1994; Schanzer, 1996). Durch Zugabe von E. coli-Rohextrakten zu den chromatographischen Fraktionen konnte jedoch die Aktivität wiederhergestellt werden. Dies bedeutete, daß die $\alpha$-Glucosidase offenbar allgemein in Zellextrakten enthaltene (also nicht Thermotoga spezifische) Cofaktoren für die Aktivität benötigte. Durch eine Vielzahl von Komplementationsexperimenten konnten letztlich $\mathrm{NAD}^{+}$und $\mathrm{Mn}^{2+}$ als 
Aktivatoren ermittelt werden. Zusätzlich bedarf es reduzierender Bedingungen, die beispielsweise durch die Zugabe von DTT erreicht werden, um eine vollständige Aktivierung des Enzyms zu erhalten. Es ist möglich, DTT durch $\beta$-Mercaptoethanol und weniger effizient durch L-Cystein zu ersetzen. Eine Aktivierung durch DTT wurde auch für eine extrazelluläre $\alpha$-Glucosidase aus Thermococcus AN1 gezeigt (Piller et al., 1996). Warum relativ hohe Mengen reduzierender Agenzien, d.h. 50 mM DTT oder 600 mM $\beta$-Mercaptoethanol bei AglA aus T. maritima oder T. neapolitana benötigt werden, bleibt zunächst unklar. Vorstellbar ist, daß die beiden Cystein-Reste (Cys25, Cys174) mit ihren sehr reaktionsfreudigen Thiol-Gruppen vor der Oxidation durch Sauerstoff geschützt werden müssen. Vor allem das in der Familie 4 hochkonservierte Cys174 könnte eine wichtige Rolle für das aktive Zentrum spielen. Dies wird vor allem auch durch die Tatsache gestützt, daß die Mutante C174S keinerlei enzymatische Aktivität mehr zeigte. Für MalH aus F. mortiferum wird eine Beteiligung von SH-Gruppen an der Katalyse nicht ausgeschlossen (Thompson et al., 1995).

Auch die anderen Vertreter der Familie 4, die bisher näher beschrieben wurden, brauchen $\mathrm{NAD}^{+}(\mathrm{NADH})$ und ein zweiwertiges Metallion für die volle enzymatische Aktivität (Tab. 19). Bereits 1971 konnten Burstein und Kepes nachweisen, daß die E. coli $\alpha$-Galactosidase MelA $\mathrm{NAD}^{+}$und $\mathrm{Mn}^{2+}$ zur Aktivierung benötigte. Diese Cofaktoren können auch die 6-Phospho- $\beta$-Glucosidase CelF aus E. coli, 6-Phospho$\alpha$-Glucosidase GlvA (GlvG) aus B. subtilis 168 und die $\alpha$-Glucosidase aus T. neapolitana stimulieren (Thompson et al., 1999, 1998; diese Arbeit).

Offenbar ist die Notwendigkeit von $\mathrm{Mn}^{2+}$ und $\mathrm{NAD}^{+}$als Cofaktor eine gemeinsame Eigenschaft der intrazellulären Enzyme der Familie 4 der Glycosylhydrolasen, wobei AglA (T. maritima) das bisher thermostabilste Protein dieser Gruppe darstellt (Raasch et al., 2000). Eine Calcium-Abhängigkeit ist bei einer Vielzahl amylolytischer Enzyme weit verbreitet (z. B. $\alpha$-Amylasen, CGTasen; Janecek, 1997). Ein ManganBedürfnis hingegen ist für Glycosylhydrolasen eher ungewöhnlich. Die meisten bekannten $\alpha$-Glucosidasen brauchen keine Metallionen für ihre Aktivität. Einige werden durch die Zugabe von $\mathrm{Mn}^{2+}$ und $\mathrm{Co}^{2+}$ sogar gehemmt (Suzuki et al., 1992; Piller et al., 1996). Die genaue Rolle der Metallionen für die Hydrolasen der Familie 4 bleibt bisher ungeklärt. Thompson et al. (1998) zeigten, daß GlvA im metallfreien Puffer als inaktives Dimer vorliegt und in Gegenwart von $\mathrm{Mn}^{2+}$ zu einem katalytisch 
Tab. 19: Cofaktor-abhängige Enzyme der Familie 4 der Glycosylhydrolasen ${ }^{1}$

\begin{tabular}{|c|c|c|c|c|}
\hline \multirow[t]{2}{*}{ Enzym/ Organismus } & \multicolumn{3}{|c|}{ Cofaktor/Funktion } & \multirow[t]{2}{*}{ Referenz } \\
\hline & Metall & Nukleotid & red. Agens & \\
\hline $\begin{array}{l}\alpha \text {-Glucosidase AglA/ } \\
\text { T. maritima }\end{array}$ & $\begin{array}{l}\mathrm{Mn}^{2+},\left(\mathrm{Co}^{2+},\right. \\
\left.\mathrm{Ni}^{2+}\right)\end{array}$ & $\begin{array}{c}\mathrm{NAD}^{+} \\
\left(\mathrm{NADP}^{+}\right)\end{array}$ & $\begin{array}{l}\text { DTT, } \beta \text {-Mer- } \\
\text { captoethanol, } \\
\text { (L-Cystein) }\end{array}$ & $\begin{array}{l}\text { Schanzer, } 1996 \\
\text { diese Arbeit }\end{array}$ \\
\hline $\begin{array}{l}\alpha \text {-Glucosidase AglA/ } \\
T . \text { neapolitana }\end{array}$ & $\mathrm{Mn}^{2+}$ & $\mathrm{NAD}^{+}$ & DTT & diese Arbeit \\
\hline $\begin{array}{l}\text { Cellobiose-6-Phos- } \\
\text { phate Hydrolase } \\
\text { CelF/ E.coli }\end{array}$ & $\begin{array}{l}\mathrm{Mn}^{2+},\left(\mathrm{Co}^{+},\right. \\
\left.\mathrm{Ni}^{2+}\right)\end{array}$ & $\mathrm{NAD}^{+}$ & --- & $\begin{array}{l}\text { Thompson et al., } \\
1999\end{array}$ \\
\hline $\begin{array}{l}\text { 6-Phospho- } \alpha \text {-Gluco- } \\
\text { sidase GlvA (GlvG)/ } \\
\text { B. subtilis } 168\end{array}$ & $\begin{array}{l}\mathrm{Mn}^{2+},\left(\mathrm{Fe}^{2+},\right. \\
\left.\mathrm{Ni}^{2+}, \mathrm{Co}^{2+}\right) ; \\
\mathrm{Mn}^{2+}: \text { Dimer } \rightarrow \\
\text { Tetramer }\end{array}$ & $\begin{array}{l}\mathrm{NAD}^{+} \\
\text {(NADH) }\end{array}$ & --- & $\begin{array}{l}\text { Thompson et al., } \\
1998\end{array}$ \\
\hline $\begin{array}{l}\text { 6-Phospho- } \alpha-D-G l u- \\
\text { cosidase MalH/ } \\
\text { F. mortiferum }\end{array}$ & $\begin{array}{l}\mathrm{Fe}^{2+},\left(\mathrm{Co}^{2+}\right. \\
\left.\mathrm{Mn}^{2+}, \mathrm{Ni}^{2+}\right)\end{array}$ & --- & $\begin{array}{c}\text { (DTT) } \\
\text { Stabilisierung }\end{array}$ & $\begin{array}{l}\text { Bouma et al., 1997; } \\
\text { Thompson et al., } \\
1995\end{array}$ \\
\hline $\begin{array}{l}\alpha \text {-Galactosidase } \\
\text { MelA/ E. coli }\end{array}$ & $\mathrm{Mn}^{2+},\left(\mathrm{Fe}^{2+}\right)$ & $\begin{array}{l}\mathrm{NAD}^{+} \\
\text {(NADH) }\end{array}$ & $\begin{array}{l}\text { 2-Mercapto- } \\
\text { ethanol, (Glu- } \\
\text { tathion, red; } \\
\text { Cystein, DTT) }\end{array}$ & $\begin{array}{l}\text { Burstein und } \\
\text { Kepes, } 1971\end{array}$ \\
\hline
\end{tabular}

${ }^{1}$ sofern sie in der Literatur näher beschrieben wurden

aktiven Tetramer assoziert. Für AglA aus T. maritima hingegen konnte in dieser Arbeit gezeigt werden, daß es sowohl in Abwesenheit von Metallen (keine Metallzugabe oder Behandlung mit 1 mM EDTA) als auch in Gegenwart von 1 bzw. $4 \mathrm{mM} \mathrm{MnCl}_{2}$ als Dimer vorliegt. Daher scheint hier eine Funktion bei der Kontrolle der Assoziation der Enzymuntereinheiten auszuscheiden. Die anderen Cofaktoren NAD ${ }^{+}$ (0,9 mM) oder DTT (50 mM) hatten bei der Gelfiltrationsanalyse ebenfalls keinen Einfluß auf den Oligomerisationsgrad des Enzyms. Potentielle Funktionen könnte das zweiwertige Metallion bei der strukturellen Konformationserhaltung der Enzymuntereinheiten, bei der Substratbindung oder gar bei der Katalyse übernehmen. Ein möglicher Kandidat ist das bereits erwähnte, in der Familie 4 hochkonserviert vorliegende Cys174, mit dem eine Metallkoordination denkbar wäre. Zur Klärung dieser Fragen ist geplant, die dreidimensionale Struktur der $\alpha$-Glucosidase aus T. maritima zu lösen. Hierbei könnte sich die Abhängigkeit der AglA-Aktivität von gleich drei Cofaktoren sogar positiv auswirken, da man eventuell keine „active site“- 
Mutanten mehr klonieren muß, sondern lediglich einen oder mehrere Cofaktoren wegläßt, um das Enzym in seiner inaktiven Form zu erhalten.

Mit Hilfe der Röntgenstruktur könnte auch die Rolle des NAD ${ }^{+}$geklärt werden. Bevor nun über eine mögliche funktionelle Rolle des $\mathrm{NAD}^{+}$gesprochen wird, ist es wichtig zu beachten, daß die Enzymaktivierung durch $\mathrm{NAD}^{+}$die Ausnahme bei den Glycosylhydrolasen darstellt und signifikant nur bei der Familie 4 nachgewiesen wurde. Durch Computeranalyse der N-terminalen Aminosäuresequenz bei verschiedenen Vertretern der Familie 4 konnte ein putatives NAD ${ }^{+}$-Bindemotiv ...-GAGSAV-...(bei AgIA, siehe 3.2.4) identifiziert werden, welches unabhängig von diesen Studien auch von Thompson et al. (1998) als NAD+-Bindemotiv für die Familie 4 vorgeschlagen wurde. Dieser Bereich umfasst eine $\beta \alpha \beta$-Einheit mit einem Glycinreichen „turn“ oder Schleife zwischen dem ersten $\beta$-Strang und der DinukleotidBindehelix (Baker et al., 1992; Wierenga et al., 1985). Sowohl $\beta A$ als auch $\beta B$ bestehen zum größten Teil aus hydrophoben Aminosäuren (z.B. V, L, I, M) und die beiden Glycin-Reste, die dem $\beta A$ folgen ( $G 10$ und $G 12$ bei AgIA), sind in der Familie 4 hochkonserviert. Anstelle des dritten Glycinrestes des „fingerprint“-Motives $\mathrm{G}(X) \mathrm{G}(\mathrm{X})(\mathrm{X}) \mathrm{G}$ (Wierenga et al., 1985; Scrutton et al., 1990) findet sich bei AglA ein Valin und auch bei den anderen Familie 4 Enzymen befindet sich meist kein Glycin. Diesem dritten Glycin-Rest wurde bisher eine Funktion bei der engen Anordnung der beiden Sekundärstrukturelemente $\beta A$ und $\alpha A$ (=Dinukleotid-Bindehelix) zugeordnet. Eventuell können andere Aminosäuren in einer modifizierten „fingerprint“-Region diese Aufgabe erfüllen. Bei Enzymen, die $\mathrm{NADP}^{+}$als Cofaktor nutzen, ist das Glycin z. B. durch Alanin, Serin oder Prolin ersetzt. Diese größeren Aminosäuren verhindern die enge Aneinanderlagerung der Sekundärstrukturelemente und gestatten so ein Entgegenkommen der Struktur zum zusätzlichen 2'-Phosphat des NADP+ (Bellamacina, 1996). Der erste Glycinrest ermöglicht einen engen „turn“ der Hauptkette, welches für die korrekte Positionierung des zweiten Glycinrestes von wichtiger Bedeutung ist. Im Gegensatz zu anderen Aminosäuren kann dieses zweite Glycin wegen des Fehlens einer Seitenkette die Bindung zum Dinukleotid nicht sterisch behindern und liegt deshalb ebenfalls konserviert vor (Wierenga et al., 1985; Scrutton et al., 1990; Bellamacina, 1996). Neuere Studien zeigen aber auch alternative Möglichkeiten der NAD-Bindung auf. So wurde für eine Aldehyd Dehydrogenase eine $\mathrm{G}(\mathrm{X}) \mathrm{T}(\mathrm{X})(\mathrm{X}) \mathrm{G}$-,,fingerprint“-Region ausfindig gemacht (Liu et al., 1997). Vielleicht liegt in der modifizierten Zusammensetzung der Aminosäuren im 
Bereich des „fingerprintes“ eine Möglichkeit der Enzyme (Enzymfamilie) zur (Fein-) Regulierung der katalytischen Aktivität. Interessanterweise folgt dem zweiten Glycinrest in der Familie 4 ein hochkonserviertes Serin. Möglicherweise bildet dieses Wasserstoffbrücken zu den Sauerstoffatomen des Nicotinamid-Phosphates aus (Thompson et al., 1998). Weitere auffällige Übereinstimmungen mit bekannten NADBindemotiven sind die Anwesenheit eines konservierten Aspartat-Restes (Asp39 bei AglA) am Ende des $\beta$ B-Stranges und ein konserviert vorliegender positiv geladener Rest (Lys5) am N-Terminus des $\beta A$-Stranges. Während für den letztgenannten Rest die genaue Funktion noch nicht vollständig geklärt ist, konnte für den Aspartat-Rest die Ausbildung von Wasserstoffbrückenbindungen zu den 2'- und 3'-Hydroxylgruppen der Adenin-Ribose gezeigt werden (Bellamacina, 1996; Baker et al., 1992). Thompson et al. (1998) konnten durch ortsspezifische Mutagenese (D41G, D41E bei GlvA) die katalytische Inaktivierung des Proteins nachweisen und erklärten dies durch die verlorengegangene $\operatorname{NAD}(\mathrm{H})$-Bindung. Im Rahmen von ortsspezifischen Mutagenesen wurden bei AglA aus T. maritima die hochkonservierten Aminosäuren Gly10, Gly12, Ser13 der „fingerprint“-Region jeweils gegen Alanin ausgetauscht (siehe 3.2.4, 3.2.5). Der Standard-Aktivitätstest zeigte sofort einen drastischen Aktivitätsverlust der G10A- (2\%) und der S13A- (11\%) Mutante, während die Aktivität bei G12A im Vergleich zum Wildtyp (AgIA, 100\%) nahezu gleich blieb. Eine genauere Analyse ergab, daß der $K_{d}$-Wert für G10A dramatisch anstieg (Faktor 406), während $V_{\max }$ sich etwa halbierte. Die Abnahme der Affinität zu NAD der Mutanten G12A und S13A zeigte sich im Anstieg der $K_{d}$-Werte um den Faktor 8 bzw. 15 gegenüber dem Wildtyp-AgIA $\left(K_{d}=0,03 \mathrm{mM}\right)$. Für G12A lag der Grenzwert $v_{\max }$ der Maximalgeschwindigkeit bei Substratsättigung sogar etwas höher (1,4-fach) als bei AglA. Während das erste Glycin G10 also essentiell für die Aktivität ist, sind die Auswirkungen des Aminosäureaustausches des zweiten Glycinrestes G12A nicht so gravierend. Wahrscheinlich hat die relativ kleine Seitenkette (Methylrest) des Alanins in dem modifizierten „fingerprint“ nur geringe negative Auswirkungen und kann die NAD-Bindung nicht wirklich beeinträchtigen. Da alle Mutationen im Bereich des NAD„fingerprintes“ lagen, ist durch die gemessene Affinitätsabnahme (also Zunahme des $K_{d}$-Wertes für $\mathrm{NAD}^{+}$) davon auszugehen, daß es sich beim $\mathrm{N}$-Terminus von AglA tatsächlich um die NAD+-Binderegion handelt. Weitere Mutagenesen (etwa von Lys5 und/oder Asp39, s.o.) könnten das Bild der Funktion dieser Region vervollständigen. 
Für die Charakterisierung der Dinukleotid-Bindestelle, d.h. der Ermittlung der minimalen strukturellen Bedürfnisse eines Bindemotives für einen (NAD-) Cofaktor ist, neben der bereits durchgeführten ortsspezifischen Mutagenese und der geplanten Röntgenstrukturanalyse, die Verwendung von NAD-Analoga eine dritte Möglichkeit. Man unterscheidet dabei vier Gruppen von Analoga: (i) Analoga ohne Affinität für die Binderegion, (ii) Analoga mit Affinität, die aber nicht permanent gebunden werden, (iii) Analoga, die einen katalytisch inaktiven Komplex bilden und (iv) Analoga, die aktives Enzym formen (Samanta und Bhaduri, 1983). Mögliche Analoga für die $\alpha$-Glucosidase AglA wären unter anderem Acetylpyridin-NAD, ThioNAD, Etheno-NAD, Aldehyd-NAD oder Hypoxantin-NAD.

Die physiologische Rolle der Aktivierung der Enzyme der Familie 4 der Glycosylhydrolasen durch $\mathrm{NAD}^{+}$bleibt weiter ungeklärt. Eine Möglichkeit wäre, daß die Enzyme das NAD $/ \mathrm{NADH}-$ Verhältnis sensieren, um so den Kohlenstoffluß in den glycolytischen Abbauweg zu regulieren. In fermentativen Stoffwechselprozessen des strikt anaeroben T. maritima erscheint es nicht sinnvoll, weiter Glucose in die Glykolyse zu leiten, wenn der NAD+-Gehalt limitiert ist. In aeroben Organismen, in denen NADH als zentrales Signal für die Energieverfügbarkeit gesehen wird, ist die Stimulierung der Oligosaccharidhydrolyse im Falle eines Energiemangels (hoher $\mathrm{NAD}^{+}$-Level) hingegen ein probates Mittel. Diese Erklärung ist aus mehreren Gründen aber unbefriedigend. So findet man die Art der $\mathrm{NAD}^{+}$-Aktivierung hauptsächlich nur in der Familie 4, während die meisten anderen intrazellulären Oligosaccharidasen und die Mehrheit der Glycosylhydrolasen nicht durch NAD ${ }^{+}$ stimuliert werden. Außerdem reicht wahrscheinlich der intrazelluläre $\mathrm{NAD}^{+}$-Level (0,8 mM bei E.coli; Penfound und Foster, 1996) ohnehin bereits aus, um die Enzyme vollständig zu aktivieren. Es bedarf deshalb weiterer Anstrengungen, um die Rolle des $\mathrm{NAD}^{+}$genauer zu definieren.

Nach den oben dargestellten Aspekten erscheinen biochemisch und strukturell betrachtet die Enzyme der Familie 4 der Glycosylhydrolasen als eine kohärente Gruppe. Zusammengefaßt ergeben sich folgende gemeinsamen Aspekte (Thompson et al., 1998; Burstein und Kepes, 1971; Nagao et al., 1988; Bouma et al., 1997; diese Arbeit):

- Bedürfnis für ein divalentes Metallion für die Aktivität $\left(\mathrm{Mn}^{2+}, \mathrm{Co}^{2+}, \mathrm{Ni}^{2+}\right.$ oder $\left.\mathrm{Fe}^{2+}\right)$

- Abhängigkeit der Aktivität von $\mathrm{NAD}^{+},(\mathrm{NADH})$

- relative Instabilität der Enzyme 
- oligomere Quartärstruktur (Homodimer oder -tetramer)

- die Untereinheitengröße beträgt mehr als $51 \mathrm{kDa}$

Durch weitere Charakterisierungen, auch der vier zusätzlich in T. maritima lokalisierten putativen Glucosidasen (s.o.), wird man in Zukunft noch ein vollständigeres Bild der Familie 4 zeichnen können.

\subsection{Optimierte Aufreinigung und Stärke-modifizierende Aktivität der rekombinanten GTase aus $T$. maritima}

Für die Reinigung der rekombinanten $4-\alpha-$-Glucanotransferase von $T$. maritima waren bereits verschiedene Methoden beschrieben worden (Liebl et al., 1992; Huber, 1994, Meissner, 1997). Meissner (1997) reinigte mittels Affinitätschromatographie an immobilisiertem $\beta$-Cylodextrin, einem kompetitiven Inhibitor des Enzyms, aus 18 I Kulturvolumen 30,6 mg (1,7 mg/l) hochreines Protein auf, hatte aber im Gegensatz zu Huber (1994) mit einer Kontamination durch das MalE-Protein des E. coli-Wirtes Probleme. Um den Aufwand einer dort verwendeten zweimaligen Affinitätschromatographie zu vermeiden, wurde im Rahmen dieser Arbeit wieder auf die bewährte Reinigung mit Hilfe eines Hitzefällungsschritt zurückgegriffen. Wie die gelungene Kristallisation und Röntgenstrukturanalyse der Maltosyltransferase zeigt, muß ein solcher Reinigungsschritt die strukturelle Integrität eines Proteins nicht grundsätzlich negativ beeinflussen. Um zusätzlich das sehr große Kulturvolumen (18 I) zu reduzieren und damit die Handhabung der gesamten Präparation zu vereinfachen, wurde die GTase in den Überexpressionsvektor pET21c kloniert. Hier unterliegt die Expression der Kontrolle durch einen T7-Promotor und wird durch Zugabe von IPTG $(0,1 \mathrm{mM}$ im Falle der GTase) in der exponentiellen Wachstumsphase induziert. Außerdem konnte die Kultivierungszeit nach der Induktion von $16 \mathrm{~h}$ (Meissner, 1997) auf 3,5 h (diese Arbeit) gesenkt werden. Nach Ernte, Waschen und Aufschluß der Zellen wurde die Hitzefällung bei $70^{\circ} \mathrm{C}$ für 20 Minuten durchgeführt bei der $90 \%$ des wirtseigenen E. coli-Proteins präzipitierte und wodurch eine Anreicherung der GTase um den Faktor 5,4 gelang. Durch die folgende Anionenaustauschchromatographie wurde die GTase zur Homogenität gereinigt und der erzielte Reinheitsgrad des Proteins reichte aus, um Kristalle für die Röntgenstrukturanalyse zu züchten (Liebl, persönl. Mitteilung). Letztlich wurden aus $5 \mathrm{I}$ Kulturvolumen $27,8 \mathrm{mg}$ Protein $(5,6 \mathrm{mg} / \mathrm{l})$ mit einer Ausbeute von $25 \%$ erzielt. Damit konnte das 
Kulturvolumen im Vergleich zu Meissner (1997) auf ein Drittel gesenkt werden, um gleiche Mengen qualitativ hochreiner GTase in sehr viel kürzerer Zeit zu reinigen.

Bei der von Huber (1994) bilanzierten affinitätschromatographischen Reinigung der GTase über $\beta$-Cyclodextrin ergab sich eine spezifische Aktivität von $712 \mathrm{U} / \mathrm{mg}$, die mit der in dieser Arbeit etablierten Methode um das 1,65-fache gesteigert werden konnte (1178 U/mg). Die extrem schwache hydrolytische Aktivität wurde in dieser Arbeit mit 0,016 U/mg bestimmt und ist damit ähnlich dem Wert von Huber (1994) von $0,012 \mathrm{U} / \mathrm{mg}$.

Mit der GTase wurden deren Stärke-modifizierenden Eigenschaften untersucht. Stärke aus verschiedenen Quellen variiert in seinen funktionellen Eigenschaften als Konsequenz der unterschiedlichen chemischen Struktur. Ein Verständnis der Beziehung zwischen der molekularen Struktur und den funktionellen Eigenschaften ist für die Grundlagenforschung, aber auch für die Selektion und Entwicklung geeigneter stärkederivatisierter Zusätze für die Nahrungsmittelindustrie von großer Bedeutung. Als wichtiger Parameter gilt dabei die Kettenlängenverteilung der beiden Stärkebestandteile Amylose und Amylopektin. Mit Hilfe der "High performance anion exchange chromatography“ bei hohen pH-Werten und gepulster Amperometrie als Detektionsmethode konnten Polysaccharide (hier: Maisstärke) mit sehr hoher Auflösung ohne vorherige Derivatisierung detektiert werden. Es war dadurch möglich, die durch GTase verursachte Veränderung der Stärke, welche bisher nur über die verschiedenen Verfärbungen im $\mathrm{I}_{2} / \mathrm{KI}$-Test sichtbar geworden war, genauer $\mathrm{zu}$ analysieren. Vor allem konnte durch Inkubation mit Amyloglucosidase auch eindeutig ausgeschlossen werden, daß bei dieser Umsetzung zyklische Verbindungen auftreten. Durch Etablierung dieser Methode ist man weitaus besser in der Lage, die Umsetzung polymerer Oligosaccharide noch detaillierter zu analysieren als beispielsweise mit der konventionellen Dünnschicht-Chromatographie, da die Technik in hohem Maße reproduzierbar und sensitiv (Picomol-Bereich) ist.

Wie bereits erwähnt konnte Huber (1994) $\beta$-Cyclodextrin als kompetitiven Inhibitor für die GTase ausfindig machen. In dieser Arbeit konnte zusätzlich auch Acarbose als Hemmstoff identifiziert werden, welches noch weitaus effektiver als $\beta$-Cyclodextrin wirkte und die GTase unter den Testbedingungen fast vollständig hemmte. Vermutlich gleicht der Pseudosaccharid-Kern der Acarbose dem Übergangszustand der GTase und inhibiert das Enzym durch Interaktionen mit den katalytischen Resten (Sögaard et al., 1993; Takase et al., 1992). Analog zu den Ergebnissen von Meissner 
(1997) für die Maltosyltransferase fungierte das Pseudotetrasaccharid Acarbose nicht als Donor sondern als Akzeptor. Kim et al. (1999) zeigten, daß Acarbose und deren Derivate Acarviosin-Glucose und Isoacarbose die $\alpha$-Glucosidase der Bäckerhefe kompetitiv bzw. eine Cyclodextrin Glucanosyltransferase (CGTase) und $\alpha$-Amylase durch einen gemischten nicht-kompetitiven Mechanismus hemmten. Die drei Inhibitoren unterscheiden sich durch die Kohlenhydratstruktur am reduzierenden Ende voneinander. Während Acarbose eine Maltoseeinheit am reduzierenden Ende aufweist, besitzen Acarviosin-Glucose D-Glucose und Isoacarbose Isomaltose am reduzierende Ende. Acarviosine-Glucose (bzw. Isoacarbose) hemmten die CGTase aus B. macerans sechsmal (zweimal) so stark wie Acarbose. Es wäre interessant zu überprüfen, ob Acarviosin-Glucose und/oder Isoacarbose die GTase (aber auch die MTase) ebenfalls hemmen können.

\subsection{Die Kristallstruktur der Maltosyltransferase}

Um mehr über den Transfermechanismus und die einzigartige Transferspezifität der T. maritima Maltosyltransferase zu lernen, sowie um Hinweise auf die molekularen Grundlagen der Thermostabilität dieses Enzyms zu erhalten, wurde die dreidimensionale Struktur dieses Enzyms aufgeklärt.

\subsubsection{Sekundär- und Domänenstruktur der MTase}

Die Analyse der Primärstruktur (Meissner, 1997) ergab in kurzen Abschnitten signifikante lokale Übereinstimmungen der MTase mit anderen Vertretern der $\alpha$-Amylase-Familie (Familie 13 der Glycosylhydrolasen, nach Henrissat, 1991). Die Enzyme dieser größten Familie der Glycosylhydrolasen katalysieren die Hydrolyse und/oder die Synthese von glycosidischen Bindungen in Stärke und verwandten Poly- und Oligosacchariden. Man kann dabei vier Reaktionstypen unterscheiden: Hydrolyse von $\alpha-1,4-$ oder $\alpha-1,6$-glycosidischer Bindungen und Transglycosylierung zur Formierung von $\alpha-1,4$ - oder $\alpha-1,6$-glycosidischer Bindungen. Für die folgenden neun verschiedenen Enzymtypen konnten bereits die 3-D-Strukturen gelöst werden: $\alpha$-Amylasen (u.a. Kamitori et al., 1999; Fujimoto et al., 1998), Oligo-1,6-Glucosidasen (Watanabe et al., 1997), Maltotetraohydrolasen (Yoshioka et al., 1997), Isoamylasen (Katsuya et al., 1998), Maltogenic Amylasen (Kim et al., 1999), Cyclodextrin Glycosyltransferasen (u.a. Lawson et al., 1994; Knegtel et al., 1996; Ishii et al., 
2000), Amylomaltasen (Przylas et al., 2000), Trehalohydrolasen (Feese et al., 2000) und Amylosucrasen (Skov et al., 2001).

Mit der Maltosyltransferase aus T. maritima steht nun die Kristallstruktur des zehnten Enzymtyps zur Verfügung (Roujeinikova et al., 2001). Es wurde eine Auflösung von 2,4 $\AA$ bzw. 2,1 $\AA$ (Kokristallisation mit Maltose) erreicht. Das Enzym ist ein Homodimer, wobei jede Untereinheit aus 637 Aminosäuren besteht, die wiederum die Domänen N, A, B und C bilden.

Die Aminosäuren 1-63 der N-terminalen Domäne bilden dort zwei $\alpha$-Helices und ein antiparalleles $\beta$-Faltblatt bestehend aus drei $\beta$-Strängen (Abb. 4). N-Domänen treten nur bei wenigen Vertretern der $\alpha$-Amylase-Familie auf. So besitzen die $\alpha$-Amylase TVAll (Reste 1-121; Kamitori et al., 1999), die Maltogenic Amylase (Reste 1-124; Kim et al., 1999) und die Isoamylase (Reste 1-160; Katsuya et al., 1998) jeweils eine extra Domäne am N-terminalen Ende. Allerdings zeigt die im Vergleich dazu kleinere $\mathrm{N}$-Domäne der MTase keine strukturellen Übereinstimmungen mit den genannten $\mathrm{N}$ Termini.

Der N-terminalen Domäne folgt die A-Domäne (Reste 64-204 und 360-572) mit der so typischen katalytischen $(\beta / \alpha)_{8}$-Topologie eines TIM-,barrels“. Neuere Forschungsergebnisse weisen darauf hin, daß viele der $\beta / \alpha-$, ,barrel" aus einem gemeinsamen Halb-,,barrel“-Vorläufermolekül durch Gen-Duplikation und -Fusion hervorgegangen sind und daß anschließend durch eine weitere Duplikation die Diversifikation der katalytischen Aktivität erfolgte (Lang et al., 2000; Miles und Davies, 2000). Die am

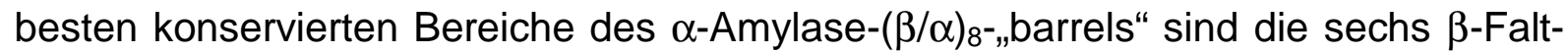
blattstrukturen $\beta 2, \beta 3, \beta 4, \beta 5, \beta 7$ und $\beta 8$ (Janecek, 1997). Diese sind in der Familie 13 besser konserviert als die entsprechenden $\alpha$-Helices, die sehr variabel in Länge und Sequenz sein können. In Übereinstimmung mit allen bisher bekannten $(\beta / \alpha)_{8^{-}}$ „barrel“-Enzymen (Farber und Petsko, 1990; Brändén, 1991) befinden sich auch bei der MTase die katalytischen Reste am C-terminalen Ende des „barrels“ und zwar auf den $\beta$-Strängen $\beta 4$ (Asp385), $\beta 5$ (Glu414) und auf der Schleife nach $\beta 7$ (Asp468). Dies entspricht den $\beta$-Strängen $\beta 9, \beta 10$ und $\beta 12$ der Nummerierung in Abbildung 4. Als weiteres konserviertes Merkmal der Familie 13 besitzt auch die MTase eine B-Domäne (Reste 205-359), welche zwischen dem dritten $\beta$-Strang und der dritten $\alpha$-Helix inseriert ist. Dieser Bereich ist in der $\alpha$-Amylase Familie diejenige Region, die die größte Variabilität bezüglich der Länge und der Sequenz aufweist. Die 
schleifenreiche Struktur der B-Domäne enthält einige kurze $\alpha$-Helices. Die B-Domäne der MTase (155 As-Reste) ist im Vergleich zu anderen B-Domänen der

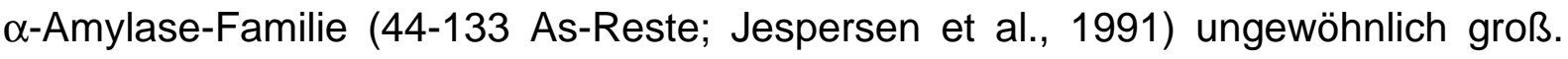
Sie wird z. B. nur noch vom Glykogen-Entzweigungs-Enzym (261 As-Reste; Jespersen et al., 1993; Liu et al., 1993) übertroffen. In Abhängigkeit von der Größe kann die Domäne das aktive Zentrum mehr oder weniger stark abschirmen und somit sicherlich auch die enzymatische Aktivität beeinflussen. Bei einigen Enzymen der Familie 13 konnten der Domäne B eine Funktion bei der Substraterkennung/-bindung zugeordnet werden, bei $\mathrm{Ca}^{2+}$-abhängigen Enzymen trägt sie durch Wechselwirkungen mit dem zweiwertigen Ion zur Stabilisierung der Proteinstruktur im Bereich des aktiven Zentrums bei (Buisson et al., 1987).

Die Domäne C (As 573-637) besteht aus acht antiparallelen $\beta$-Strängen, die ein sogenanntes ,jellyroll Greek key $\beta$ barrel“ ähnlich dem des $\gamma$-Crystallins (Richardson, 1981) bilden. Auf Aminosäuresequenzebene gab es bisher keine signifikanten Homologien zu anderen Proteinen (Meissner und Liebl, 1998). Eine strukturelle Ähnlichkeitssuche (Roujeinikova et al., 2001) ergab, daß die C-Domäne der MTase gewisse strukturelle Ähnlichkeiten zur C-Domäne der B. circulans CGTase (Uitdehaag et al., 1999) bzw. zur Oligo-1,6-Glucosidase aus B. cereus (Watanabe et al., 1997) aufwies, wobei die Erstere funktionell in die Kohlenhydratbindung eingebunden zu sein scheint (Knegtel et al., 1995). Die Überlagerung entsprechender Aminosäurereste (der C-Domäne) der CGTase und der Oligo-1,6-Glucosidase mit der MTase ergab Sequenzidentitäten von $18 \%$ bzw. $15 \%$. Weiterhin konnten wir eine entfernte Ähnlichkeit der C-Domäne der MTase mit der räumlichen Anordnung der Cellulose-Binde-Domänen (CBD) der Familie III zeigen (Roujeinikova et al., 2001), obwohl sich die beiden Strukturen in der Größe ( $\approx 150$ Aminosäurereste bei den CBDs und 65 Reste bei der MTase) deutlich unterscheiden. Aufgrund der strukturellen Ähnlichkeit könnte eine mögliche Funktion des C-Terminus der MTase die einer Polysaccharid-Bindedomäne sein.

\subsubsection{Maltosebindung}

Maltose wird von der MTase nicht als Donor-Substrat akzeptiert (Meissner, 1997) und konnte deshalb zur Kokristallisation eingesetzt werden. Es war zu erwarten, daß in der dreidimensionalen Organisation des MTase-Maltose-Komplexes sich somit der Zustand unmittelbar nach der Substratspaltung darstellte. Tatsächlich zeigten 
Kristalle, welche in Gegenwart von $50 \mathrm{mM}$ Maltose gewachsen waren, nach ihrer Strukturauflösung mit 2,1 $\AA$ zwei Maltose-Bindestellen (Abb. 29, 30). Die erste Maltose-Bindestelle befindet sich in einer Tasche im Bereich des aktiven Zentrums. In Übereinstimmung mit anderen Enzymen der $\alpha$-Amylase Familie (Buisson et al., 1987) ist der Bindungsbereich für die -2 und -1 Glucoseeinheiten von polaren (Lys151, Arg383) und aromatischen (Tyr158, Phe537) Aminosäuren der Domänen A und B umgeben. Die Bindung der Maltose erfolgt hauptsächlich über Wechselwirkungen des Glucoseringes $g_{-1}$ (reduzierendes Ende) mit dem aromatischen Ring des Tyrosins158 und durch ein Netzwerk von Wasserstoffbrückenbindungen, welches die meisten der O-Atome der Zuckerhydroxylgruppen umfasst (Tab. 20). So bestehen direkte Wasserstoffbrücken zu Asp468 OD1 und OD2, Glu414 OE1, Arg383 NH2, Asn512 ND2, Lys151 NZ, Asp317 OD1 und OD2 und Ser156 OG. Wasser-vermittelte Wasserstoffbrückenbindungen bestehen zwischen der nichtreduzierenden Glucose-Ring ( $\left.g_{-2}\right)$ C2-Hydroxylgruppe und Asn512 OD1 und zwischen der g-1 C6-Hydroxylgruppe und Thr206 OG1 und dem Tyr158 Carbonylsauerstoffatom. Lediglich die $\mathrm{O} 4$ und $\mathrm{O} 5$ Atome des $\mathrm{g}_{-1}$-Restes bilden keine Wasserstoffbrückenbindungen aus. Es gibt aber noch van der Waals Kontakte des reduzierenden Glucoserestes mit der Seitenkette des Phe537.

Tab. 20: Wasserstoffbrückenbindungen des MTase-Maltose-Komplexes

\begin{tabular}{|c|c|c|}
\hline Atom & Protein Atom oder Wassermolekül & Abstand $(\AA)$ \\
\hline \multicolumn{3}{|l|}{ Maltose1 } \\
\hline $\mathrm{g}_{-1}-\mathrm{O} 1$ & Glu414-OE1 & 2,34 \\
\hline \multirow[t]{2}{*}{$\mathrm{g}_{-1}-\mathrm{O} 2$} & Arg383-NH2 & 3,15 \\
\hline & Asp468-OD2 & 2,71 \\
\hline$g_{-1}-\mathrm{O} 3$ & Asp468-OD1 & 2,78 \\
\hline $\mathrm{g}_{-1}-\mathrm{O} 6$ & $\mathrm{H}_{2} \mathrm{O} 63^{1}$ & 3,06 \\
\hline \multirow[t]{2}{*}{$\mathrm{g}_{-2}-\mathrm{O} 2$} & Asn512-ND2 & 3,26 \\
\hline & $\mathrm{H}_{2} \mathrm{O} 293$ & 3,11 \\
\hline$g_{-2}-\mathrm{O} 3$ & Lys151-NZ & 2,49 \\
\hline $\mathrm{g}_{-2}-\mathrm{O} 4$ & Asp317-OD1 & 3,12 \\
\hline $\mathrm{g}_{-2}-\mathrm{O} 5$ & Ser156-OG & 3,16 \\
\hline $\mathrm{g}_{-2}-\mathrm{O} 6$ & Asp3170D2 & 2,70 \\
\hline \multicolumn{3}{|l|}{ Maltose2 } \\
\hline \multirow[t]{2}{*}{$g_{-2}-\mathrm{O} 3$} & Glu415-OE2 & 2,61 \\
\hline & Ser424-OG & 2,66 \\
\hline $\mathrm{g}_{-2}-\mathrm{O} 6$ & Tyr429-OH & 2,51 \\
\hline
\end{tabular}

$1 \mathrm{H}_{2} \mathrm{O} 63$ bildet zusätzlich noch Wassersoffbrücken zu Thr206 OG1 (2,81 $\AA$ ) und zum Carbonylsauerstoff von Tyr158 (3,07 $\AA$ ), und $\mathrm{H}_{2} \mathrm{O} 293$ bildet eine Brücke zu Asp512 OD1 $(2,69 \AA)$ aus (aus Roujeinikova et al., 2001). 
An der Bildung der -1,subsite“ der MTase sind fünf Aminosäurereste (Tyr158, Arg383, Asp385, Glu414 und Asp468) beteiligt, die innerhalb der Familie 13 hochkonserviert vorliegen (Janecek, 1997). Es ist daher anzunehmen, daß die Interaktionen an dieser „subsite“ einen entscheidenden Beitrag zur Substratbindung und zur Katalyse leisten. Im Gegenzug dazu nehmen die Reste an der -2 „subsite“ wahrscheinlich eine wichtige Aufgabe bei der Erkennung des nicht-reduzierenden Substratendes wahr und könnten deshalb auch für die Transferspezifität der MTase von Bedeutung sein. Vor allem Lys151 erscheint aufgrund seiner räumlichen Position von besonderer Wichtigkeit. Die Seitenkette dieses Restes bildet eine sterische Barriere an der Stelle, wo sich die -3 „subsite“ bei homologen Enzymen befindet. Dies könnte einer der Gründe sein, die eine Abspaltung längerer Zuckereinheiten als Maltose vom Substrat verhindern. Auf die Auswirkungen des Austausches von Lys151 gegen Alanin wird im nächsten Kapitel näher eingegangen.

An der zweiten Maltose-Bindestelle in einer Distanz von $10 \AA$ zum aktiven Zentrum (Abb. 29) wird der Glycosylrest von Wasserstoffbrücken zu Glu415 OE2, Ser424 OG und Tyr429 OH und durch van der Waals Kontakte mit Gly387, His388 uns Ala423 stabilisiert. Die funktionelle Rolle bleibt zunächst im Unklaren und es bedarf weiterer biochemischer Studien, um diese Frage zu klären. Eine Möglichkeit wäre eine regulatorische Funktion oder die Beteiligung an der Bindung verzweigter (komplexer) Substrate. Im Rahmen einer Computersimulation war es möglich, eine Verbindung zwischen den beiden Maltose-Bindestellen durch das Einfügen von vier Zuckerringen herzustellen (nicht gezeigt). Die Problematik der biochemischen Analyse besteht darin, daß kurze definiert verzweigte Substrate kommerziell nicht zur Verfügung stehen. Das Auftreten mehrerer Maltose-Bindestellen wurde auch für die Cyclodextrin Glycosyltransferase aus Bacillus circulans Stamm 251 nachgewiesen (Lawson et al., 1994). Dort ist eine Bindestelle in der Domäne C und zwei MaltoseBindestellen in der Domäne E lokalisiert, wobei die beiden letztgenannten Wechselwirkungen mit solchen Aminosäureresten eingehen, die zusammen ein konserviertes Stärke-Bindemotiv bilden.

\subsection{Ortsspezifische Mutagenese der Maltosyltransferase}

Der Unterschied des Reaktionsmechanismus zwischen Transferasen und Hydrolasen wird nach wie vor nicht vollständig verstanden. Es wird aber angenommen, daß beide Reaktionen (Hydrolyse und Transglycosylierung) über eine ähnliche nukleo- 
phile Reaktion zwischen dem anomeren C-Atom des Substrates und einem Nukleophil verlaufen, wobei der wesentliche Unterschied darin besteht, daß im Falle der Hydrolyse das Reaktionsintermediat von einem aktivierten Wassermolekül und im Fall der Transglycosylierung das Intermediat von einem aktivierten Kohlenhydratmolekül angegriffen wird. Im folgenden Kapitel werden nun der Reaktionsmechanismus und die entsprechenden ortsspezifischen Mutagenesen bei der MTase näher erläutert.

\subsubsection{Aktives Zentrum, Reaktionsmechanismus, Substratbindung und Transferspezifität}

Glycosyl-Hydrolasen und Transferasen arbeiten nach vier Grundmechanismen, deren Bezeichnung sich anhand der anomeren Konfiguration des Substrates ( $\alpha$ - oder $\beta$-glycosidische Bindungen) und der stereochemischen Ausrichtung des Reaktionsproduktes (Retention oder Inversion) orientiert. Die $\alpha$-Amylase-Familie nutzt den $\alpha$-retentierenden Reaktionsmechanismus. Damit katalysiert die Maltosyltransferase eine enzymatische Reaktion, bei der die Konfiguration am anomeren C-Atom beibehalten wird. Diese Reaktion wird als „double displacement“-Mechanismus (McCarther und Withers, 1994) bezeichnet und verläuft in zwei Stufen über ein Glycosyl-Enzym-Intermediat (Abb. 44), wobei noch nicht geklärt ist, ob es sich dabei um eine $S_{N} 1$ oder $S_{N} 2$ Substitution handelt. Das Modell des katalytischen Mechanismus der MTase sieht folgendermaßen aus:

Im Falle einer $S_{N} 1$-Reaktion wird das Sauerstoff-Atom der glycosidischen Bindung des Substrates durch eine als Säure wirkende As (Glu414 der MTase) protoniert und die $\alpha-1,4-g$ lycosidische Bindung des Substrates gespalten, so daß das reduzierende Substratfragment freigesetzt wird. Das (in den -2 und -1 „subsites“ im Falle der MTase) verbleibende Carbenium-Ion (Maltosylrest) wird mittels eines zweiten katalytischen Restes (Asp385 bei der MTase) durch elektrochemische Wechselwirkungen im aktiven Zentrum des Enzyms stabilisiert. Dann greift ein Wassermolekül im Falle der Hydrolyse bzw. ein Kohlenhydratmolekül (Akzeptor) im Falle einer Transglycosylierungsreaktion an das Carbenium-Ion an. Zuvor wurden diese Verbindungen durch Deprotonierung mit Hilfe einer Base (Glu414 bei der MTase) aktiviert. Schließlich wird die Reaktion durch Bildung einer $\alpha$-1,4-glycosidischen Bindung vollendet, wobei bei der Hydrolyse eine aktivierte Hydroxylgruppe und bei der Transferase-Reaktion die $\mathrm{OH}-4-G r u p p e$ eines aktivierten Kohlenhydratmoleküls 
als Akzeptor fungiert. In einer $S_{N} 2-$ Reaktion greift der zweite katalytische Rest (Asp385) als Nukleophil das anomere C1-Atom an und es wird eine kovalente Bindung zwischen dem im aktiven Zentrum verbleibenden Glycosyl- (Maltosyl-) rest und dem Nukleophil ausgebildet. Der weitere Ablauf erfolgt analog zum $S_{N} 1-$ Mechanismus.

Kürzlich konnten Uitdehaag et al. (1999) für die Cyclodextrin Glycosyltransferase die kovalente Bindung eines Reaktionsintermediates nachweisen. Ob sich diese Aussagen allerdings auf die Enzyme der Familie 13 allgemein übertragen lassen, bleibt vorerst abzuwarten.

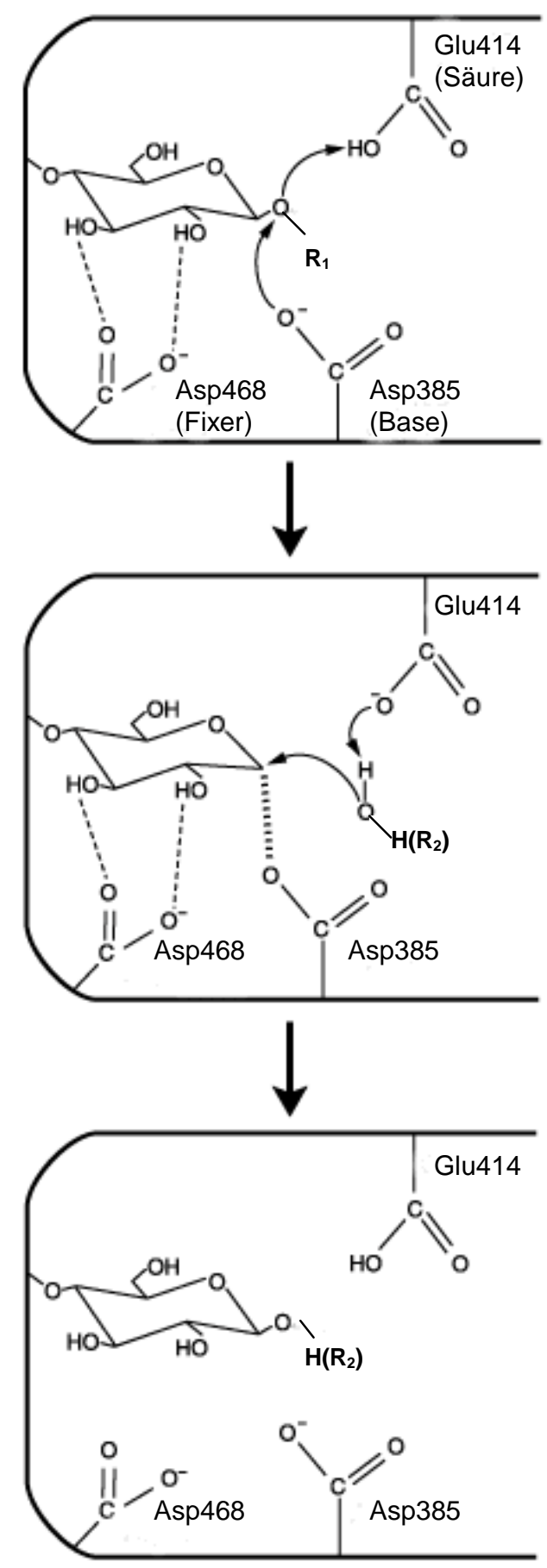

Abb. 44: Schematische Darstellung des Reaktionsmechanismus einer retentierenden Glycosylhydrolase oder -transferase (die Bezeichnung der katalytischen Reste erfolgte analog zur MTase). Erläuterungen, siehe Text. 
Dem durch Mutagenese-Studien (Takase et al., 1992; Klein et al., 1992; Sögaard et al., 1993) ermittelten putativen dritten katalytischen Rest (Asp468 der MTase) wird eine Rolle bei der korrekten Ausrichtung und damit Fixierung des Substrates zugesprochen, um eine möglichst leichte Spaltung der glycosidischen Bindung zu erreichen. Bei der MTase bildet dieser Rest zwei Wasserstoffbrückenbindungen zu den O2- und O3-Hydroxylgruppen der -1 Glucoseeinheit aus, so daß die Substraterkennung und -ausrichtung auch hier im Vordergrund stehen dürfte. Eine weitere Funktion könnte die Stabilisierung der positiven Ladung am C1-Atom des Oxocarbeniumions sein, d.h. die Stabilisierung des Übergangzustandes, welcher nach der Spaltung der glycosidischen Bindung des Substrates entsteht (McCarter und Withers, 1994).

Bei der Hydrolyse wird der Abstand von Asp468 und Glu414 als bedeutend angesehen. Diese beiden Reste sind wahrscheinlich für die korrekte Positionierung und damit Aktivierung eines Wassermoleküls verantwortlich. Ist der Abstand zwischen diesen beiden katalytischen Resten größer als etwa $4 \AA$, so verhindert letztlich die Geometrie im aktiven Zentrum die Bindung und Aktivierung des Wassermoleküls und somit eine hydrolytische Reaktion. Um die Frage zu klären, warum die MTase hauptsächlich nur Transglycosylierungsaktivität und nur minimale hydrolytische Aktivität zeigt, bietet sich ein Vergleich der genauen Anordnung der katalytischen Reste im aktiven Zentrum verwandter Enzyme an. Abb. 45 zeigt, daß der Abstand zwischen Asp468 und Glu414 bei der MTase mit 5,6-6,1 $\AA$ größer ist als bei der CGTase aus $B$. circulans, der TAKA-Amylase A und als bei der Oligo-1,6Glucosidase aus $B$. cereus (3,6-4,1 $\AA$; Roujeinikova et al., 2001). Es ist nun naheliegend anzunehmen, daß die fast vollständig fehlende Hydrolyse der MTase durch den vergrößerten Abstand der beiden katalytischen Reste verursacht wird. Die größere Entfernung der Reste voneinander, d.h. die veränderte Geometrie in der 3 D-Struktur, macht wahrscheinlich eine gemeinsame Funktion bei der Bindung und Aktivierung eines katalytischen Wassermoleküls unmöglich. Der Austausch T466N scheint den Abstand zwischen Asp468 und Glu414 nicht so zu beeinflussen, daß die hydrolytische Aktivität zunimmt. Bei dieser Mutante nahm sowohl die Transfer- als auch die hydrolytische Aktivität ab, wobei die hydrolytische Aktivität sogar stärker abnahm als die Transferaktivität (siehe Abb. 42). 


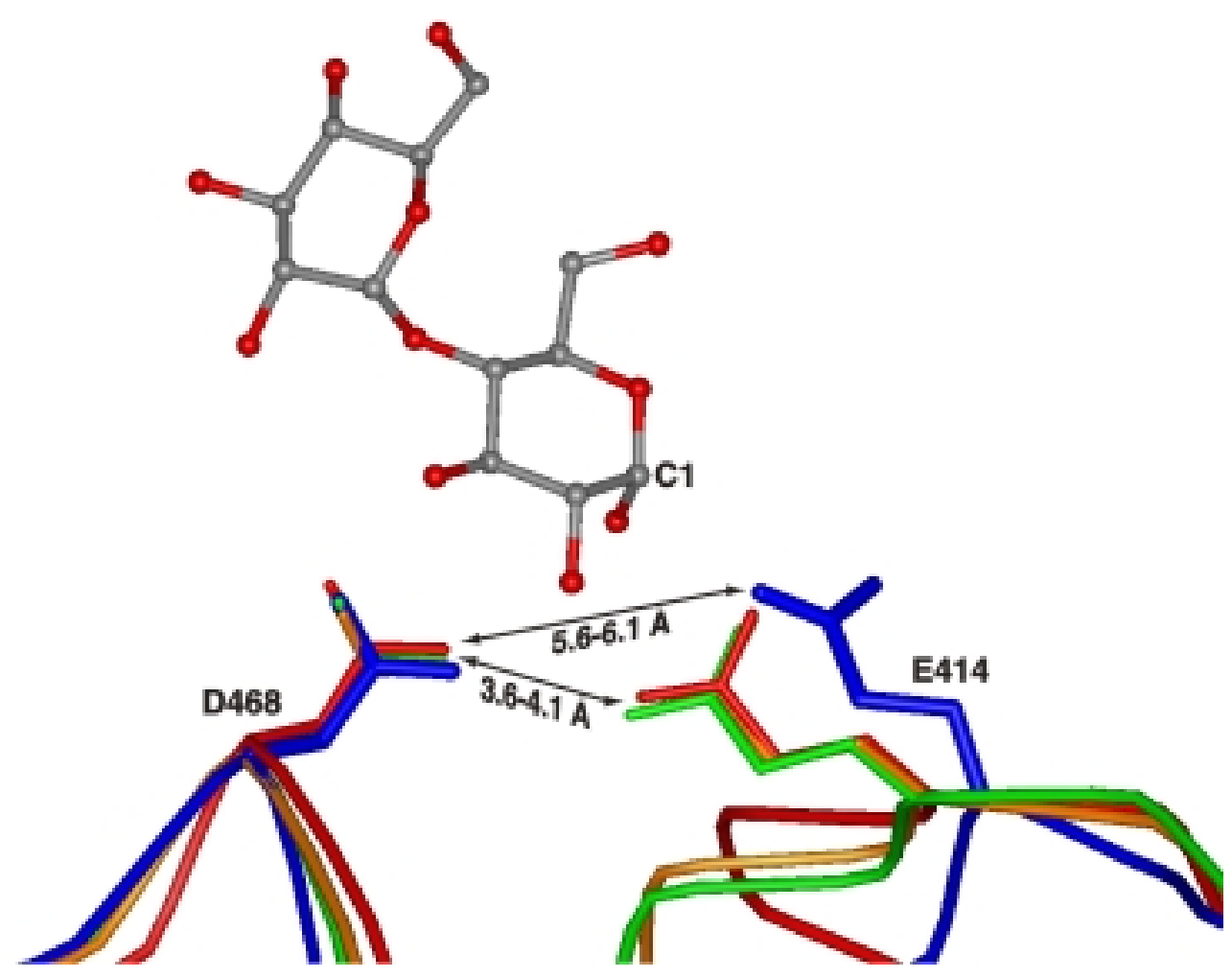

Abb. 45: Relative Positionen von Glu414 und Asp468 in der MTase (5,6 - 6,1 A) im Vergleich mit den Positionen der äquivalenten Reste im aktiven Zentrum der TAKA-Amylase A, der CGTase aus B. circulans und der Oligo-1,6-Glucosidase aus B. cereus (3,6 - 4,1 $\mathrm{A})$

Durch ortsspezifische Mutagenese wurden die Mutanten D385N und E414Q hergestellt, die aufgrund ihrer Konserviertheit in der $\alpha$-Amylase Familie als die katalytischen Reste angesehen werden. Der beobachtete drastische Abfall in der katalytischen (Transfer-) Aktivität der Mutanten auf $\leq 0,3 \%$ (Tab. 18) bestätigte die Einbindung dieser Aminosäuren in die Katalyse. Die verbliebene minimale Restaktivität konnte nach ausgedehnter Inkubation von mutiertem Enzym mit Substrat und anschließender dünnschichtchromatographischer Analyse sichtbar gemacht werden (Abb. 41). Restaktivitäten bei „active site“-Mutanten wurden bereits früher beobachtet (Uitdehaag et al., 2000; Yoshioka, et al., 1997; Takase et al., 1992). In der Regel sind sie unter normalen Testbedingungen nicht detektierbar, sondern können nur durch extrem lange Inkubationszeiten mit konzentrierten Enzymproben gezeigt werden. Die Ursache der verbleibenden Aktivität wird folgenden Möglichkeiten zugeschrieben: (teilweise) Reversion der Mutation; (teilweise) Deamidierung bei der Kultivierung und/oder hohen Temperaturen (z.B. Hitzefällungsschritt bei der Aufreinigung); Kontamination während der Aufreinigung (z.B. bei der Affinitätschromatographie); andere potentiell weniger aktive Protonendonatoren/Nukleophile 
(Wasser und/oder gelöste Moleküle) übernehmen die Funktion der ehemaligen katalytischen Reste. Trotz der bekannten Restaktivität der „active site“-Mutanten wurde versucht, eine Kokristallisation mit Maltooligosacchariden durchzuführen, um die dreidimensionale Struktur eines Enzym-Substrat-Komplexes und insbesondere die Bindung eines Donorsubstrates in der Substratbindungstasche zu beobachten. Leider wurde nur gebundene Maltose im aktiven Zentrum lokalisiert, d.h. ein Zustand nach der Substratspaltung. Um das Problem der Restaktivität weiter zu minimieren, wäre die Konstruktion einer Doppelmutante (D385A / E414A) denkbar. Uitdehaag et al. (2000) zeigten, daß eine E257A/D229A-Mutante eine 1000-fach niedrigere Aktivität aufweist, als eine E257Q/D229N CGTase, welche ihrerseits eine 700000fach reduzierte Aktivität im Vergleich zum Wildtyp hat. Zusätzlich verwendeten sie 4-Deoxymaltose als inkompetenten Akzeptor während der Kristallisation und konnten so eine unerwünschte Transglycosylierungsreaktion vermeiden.

Der Lysinrest 151 (siehe 3.4.4) und Aspartat 317 werden als bedeutend bei der Erkennung des nicht reduzierenden Substratendes durch die MTase angesehen. Zusätzlich findet man bei der dimeren MTase van der Waals Interaktionen zwischen Lys151 des einen Monomers mit Tyr104 des anderen Monomers, welche zur stabilisierten und korrekten Ausrichtung der Lysin-Seitenkette beitragen. Deshalb wurden die Mutanten K151A, D317A und die Doppelmutante K151A/D317A konstruiert. Gelfiltrationsexperimente zeigten, daß die Dimerisierung durch die K151A-Mutante nicht beeinträchtigt wurde (Tab. 17; Abb. 37). Bei allen drei Mutanten war die Transferspezifität unverändert: Bei der dünnschichtchromatographischen Analyse von Reaktionsprodukten aus definierten Maltooligosacchariden wurden analog zur MTase typische Produktmuster erhalten, d.h., daß Lys151 als sterische Barriere nicht allein für die hohe Transferspezifität der MTase verantwortlich ist, sondern noch andere bisher unbekannte Faktoren eine Rolle spielen. Wohl aber sind die Aminosäuren bei der Erkennung (über Wasserstoffbrückenbindungen; Tab. 20) des nicht reduzierenden Substratendes von essentieller Bedeutung. Im $\mathrm{I}_{2} / \mathrm{KI}$-Test, durch den die Transferaktivität gemessen wird, war unter Testbedingungen bei allen drei Mutanten praktisch keine Aktivität mehr festzustellen (Tab. 18).

Vergleichende Strukturanalysen offenbarten das Fehlen zweier streng konservierter Histidinreste bei der MTase (Meissner und Liebl, 1998). Diese (entsprechend His122 und His296 bei der TAKA-Amylase) sind bei der MTase durch Thr206 und Pro467 ersetzt und flankieren die -1 "subsite“. Postuliert man, daß eine räumlich konservierte 
Anordnung (siehe Abb. 31) bestimmter Aminosäuren im Bereich des aktiven Zentrums in der $\alpha$-Amylase-Familie einen ähnlichen Reaktionsmechanismus begünstigen, so kann man für Thr206 und Pro467 eine Bedeutung bei der MTase-spezifischen Transferaseaktivität fordern. In der Familie 13 haben die beiden Histidinreste eine Funktion bei der Substratbindung und bei der Stabilisierung des Übergangszustandes, sind aber nicht direkt an der Katalyse beteiligt (Sögaard et al., 1993). Die Mutanten T206H, P467H und T206H/P467H verhielten sich bei der DC-Analyse wie die MTase, d.h. ihr Produktmuster und die Transferspezifität waren nahezu unverändert (Abb. 41). Die quantitative Auswertung (Tab. 18; Abb. 42) ergab, daß bei T206H die hydrolytische Aktivität gegenüber der Transferaktivität (relativ zum Hydrolyse/Transfer-Verhältnis bei der Wildtyp-MTase) um das 1,9-fache gesteigert war. Bei P467 war das Verhältnis fast unverändert und bei der Doppelmutante konnten aufgrund der schwachen Aktivitäten keine sicheren Aussagen getroffen werden. Eine Überprüfung der Ergebnisse für die Mutante T206H, also die tatsächlichen strukturellen Auswirkungen der Mutation auf die enzymatische Aktivität, kann mit Hilfe der Röntgenstrukturanalyse durchgeführt werden. Wahrscheinlich kommt es beim Austausch von Thr206 und Pro467 gegen Histidin zu einer (strukturell) veränderten Form der Substratbindung, die auf die enzymatische Katalyse insgesamt einen negativen Einfluß hat, aber zumindest im Falle von $\mathrm{T} 206 \mathrm{H}$ zu einer Verschiebung des Verhältnisses von Transfer- zu Hydrolyseaktivität in Richtung Hydrolyseaktivität führt.

Eventuell könnte ein weiterer/anderer Aminosäureaustausch helfen, die hydrolytische Aktivität der MTase zu steigern. Kim et al. (2000) ersetzten Glu332 (entsprechend His210 bei der TAKA-Amylase und Ala389 bei der MTase) einer Maltogenic-Amylase mit einem Histidinrest und erhielten eine verminderte Transferase- und eine gesteigerte hydrolytische Aktivität, wobei sie davon ausgehen, daß der Austausch der sauren Seitenkette des Glutamats für diesen Effekt verantwortlich ist. Vielleicht hat eine Modifizierung von Ala389 der MTase einen ähnlichen Effekt auf die Aktivität.

\subsubsection{Oligomerisation und Thermostabilität}

Das Studium der Thermostabilität von Proteinen ist nicht nur von theoretischem Interesse, sondern spielt auch im Hinblick auf biotechnologische Anwendungen eine wichtige Rolle. Aus diesen Gründen ist es notwendig, ein möglichst vollständiges Bild aller Faktoren, welche die Stabilität und die katalytische Aktivität bei verschiedenen 
Temperaturen beeinflussen, zu erhalten. Neben ortsspezifischen Mutagenesestudien können Vergleiche hochaufgelöster Proteinkristallstrukturen thermolabiler und thermostabiler Enzyme mit ähnlicher Faltung und Funktion eine Reihe von möglichen stabilisierenden Faktoren liefern (u.a. Macedo-Ribeiro et al., 1996; Szilágyi und Závodszky, 2000; Sterner und Liebl, 2001). Dabei gibt es keine allgemeingültigen Regeln, um die Thermostabilität von Proteinen zu erklären. Vielmehr beruht sie oftmals auf kleinen Veränderungen unterschiedlicher Einzelfaktoren bzw. auf der Kombination mehrerer derartiger Veränderungen und diese wiederum können zwischen verschiedenen Enzymen stark variieren. Das Problem bei der Analyse einzelner Faktoren liegt in der genauen Zuordnung, d.h. des wirklichen Beitrages einer Interaktion zur Stabilität in einem hohen kooperativem komplexen System, wie es in einem nativen Enzym der Fall ist. Letztlich beträgt die Energiedifferenz in der Stabilität zwischen mesophilen und (hyper-) thermophilen Proteinen, $\Delta G_{N \rightarrow D}\left(=G_{D}-G_{N}\right.$ $=\Delta \mathrm{H}_{\mathrm{N} \rightarrow \mathrm{D}}-\mathrm{T} \Delta \mathrm{S}_{\mathrm{N} \rightarrow \mathrm{D}}$ ), meist weniger als $100 \mathrm{~kJ} / \mathrm{mol}$ (Wassenberg et al., 2000; Jaenicke und Böhm, 1998; Vielle und Zeikus, 1996), was gleichbedeutend mit einigen wenigen nicht-kovalenten Interaktionen ist. Bei Wasserstoffbrücken beispielsweise reichen die Bindungsenergien von etwa 12 bis $29 \mathrm{~kJ} / \mathrm{mol}$. Folgende Typen intermolekularer Interaktionen können allein oder auch gemeinsam zur Thermostabilisierung einer Proteinstruktur beitragen: Wasserstoff- und/oder Salzbrückenbindungen, entweder alleine oder in Netzwerken (= elektrostatische Interaktionen; Scandurra et al., 1998; Vogt et al., 1997; Rice et al., 1996; Tanner et al., 1996; Goldman, 1995), Bildung oder Stabilisierung von $\alpha$-Helices und $\beta$-Faltblattstrukturen in der Sekundärstruktur (Verminderung von irregulären Regionen) und allgemeine Schleifenverkürzung, zunehmende Oligomerisierung verbunden mit vermehrten hydrophoben Interaktionen an der Untereinheiten-Nahtstelle (Dams et al., 2000; Maes et al., 1999; Hennig et al., 1997), mehr Prolin- und weniger Glycinreste (Watanabe et al., 1997), höherer Anteil geladener Aminosäuren und Verminderung der chemisch instabilen Methionin- und Asparaginreste (Szilágyi und Závodszky, 2000), stabilisierende Metallionen, Fixierung des $\mathrm{N}$ - und des C-Terminus an das Kernprotein (Macedo-Ribeiro et al., 1996) und kleineres Oberflächen-Volumen-Verhältnis (Verringerung von Oberflächen und Hohlräumen; Szilágyi und Závodszky, 2000; Tanner et al., 1996) durch bessere und kompaktere Anordnung (Erhöhung der van der Waals Kontakte $\rightarrow$ erhöhte Rigidität). Es sei an dieser Stelle darauf hingewiesen, daß beim Vergleich von mesophilen und (hyper-) thermophilen Enzymen oftmals auch fehlerhafte oder gar unvollständige 
Strukturen mit minderer Qualität verwendet wurden, so daß die Qualität eines Faktors für die Thermostabilität zum Teil völlig falsch beurteilt wurde. Dies betrifft vor allem Wasserstoffbrückenbindungen, deren Anteil an der Thermostabilität nach wie vor kontrovers diskutiert wird (Szilágyi und Závodszky, 2000).

Die MTase zeigt eine bemerkenswerte Stabilität gegenüber thermischer Inaktivierung mit Halbwertszeiten von $2,5 \mathrm{~h}$ bei $90^{\circ} \mathrm{C}, 17 \mathrm{~h}$ bei $85^{\circ} \mathrm{C}$ und 21 Tagen bei $70^{\circ} \mathrm{C}$ (jeweils pH 6,5; Meissner, 1997). Von den oben aufgeführten Möglichkeiten zur Stabilisierung eines Proteins konnten für die MTase unter anderem ein erhöhter Anteil (31,6\%) geladener Aminosäuren (Arg, Lys, His, Asp und Glu) im Vergleich zum mesophilen Durchschnitt (24,1\%; Deckert et al., 1998) festgestellt werden. Dieser modifizierte Aminosäuregebrauch entspricht einem generellen Trend in thermophilen Mikroorganismen. Weiterhin finden sich bei der MTase eine Vielzahl (47) von Salzbrücken, vier Cluster von dreifach-Salzbrücken und vier Intra-Helix Ionenpaare (Roujeinikova et al., 2001). Der genaue Beitrag einer Salzbrücke zur thermischen Stabilisierung muß aber noch untersucht werden.

Auf die Stabilisierung durch Oligomerisierung (u. a. Dams et al., 2000; Jaenicke und Böhm, 1998; Hennig et al., 1997) deuten bei der MTase starke hydrophobe Wechselwirkungen an der dimeren Nahtstelle hin. Das hydrophobe Cluster am Dimer-Interface umfaßt 11 Aminosäuren (siehe 3.4.4). Durch Zusammenlagerung der beiden monomeren Untereinheiten verringert sich die zugängliche Oberfläche um 7,9\% (Roujeinikova et al., 2001), d.h. die Dimerisierung der MTase führt zur Abnahme der hydrophoben Oberfläche im Bereich der Monomer-MonomerKontaktstelle. Der Bedeutung der Dimerisierung wurde durch die Konstruktion einer Monomer-Mutante der MTase (V110R bzw. V110R/A230R) nachgegangen. Frühere Studien (Meissner und Liebl, 1998) wiesen darauf hin, daß die MTase im nativen Zustand als ein Komplex mit mehr als 450 kDa assembliert. In dieser Arbeit konnte jedoch gezeigt werden, daß die gereinigte MTase sowohl in saurer $(\mathrm{pH} 4,8)$ als auch in neutraler Lösung $(\mathrm{pH} \mathrm{7,0)}$ als Homodimer vorliegt. Für die Mutante V110R wurde eine Monomerisierung (65 $\pm 5 \mathrm{kDa}$ ) durch Gelfiltration und native Gelelektrophorese nachgewiesen (siehe 3.5.4). Eine modifizierte Oberflächenhydrophobizität des mutierten Enzymderivats konnte bereits bei der Aufreinigung durch hydrophobe Interaktionschromatographie anhand des veränderten Elutionsverhaltens beobachtet werden. Das MTase-Derivat V110R wies im Vergleich zur dimeren MTase ein um etwa $10^{\circ} \mathrm{C}$ vermindertes Temperaturoptimum auf. Die Thermoinaktivierungskinetik 
der Monomer-Mutante war gegenüber der MTase beschleunigt, wobei sich das „Temperaturfenster“, bei dem die Destabilisierung von V110R erfolgte, als äußerst schmal (etwa $2^{\circ} \mathrm{C}$ ) erwies. Es ist offensichtlich, daß bei der MTase gerade die Dimerisierung einen entscheidenen Beitrag zur Thermostabilisierung des Enzyms leistet. Dams et al. (2000) ordneten der Thermostabilität bei der DihydrofolatReduktase aus T. maritima ebenfalls Dimerisierung als Hauptursache zu und auch Consalvi et al. (2000) betrachten die Interdomänen-Wechselwirkung als wesentliche Ursache für die Stabilität der Domäne II der Glutamat Dehydrogenase aus T. maritima. Zum Nachweis des Anteils der Oligomerisierung an der extremen Thermostabilität der MTase bedarf es zusätzlicher thermodynamischer Studien zur Entfaltungskinetik und Konformationsstabilität. Es gibt auf der anderen Seite auch Beispiele, die gegen einen generellen Mechanismus der thermischen Stabilisierung durch zunehmende Oligomerisierung sprechen, z.B. die vermutlich dimere Enolase aus dem hyperthermophilen Archaeon Pyrococcus furiosus (Peak et al., 1994), da andere mesophile Enolasen Oktamere darstellen (Schurig et al., 1995).

Oligomerisierung wird von Park et al. (2000) auch als mögliche Ursache für die breite Substratspezifität einer Cyclomaltodextrinase (CDase) und anderen amyloIytischen Enzymen angesehen. Ob dies auch für die MTase zutrifft, müßte durch Analyse der Substratspezifität der Monomer-Mutante V110R experimentell belegt werden. Diese zeigte interessanterweise eine gesteigerte hydrolytische Aktivität bei gleichzeitig verminderter Transglycosylierungsaktivität. Die Ursachen hierfür sind vermutlich veränderte Bindungsaffinitäten im aktiven Zentrum. Experimentell lassen sich diese Bindungsaffinitäten nur schwer messen. Es ist aber offensichtlich, daß bei einer längeren Bindung des Substrates im katalytischen Bereich die Hydrolysegegenüber der Transferrate ansteigen muß.

Die Identifizierung einzelner oder mehrerer Eigenschaften als Faktoren der Thermostabilität bei der MTase wird durch das bisherige Fehlen der 3D-Struktur eines homologen mesophilen Pendants erschwert. Da bisher in den Datenbanken keine Proteinsequenz über längere Abschnitte signifikante Ähnlichkeiten zur MTase aufweist, hat auch ein Screening mit den MTase-Antikörpern nur geringe Erfolgsaussichten, ein entsprechendes mesophiles Protein aufzuspüren. Aus diesem Grund bieten sich für die Zukunft nur weitere ortsspezifische Mutagenesen zur weiteren Aufklärung an. 


\subsubsection{Potentielle Funktion der MTase}

Die strikte Transferspezifität des Stärke- und Maltodextrin-umsetzenden Enzyms MTase aus T. maritima ist bisher einzigartig. Zur Zeit können deshalb über die physiologische Rolle der MTase nur Vermutungen angestellt werden, zumal auch über das physiologische Substrat immer noch Unklarheit herrscht. Es wurde kürzlich durch elektronenmikroskopische Aufnahmen und durch Zellfraktionierungsexperimente mit Hilfe der in dieser Arbeit hergestellten polyklonalen Antikörper gezeigt, daß das Enzym im Zytoplasma der T. maritima-Zellen lokalisiert ist (Armbrecht, persönl. Mitteilung). Hinsichtlich der Verbreitung des Enzyms wurde die bisherige Ausnahmestellung der MTase ein wenig relativiert, da Weber (2000) mit MTaseAntikörpern positive Western-Blot Signale bei $T$. neapolitana und Fervidobacterium nodosum, nicht aber bei $F$. islandicum und $T$. thermarum detektieren konnte. Trotzdem bleibt die Maltosyltransferase in ihrer Struktur und Biochemie einzigartig. Die katalytischen Eigenschaften ähneln am meisten denen einer Amylomaltase. Dieses Protein (MalQ in E. coli) stellt eine Maltodextrin Glycosyltransferase dar und überträgt Maltosyl- und größere Dextrinyleinheiten auf Glucose, Maltose und längeren Maltodextrine (Boos und Shuman, 1998). Die dabei entstehenden längerkettigen Maltooligosaccharide dienen als bevorzugte Substrate für eine Maltodextrin Phosphorylase (MalP in E.coli), welche Glucose-1-Phosphat bildet. Ein analoges konstitutives System bestehend aus $4-\alpha$-Glucanotransferase und Maltodextrin Phosphorylase (MalP) wurde kürzlich auch beim hyperthermophilen Archeon Thermococcus litoralis charakterisiert (Xavier et al., 1999). Hierbei entsteht durch das erste Enzym Glucose und eine Serie von Maltodextrinen, die ab einer Länge von $\geq$ vier Glucoseresten als Substrate für MalP fungieren. Ob die MTase mit ähnlicher Funktion am Kohlenhydratkatabolismus beteiligt ist, bleibt unsicher. Vor allem das Vorhandensein einer weiteren Transferase in T. maritima, der 4- $\alpha$-Glucanotransferase, läßt es fraglich erscheinen, warum die MTase mit ihrer außerordentlichen Transferspezifität ebenfalls an der Aufrechterhaltung eines Maltodextrin-Pools mitwirken sollte.

Maltosylreste sind Bestandteile zweier Glycolipide in T. maritima (Manca et al., 1992). Für eine potentielle Funktion der MTase bei der Glycolipidsynthese konnten bisher jedoch keine Hinweise gefunden werden (Meissner, 1997).

$\mathrm{Da}$ die Maltosyltransferase mehr längerkettige Produkte bildet als die 4- $\alpha$ Glucanotransferase (Meissner, 1997), könnte sie beim Aufbau von Reserve- oder 
Speicherpolysacchariden involviert sein. Durch die Genomsequenzierung (Nelson et al., 1999) gibt es nun deutliche Hinweise darauf, daß T. maritima in der Lage ist, Glykogen als Speichersubstanz nach folgendem Schema zu synthetisieren:

$$
\begin{aligned}
& \text { Glucose-1-P + ATP } \stackrel{\text { Pyrophosphorylase }}{\stackrel{\text { Glykogen Synthase }}{\longrightarrow}} \text { ADP-Glucose }+P^{\prime}(\text { Glucose })_{n}+n A D P
\end{aligned}
$$

Das Genom von T. maritima enthält neben einer Glucose-1-Phosphat Adenylyltransferase (TM0239 und TM0240) auch eine Glykogen Synthase (TM0895). Ein Verzweigungsenzym wurde dagegen noch nicht identifiziert, es sei aber angemerkt, daß die Zuordnung einer genauen Funktion bei einer Vielzahl von offenen Leserahmen (863 mit unbekannter Funktion) noch unklar ist. Neben einer Funktion der MTase bei der Glykogensynthese wären durch ihre disproportionierenden Eigenschaften eine Funktion bei der Kontrolle der Kettenlänge in Speicherpolysacchariden denkbar. Auch eine Beteiligung bei der Mobilisierung von intrazellulären Speicherstoffen erscheint möglich. So ist bekannt, daß das bei der phosphorylytischen Spaltung von Glykogen entstandene Glucose-1-Phosphat durch eine Glucose-Phosphat Mutase in Glucose-6-Phosphat umgewandelt wird, wobei Glucose-1,6-Diphoshat als Zwischenprodukt entsteht. Im Rahmen dieser Arbeit konnte gezeigt werden, daß $10 \mathrm{mM}$ Glucose-1,6-Diphoshat die Aktivität der Maltosyltransferase auf 55 - 65\% reduziert.

Die außergewöhnliche Transferspezifität und die ungeklärte physiologische Funktion der Maltosyltransferase bedürfen weiterer experimenteller Studien. Durch die Aufklärung der dreidimensionalen Struktur der MTase im Rahmen dieser Arbeit, sind günstige Voraussetzungen für dieses Unterfangen geschaffen worden. 


\section{ZUSAMMENFASSUNG}

Das hyperthermophile Bakterium Thermotoga maritima MSB8 besitzt eine ungewöhnliche Cofaktor-abhängige $55 \mathrm{kDa} \alpha$-Glucosidase (AglA) sowie zwei thermostabile Maltodextrin Glycosyltransferasen (GTase, MTase). Im Mittelpunkt dieser Arbeit standen Untersuchungen zur biochemischen Charakterisierung von AgIA, zur dreidimensionalen Struktur der MTase und zur Analyse von funktionell und strukturell essentiellen Aminosäureresten von AgIA und MTase.

- Das stromaufwärts von aglA gelegene ag/B-Gen aus T. maritima und das Gen für die zu AglA auf Aminosäuresequenzebene zu 90\% identische $\alpha$-Glucosidase aus $T$. neapolitana wurden kloniert und in E. coli BL21 (DE3) heterolog exprimiert. AglA ( $T$. neapolitana) wurde gereinigt und charakterisiert und zeigte analog zu AglA ( $T$. maritima) eine essentielle Abhängigkeit der enzymatischen Aktivität von der gemeinsamen Anwesenheit von $\mathrm{NAD}^{+}(0,9 \mathrm{mM}), \mathrm{MnCl}_{2}$ (1 mM) und DTT (50$60 \mathrm{mM})$.

- T. maritima AgIA ist die bisher thermostabilste $\mathrm{NAD}^{+}-, \mathrm{Mn}^{2+}$ - und thiol-abhängige $\alpha$-Glucosidase der Familie 4 der Glycosylhydrolasen. $\mathrm{Co}^{2+}$ und $\mathrm{Ni}^{2+}$ aktivieren AglA ebenfalls, sind aber nicht so effizient wie $\mathrm{Mn}^{2+}$. DTT kann durch $\beta$-Mercaptoethanol und weniger effektiv auch durch L-Cystein ersetzt werden. Durch Gelfiltrationsstudien konnte gezeigt werden, daß das native AglA als Homodimer aus zwei identischen $55 \mathrm{kDa}$ Untereinheiten vorliegt. Dabei spielt die An- oder Abwesenheit von Metallionen, $\mathrm{NAD}^{+}$oder DTT für die Dimerisierung keine Rolle. Es wurden kinetische Parameter für die synthetischen Substrate pNP- $\alpha$-D-Glucosid und pNP- $\alpha$-D-Galactosid und für Maltooligosaccharide sowie die Inhibitorkonstante $K_{\mathrm{i}}$ der vermutlich nicht-kompetitiven Hemmung durch Fructose-1,6-Diphosphat ermittelt. Nach der ortsspezifischen Mutagenese konservierter Aminosäurereste (G10A, G12A, S13A) im N-Terminus von AglA wurde die $N A D^{+}$-Bindung untersucht. Die Ergebnisse weisen darauf hin, daß die $N A D^{+}-$ Bindungsstelle von AglA am N-Terminus lokalisiert ist. 
- Die Analyse der Stärkeumsetzung der 4- $\alpha$-Glucanotransferase (GTase) mittels HPLC-PAD zeigte eine Veränderung der Kettenlängenverteilung hin zu kürzeren Kettenlängen mit zwei Polymerisationsgradmaxima bei 4-6 und 13-15. Die heterologe Überexpression der GTase aus T. maritima konnte weiter optimiert und ein vereinfachtes, hocheffizientes, zweistufiges Aufreinigungsschema entwickelt werden. Das Enzym wurde 7,1-fach angereichert, wobei die Ausbeute $25 \%$ betrug. Acarbose konnte als Inhibitor der GTase identifiziert werden.

- In Kooperation mit der Arbeitsgruppe von Prof. Dr. D.W. Rice (Sheffield, UK) gelang die Kristallisation (,hanging-drop"-Methode; Ammoniumphosphat als Präzipitationslösung) und die Röntgenstrukturaufklärung der MTase (MTaseMaltose-Komplex) mit einer Auflösung von 2,4 $\AA$ (2,1 $\AA$ ). Jede Untereinheit des homodimeren Enzyms ist aus vier Domänen aufgebaut, von denen zwei strukturelle Ähnlichkeit zu entsprechenden Bereichen anderer Enzyme der $\alpha$-Amylase Familie aufweisen. Die Domäne $A$ enthält die typische katalytische

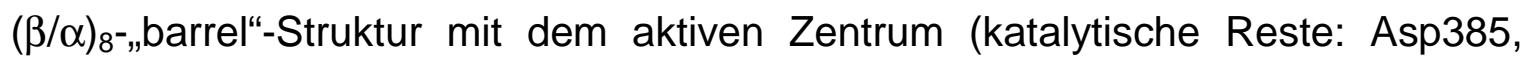
Glu414 und Asp468) am C-terminalen Ende des „barrels“. Es wurden zwei Maltose-Bindestellen identifiziert: eine befindet sich im aktiven Zentrum und definiert die „subsites“ -2 und -1, die zweite liegt in einer Tasche in unmittelbarer Nachbarschaft zum aktiven Zentrum und könnte an der Erkennung/Bindung verzweigter Substrate beteiligt sein.

- Durch gezielte ortsspezifische Mutagenese wurden Aminosäureaustausche zweier katalytisch wesentlicher Reste des aktiven Zentrums der MTase (D385N, E414Q) durchgeführt, die jedoch nicht zur vollständigen Eliminierung der enzymatischen Aktivität führten. Die Mutagenisierung ausgewählter Positionen in der Region der Substratbindung (K151A, P467H,...) ergab bisher keine Modifizierung der spezifischen Transfereigenschaften des Enzyms.

- Durch die Einführung der Mutation V110R gelang die Monomerisierung der MTase. Die höchste katalytische Aktivität der V110R-Mutante wurde mit einem 10 min Enzymtest bei einer Temperatur von $75-80^{\circ} \mathrm{C}$ bestimmt. Die Thermoinaktivierungskinetik dieses MTase-Derivats war beschleunigt. Bei $78,5^{\circ} \mathrm{C}$ wurde eine Inaktivierungs-Halbwertzeit von 125 min ermittelt, während für die Wildtyp- 
MTase die Halbwertszeit der Thermoinaktivierung bei $90^{\circ} \mathrm{C}$ mehr als $6 \mathrm{~h}$ beträgt. Die Monomer-Mutante V110R wurde innerhalb einer viel engeren Temperaturspanne thermoinaktiviert als die dimere MTase. Die Bedeutung der Dimerisierung geht noch über die Einflüsse bei der Thermostabilisierung hinaus: Interessanterweise ist das Hydrolyse/Transfer-Verhältnis der Monomermutante V110R im Vergleich zur Wildtyp-MTase um das 3,8-fache gesteigert. 


\section{LITERATUR}

Achenbach-Richter, L., Gupta, R., Stetter, K.O., Woese, C.R., (1987), Were the original eubacteria thermophiles? Syst. Appl. Microbiol. 9, 34-39

Bachmann B. J., (1987), Linkage map of Escherichia coli K12. In: Neidhardt, F. C., Ingraham, J. L., Low, K. B., Magasanik, B., Schaechter, M. und Umbarger, H. E. (Hrsg.), Escherichia coli and Salmonella typhimurium: cellular and molecular biology, 7. Aufl., Vol 2, 807-876, ASM, Washington, D. C.

Badr, H.R., Sims, K.A., Adams, M.W.W., (1994), Purification and characterization of sucrose $\alpha$-glucosidase (invertase) from the hyperthermophilic archaeon Pyrococcus furiosus. Syst. Appl. Microbiol. 17, 1-6

Baker, P.J., Britton, K.L., Rice, D.W., Rob, A., Stillman, T.J., (1992), Structural consequences of sequence patterns in the fingerprint region of the nucleotide binding fold. J. Mol. Biol. 228, 662-671

Bellamacina, C.R., (1996), The nicotinamide dinucleotide binding motif: a comparison of nucleotide binding proteins. FASEB J. 10, 1257-1269

Bibel, M., (1994), Thermotoga maritima MSB8 $\alpha$-Glucosidase: Reinigung des rekombinanten Enzyms und Sequenzierung des Gens. Diplomarbeit am Lehrstuhl für Mikrobiologie der Technischen Universität München

Bibel, M., Brettl, C., Gosslar, U., Kriegshäuser, G., Liebl, W., (1998), Isolation and analysis of genes for amylolytic enzymes of the hyperthermophilic bacterium Thermotoga maritima. FEMS Microbiol. Lett. 158, 9-15

Binder, F., (1987), Genetische und biochemische Analyse der CyclodextrinGlycosyltransferase aus Klebsiella pneumoniae M5A1. Dissertation, LudwigMaximilians-Universität München 
Birnboim, H., Doly, J., (1979), A rapid alkaline extraction procedure for screening recombinant plasmid DNA. Nucleic Acids Res. 7, 1513-1518

Boos, W., Shuman, H., (1998), Maltose/maltodextrin system of Escherichia coli: transport, metabolism, and regulation. Microbiol. Mol. Biol. Rev. 62 (1), 204-229

Boos, W., Lucht, J.M., (1996), Periplasmatic binding protein-dependent ABC transporters. In: Neidhardt, F.C., Curtiss, R.III, Ingraham, J.L., Lin, E.C.C., Low, K.B., Magasanik, B., Reznikoff, W.S., Riley, M., Schaechter, M., Umbarger, H.E. (Eds.), Escherichia coli and Salmonella typhimurium: cellular and molecular biology. American Society for Microbiology, Washington, DC, 1175-1209

Bouma, C.L., Reizer, J., Reizer, A., Robrish, S.A., Thompson, J., (1997), 6-Phospho$\alpha$-D-glucosidase from Fusobacterium mortiferum: cloning, expression, and assignment to family 4 of the glycosylhydrolases. J. Bacteriol. 179, 4129-4137

Bradford, M. M., (1976), A rapid and sensitive method for the quantitation of microgram quantities of protein utilizing the principle of protein dye-binding. Anal. Biochem. 72, 248-254

Brändén, C.I., (1991), The TIM barrel - the most frequently occurring folding motif in proteins. Curr. Opin. Struc. Biol. 1, 978-983

Buisson, G., Duée, E., Haser, R., Payan, F., (1987), Three dimensional structure of porcine pancreatic $\alpha$-amylase at $2.9 \AA$ resolution. Role of calcium in structure and activity. EMBO J. 6, 3909-3916

Bullock, W. O., Fernandez, J. M., Short, J. M., (1987), XL1-blue: a high efficiency plasmid transforming recA Escherichia coli strain with beta-galactosidase selection. Bio Techniques 5, 376-378 
Burke, J., Roujeinikova, A., Baker, P.J., Sedelnikova, S., Raasch, C., Liebl, W., Rice, D.W., (2000), Crystallization and preliminary X-ray crystallographic studies on maltosyltransferase from Thermotoga maritima. Acta Cryst. D56, 1049-1050

Burstein, C., Kepes, A., (1971), The $\alpha$-galactosidase from Escherichis coli $\mathrm{K}_{12}$. Biochim. Biophys. Acta 230, 52-63

Consalvi, V., Chiaraluce, R., Giangiacomo, L., Scandurra, R., Christova, P., Karshikoff, A., Knapp, S., Ladenstein, R., (2000), Thermal unfolding and conformational stability of the recombinant domain II of glutamate dehydrogenase from the hyperthermophile Thermotoga maritima. Prot. Engin. 13 (7), 501-507

Constantino, H.R., Brown, S.H, Kelly, R.M., (1990), Purification and characterization of an $\alpha$-glucosidase from a hyperthermophilic archaebacterium, Pyrococcus furiosus, exhibiting a temperature optimum of $105-115^{\circ} \mathrm{C}$.

J. Bacteriol. 172, 3654-3660

Dams, T., Auerbach, G., Bader, G., Jacob, U., Ploom, T., Huber, R., Jaenicke, R., (2000), The crystal structure of dihydrofolate reductase from Thermotoga maritima: molecular features of thermostability. J. Mol. Biol. 297, 659-672

Davies, G.J., Wilson, K.S., Henrissat, B., (1997), Nomenclature for sugar-binding sites in glycosyl hydrolases. Biochem. J. 321, 557-559

Deckert, G., Warren, P.V., Gaasterland, T., Young, W.G., Lenox, A.L., Graham, D.E., Overbeek, R., Snead, M.A., Keller, M., Aujay, M., Huber, R., Feldman, R.A., Short, J.M., Olsen, G.J., Swanson, R.V., (1998), The complete genome of the hyperthermophile bacteria Aquifex aeolicus. Nature 392, 353-358

Farber, G.K., Petsko, G.A., (1990), The evolution of $\alpha / \beta$ barrel enzymes.

Trends Biochem. Sci. 15, 228-234 
Feese., M.D., Kato, Y., Tamada, T., Kato, M., Komeda, T., Miura, Y., Hirose, M., Hondo, K., Kobayashi, K., Kuroki, R., (2000), Crystal structure of glycosyltrehalose trehalohydrolase from the hyperthermophilic archaeum Sulfolobus solfataricus. J. Mol. Biol. 301, 451-464

Fujimoto, Z., Takase, K., Doui, N., Momma, M., Matsumoto, T., Mizuno, H., (1998), Crystal structure of a catalytic-site mutant $\alpha$-amylase from Bacillus subtilis complexed with maltopentaose. J. Mol. Biol. 277, 393-407

Galtier, N., Tourasse, N., Gouy, M., (1999), A nonhyperthermophilic common ancestor to extant life forms. Science 283, 220-221

Goldman, A., (1995), How to make my blood boil. Structure 3, 1277-1279

Goßlar, U., (1992), Charakterisierung einer in E. coli klonierten $\alpha$-Glucosidase aus Thermotoga maritima MSB8. Diplomarbeit am Lehrstuhl für Mikrobiologie der Technischen Universität München

Hanahan, D., (1983), Studies on transformation of Escherichia coli with plasmids. J. Mol. Biol. 166, 557-580

Hennig, M., Sterner, R., Kirschner, K., Jansonius, J.N., (1997), Crystal structure at 2.0 A resolution of phosphoribosyl anthranilate isomerase from the hyperthermophile Thermotoga maritima: possible determinants of protein stability. Biochem. 36, 6009-6016

Henrissat, B., (1991), A classification of glycosyl hydrolases based on amino acid sequence similarities. Biochem. J. 280, 309-316

Henrissat, B., Bairoch, A., (1993), New families in the classification of glycosyl hydrolases based on amino acid sequence similarities.

Biochem. J. 293, 781-788 
Henrissat, B., Davies, G., (1997), Structural and sequence-based classification of glycoside hydrolases. Curr. Opin. Structl. Biol. 7, 637-644

Horlacher, R., Xavier, K.B., Santos, H., DiRuggiero, J., Kossmann, M., Boos, W., (1998), Archaeal binding protein-dependent ABC transporter: molecular and biochemical analysis of the trehalose/maltose transport system of the hyperthermophilic archaeon Thermococcus litoralis. J. Bact. 180, 680-689

Huber, R., Langworthy, T.A., König, H., Thomm, M., Woese, C.R., Sleytr, U.B., Stetter, K.O., (1986), Thermotoga maritima sp. nov. represents a new genus of unique extremely thermophilic eubacteria growing up to $90^{\circ} \mathrm{C}$.

Arch. Microbiol. 144, 324-333

Huber, W., (1994), Reinigung und biochemische Charakterisierung einer rekombinanten 4- $\alpha$-Glucanotransferase von Thermotoga maritima. Dissertation an der Fakultät für Chemie, Biologie und Geowissenschaften der Technischen Universität München

Inoue, H., Nojima, H., Okayama, H., (1990), High efficiency transformation of Escherichia coli with plasmids. Gene 96, 23-28

Ishii, N., Haga, K., Yamane, K., Harata, K., (2000), Crystal structure of asparagine 233-replaced cyclodextrin glucanotransferase from alkalophilic Bacillus sp. 1011 determined at 1.9 Å resolution. J. Mol. Recognit. 13, 35-43

Jaenicke, R., Böhm, G., (1998), The stability of proteins in exteme environments. Curr. Opin. Struct. Biol. 8, 738-748

Janecek, Š., (1997), $\alpha$-Amylase family: Molecular biology and evolution. Prog. Biophys. Molec. Biol. 67, 67-97 
Jespersen, H.M., MacGregor, E.A., Henrissat, B., Sierks, M.R., Svensson, B., (1993), Starch- and glycogen-debranching and branching enzymes: prediction of structural features of the catalytic $(\beta / \alpha)_{8}$-barrel domain and evolutionary relationship to other amylolytic enzymes. J. Protein Chem.12, 791-805

Jespersen, H.M., MacGregor, E.A., Sierks, M.R., Svensson, B., (1991), Comparison of the domain-level organization of starch hydrolases and related enzymes. Biochem. J. 280, 51-55

Kamitori, S., Kondo, S., Okuyama, K., Yokota, T., Shimura, Y., Tonozuka, T., Sakano, Y., (1999), Crystal structure of Thermoactinomyces vulgaris R-47 $\alpha$-amylase II (TVAII) hydrolyzing cyclodextrins and pullulan at 2.6 $\mathrm{E}$ resolution. J. Mol. Biol. 287, 907-921

Katsuya, Y., Mezaki, Y., Kubota, M., Matsuura, Y., (1998), Three-dimensional structure of Pseudomonas isoamylase at $2.2 \mathrm{E}$ resolution. J. Mol. Biol. 281, 885-897

Kelly, R.M., Adams, M.W.W., (1994), Metabolism in hyperthermophilic microorganisms. Antonie van Leeuwenhoek 66, 247-270

Kim, T.J., Park, C.S., Cho, H.Y., Cha, S.S., Kim, J.S., Lee, S.B., Moon, T.W., Kim, J.W., Oh, B.H., Park, K.H., (2000), Role of the glutamate 332 residue in the transglycosylation activity of Thermus maltogenic amylase.

Biochem. 39, 6773-6780

Kim, J.S., Cha, S.S., Kim, H.J., Kim, T.J., Ha, N.C., Oh, S.T., Cho, H.S., Cho, M.J., Kim, M.J., Lee, H.S., Kim, J.W., Choi, K.Y., Park, K.H., Oh, B.H, (1999), Crystal structure of a maltogenic amylase provides insights into a catalytic versatility. J. Biol. Chem. 274, 26279-26286 
Kim, M.J., Lee, S.B., Lee, H.S., Lee, S.Y., Baek, J.S., Kim, D., Moon, T.W., Robyt, J.F., Park, K.H., (1999), Comparative study of the inhibition of $\alpha$-glucosidase, $\alpha$-amylase, and cyclomaltodextrin glycanosyltransferase by acarbose, isoacarbose, and acarviosine-glucose. Arch. Biochem. Biophys. 371 (2), 277-283

Klein, C., Hollender, J., Bender, H., Schulz, G.E., (1992), Catalytic center of cyclodextrin glycosyltransferase derived from $\mathrm{X}$-ray structure analysis combined with site-directed mutagenesis. Biochem. 31, 8740-8746

Knegtel, R.M.A., Wind, R.D., Rozeboom, H. J., Kalk, K.H., Buitelaar, R.M., Dijkhuizen, L., Dijkstra, B.W., (1996), Crystal structure at $2.3 \AA$ A resolution and revised nucleotide sequence of the thermostable cyclodextrin glycosyltransferase from Thermoanaerobacterium thermosulfurigenes EM1. J. Mol. Biol. 256, 611-622

Knegtel, R.M.A., Strokopytov, B., Penninga, D., Faber, O.G., Rozeboom, H.J., Kalk, K.H., Dijkhuizen, L., Dijkstra, B.W., (1995), Crystallographic studies of the interaction of cyclodextrin glycosyltransferase from Bacillus circulans strain 251 with natural substrates and products. J. Biol. Chem. 270, 29256-29264

Kriegshäuser, G., Liebl, W., (2000), Pullulanase from the hyperthermophilic bacterium Thermotoga maritima: purification by $\beta$-cyclodextrin affinity chromatography. J. Chromatogr. B 737, 245-251

Kuriki, T., Imanaka, T., (1999), The concept of the $\alpha$-Amylase family: structural similarity and common catalytic mechanism. J. Biosci. Bioeng. 87, 557-565

Laemmli, U. K., (1970), Cleavage of structural proteins during the assembly of the head of bacteriophage T4. Nature 227, 680-685

Lang, D., Thoma, R., Henn-Sax, M., Sterner, R., Wilmanns, M., (2000), Structural evidence for evolution of the $\beta / \alpha$ barrel scaffold by gene duplication and fusion. Science 289, 1546-1550 
Lapidus, A., Galleron, N., Sorokin, A., Ehrlich, S.D., (1997), Sequencing and functional annotation of the Bacillus subtilis genes in the $200 \mathrm{~kb} \mathrm{rnB}-\mathrm{dnaB}$ region. Microbiology 143, 3431-3441

Lawson, C.L., van Montfort, R., Strokopytov, B., Rozeboom, H.J., Kalk, K.H., de Vries, G.E., Penninga, D., Dijkhuizen, L., Dijkstra, B.W., (1994), Nucleotide sequence and X-ray structure of cyclodextrin glycosyltransferase from Bacillus circulans strain 251 in a maltose-dependent crystal form.

J. Mol. Biol. 236, 590-600

Liebl, W., Feil, R., Gabelsberger, J., Kellermann, J., Schleifer, K.H., (1992), Purification and characterization of a novel thermostable $4-\alpha-$ glucanotransferase of Thermotoga maritima cloned in Escherichia coli. Eur. J. Biochem. 207, 81-88

Liebl, W., Stemplinger, I., Ruile, P., (1997), Properties and gene structure of the Thermotoga maritima $\alpha$-amylase AmyA, a putative lipoprotein of a hyperthermophilic bacterium. J. Bacteriol. 179, 941-948

Liljeström, P.L., Liljeström, P., (1987), Nucleotide sequence of the melA gene, coding for $\alpha$-galactosidase in Escherichia coli K-12. Nucleic Acids Res. 15, 2213-2220

Liu, Z.J., Sun, Y.J., Rose, J., Chung, Y.J., Hsiao, C.D., Chang, W.R., Kuo, I., Perozich, J., Lindahl, R., Hempel, J., Wang, B.C., (1997), The first structure of an aldehyde dehydrogenase reveals novel interactions between NAD and the Rossmann fold. Nat. Structl. Biol. 4 (4), 317-326

Liu, W., de Castro, M.L., Takrama, J., Bilous, P.T., Vinayagamoorthy, T., Madsen, N. B., Bleackley, R.C., (1993), Molecular cloning, sequencing, and analysis of the cDNA for rabbit muscle glycogen debranching enzyme.

Arch. Biochem. Biophys. 306, 232-239 
Macedo-Ribeiro, S., Darimont, B., Sterner, R., Huber, R., (1996), Small structural changes account for the high thermostability of 1 [4Fe-4S] ferredoxin from the hyperthermophilic bacterium Thermotoga maritima. Structure 4, 1291-1301

Maes, D., Zeelen, J.P., Thanki, N., Beaucamp, N., Alvarez, M., Thi, M.H.D., Backmann, J., Martial, J.A., Wyns, L., Jaenicke, R., Wierenga, R.K., (1999), The crystal structure of triosephosphate isomerase (TIM) from Thermotoga maritima: a comparative thermostability structural analysis of ten different TIM structures. Proteins 37, 441-453

Manca, M.C., Nicolaus, B., Lanzotti, V., Trincone, A., Gambacorta, A., PeterKatalinic, J., Egge, H., Huber, R., Stetter, K.O., (1992), Glycolipids from Thermotoga maritima, a hyperthermophilic microorganism belonging to Bacteria domain. Biochim. Biophys. Acta 1124, 249-252

Marmur, J., (1961), A procedure for the isolation of DNA from microorganisms. J. Mol. Biol. 3, 208-218

Matsuura, Y., Kusunoki, M., Harada, W., Kakudo, M., (1984), Structure and possible catalytic residues of TAKA-amylase A. J. Biochem. 95, 697-702

McCarter, J.D., Withers, S.G., (1994), Mechanisms of enzymatic glycoside hydrolysis. Curr. Opin. Struct. Biol. 4, 885-892

Meissner, H., (1997), Biochemische Charakterisierung einer ungewöhnlichen Maltodextrin Glycosyltransferase von Thermotoga maritima und molekulargenetische Untersuchung des Strukturgens. Dissertation an der Fakultät für Chemie, Biologie, und Geowissenschaften der Technischen Universität München

Meissner, H., Liebl, W., (1998), Thermotoga maritima maltosyltransferase, a novel type of maltodextrin glycosyltransferase acting on starch and maltooligosaccharides. Eur. J. Biochem. 250, 1050-1058 
Miles, E.W., Davies, D.R., (2000), On the ancestry of barrels. Science 289, 1490

Nagao, Y., Nakada, T., Imoto, M., Shimamoto, T., Sakai, S., Tsuda, M., Tsuchiya, T., (1988), Purification and analysis of the structure of $\alpha$-galactosidase from Escherichia coli. Biochem. Biophys. Res. Comm. 151 (1), 236-241

Nelson. K.E., Clayton, R.A., Gill, S.R., Gwinn, M.L., Dodson, R.J., Haft, D.H., Hickey, E.K., Peterson, J.D., Nelson, W.C., Ketchum, K.A., McDonald, L., Utterback, T.R., Malek, J.A., Linher, K.D., Garrett, M.M., Stewart, A.M., Cotton, M.D., Pratt, M.S., Phillips, C.A., Richardson, D., Heidelberg, J., Sutton, G.G., Fleischmann, R.D., Eisen, J.A., White, O., Salzberg, S.L., Smith, H.O., Venter, J.C., Fraser,C.M., (1999), Evidence for lateral gene transfer between archaea and bacteria from genome sequence of Thermotoga maritima.

Nature (Lond) 399, 323-329

Nicholls, A., Sharp, K., Honig, B., (1991), Protein folding and association: insights from the interfacial and thermodynamic properties of hydrocarbons. Proteins Struct. Funct. Genet. 11, 281-296

Park, K.H., Kim, T.J., Cheong, T.K., Kim, J.W., Oh, B.H., Svensson, B., (2000), Structure, specificity and function of cyclomaltodextrinase, a multispecific enzyme of the $\alpha$-amylase family. Biochim. Biophys. Acta 1478, 165-185

Parker, L.L., Hall, B.G., (1990), Characterization and nucleotide sequence of the cryptic cel operon of Escherichia coli K12. Genetics 124, 455-471

Peak, M.J., Peak, J.G., Stevens, F.J., Blamey, J., Mai, X., Zhou, Z.H., Adams, M.W.W., (1994), The hyperthermophilic glycolytic enzyme enolase in the archaeon, Pyrococcus furiosus: comparison with mesophilic enolases. Arch. Biochem. Biophys. 313 (2), 280-286 
Penfound, T., Foster, J.W., (1996), Biosynthesis and recycling of NAD. In: Neidhardt, F.C., Curtiss, R.III, Ingraham, J.L., Lin, E.C.C., Low, K.B., Magasanik, B., Reznikoff, W.S., Riley, M., Schaechter, M., Umbarger, H.E. (Eds.), Escherichia coli and Salmonella typhimurium: cellular and molecular biology. American Society for Microbiology, Washington, DC, 721-730

Piller, K., Daniel, R.M., Petach, H.H., (1996), Properties and stabilization of an extracellular $\alpha$-glucosidase from the extremely thermophilic archaebacteria Thermococcus strain AN1: enzyme activity at $130^{\circ} \mathrm{C}$.

Biochim. Biophys. Acta 1292, 197-205

Przylas, I., Tomoo, K., Terada, Y., Takaha, T., Fujii, K., Saenger, W., Sträter, N., (2000), Crystal structure of amylomaltase from Thermus aquaticus, a glycosyltransferase catalysing the production of large cyclic glucans. J. Mol. Biol. 296, 873-886

Raasch, C., Streit, W., Schanzer, J., Bibel, M., Gosslar, U., Liebl, W., (2000), Thermotoga maritima AglA, an extremely thermostable $\mathrm{NAD}^{+}-, \mathrm{Mn}^{2+}$,- and thiol-dependent $\alpha$-glucosidase. Extremophiles 4, 189-200

Rachel, R., Engel, A.M., Huber, R., Stetter, K.O., Baumeister, W., (1990), A porintype protein is the main constituent of the cell envelope of the ancestral eubacterium Thermotoga maritima. FEBS Lett. 262, 64-68

Reizer, J., Michotey, V., Reizer, A., Saier, Jr, M.H., (1994), Novel phosphotransferase system genes revealed by bacterial genome analysis: unique, putative fructose- and glucoside-specific systems. Protein Sci. 3, 440-450

Rice, D.W., Yip, K.S.P., Stillman, T.J., Britton, K.L., Fuentes, A., Connerton, I., Pasquo, A., Scandurra, R., Engel, P.C., (1996), Insights into the molecular basis of thermal stability from the structure determination of Pyrococcus furiosus glutamate dehydrogenase. FEMS Microbiol. Rev. 18, 105-117 
Richardson, J.S., (1981), The anatomy and taxanomy of protein structure. Advan. Protein. Chem. 34, 167-339

Rolfsmeier, M., Blum, P., (1995), Purification and characterization of a maltase from the extremely thermophilic crenarchaeote Sulfolobus solfataricus.

J. Bacteriol. 177, 482-485

Rolfsmeier, M., Haseltine, C., Bini, E., Clark, A., Blum, P., (1998), Molecular characterization of the $\alpha$-glucosidase gene ( $\mathrm{malH}$ ) from the hyperthermophilic archaeon Sulfolobus solfataricus. J. Bacteriol. 180, 1287-1295

Rossmann, M.G., Liljas, A., Brändén, C.-I., Banaszak, L.J., (1975), Evolutionary and structural relationships among dehydrogenases. In The Enzymes. Vol. 11, Part A, Boyer, P.D. (ed.), New York: Academic Press, 61-102

Roujeinikova, A., Raasch, C., Burke, J., Baker, P.J., Liebl, W., Rice, D.W., (2001), The crystal structure of Thermotoga maritima maltosyltransferase reveals the molecular basis of its novel transfer specificity. Proc. Natl. Acad. Sci. USA, (eingereicht)

Samanta, A.K., Bhaduri, A., (1983), Characterization of pyridine nucleotide binding site of UDP-glucose 4-epimerase from Saccharomyces fragilis. J. Biol. Chem. 258 (18), 11118-11122

Sambrook, J., Fritsch, E.F., Maniatis, T., (1989), Molecular cloning - A laboratory manual, $2^{\text {nd }}$ edition, Cold Spring Harbor Laboratory Press, USA

Scandurra, R., Consalvi, V., Chiaraluce, R., Politi, L., Engel, P.C., (1998), Protein thermostability in extremophiles. Biochimie $\mathbf{8 0}, 933-941$

Schanzer, J., (1996), Reinigung und enzymatische Untersuchung einer thermostabilen $\alpha$-Glucosidase. Diplomarbeit am Lehrstuhl für Mikrobiologie der Technischen Universität München 
Schlegel, H.G., (1992), Allgemeine Mikrobiologie. 7., überarb. Aufl./unter Mitarb. von Christiane Zaborosch. Stuttgart; New York: Thieme

Schönert, S., Buder, T., Dahl, M.K., (1998), Identification and enzymatic characterization of the maltose-inducible $\alpha$-glucosidase MalL (sucraseisomaltase-maltase) of Bacillus subtilis. J. Bacteriol. 180, 2574-2578

Schurig, H., Rutkat, K., Rachel, R., Jaenicke, R., (1995), Octameric enolase from the hyperthermophilic bacterium Thermotoga maritima: purification, characterization, and image processing. Prot. Science 4, 228-236

Scrutton, N.S., Berry, A., Perham, R.N., (1990), Redesign of the coenzym specificity of a dehydrogenase by protein engineering. Nature $343,38-43$

Selig, M., Xavier, K.B., Santos, H., Schönheit, P., (1997), Comparative analysis of Embden-Meyerhof and Entner-Doudoroff glycolytic pathways in hyperthermophilic archaea and the bacterium Thermotoga. Arch. Microbiol. 167, 217-232

Skov, L.K., Mirza, O., Henriksen, A., Potocki de Montalk, G., Remaud-Simeon, M., Sarcabal, P., Willemot, R.M., Monsan, P., Gajhede, M., (2001), Amylosucrase from Neisseria polysaccharea. (hold; release date: 31.10.2001; PDB1G5A)

Sögaard, M., Kadziola, A., Haser, R., Svensson, B., (1993), Site-directed mutagenesis of histidine 93, aspartic acid 180, glutamic acid 205, histidine 290, and aspartic acid 291 at the active site and tryptophan 279 at the raw starch binding site in barley amylase 1. J. Biol. Chem. 268, 22480-22484

Sterner, R., Liebl, W., (2001), Thermophilic adaptation of proteins.

Crit. Rev. Biochem. Mol. Biol., in press

Stetter, K.O., (1996), Hyperthermophilic procaryotes.

FEMS Microbiol. Rev. 18, 149-158 
Studier, F. W., Moffat, B. A., (1986), Use of bacteriophage T7 RNA polymerase to direct selective high expression of cloned genes. J. Mol. Biol. 189, 113-130

Suzuki, Y., Yonezawa, K., Hattori, M., Takii, Y., (1992), Assignment of Bacillus thermoamyloliquefaciens KP1071 $\alpha$-glucosidase I to an exo- $\alpha-1,4-$ glucosidase, and its striking similarity to bacillary oligo-1,6-glucosidases in Nterminal sequence and in structural parameters calculated from the amino acid composition. Eur. J. Biochem. 205, 249-256

Szilágyi, A., Závodszky, P., (2000), Structural differences between mesophilic, moderately thermophilic and extremely thermophilic protein subunits: results of a comprehensive survey. Structure 8, 493-504

Takase, K., Matsumoto, T., Mizuno, H., Yamane, K., (1992), Site-directed mutagenesis of active site residues in Bacillus subtilis $\alpha$-amylase. Biochim. Biophys. Acta 1120, 281-288

Tanner, J.T., Hecht, R.M., Krause, K.L., (1996), Determinants of enzyme thermostability observed in the molecular structure of Thermus aquaticus Dglyceraldehyde-3-phosphate dehydrogenase at $2.5 \AA$ resolution. Biochem. 35, 2597-2609

Thompson, J., Ruvinov, S.B., Freedberg, D.I., Hall, B.G., (1999), Cellobiose-6phosphate hydrolase (CelF) of Escherichia coli: Characterization and assignment to the unusual family 4 of glycosylhydrolases.

J. Bact. 181 (23), 7339-7345

Thompson, J., Pikis, A., Ruvinov, S.B., Henrissar, B., Yamamoto, H., Sekiguchi, J., (1998), The gene glvA of Bacillus subtilis 168 encodes a metal-requiring $\operatorname{NAD}(\mathrm{H})$-dependent 6-phospho- $\alpha$-glucosidase.

J. Biol. Chem. 273, 27347-27356 
Thompson, J., Gentry-Weeks, C.R., Nguyen, N.Y., Folk, J.E., Robrish, S.A., (1995), Purification from Fusobacterium mortiferum ATCC 25557 of a 6-Phosphoryl-O$\alpha$-D-Glucopyranosyl:6-Phosphoglucohydrolase that hydrolyzes Maltose 6-

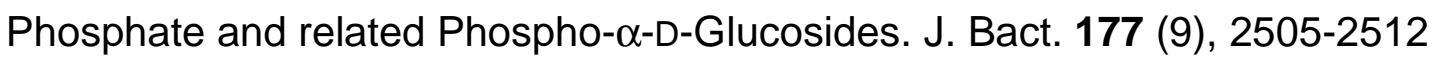

Thorn, W., Mohazzeb, S., (1990), Molecular weights, lengths, and distribution of sidechains in $\alpha$-D-polyglucanes. Starch/Stärke 42, 373-376

Tobisch, S., Glaser, P., Krueger, S., Hecker, M., (1997), Identification and characterization of a new beta-glucoside utilization system in Bacillus subtilis. J. Bacteriol. 179, 496-506

Towbin, H., Staehelin, T., Gordon, J., (1979), Electrophoretic transfer of proteins from polyacrylamide gels to nitrocellulose sheets: procedure and some applications. Proc. Natl. Acad. Sci. USA 76, 4350-4354

Uitdehaag, J.C.M., van Alebeek, G.J.W.M., van der Veen, B.A., Dijkhuizen, L., Dijkstra, B.W., (2000), Structures of maltohexaose and maltoheptaose bound at the donor sites of cyclodextrin glycosyltransferase give insight into the mechanisms of transglycosylation activity and cyclodextrin size specificity. Biochem. 39, 7772-7780

Uitdehaag, J.C.M., Mosi, R., Kalk, K.H., van der Veen, B.A., Dijkhuizen, L., Withers, S.G., Dijkstra, B.W., (1999), X-ray structures along the reaction pathway of cyclodextrin glycosyltransferase elucidate catalysis in the $\alpha$-amylase family. Nat. Structl. Biol. 6 (5), 432-436

Veith, B., (2001), Die thermostabilen $\alpha$-Glucosidasen AglB aus Thermotoga maritima MSB 8 und MalA aus Thermotoga neapolitana NS-E: Expression, Reinigung und biochemische Charakterisierung der rekombinanten Enzyme. Diplomarbeit, Universität Göttingen, unveröffentlicht

Vielle, C., Zeikus, J.G., (1996), Thermozymes: identifying molecular determinants of protein structural and functional stability. TIBTECH 14, 183-190 
Vogt, G., Woell, S., Argos, P., (1997), Protein thermal stability, hydrogen bonds, and ion pairs. J. Mol. Biol. 269, 631-643

Wassenberg, D., Liebl, W., Jaenicke, R., (2000), Maltose-binding protein from the hyperthermophilic bacterium Thermotoga maritima: stability and binding properties. J. Mol. Biol. 295, 279-288

Watanabe, K., Hata, Y., Kizaki, H., Katsube, Y., Suzuki, Y., (1997), The refined crystal structure of Bacillus cereus oligo-1,6-glucosidase at $2.0 \mathrm{E}$ resolution: structural characterization of proline-substitution sites for protein thermostabilization. J. Mol. Biol. 269, 142-153

Weber, C., (2000), Untersuchungen zum Vorkommen einer Maltosyltransferase in Thermotoga- und Fervidobacterium-Arten. Diplomarbeit, Universität Göttingen, unveröffentlicht

Weber, K., Osborn, M., (1969), The reliability of molecular weight determinations by dodecyl sulfate-polyacrylamide gel electrophoresis.

J. Biol. Chem. 224, 4406-4412

Wierenga, R.K., de Maeyer, M.C.H., Hol, W.G.J., (1985), Interaction of pyrophosphate moieties with $\alpha$-helixes in dinucleotide binding proteins. Biochem. 24 (6), 1346-1357

Xavier, K.B., Peist, R., Kossmann, M., Boos, W., Santos, H., (1999), Maltose metabolism in the hyperthermophilic archeon Thermococcus litoralis: purification and characterization of key enzymes. J. Bact. 181 (11), 3358-3367

Yamamoto, H., Uchiyama, S., Fajar, A.N., Ogasawara, N., Sekiguchi, J., (1996), Determination of a $12 \mathrm{~kb}$ region of the Bacillus subtilis chromosome. Microbiology 142, 1417-1421 
Yanish-Perron, C., Vieira, J., Messing, J., (1985), Improved M13 phage cloning vectors and host strains: nucleotide sequences of M13mp18 and pUC19 vectors. Gene 33, 103-109

Yoshioka, Y., Hasegawa, K., Matsuura, Y., Katsube, Y., Kubota, M., (1997), Crystal structures of a mutant maltotetraose-forming exo-amylase cocrystallized with maltopentaose. J. Mol. Biol. 271, 619-628 


\section{DANKSAGUNGEN}

Herrn Prof. Dr. Wolfgang Liebl sei für die fachlich äußerst kompetente Betreuung und die in jeder Hinsicht gewährte Unterstützung herzlich gedankt.

Der Arbeitsgruppe um Prof. Dr. D.W. Rice (Sheffield, UK) danke ich für die erfolgreiche Kooperation bei der Kristallisation und Röntgenstrukturanalyse der Maltodextrin Glycosyltransferasen.

Herrn Prof. Dr. Gerhard Gottschalk danke ich für die Übernahme des Korreferats.

Herrn Dr. Wolfgang Streit gebührt Dank für die Betreuung während der Anfangsphase der Promotion und für seine ständige Diskussions- und Hilfsbereitschaft.

Ein besonderer Dank gilt allen ehemaligen und jetzigen Labormitstreitern: Kirsten Meißner, Ute Ludwig (und Anna), Elke Heinz, Plamena Entcheva, Julia Busse, Kirsten Kerkhoff, Karin Türk, Martin Armbrecht, Kai Hofmann, Mladen Tzvetkov, Manuela Köthe, Arnim Wiezer, Christel Schmeißer, Nina Fricke, Maike Rudolph und Jörg Kleine. Patrick „Pancho“ Müller, Cati Weber und Birgit Veith sei für die stets freundschaftliche Arbeitsatmosphäre an der gemeinsamen Laborbank und Ole Fütterer für die fachlichen, politischen und philosophischen Diskussionen gedankt.

Beim Werkstatt-Team Charlie Bertram, Gerd Birke und Jürgen Steckel, sowie bei Manfred Hellwig und Ingrid Bahr möchte ich mich für die rasche Lösung aller nicht-biologischen Probleme ebenfalls bedanken.

Allen weiteren Mitgliedern des Institutes, die mir mit Rat und Tat zur Seite standen und zum Gelingen dieser Arbeit beigetragen haben, sei an dieser Stelle gedankt.

Meinen Eltern und meiner Familie gilt ein herzlicher Dank für ihr Verständnis und die gesamte Unterstützung während der Studien- und Promotionszeit.

Allen meinen Freunden und besonders Elke Heinz und Kay Schreiter danke ich für das gemeinsame Durchleben aller Höhen und Tiefen inner- und außerhalb des Laboralltages, für Hilfen jeglicher Art (z. B. das Korrekturlesen dieser Arbeit) und vor allem für den vielen Spaß, den wir gemeinsam hatten. 


\section{Lebenslauf}

14. Juni 1972 Geburt in Northeim

1978-1982

Besuch der Grundschule in Katlenburg-Lindau

1982-1984

Besuch der Orientierungsstufe in Katlenburg-Lindau

1984-1991

Besuch des Gymnasiums Corvinianum in Northeim

Mai 1991

Abitur

Juli 1991-Juni 1992 Grundwehrdienst in Leer/Ostfriesland und in Northeim

Oktober 1992 Immatrikulation an der Georg-August-Universität zu

Göttingen im Fach Biologie

Oktober $1994 \quad$ Vordiplom in den Fächern Mikrobiologie, Zoologie, Chemie und Physik

Oktober 1996 Diplomprüfung in den Fächern Mikrobiologie, Zoologie und Chemie

Dezember 1996 Experimentelle Diplomarbeit unter der Leitung von Prof. Dr. G.

- Januar 1998 Gottschalk am Institut für Mikrobiologie und Genetik der

Georg-August-Universität zu Göttingen mit dem Titel:

Untersuchungen zur Endenstruktur des linearen katabolen

Plasmides pBD2 in Rhodococcus erythropolis BD2

Mai 1998

Beginn der experimentellen Arbeiten zur vorliegenden

Dissertation 